Final Report

FHWA/IN/JTRP-2006/24

\title{
Determination of Ash Mixture Properties and Construction of Test Embankment - Part A
}

\author{
by \\ Bumjoo Kim, Sungmin Yoon and Umashankar Balunaini \\ Graduate Research Assistants \\ Monica Prezzi \\ Assistant Professor \\ and \\ Rodrigo Salgado \\ Professor \\ School of Civil Engineering \\ Purdue University \\ Joint Transportation Research Program \\ Project No. C-36-36KK \\ File No. 6-14-37 \\ SPR-2591 \\ Conducted in Cooperation with the \\ Indiana Department of Transportation \\ and the U.S. Department of Transportation \\ Federal Highway Administration
}

The contents of this report reflect the views of the authors who are responsible for the facts and accuracy of the data presented herein. The contents do not necessarily reflect the official views or policies of the Federal Highway Administration or the Indiana Department of Transportation. This report does not constitute a standard, specification, or regulation.

\author{
Purdue University \\ West Lafayette, Indiana
}

November 2006 
TABLE OF CONTENTS

Page

LIST OF TABLES ....................................................................................... IV

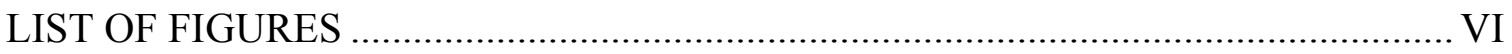

ACKNOWLEDGEMENTS ................................................................................

IMPLEMENTATION REPORT …................................................................... XIII

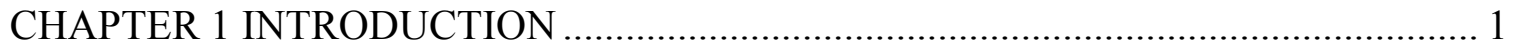

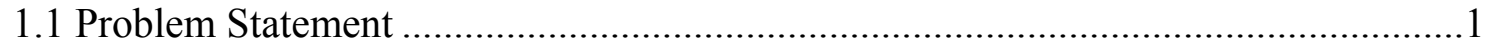

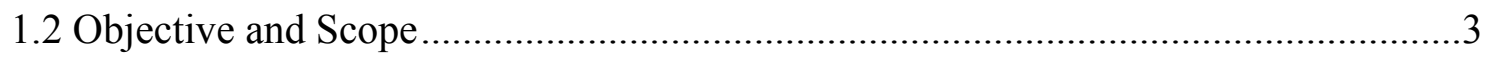

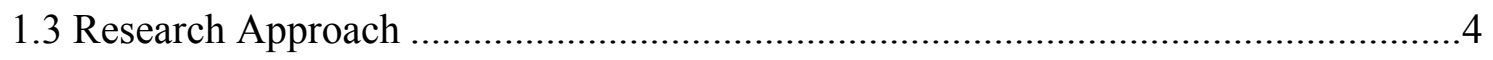

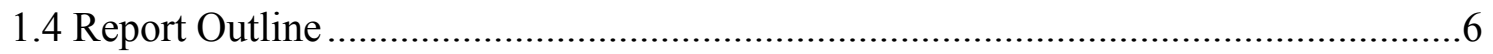

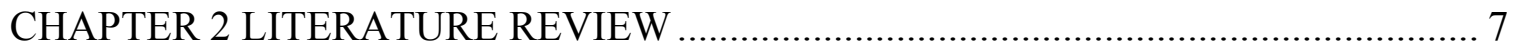

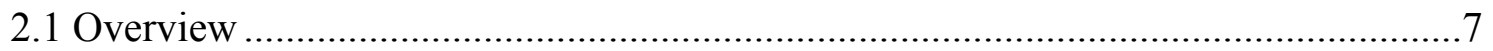

2.2 Coal Consumption in the United States and Indiana.........................................8

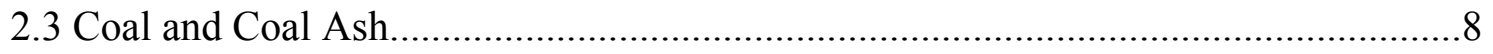

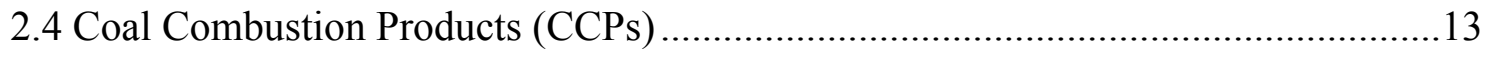

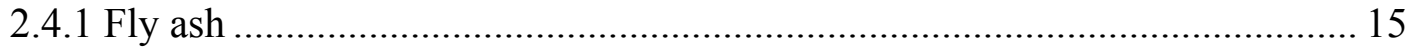

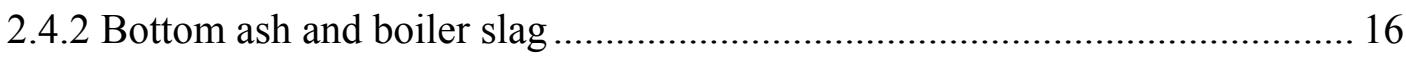

2.4.3 Flue gas desulfurization (FGD) scrubber sludge ...................................... 17

2.5 Production, Use, and Disposal of Coal Ash in the United States and Indiana..........18

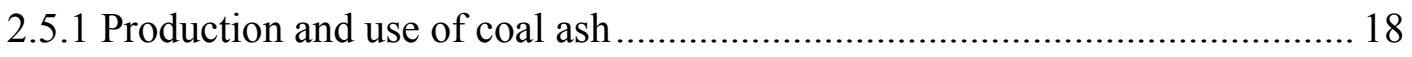

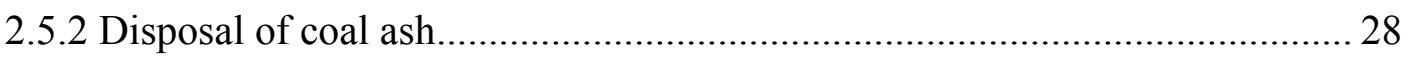

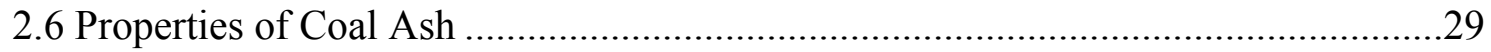

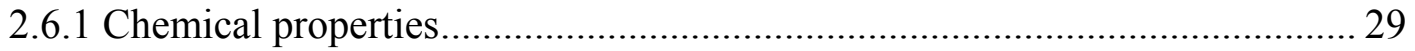

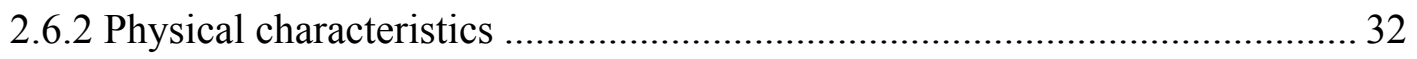

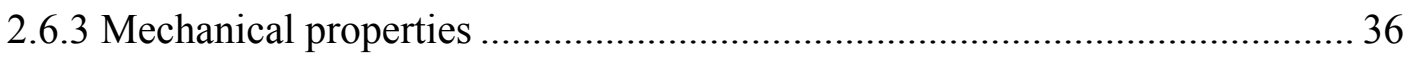

2.7 Utilization of Coal Ash in Highway Embankment .............................................55

2.7.1 Current practices of coal ash utilization in highway construction ................ 56

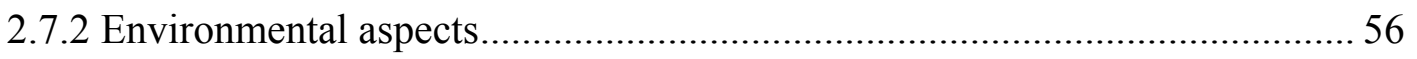


2.7.3 Design and construction considerations for highway embankment constructed using coal ash 64

CHAPTER 3 EXPERIMENTAL PROGRAM 70

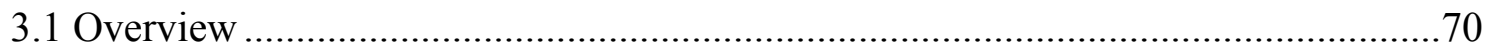

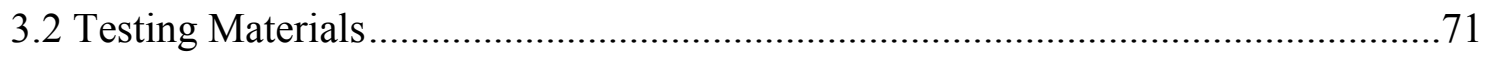

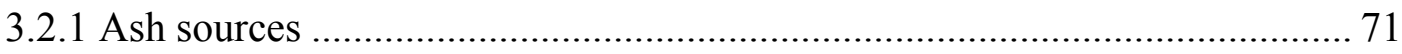

3.2.2 Ash generation and disposal procedures in ash sources................................. 71

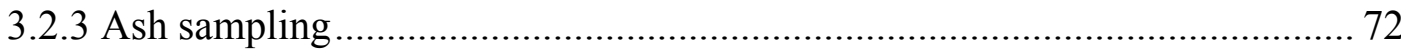

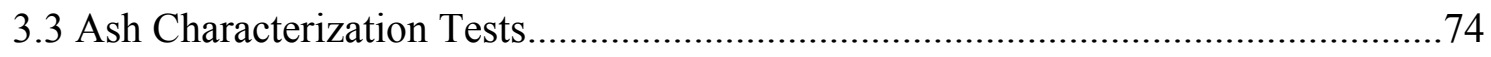

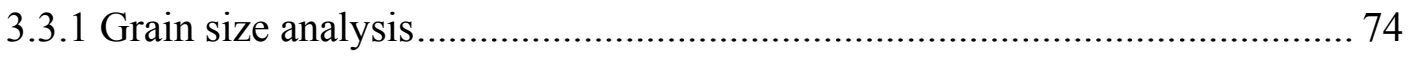

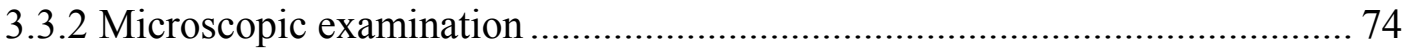

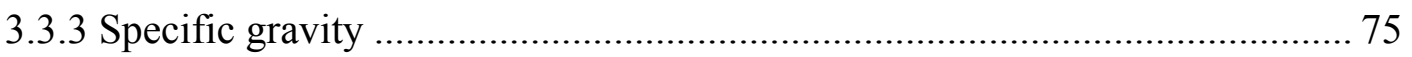

3.4 Engineering Property Tests of Coal Ash Mixtures ...............................................

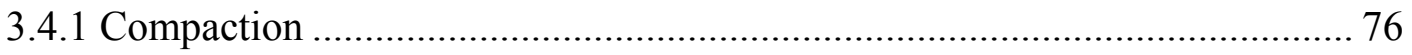

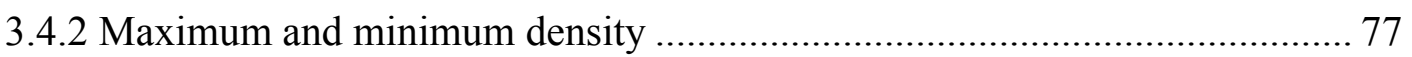

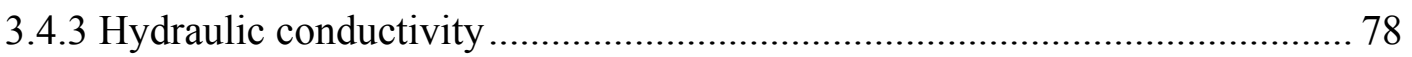

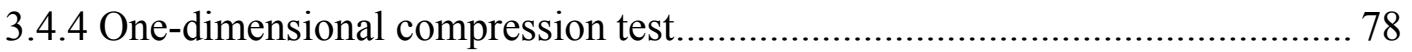

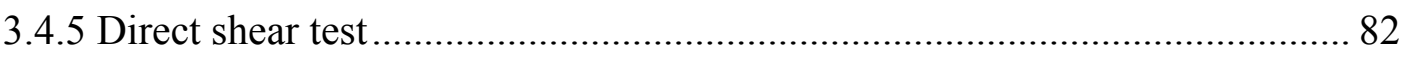

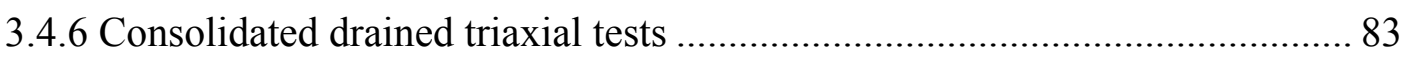

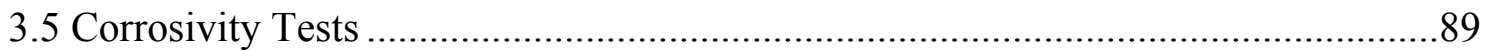

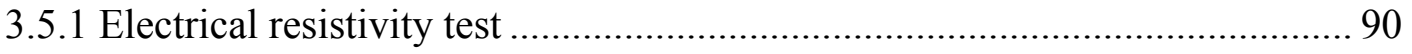

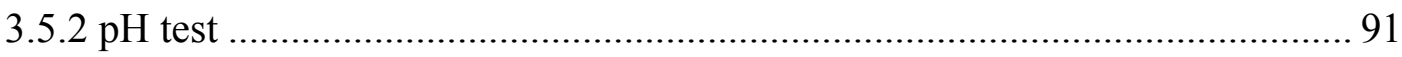

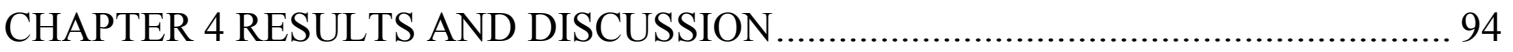

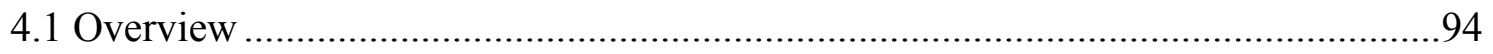

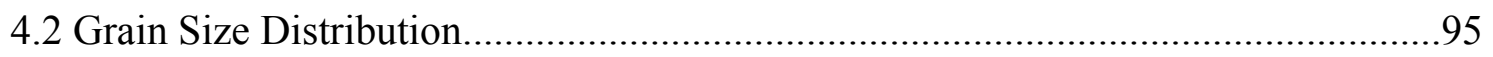

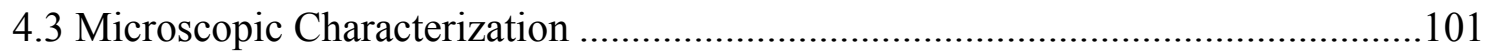

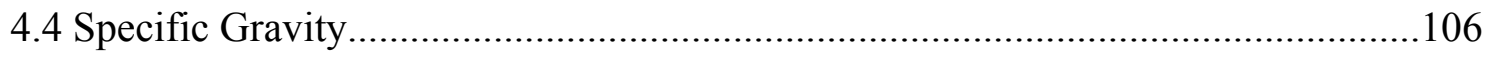

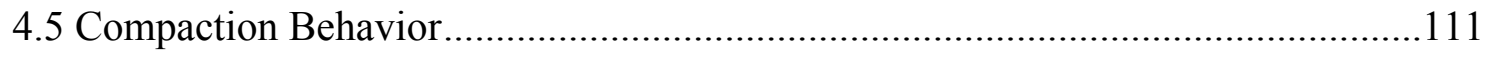

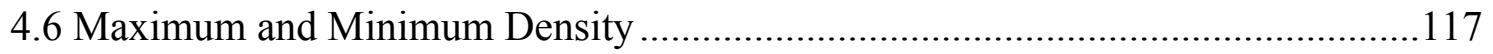

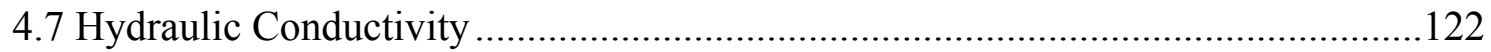

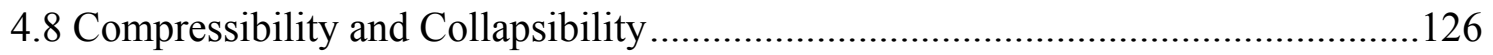

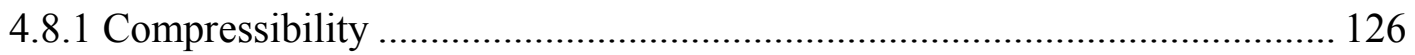

4.8.2 Effect of compaction water content on compressibility ............................... 133

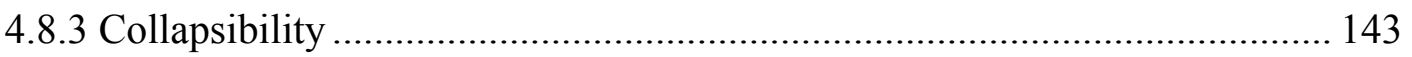




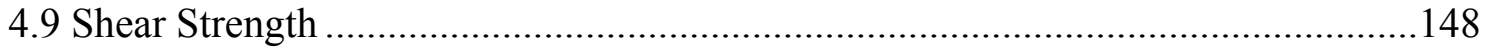

4.9.1 Effect of compaction water content and saturation..................................... 148

4.9.2 Stress-strain and volumetric behaviors of ash mixtures and their shear

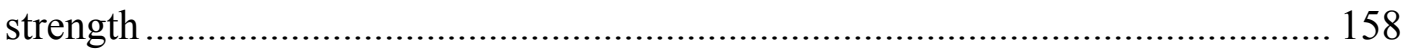

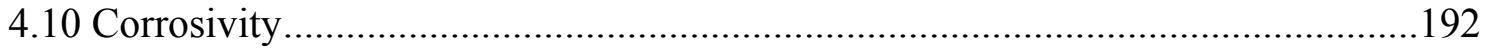

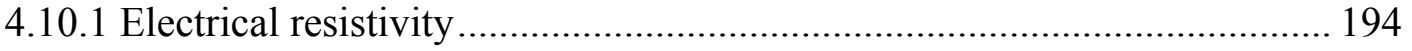

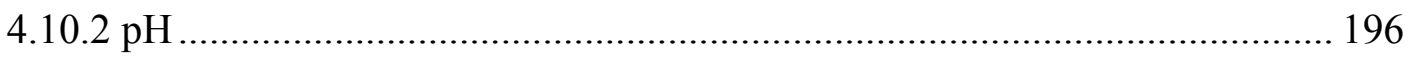

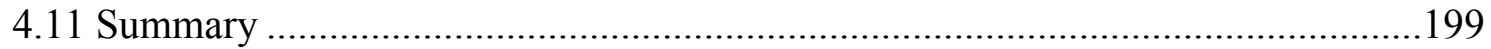

CHAPTER 5 USE OF COAL ASH IN HIGHWAY EMBANKMENTS ...................... 205

5.1 Overview

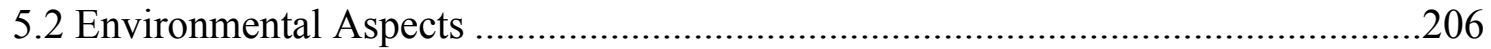

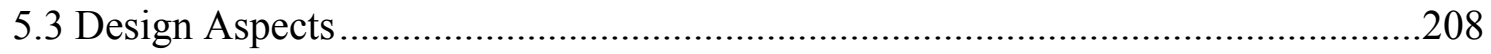

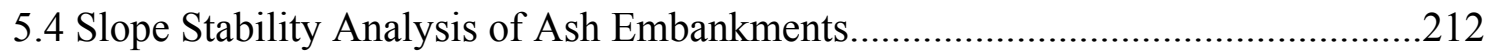

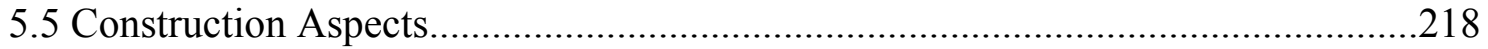

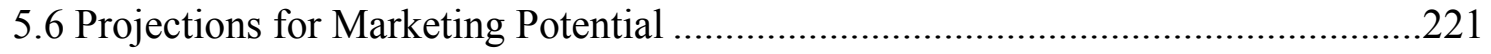

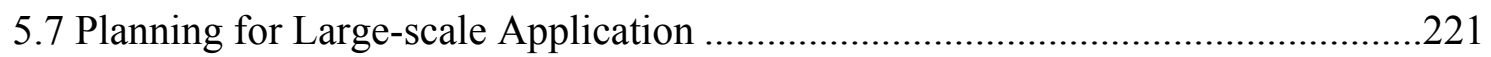

CHAPTER 6 CONCLUSIONS AND RECOMMENDATIONS ................................... 222

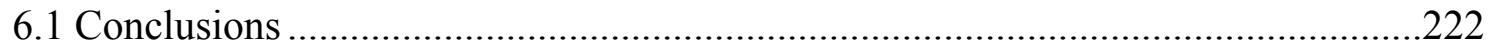

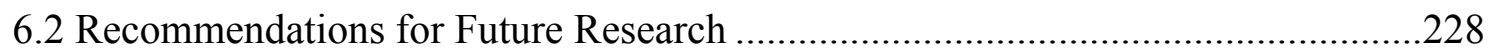

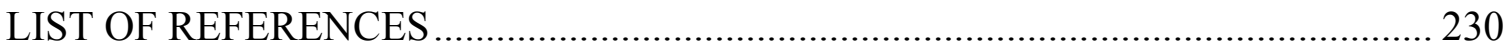




\section{LIST OF TABLES}

Table

Page

Table 2.1 Classification of Coals by Rank ${ }^{\mathrm{A}}$ (ASTM D 388-99). 11

Table 2.2 Quantities and Types of Coal Combustion Products (CCP's) Generated by Indiana Power Plants (GAI and USIFCAU 1993).

Table 2.3 Application Areas of CCPs and Quantities Used in Each Area During 2001 in the United States (ACAA 2001)...................................................................... 26

Table 2.4 CCP Disposal Rates and Methods in Indiana ${ }^{\mathrm{a}}$ (GAI and USIFCAU 1993)... 30

Table 2.5 Results of Direct Shear Tests on Indiana Bottom Ashes (Huang 1990)....... 48

Table 2.6 Uses of Coal Combustion Products in Highway Applications ...................... 57

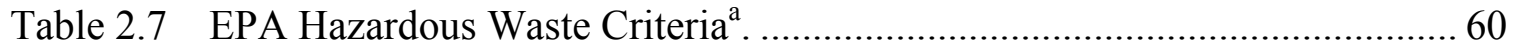

Table 2.8 TCLP Results of Coal Combustion Products (mg/L) (Mason and Carlile

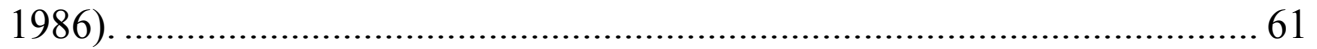

Table 2.9 Indiana Administrative Code Restricted Waste Site Type Criteria .............. 63

Table 3.1 CID Triaxial Compression Tests on Ash Mixtures. ................................... 85

Table 4.1 Specific Gravities of Fly and Bottom Ash............................................ 110

Table 4.2 Chemical Compositions of Fly and Bottom Ash.................................... 111

Table 4.3 Compaction Properties of Ash Mixtures. .................................................. 116

Table 4.4 Maximum and Minimum Densities of Ash Mixtures............................... 118

Table 4.5 Relative Density (R.D.) vs. Relative Compaction (R).............................. 121 
Table

Table 4.6 Hydraulic Conductivities of Ash Mixtures. 122

Table 4.7 Hydraulic Conductivities of Typical Soils (Terzaghi et al. 1996). 125

Table 4.8 Vertical Strains of Ash Mixtures at Various Stress Levels. 129

Table 4.9 Relative Compaction Levels and Compaction Water Contents of Samples (One Dimensional Compression Test).

Table 4.10 Vertical Strains at Various Vertical Stresses for Ash Mixtures Compacted Dry and Wet of Optimum. 138

Table 4.11 Classification of Collapse Potential (ASTM D 5333-92).......................... 144

Table 4.12 Collapse Potentials of Ash Mixtures at Vertical Stress of $100 \mathrm{kPa}$.

Table 4.13 Relative Compaction Levels and Compaction Water Contents of Samples (Direct Shear Test).

Table 4.14 Results of Direct Shear Tests (Peak Friction Angle) 155

Table 4.15 Results of Direct Shear Tests (Cohesion Intercept). 155

Table 4.16 Results of CID Triaxial Tests (Peak Friction Angles of Ash Mixtures Compacted at $\mathrm{R}=95 \%$ ).

Table 4.17 Results of CID Triaxial Tests (Peak Friction Angles of Ash Mixtures Compacted at $\mathrm{R}=90 \%$ ). 182

Table 4.18 Results of CID Triaxial Tests (Critical Friction Angles). 189

Table 4.19 Soil Corrosivity Classification. 193

Table 4.20 Electrical Resistivities of Ash Mixtures. 194

Table $4.21 \mathrm{pH}$ Values of Ash Mixtures. 196 


\section{LIST OF FIGURES}

Figure

Page

Figure 2.1 Trends of Annual Production of Total Electricity and Coal-Generated Electricity in the United States (1950-2000) (EIA 2002). 9

Figure 2.2 Coal Consumption by Electric Utilities in the United States (1950-2000) .... 9

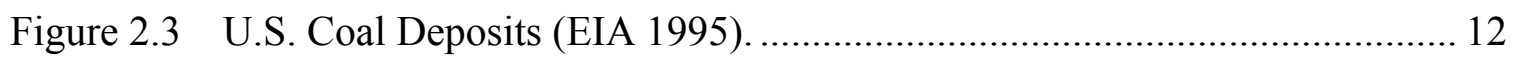

Figure 2.4 Schematic Diagram of Coal Ash Generation (FHWA 2002).................... 14

Figure 2.5 Historical Production and Use of Total CCPs in the US (ACAA 1996), (Tyson and Kalyoncu 2000)................................................................ 20

Figure 2.6 Production of CCPs in the US (ACAA 1996), (ACAA 2001), (Kalyoncu

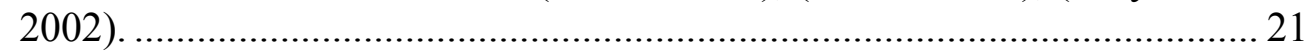

Figure 2.7 Use of CCPs in the US (ACAA 1996), (ACAA 2001), (Kalyoncu 2002)... 21

Figure 2.8 Average Production Ratio of CCPs through 1992-2001 in the US............. 22

Figure 2.9 Average \% Use of CCPs through 1992-2001 in the US........................... 22

Figure 2.10 Production of Fly Ash in Indiana (GAI and USIFCAU 1993)................... 23

Figure 2.11 Production of Bottom Ash, Boiler Slag and FGD Material in Indiana ....... 24

Figure 2.12 Annual Production and Utilization of Coal Combustion Products in Indiana (GAI and USIFCAU 1993)......

Figure 2.13 Typical Gradation Ranges of Coal Ash (McLaren and Digioia 1987), (Huang 1990). 35

Figure 2.14 Typical Compaction Curve (Rodriguez et al. 1988). 38 
Figure

Figure 2.15 Typical Compaction Curve for Cohesionless Soils (Foster 1962). 41

Figure 2.16 Typical Compaction Curves for Western Pennsylvania Bituminous Fly Ashes (DiGioia et al. 1986)

Figure 2.17 Typical Compaction Curves for Western United States Lignite 43

Figure 2.18 Compaction Curve for Bottom Ash from Gallagher Power Plant, Indiana (Huang 1990).

Figure 2.19 One-Dimensional Compression Curves of West Virginia Bottom Ash....... 53

Figure 2.20 One-Dimensional Compression Curves of Indiana Bottom Ash ................. 54

Figure 3.1 One-Dimensional Compression Tests for Compressibility and Collapsibility of Ash Mixtures. 81

Figure 3.2 Soaked Specimen for Direct Shear Test............................................. 84

Figure 3.3 CKC Triaxial Testing System Including $\mathrm{CO}_{2}$ Percolation Equipment. ....... 87

Figure 3.4 Electrical Resistivity Test on Ash Mixture ............................................ 92

Figure $3.5 \mathrm{pH}$ Measurement of Ash Mixture............................................................. 93

Figure 4.1 Particle Size Distributions of the Wabash River Plant Ash. ....................... 96

Figure 4.2 Particle Size Distributions of the Wabash River Plant Fly Ash, Bottom Ash, and Fly/Bottom Ash Mixtures. 98

Figure 4.3 Particle Size Distributions of the A.B.Brown Plant Fly Ash, Bottom Ash, and Fly/Bottom Ash Mixtures.

Figure 4.4 Particle Size Distributions of the F.B.Culley Plant Fly Ash. 100

Figure 4.5 SEM Micrograph of Fly Ash Particles from the Wabash River Plant: (a) Magnification $\times 1000$ (b) Magnification $\times 2000$. 102

Figure 4.6 SEM Micrograph of Fly Ash Particles from the A.B.Brown Plant: (a) Magnification $\times 880$ (b) Magnification $\times 2000$ (c) Magnification $\times 2000 \ldots 103$ 
Figure

Figure 4.7 SEM Micrograph of Fly Ash Particles from the F.B.Culley Plant: (a) Magnification $\times 500$ (b) Magnification $\times 2000$. 105

Figure 4.8 LM Micrograph of Bottom Ash Particles from the Wabash River Plant: (a) Magnification $\times 20$, Several Particles (b) Magnification $\times 50$, A Single Particle (c) Magnification $\times 50$, A Large, Porous Particle. 107

Figure 4.9 LM Micrograph of Bottom Ash Particles from the A.B.Brown Plant: (a) Magnification $\times 20$, Several Particles (b) Magnification $\times 50$, A Single Particle.

Figure 4.10 Compaction Curves of Fly Ash and Bottom Ash Mixtures from the Wabash River Plant. 113

Figure 4.11 Compaction Curves of Fly Ash and Bottom Ash Mixtures from the A.B.Brown Plant.

Figure 4.12 Compaction Curves of Fly Ash from the F.B.Culley Plant.

Figure 4.13 Results of Hydraulic Conductivity Tests: (a) Wabash River Plant Ash Mixyures (b) A.B.Brown Plant Ash Mixtures.

Figure 4.14 One-Dimensional Compression Curves of Ash Mixtures: (a) Wabash River Plant (b) A.B.Brown Plant (c) F.B.Culley Plant. 127

Figure 4.15 Constrained Moduli of Ash Mixtures and Sands. 132

Figure 4.16 One-Dimensional Compression Curves of Fly Ashes Compacted Dry of Optimum and Wet of Optimum: (a) Wabash River Plant (b) A.B.Brown Plant (c) F.B.Culley Plant.

Figure 4.17 One-Dimensional Compression Curves of Ash Mixtures ( $\mathrm{F}=50 \%, \mathrm{~B}=$ 50\%) Compacted Dry of Optimum and Wet of Optimum: (a) Wabash River Plant (b) A.B.Brown Plant.

Figure 4.18 Constrained Moduli of Fly Ashes Compacted Dry of Optimum and Wet of Optimum: (a) Wabash River Plant (b) A.B.Brown Plant (c) F.B.Culley Plant. 
Figure

Page

Figure 4.19 Constrained Moduli of Ash Mixtures ( $\mathrm{F}=50 \%, \mathrm{~B}=50 \%)$ Compacted Dry of Optimum and Wet of Optimum: (a) Wabash River Plant (b) A.B.Brown Plant.

Figure 4.20 Results of Collapsibility Tests: (a) Wabash River Plant (b) A.B.Brown Plant (c) F.B.Culley Plant. 146

Figure 4.21 Results of Direct Shear Tests on Samples from the Wabash River Plant Ash Mixtures: (a) $\mathrm{F}=100 \%$ (b) $\mathrm{F}=75 \%, \mathrm{~B}=25 \%$ (c) $\mathrm{F}=50 \%, \mathrm{~B}=50 \%$... 151

Figure 4.22 Results of Direct Shear Tests on Samples from the A.B.Brown Plant and F.B.Culley Plant: (a) $F=100 \%$ (b) $F=75 \%, B=25 \%$ (c) $F=50 \%, B=50 \%$ (d) $\mathrm{F}=100 \%$ (F.B.Culley Plant). 153

Figure 4.23 Peak Friction Angles of Ash Mixtures Compacted Dry of Optimum and Wet of Optimum (Results of Direct Shear Tests): (a) Wabash River Plant (b) A.B.Brown Plant and F.B.Culley Plant. 156

Figure 4.24 Peak Friction Angles of As-Compacted and Soaked Samples (Results of Direct Shear Tests): (a) Wabash River Plant (b) A.B.Brown Plant and F.B.Culley Plant.

Figure 4.25 Triaxial Sample: Failure with Shear Plane. 161

Figure 4.26 Triaxial Samples: Bulging Failures 162

Figure 4.27 Triaxial Sample: Combined Pattern of Shear Banding and Bulging. 163

Figure 4.28 CID Triaxial Tests on $\mathrm{F}=100 \%$ from the Wabash River Plant $(\mathrm{R}=95 \%)$ : (a) Deviatoric Stress vs. Axial Strain (b) Volumetric Strain vs. Axial Strain. 165

Figure 4.29 CID Triaxial Tests on $F=100 \%$ from the A.B.Brown Plant ( $\mathrm{R}=95 \%$ ): (a) Deviatoric Stress vs. Axial Strain (b) Volumetric Strain vs. Axial Strain.. 166

Figure 4.30 CID Triaxial Tests on $F=100 \%$ from the F.B.Culley Plant $(\mathrm{R}=95 \%)$ : (a) Deviatoric Stress vs. Axial Strain (b) Volumetric Strain vs. Axial Strain.. 167

Figure 4.31 CID Triaxial Tests on $\mathrm{F}=75 \%, \mathrm{~B}=25 \%$ from the Wabash River Plant $(\mathrm{R}=$ 95\%): (a) Deviatoric Stress vs. Axial Strain (b) Volumetric Strain vs. Axial Strain. 168 
Figure

Page

Figure 4.32 CID Triaxial Tests on $\mathrm{F}=75 \%, \mathrm{~B}=25 \%$ from the A.B.Brown Plant $(\mathrm{R}=$ 95\%): (a) Deviatoric Stress vs. Axial Strain (b) Volumetric Strain vs. Axial

Strain. 169

Figure 4.33 CID Triaxial Tests on $\mathrm{F}=50 \%, \mathrm{~B}=50 \%$ from the Wabash River Plant $(\mathrm{R}=$ 95\%): (a) Deviatoric Stress vs. Axial Strain (b) Volumetric Strain vs. Axial

Strain. 170

Figure 4.34 CID Triaxial Tests on $\mathrm{F}=50 \%, \mathrm{~B}=50 \%$ from the A.B.Brown Plant $(\mathrm{R}=$ 95\%): (a) Deviatoric Stress vs. Axial Strain (b) Volumetric Strain vs. Axial Strain. 171

Figure 4.35 CID Triaxial Tests on $\mathrm{F}=100 \%$ from the Wabash River Plant $(\mathrm{R}=90 \%)$ : (a) Deviatoric Stress vs. Axial Strain (b) Volumetric Strain vs. Axial Strain. 174

Figure 4.36 CID Triaxial Tests on $F=100 \%$ from the A.B.Brown Plant ( $R=90 \%$ ): (a) Deviatoric Stress vs. Axial Strain (b) Volumetric Strain vs. Axial Strain.. 175

Figure 4.37 CID Triaxial Tests on $F=100 \%$ from the F.B.Culley Plant ( $\mathrm{R}=90 \%$ ): (a) Deviatoric Stress vs. Axial Strain (b) Volumetric Strain vs. Axial Strain.. 176

Figure 4.38 CID Triaxial Tests on $\mathrm{F}=75 \%, \mathrm{~B}=25 \%$ from the Wabash River Plant $(\mathrm{R}=$ 90\%): (a) Deviatoric Stress vs. Axial Strain (b) Volumetric Strain vs. Axial Strain. 177

Figure 4.39 CID Triaxial Tests on $\mathrm{F}=75 \%, \mathrm{~B}=25 \%$ from the A.B.Brown Plant $(\mathrm{R}=$ 90\%): (a) Deviatoric Stress vs. Axial Strain (b) Volumetric Strain vs. Axial Strain. 178

Figure 4.40 CID Triaxial Tests on $\mathrm{F}=50 \%, \mathrm{~B}=50 \%$ from the Wabash River Plant $(\mathrm{R}=$ 90\%): (a) Deviatoric Stress vs. Axial Strain (b) Volumetric Strain vs. Axial

Strain. 179

Figure 4.41 CID Triaxial Tests on $\mathrm{F}=50 \%, \mathrm{~B}=50 \%$ from the A.B.Brown Plant $(\mathrm{R}=$ 90\%): (a) Deviatoric Stress vs. Axial Strain (b) Volumetric Strain vs. Axial Strain. 180

Figure 4.42 Effects of Fly Ash Content and Confining Stress on Peak Friction Angle: (a) $\mathrm{R}=95 \%$ (b) $\mathrm{R}=90 \%$ (Wabash River Plant). 184 
Figure

Figure 4.43 Effects of Fly Ash Content and Confining Stress on Peak Friction Angle: (a) $\mathrm{R}=95 \%$ (b) $\mathrm{R}=90 \%$ (A.B.Brown Plant). 185

Figure 4.44 Effect of Fly Ash Content on Critical Friction Angle............................ 187

Figure 4.45 Visual Illustration of Q and R Values for Triaxial Tests on Fly Ashes. .... 191

Figure 4.46 The Effect of Solution $\mathrm{pH}$ upon the Corrosion Rate of Iron ..................... 198

Figure 5.1 Proposed Ash Mixture Embankment................................................... 211

Figure 5.2 Bishop Simplified Method (Bishop 1955), (Nash 1987)......................... 215

Figure 5.3 Slope Stability of Ash Embankments with Different Geometries: (a) Wabash River Plant (b) A.B.Brown Plant. ....................................................... 217 


\section{ACKNOWLEDGEMENTS}

This research was funded with the support of the Indiana Department of Transportation and the Indiana Department of Commerce through the Joint Transportation Research Program at Purdue University. The authors would like to thank both of these agencies for their financial support. The authors would also like to thank Cinergy/PSI and Vectren Corporation for their support. Thanks are also due to Howard Lewis and Nayyar Zia for their valuable contributions and suggestions. The authors are thankful as well for the support of the Study Advisory Committee throughout the duration of the project. 


\section{IMPLEMENTATION REPORT}

This research study aimed to evaluate the suitability of coal fly/bottom ash mixtures with high fly ash content as substitutes for conventional fill materials in highway embankments. Representative large samples of class F fly ash and bottom ash, collected from three utility power plants in Indiana, were extensively studied in the laboratory for the mechanical evaluation of fly/bottom ash mixtures. Fly ash contents of $50 \%, 75 \%$, and $100 \%$ were used in the study. Slope stability analyses were performed to investigate stability of ash embankments and determine stable embankment geometries by using the properties of ash mixtures found in the laboratory. Although focus was placed on the geotechnical evaluation of the materials for highway embankments, environmental aspects of their utilization were also reviewed and documented. The following conclusions are drawn from the study:

1) Fly ash is composed of fine, nearly spherical particles with sizes ranging from mostly silt to fine sand, whereas bottom ash is made of coarse, angular particles with sizes ranging from sand to small gravel sizes. Fly and bottom ash exhibit some special morphological characteristics that are distinctly different from typical soils. 
Some fly ash particles are hollow spheres with thin walls. Some bottom ash particles have complex pore structures. Also, some of the fly ash or bottom ash particles are agglomerations of finer particles. The morphological characteristics of fly and bottom ash affect their specific gravity, particle strength, and consequently other mechanical properties to varying degrees. The impact of these morphological characteristics on mechanical properties tends to be constant for a given ash source, but vary between different ash sources.

2) Fly/bottom ash mixtures (with mixture ratios ranging from $50 \%$ to $100 \%$ fly ash content) exhibit relatively well-defined moisture-density relationships, and the relationships vary with mixture ratios. As the fly ash content increases from $50 \%$ to $100 \%$ (i.e., as bottom ash content decreases from $50 \%$ to zero), $w_{\text {opt }}$ increases, and $\gamma_{\mathrm{d}, \max }$ decreases gradually. The values of $\gamma_{\mathrm{d}, \max }$ for compacted ash mixtures tend to vary greatly from plant to plant, due to a relatively wide range of specific gravity values from plant to plant. However, overall, the values of $\gamma_{\mathrm{d}, \max }$ of ash are lower than those of typical compacted soils.

3) In general, compacted ash mixtures are slightly more compressible than typical compacted sands at the same compaction levels, mainly due to the higher crushability of fly and bottom ash. The source of crushing in fly ash is due to agglomerations of finer fly ash particles rather than individual fly ash particles, while for bottom ash the cause is agglomerations plus individual bottom ash particles. Hence, with more significant quantities of agglomerations in fly or bottom ash, larger deformations occur with increased loading. Moreover, for a given ash source, mixtures rich in bottom ash tend to have more deformation than those with less bottom ash, due to the additional 
effect of crushing occurring in relatively weak bottom ash particles. The significance of agglomerations in fly or bottom ash and weak bottom ash particles varies typically from ash source to source, which results in a variation in the compressibility of ash mixtures between different ash sources. For a given source, however, the increase in compressibility of ash mixtures with increasing bottom ash is small. And, at the low to moderate stress levels expected in typical highway embankments, the compressibility of compacted ash mixtures is comparable to that of typical compacted sands.

4) Ash mixtures exhibit both relatively high peak and critical state shear strength (i.e. $\phi_{p}^{\prime}$ and $\left.\phi_{c}^{\prime}\right)$. Compacted ash mixtures at moderately high compaction levels (e.g., $95 \%$ relative compaction) exhibit comparable or even higher peak shear strength than that of compacted sands of similar compaction levels. The critical state shear strength of ash mixtures is in a very similar range to that of typical sands. The addition of bottom ash to fly ash increases critical state friction angles gradually (i.e., about $2^{\circ}$ for every $25 \%$ increase of bottom ash content in a mixture), while peak friction angles do not change significantly with increasing bottom ash content.

5) The degree of relative compaction, confining stress, and mixture ratio affect significantly the stress-strain and volumetric behavior of an ash mixture under shearing, and therefore its peak shear strength. Ash mixtures at 95\% relative compaction typically exhibit a similar behavior to granular soils in dense states (i.e. dilatant behavior), whereas those at $90 \%$ relative compaction resemble sand in loose states (i.e. contractive behavior). Increasing confining stress decreases dilation or a tendency for dilation, and thus decreases peak friction angles. Increasing bottom ash content also tends 
to decrease dilation (or a tendency for dilation), primarily due to crushing bottom ash particles in a shear plane during shearing.

6) The effects of compaction water content and inundation (saturation) on the shear strength and compressibility of compacted ash mixtures do not appear to be significant. In general, ash mixtures compacted dry of optimum exhibit slightly higher shear strength and lower compressibility. Inundation leads to a slight decrease in the shear strength and increase in the deformation of ash mixtures.

7) Slope stability of an embankment is primarily a function of the shear strength of the embankment material. Limit equilibrium slope stability analyses of embankments with different geometries using large displacement strengths (i.e. critical state shear strength) of all ash mixtures with mixture ratios ranging from $50 \%$ to $100 \%$ fly ash content were performed. Due to relatively high shear strength, analysis confirmed that for embankments with heights less than $20 \mathrm{~m}$, a $2 \mathrm{H}: 1 \mathrm{~V}$ or flatter slope satisfies stability requirements (i.e., factor of safety higher than 1.3).

8) Appropriate compaction control is important for ash mixtures to possess certain desirable properties, such as a minimum acceptable shear strength and compressibility. The degree of compaction (i.e. relative compaction) can be used effectively to control the compaction of ash mixtures. Difficulties may arise when compacting ash mixtures in a wide range of mixture ratios resulting from current disposal practices. For proper compaction control, a family of compaction curves can be constructed for the range of existing mixtures in a power plant. The relative compaction can then be checked against a compaction curve for a material with grain-size distribution similar to the field-compacted fill. The compaction moisture range and the compaction 
effort must be adjusted so that the minimum value expected for the relative compaction reaches the target value (e.g., at least 95\%).

9) The environmental impact of construction utilizing coal fly/bottom ash mixtures may be a concern to potential users of these materials. Previous laboratory and field experiences confirmed that most coal (fly or bottom) ash used in the constructions did not have detrimental effects on their surrounding environments, such as groundwater contamination due to leaching. To minimize any potential for environmental problems, landfill construction techniques need to be incorporated in building embankments utilizing ash mixtures. Environmental considerations (i.e., limiting water flow through ash fill) also provide beneficial effects to embankment performance by enhancing the mechanical properties of ash mixtures.

10) Compacted ash mixtures are potentially corrosive. If any pipes or structural members are embedded in ash fill, it is recommended to use corrosion-resistant materials. If metallic components need to be used, they must be protected from corrosion by employing adequate protection methods, such as cathodic protection or protective coating. 


\section{CHAPTER 1 INTRODUCTION}

\section{$\underline{1.1 \text { Problem Statement }}$}

Coal-burning power plants produce solid residue by-products, referred to as coal ash or coal combustion products $(\mathrm{CCP})$, in the production of electricity. The solids included in CCP are fly ash, bottom ash, boiler slag, and flue gas desulfurization (FGD) material. In the United States (US), electricity is an important energy resource, accounting for more than one-third of the primary energy used. Over one-half of this electricity is generated by burning coal. The large consumption of coal generates a large volume of coal ash. In the US, the coal ash produced annually by coal-burning power plants amounts to more than 100 million tons (Kalyoncu 1999). This huge amount of coal ash has been a significant disposal concern to electric utility companies due to a need for expanding ash storage areas and thus rising disposal costs to acquire more space. The disposal problem that the utility companies face is fast becoming a social problem, since the enlargement of disposal areas may become another environmental problem and the increased disposal costs will be eventually transferred to consumers. Accordingly, use of coal ash in construction projects requiring large volume materials, such as highway embankment construction, is highly promising in solving the disposal problem.

Several projects that successfully recycled a single type of CCP as construction 
materials have shown financial savings to both highway agencies and electric utility plants (Srivastava and Collins 1989; Brendel and Glogowski 1989; GAI and USIFCAU 1993). In common disposal practice, however, fly ash and bottom ash, which account for most CCP production, are either ponded or landfilled together in the form of mixtures to minimize disposal costs. The disposed ash, therefore, develops different properties depending on the mixture proportion. Karim (1997) examined the effect of mixture proportions of fly ash and bottom ash on compaction and shear strength. He reported that the behavior of a mixture of fly ash and bottom ash varies with the mixture proportions.

According to the American Coal Ash Association (ACAA 2001), in the US, the general production ratio of fly ash and bottom ash is approximately 80:20, which represents either ponded or landfilled ash consisting of high proportions of fly ash. In Indiana, most coal power plants produce class F fly ash and bottom ash with a typical production ratio of $80 \%$ fly ash and $20 \%$ bottom ash. These ash types are typically disposed together in mixtures. However, the current Indiana Department of Transportation (INDOT) specifications of coal ash utilization in highway construction allow only mixtures with fly ash content less than $40 \%$. If both fly ash and bottom ash were to be used in the construction of highway embankments, which generally demands large amounts of materials, most power utilities would have difficulties in providing the large quantities of bottom ash, while much greater quantities of fly ash still remain in ponds or landfills. Therefore, to maximize the use of the coal ash, and thus significantly reduce the disposal problem that electric utility companies and our society in general face, the direct use of ponded or landfilled ash that is composed of high proportions of fly ash would be desirable. However, a general understanding of the behavior of high 
volume fly ash mixtures is needed. This need is a motivation for this study.

Although there have been investigations into the properties of separated single types of ash, the studies of the fly/bottom ash mixtures, especially with high fly ash contents, are very limited (Huang 1990; DiGioia et al. 1986; Diamond 1985; Seals et al. 1972; Karim 1997). An extensive evaluation of the properties of the fly/bottom ash mixtures with high fly ash content should be the first step in their utilization in highway embankment construction in place of natural borrow soils.

\subsection{Objective and Scope}

The primary objective of this research is to develop guidelines on the utilization of disposed coal ash in highway embankment construction in order to maximize its beneficial use and thus reduce the disposal problem.

Evaluations of the environmental, physical and chemical characteristics of Indiana fly and bottom ash have been made previously (Diamond 1985; Huang 1990; Ke 1990). In this study, both Indiana class F fly ash and bottom ash are selected for investigation, and a focus is given to investigations of fly/bottom ash mixtures with high fly ash contents. Since the intended use of these materials is as embankment construction materials, emphasis is on their mechanical characteristics including compaction (moisture-density relationship), permeability, strength, stiffness, compressibility and collapsibility. Since the mechanical properties of ash mixtures are dependent on the mixture proportions, the investigations evaluate fly/bottom ash mixtures with different mixture ratios. The results obtained are merged with other considerations relevant to 
embankment design and construction and used to develop guidelines on coal ash utilization in highway embankments.

\subsection{Research Approach}

This research aims to evaluate the mechanical characteristics of fly/bottom ash mixtures with high fly ash contents and demonstrate their suitability for use in embankment construction. To accomplish the aims, representative, large samples of class

F fly ash and bottom ash were collected from three utility power plants in Indiana and subjected to an extensive laboratory investigation.

First, a series of characterization tests were performed on fly and bottom ash samples. Following the characterization of the fly and bottom ash, the experiments focused on the investigation of mechanical behaviors of the fly/bottom ash mixtures. The evaluation is accomplished by performing various engineering property tests on ash mixture samples with different mixture ratios. Fly ash contents of $50 \%, 75 \%$, and $100 \%$ are used.

Additionally, the corrosion potential to metal structures, which are commonly included in highway construction, is examined by performing corrosivity tests on the ash mixtures. 
The total experimental program consisted of the following:

1. Material Characterization

- Particle size distribution (ASTM D 422)

- Microscopic examination (Scanning Electron Microscopy, SEM)

- Specific gravity (ASTM D 854)

2. Mechanical properties

- Compaction (Moisture-density relationship) (ASTM D 698)

- Maximum and minimum density (ASTM D 4253 and D 4254)

- Hydraulic conductivity (ASTM D 5856)

- Compressibility and Collapsibility (ASTM D 2435 and D 5333)

- Shear strength (ASTM D 3080 and CID Triaxial Test)

3. Corrosivity

- Resistivity (ASTM G 57)

- pH (ASTM G 51)

The results obtained from the laboratory investigations can be used as material data for the stability assessment of high-volume fly ash embankments. In order to examine suitable fly/bottom ash mixture compositions and embankment geometries, slope stability analyses were performed on ash embankments with different geometries using the different properties of the ash mixtures with different mixture ratios. The limit equilibrium method was used for the stability analyses. 


\subsection{Report Outline}

This report consists of six chapters, including this introduction.

Chapter 2 reviews the generation of coal ash, its collection, disposal and utilization in the United States. An overview of the physical characteristics, chemical and engineering properties of the ash will be presented. The environmental aspects of ash utilization in highway embankment construction will also be discussed.

Chapter 3 introduces the experimental program followed in this study. The testing materials, the testing methods, and the procedures will be described.

Chapter 4 discusses and summarizes the results of all the tests. They include the ash characterization and the mechanical properties of ash mixtures, including compaction, permeability, strength, stiffness, compressibility/collapsibility, and the corrosivity of ash mixtures.

Chapter 5 addresses the application of the results of this study to the design and construction of highway embankments. The results of slope stability analyses are presented. Considerations related to the use of ash mixtures in embankment construction are discussed.

Chapter 6 presents the conclusions drawn from this study. 


\section{CHAPTER 2 LITERATURE REVIEW}

\subsection{Overview}

More than 200 relevant documents were reviewed on the nature, properties, production, disposal and use, and utilization for highway embankments of coal ash. This review focused on publications concerning:

- Coal consumption in the United States and Indiana.

- Nature of coal ash (including fly ash, bottom ash, boiler slag, and flue gas desulfurization material (FGD))

- Production, use, and disposal of coal ash in the United States and Indiana

- Chemical, physical, and mechanical properties of fly and bottom ash

- Use of coal ash in highway embankment: environmental aspects, design, and construction considerations.

Most publications concentrated their attention on a single type of ash, with limited

discussion on mixtures of fly and bottom ash. This chapter will provide a summary of reviews. 


\subsection{Coal Consumption in the United States and Indiana}

Coal is a primary energy source in the United States. More than $50 \%$ of electricity in the country is generated by burning coal (EIA 2000). The consumption of coal by coal fired electric utilities has increased over the years. Figure 2.1 shows the trends of annual production of total electricity and coal-generated electricity from 1950 to 2000 . Increasing demand for electricity has led to a continuous increase in coal consumption.

Figure 2.2 shows the amount of coal consumed by electric utilities for electricity generation for the same period of time. Although there has been a slight drop since 1998, the amount of coal consumed in 1950, 92 million tons, has dramatically increased to 858 million tons in 2000. The decline in consumption through 1999 and 2000 is primarily due to a reduction in total coal stocks, a lack of excess coal production capacity at some mines, and reluctance on the part of some producers to expand production to meet increasing demands in the latter part of the year (EIA 2000).

The state of Indiana is the 10th leading coal-producing state in the United States. Moreover, more than $95 \%$ of total Indiana electricity is generated by burning coal, which makes Indiana second, after Texas, in coal consumption (EIA 1995). Accordingly, Indiana is one of the major coal ash generating states in the United States.

\section{$\underline{2.3 \text { Coal and Coal Ash }}$}

Coal is a combustible, black sedimentary rock of organic origin. It is composed primarily of carbon, hydrogen and oxygen together with smaller amounts of nitrogen and 


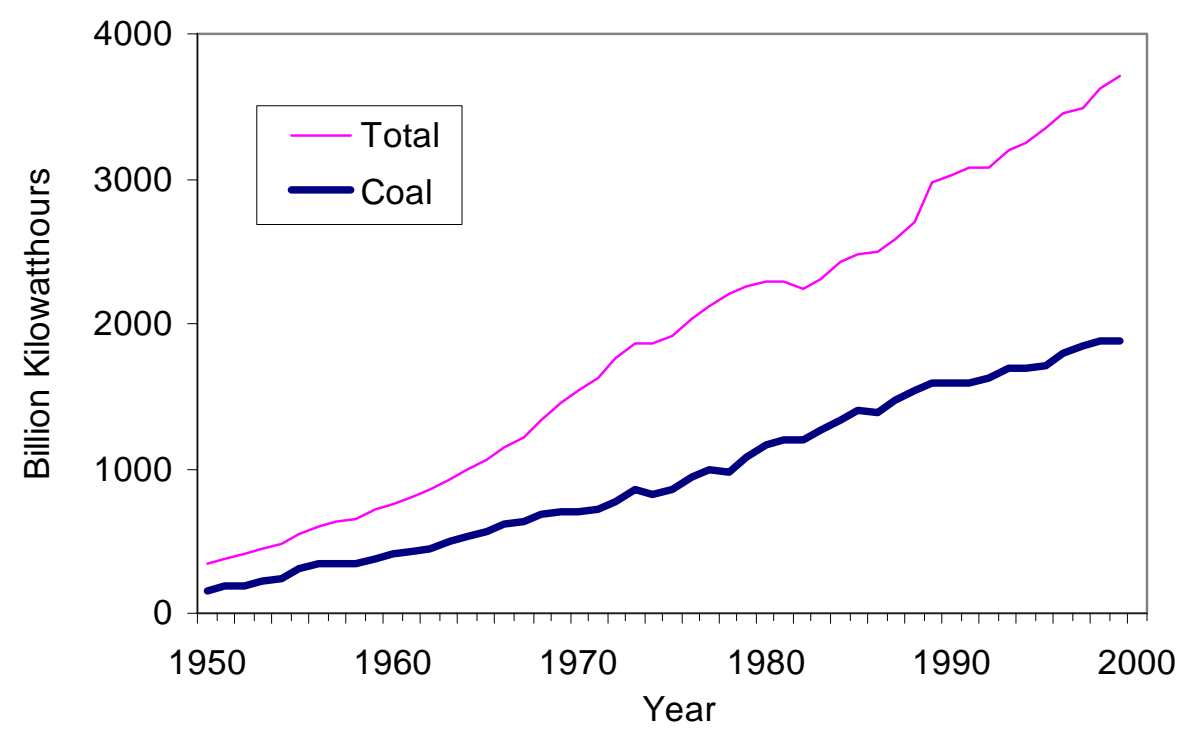

Figure 2.1 Trends of Annual Production of Total Electricity and Coal-Generated Electricity in the United States (1950-2000) (EIA 2002).

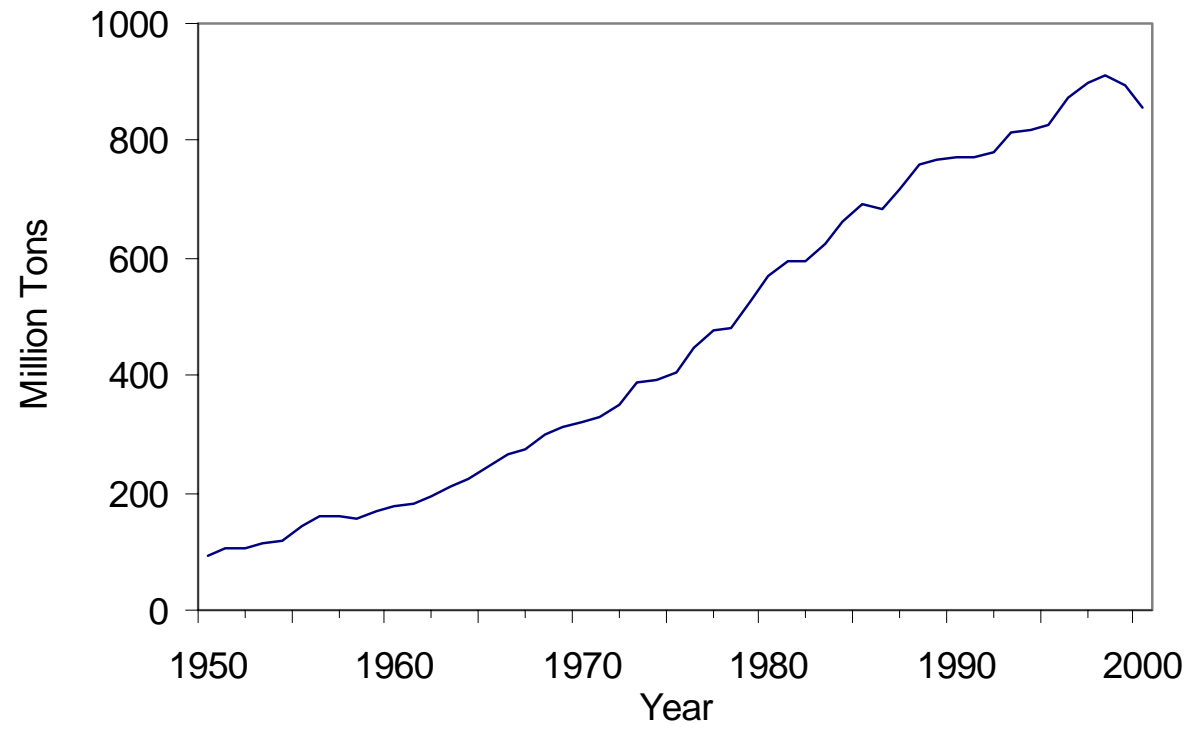

Figure 2.2 Coal Consumption by Electric Utilities in the United States (1950-2000) (EIA 2002). 
sulfur. Coal is ranked according to its carbon content, volatile matter, and heating value into four types: 1) Anthracite, 2) Bituminous, 3) Sub-bituminous, and 4) Lignite. The rank of coal increases progressively from lignite (low rank coal) to anthracite (high rank coal). It has been known that the differences in rank are caused by different amounts of heat and pressure during the geochemical stage of coal development. Table 2.1 shows the ASTM classification of coals by rank (ASTM D 388-99).

The United States contains some of the world's largest coal deposits. The coal producing areas account for about 13 percent of the land area of the nation (EIA 1995). As can be seen in Figure 2.3, bituminous coal is the most abundant type of coal in the US. The majority of electric power utilities, especially in the Eastern and the Midwestern States, burn bituminous coals for the production of electricity. In the state of Indiana, most of the coal burned is from the Illinois basin.

The combustion of coal produces solid residues consisting of mostly incombustible inorganic mineral matter and organic matter that is not fully burned. The amount of unburned residues (ash) is generally associated with the rank of the coal. In other words, the higher the rank of the coal, the less the amount of ash produced. For instance, the bituminous coal used for power generation in the U.S. has an ash content in the range of 6 to 20 percent. Some lignite coals have ash contents as high as 30 percent. In general, approximately $10 \%$ of the coal burned turns into ash (Huang 1990; Karim 1997). 
Table 2.1 Classification of Coals by Rank ${ }^{\mathrm{A}}$ (ASTM D 388-99).

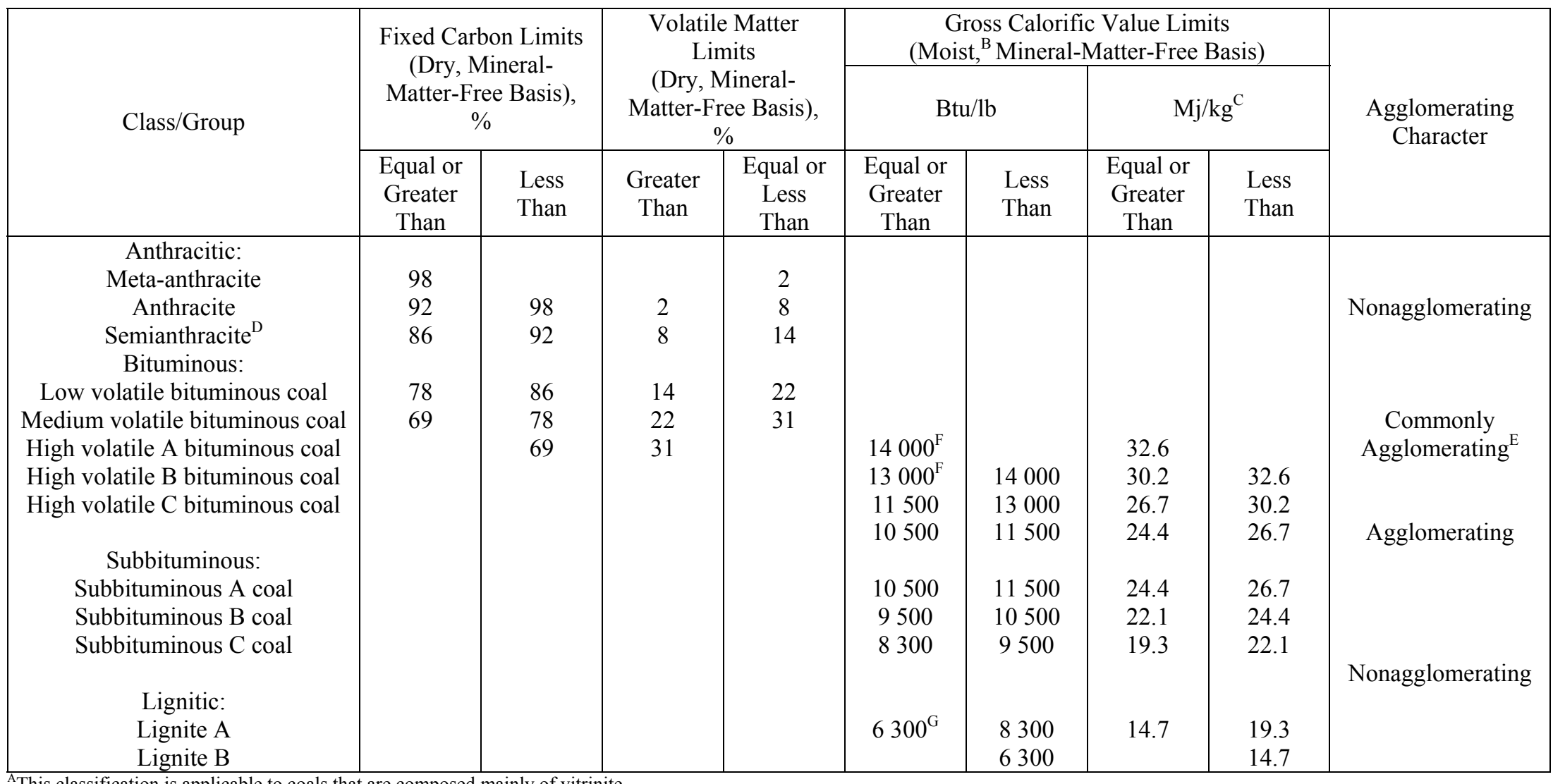

${ }_{\mathrm{A}}^{\mathrm{A}}$ This classification is applicable to coals that are composed mainly of vitrinite.
${ }^{\mathrm{B}}$ Moist refers to coal containing its natural inherent moisture but not including visible water on the surface of the coal.

${ }^{\mathrm{C}}$ Megajoules per kilogram. To convert British thermal units per pound to megajoules per kilogram, multiply by 0.002326 .

DIf agglomerating, classify in low volatile group of the bituminous class.

${ }^{\mathrm{E}} \mathrm{It}$ is recognized that there may be nonagglomerating varieties in these groups of the bituminous class, and that there are notable exceptions in the high volatile $\mathrm{C}$ bituminous group.

${ }^{\mathrm{F}}$ Coals having $69 \%$ or more fixed carbon on the dry, mineral-matter-free basis shall be classified according to fixed carbon, regardless of gross calorific value.

${ }^{\mathrm{G}}$ Editorially corrected. 


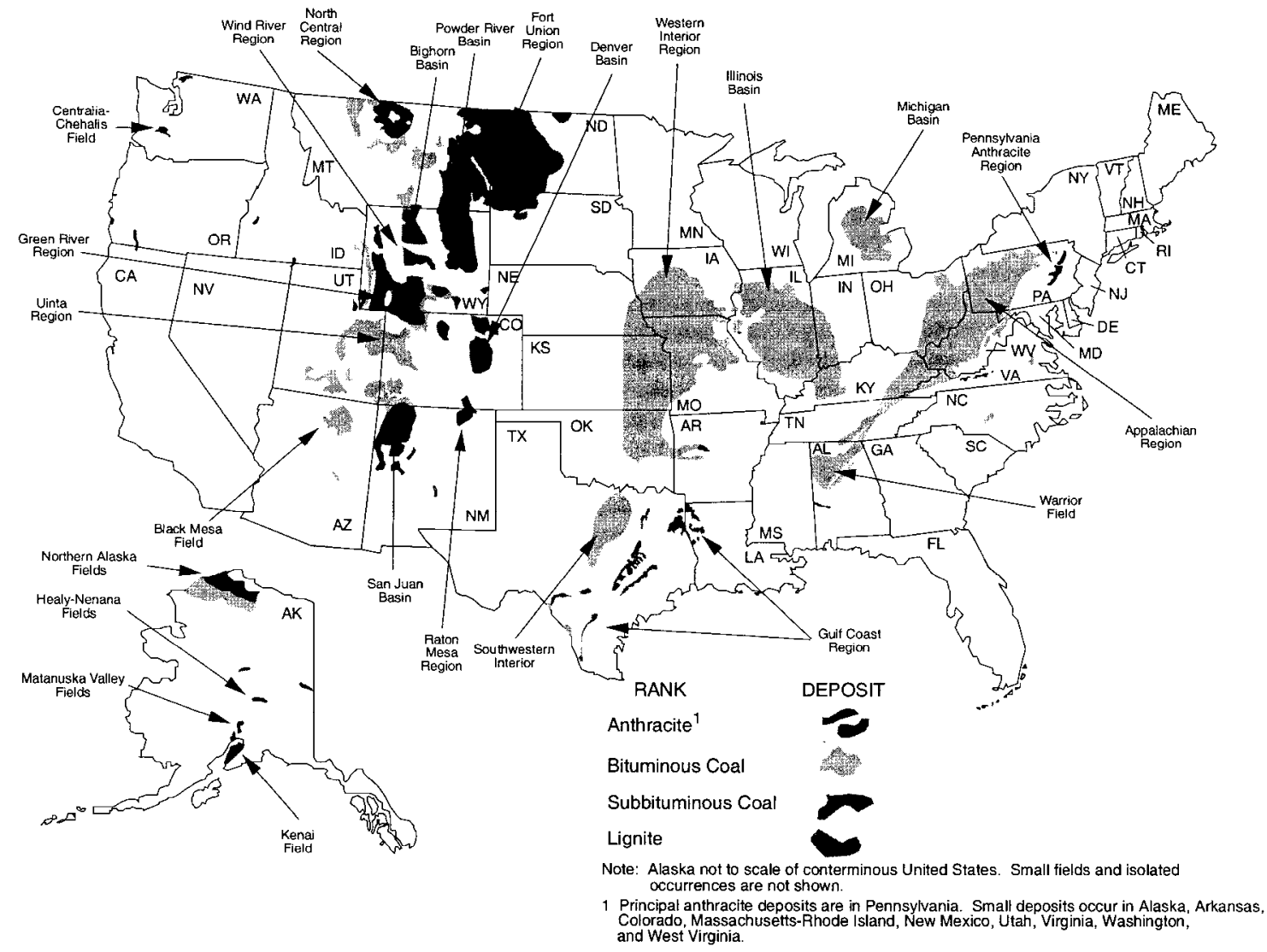

Figure 2.3 U.S. Coal Deposits (EIA 1995). 


\section{$\underline{2.4 \text { Coal Combustion Products (CCPs) }}$}

Coal ash is a collective term referring to any materials or residues produced from the combustion of coal. Coal ash includes fly ash, bottom ash, boiler slag and flue gas desulfurization materials (FGD). Other equivalent terms, such as coal combustion wastes (CCWs), coal combustion by-products (CCBPs), and coal combustion products (CCPs), have also been used to refer to coal ash. Lately, coal combustion products (CCPs) has become a household term for those in the power industry, the ash marketers, and most users of these materials (Kalyoncu 2000).

During combustion in an electric power plant, the coal is first crushed and pulverized, then injected into the boiler furnaces, where the coal is burned. During the burning process, the organic matter in the coal is burned off immediately, whereas the incombustible material undergoes particle melting and tends to fuse together to form ash (Huang 1990). The ash either remains in the boiler furnace or is carried by the flue gas stream. The coarse portion of the ash, referred to as bottom ash and boiler slag, settles at the bottom of the boiler furnace. Fine particles, referred to as fly ash, remain suspended in the flue gas stream. While the bottom ash (or boiler slag) is collected directly from the boiler furnace, the fly ash is usually removed from the flue gas and collected by ash precipitators and other scrubbing systems, such as a mechanical dust collector (Kalyoncu 1999). When the fly ash is collected by a flue gas desulfurization (FGD) unit, the material is called FGD product. Figure 2.4 shows a typical schematic diagram of the ash generation at coal-fired electric utilities. 


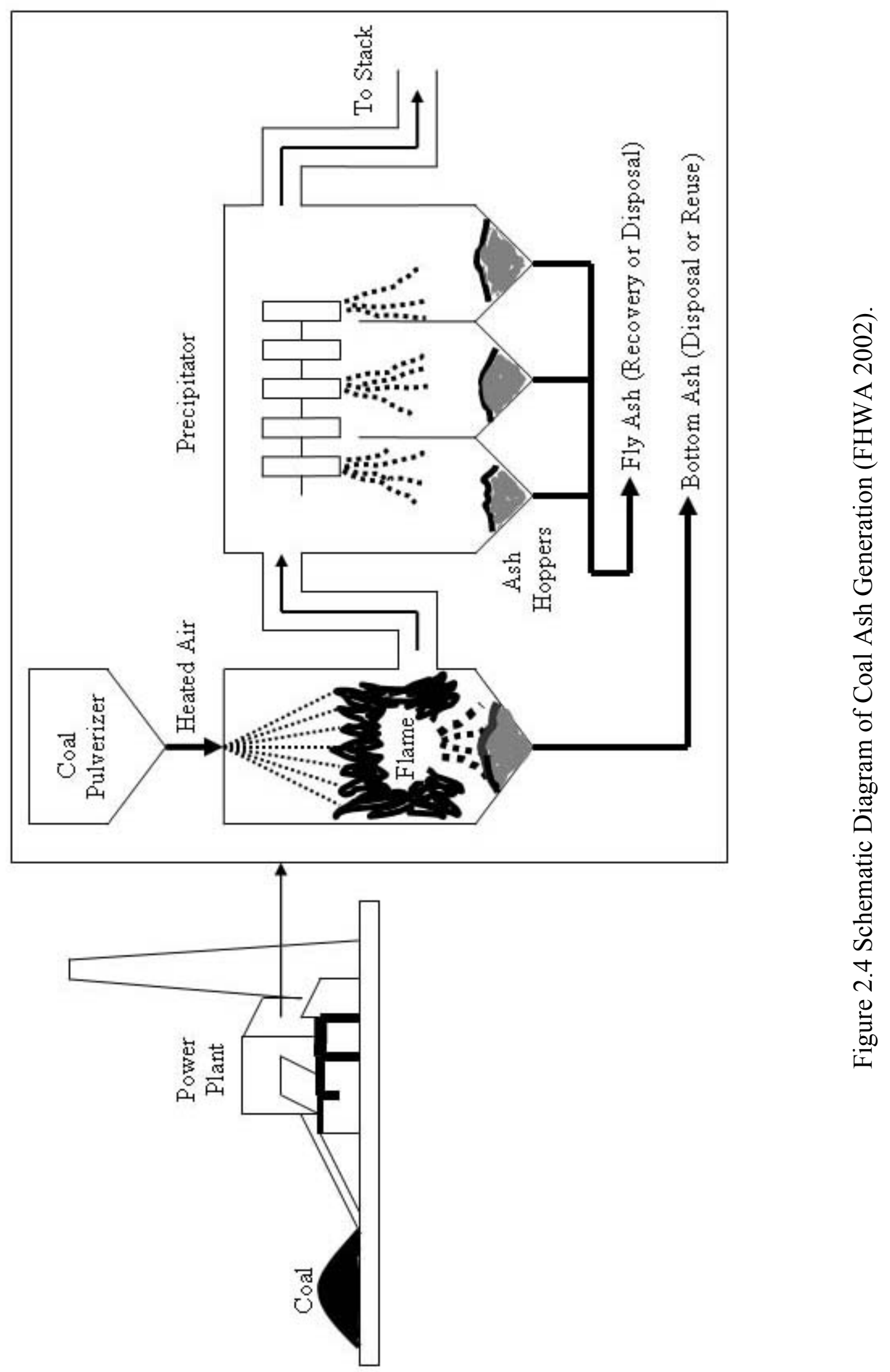




\subsubsection{Fly ash}

Fly ash is a fine fraction of the coal combustion products (CCPs). It is a powdery particulate material that has particle sizes ranging between fine silts and fine sands. The fly ash particles remain suspended and are carried away by the flue gas in the boiler during the combustion due to their small size and light weight. Prior to being released to the atmosphere with the flue gas through the stack, the fly ash is usually removed from the flue gas and collected by means of electrostatic precipitators, baghouses, or mechanical collection systems such as cyclones.

There are two types of fly ash generated by burning coal. They are referred as class $\mathrm{C}$ and class $\mathrm{F}$ fly ash, respectively. The classification of the two types of fly ash is based on the types of the coal burned. Class C fly ash is normally generated from burning subbituminous or lignite coals, whereas burning bituminous or anthracite coals produce class F fly ash. The common type of fly ash produced in the United States is class F fly ash resulting from burning bituminous coal. They both have pozzolanic properties. ASTM C 618-91 defines the pozzolans as:

"The siliceous or siliceous and aluminous materials which in themselves possess little or no cementitious value but will, in finely divided form and in the presence of moisture, chemically react with calcium hydroxide at ordinary temperatures to form compounds possessing cementitious properties."

It has been known that the pozzolanic properties in fly ash depend on many factors, including quality of coal, degree of pulverization of coal, proportion of free lime and unburned carbon (Sahu and Piyo 2000). High carbon content tends to inhibit pozzolanic reactions. The efficiency of coal-burning may be associated with the amount 
of unburned carbon content, which is measured by weight loss ignition (LOI). An efficient power plant may generate an ash with values of LOI as low as 3\% (Karim 1997). The difference between class C and class F fly ash is basically due to the presence of self-cementitious properties. Class $\mathrm{F}$ fly ash needs both added lime and water to develop cementitious reactions, whereas class $\mathrm{C}$ fly ash contains lime itself, exhibiting cementitious properties in addition to its pozzolanic properties.

\subsubsection{Bottom ash and boiler slag}

Bottom ash and boiler slag are coarse, granular by-products with sizes generally varying from sand to gravel. They are composed of noncombustible matter plus unburned carbon, similar to fly ash. During coal combustion, they are accumulated in the bottom of the boiler furnace, then collected in the ash hoppers or conveyers connected to the furnace bottom.

Depending on the boiler type, the bottom ash collected is classified into one of two types, dry bottom ash and wet bottom ash. Dry bottom ash is produced as a solid in the dry bottom boiler whereas the wet bottom boilers produce wet bottom ash that is kept in the molten state and leaves the furnace as a liquid. The wet bottom ash is more commonly referred to as boiler slag. There are two types of wet bottom boilers: slag-tap boiler and cyclone boiler. The slag-tap boiler burns pulverized coal, and the cyclone boiler burns crushed coal. The ash hopper in each boiler contains quenching water. When the ash in the molten state is quenched in the hopper, it fractures and crystallizes, forming a coarse, angular and glassy material.

In a dry bottom boiler, the ash that is not fine enough to be carried by flue gas 
solidifies and agglomerates into coarse particles and falls into the bottom of the furnace. When a sufficient amount of bottom ash settles at the bottom of the boiler and drops into the ash hopper that is usually filled with water, it is removed by means of high pressure water jets and conveyed by a sluceways either to a disposal pond or to a storage area.

\subsubsection{Flue gas desulfurization (FGD) scrubber sludge}

Flue gases that entrain fly ash during coal-burning are usually discharged to the atmosphere via the stack after passing through an ash precipitator where fly ash is removed. The flue gases contain sulfur dioxide $\left(\mathrm{SO}_{2}\right)$. The emission of the sulfur gas from power generation utilities has been an environmental concern since it can contribute to acid rain. To address this problem effectively, the US Congress passed the Clean Air Act Amendments of 1990 (CAAA '90) (Public Law 101-549) that mandated the reduction of power plant sulfur dioxide emissions (Kalyoncu 2002).

The wet scrubber flue gas desulfurization (FGD) system is a technology developed to reduce the problem by removing the $\mathrm{SO}_{2}$ from the flue gas. The FGD system is designed to introduce a chemical sorbent in a spray form into the exhaust gas system of a coal-fired boiler. Limestone is the most commonly used sorbent, but lime or another alkali sorbent can be used. The chemical sorbent is mixed with water and sprayed into the flue gas where it combines with gas's sulfur compounds. This technique is known as wet scrubbing. The resultant material is collected in liquid form as calcium sulfite $\left(\mathrm{CaSO}_{3}\right)$ or calcium sulfate $\left(\mathrm{CaSO}_{4}\right)$ slurry. The FGD scrubber sludge is the wet solid residue produced from the treatment of these gas emissions. It also contains some fly ash because the FGD system is usually combined with a fly ash removal system. 
Accordingly, the FGD is a mixture of gypsum, calcium sulfite (or calcium sulfate), fly ash and unreacted lime or limestone (Kalyoncu 2002).

2.5 Production, Use, and Disposal of Coal Ash in the United States and Indiana

\subsubsection{Production and use of coal ash}

As stated earlier, coal is a major source for electric power generation in the United States. The amount of coal ash produced has gradually increased with the increased demand by electric utilities. Figure 2.5 summarizes the historical production and use of total CCPs for the last 30 years in the US (ACAA 1996; Tyson and Kalyoncu 2000). The statistics show both the production and the use of total CCPs have been steadily increasing with the rising rate in production. Figure 2.6 and Figure 2.7 summarizes the statistics on the production and the use of each CCP for the years 1992 through 2001 in the US (ACAA 1996; ACAA 2001; Kalyoncu 2002). Annual production of total CCPs has increased from 74.3 million tons in 1992 to 110.2 million tons in 2001. Except for boiler slag, both the production and the use of all other CCPs such as fly ash, bottom ash and FGD material have increased. When comparing the production ratios of each CCP, the production of fly ash accounts for nearly $60 \%$ by weight of the total CCP production (Figure 2.8). If the FGD materials are excluded in the statistics, fly ash production accounts for $75 \%$ of the total.

The statistics on the historical ash production and use in the state of Indiana were not available. However, it was reported that the electric utilities in Indiana produce more 
than 6 million tons of CCPs per year (GAI and USIFCAU 1993). Figure 2.10 and Figure 2.11 and Table 2.2 show the types and amounts of CCPs produced in Indiana. Fly ash and bottom ash account for about $70 \%$ of total CCPs produced and most electric utilities generate class F type fly ash. As mentioned earlier, Indiana is a major coal consuming state in the United States. Accordingly, it is expected that the large demand for coal for electricity generation will lead to a continuous increase in coal ash production.

CCPs have been used beneficially in a number of areas, primarily in cement and concrete, structural fills, waste stabilizations, road base/subbase, and mining applications. The components of CCPs have different uses since they have distinct chemical, physical and mechanical properties. Table 2.3 shows the application areas of types of CCPs and the quantities of the CCPs used in each area during 2001 in the US. Most boiler slags produced are recycled for applications such as blasting grit, roofing granules, and snow and ice control. Fly ash, bottom ash and FGD materials are in a relatively low use, about $30 \%$, although they are used in more diverse applications compared to boiler slags (Figure 2.9). The use of CCPs in Indiana is relatively low, compared to the national scale. As shown in the Figure 2.12, class F fly ash and FGD material is especially underutilized. The low percent use of CCPs indicates that a substantial volume of ash generated is just disposed. 


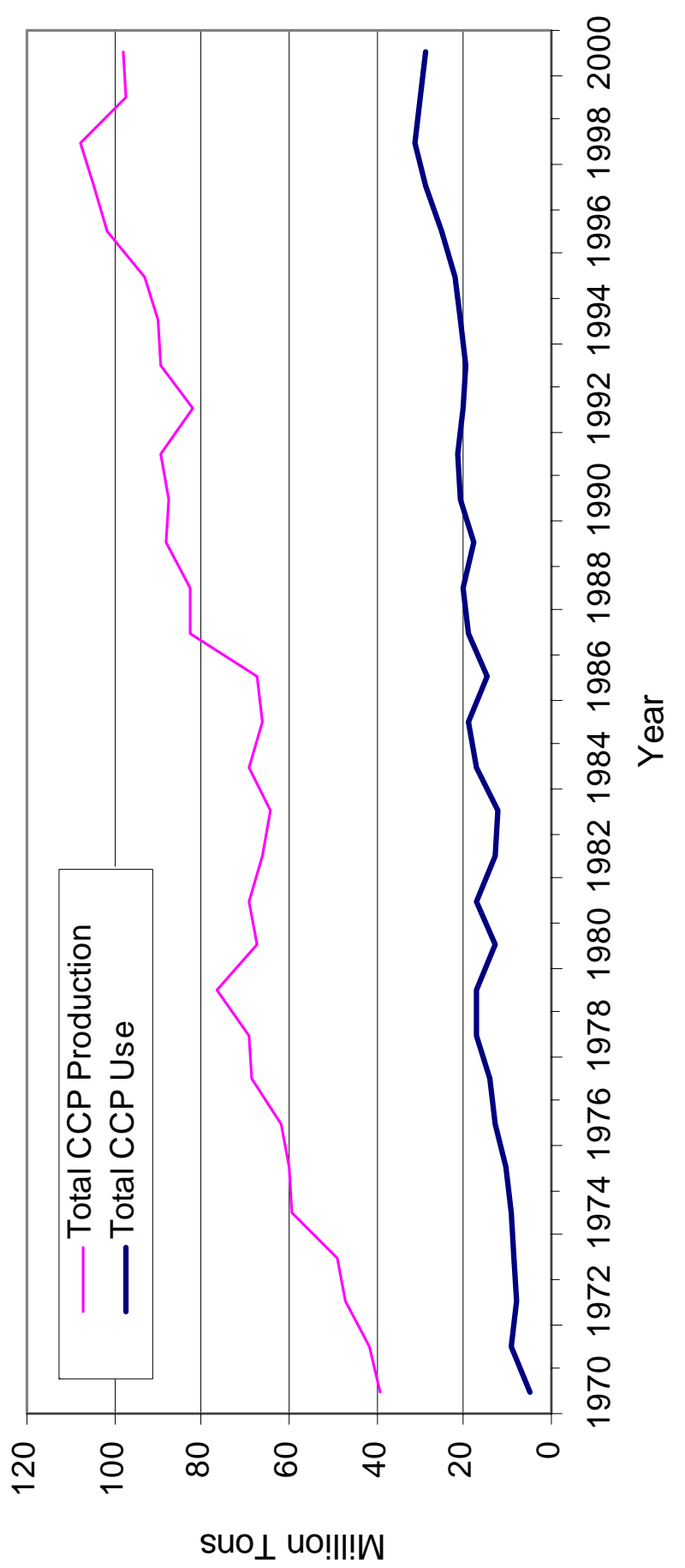

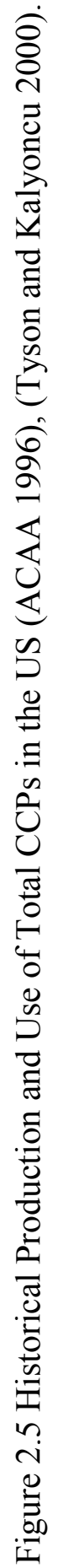




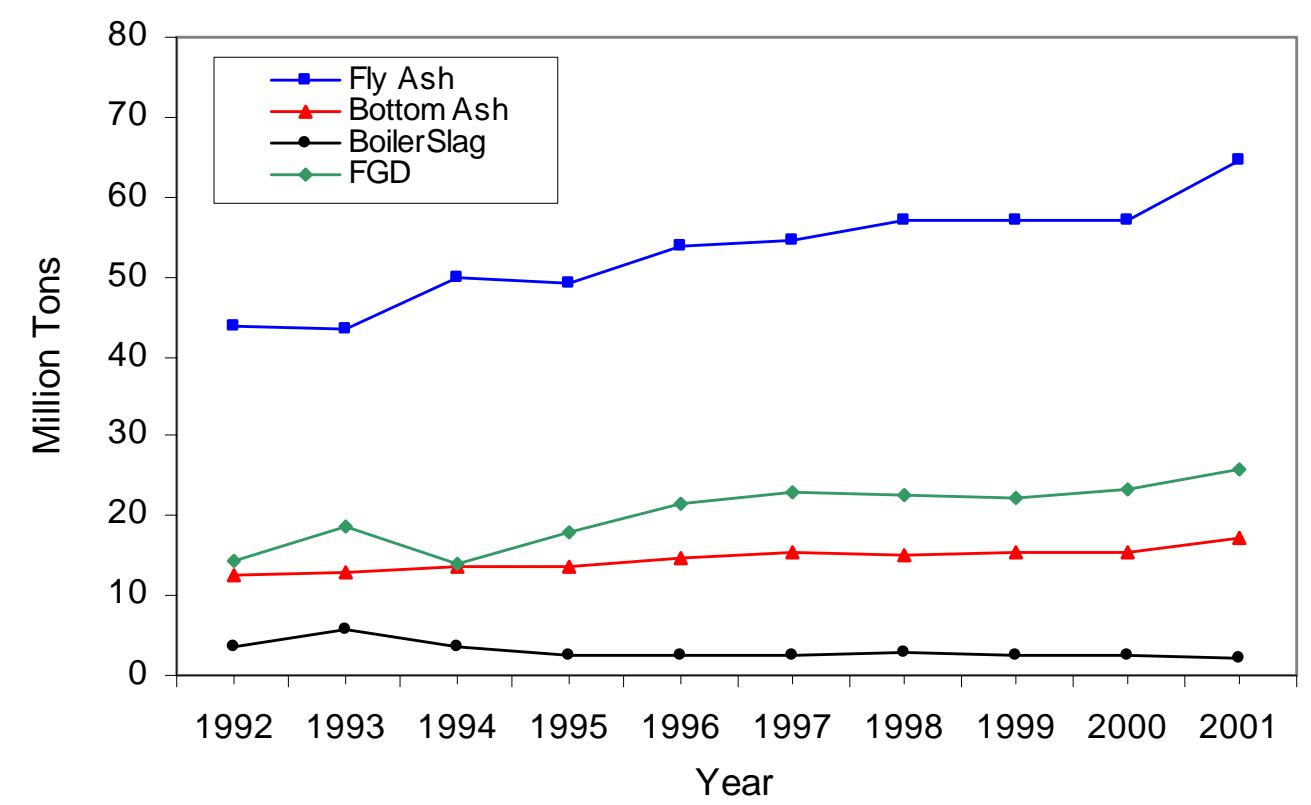

Figure 2.6 Production of CCPs in the US (ACAA 1996), (ACAA 2001), (Kalyoncu 2002).

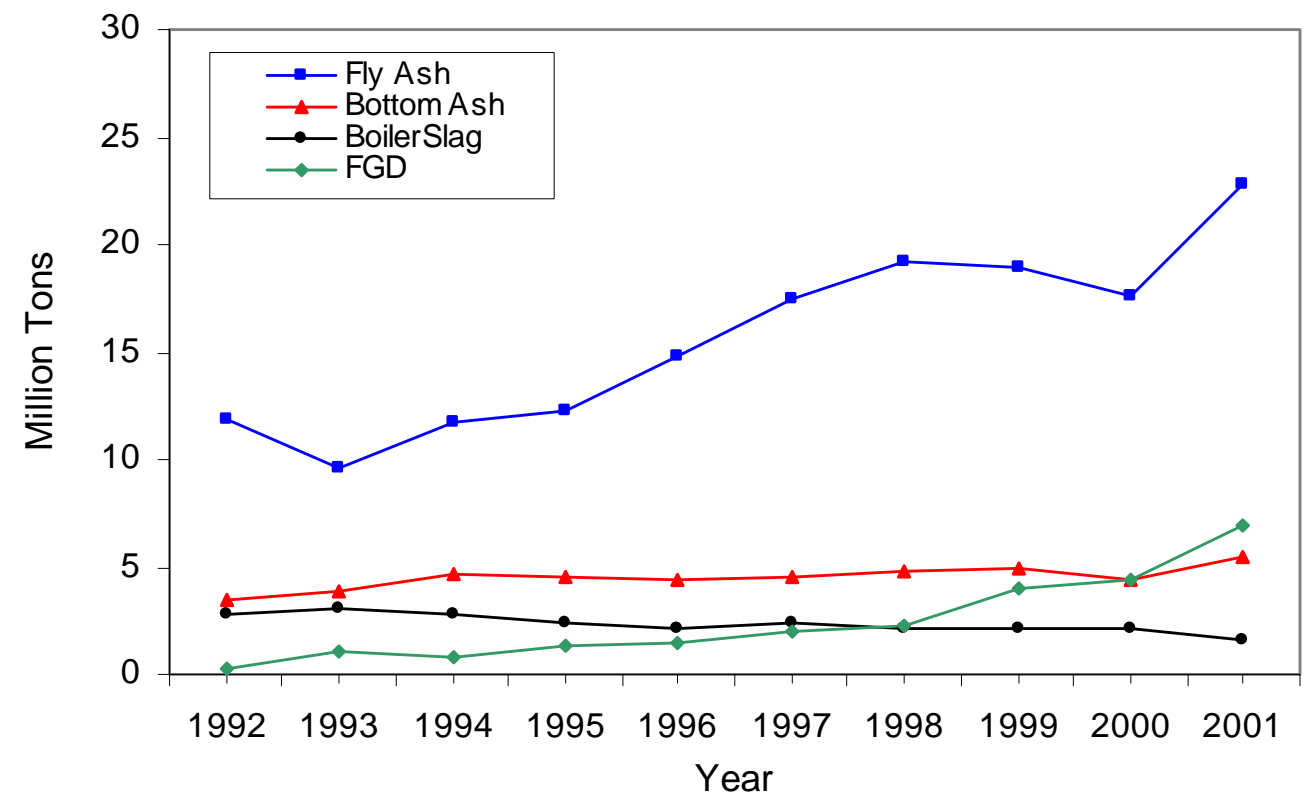

Figure 2.7 Use of CCPs in the US (ACAA 1996), (ACAA 2001), (Kalyoncu 2002). 


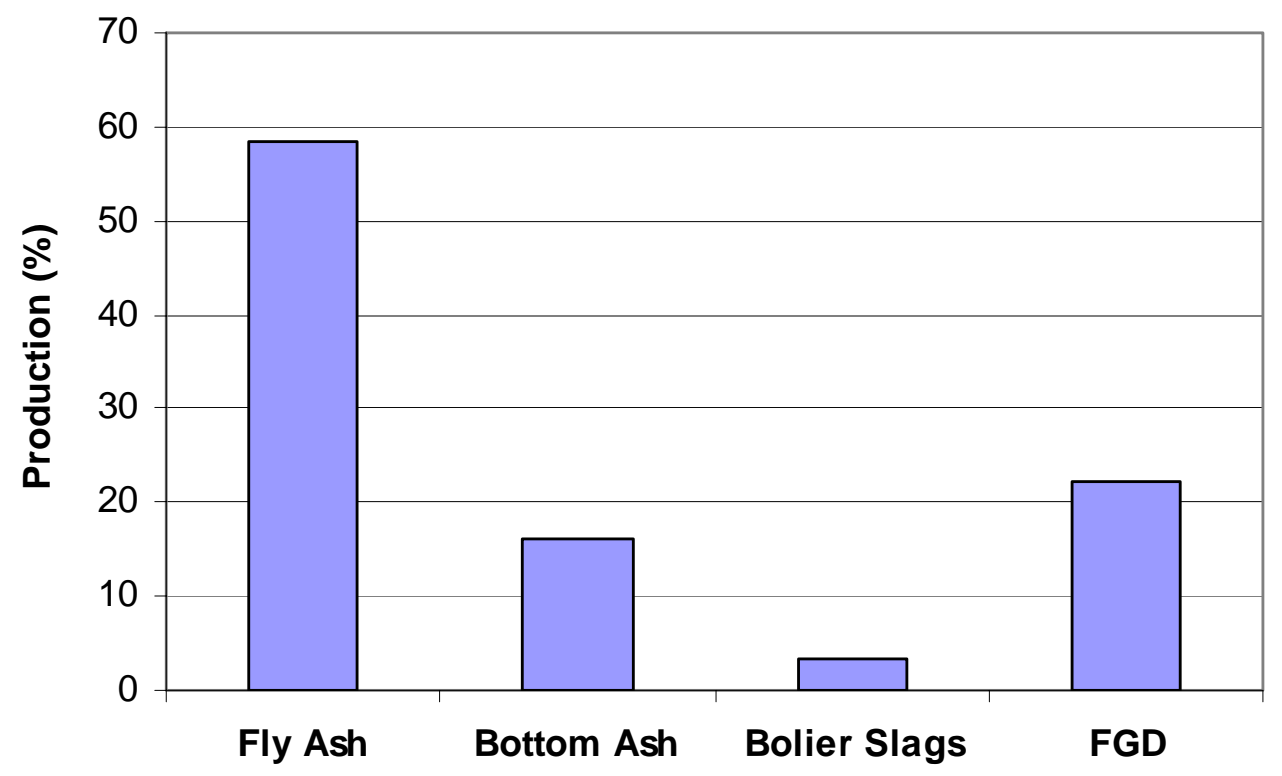

Figure 2.8 Average Production Ratio of CCPs through 1992-2001 in the US.

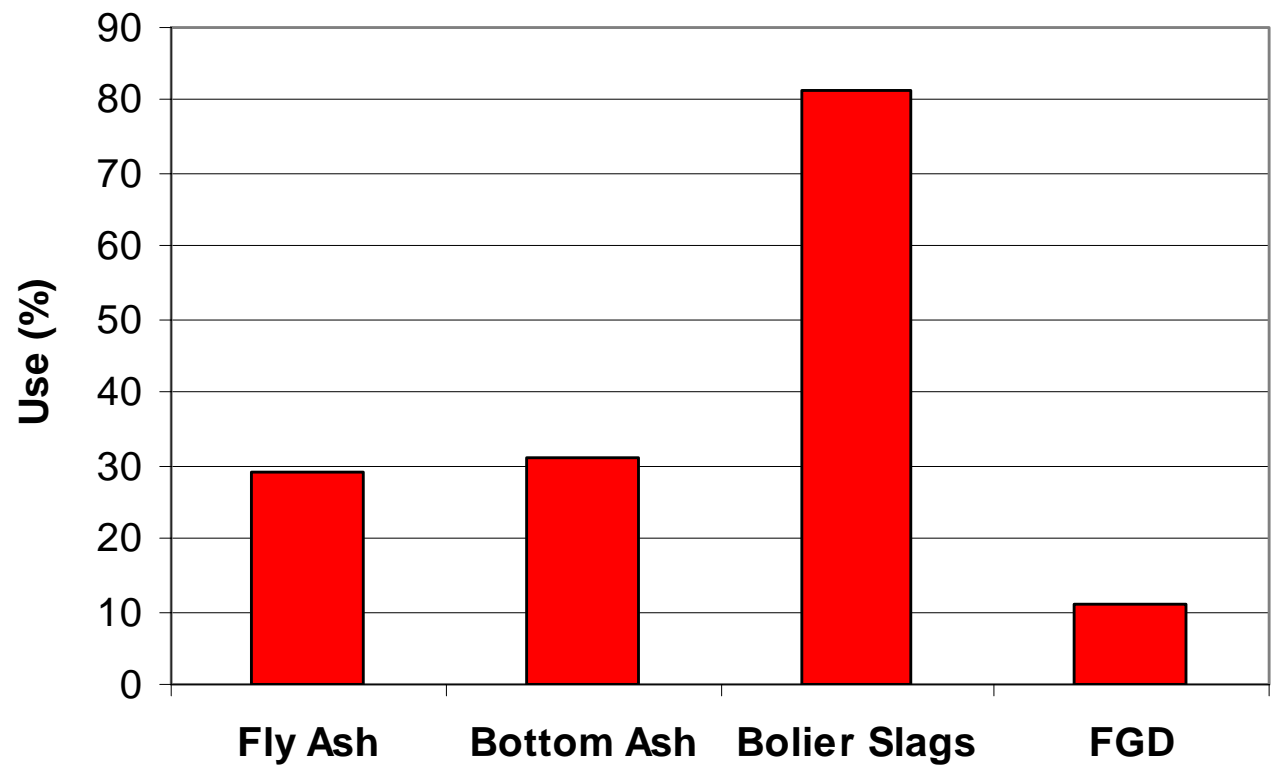

Figure 2.9 Average \% Use of CCPs through 1992-2001 in the US. 


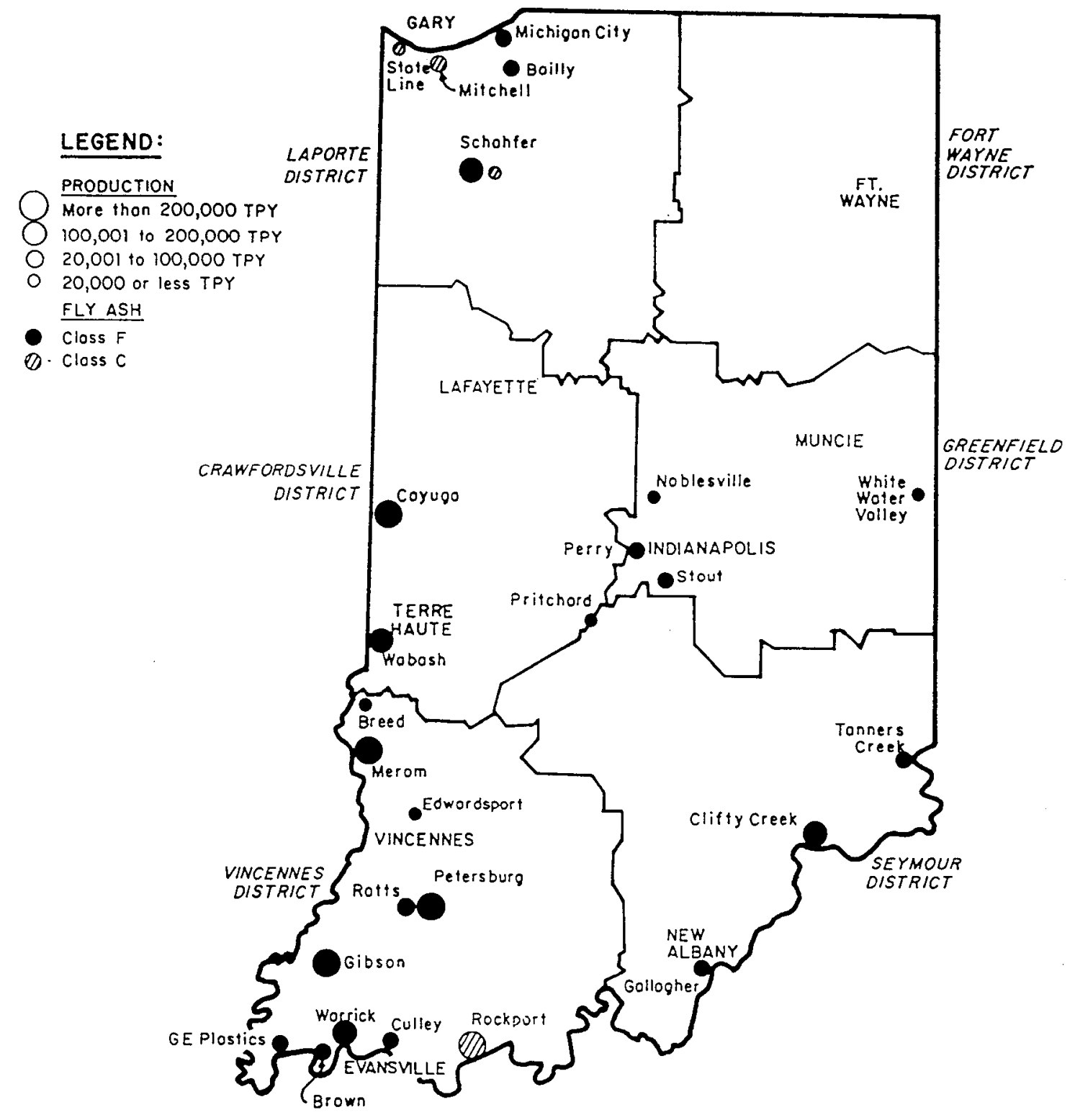

Figure 2.10 Production of Fly Ash in Indiana (GAI and USIFCAU 1993). 


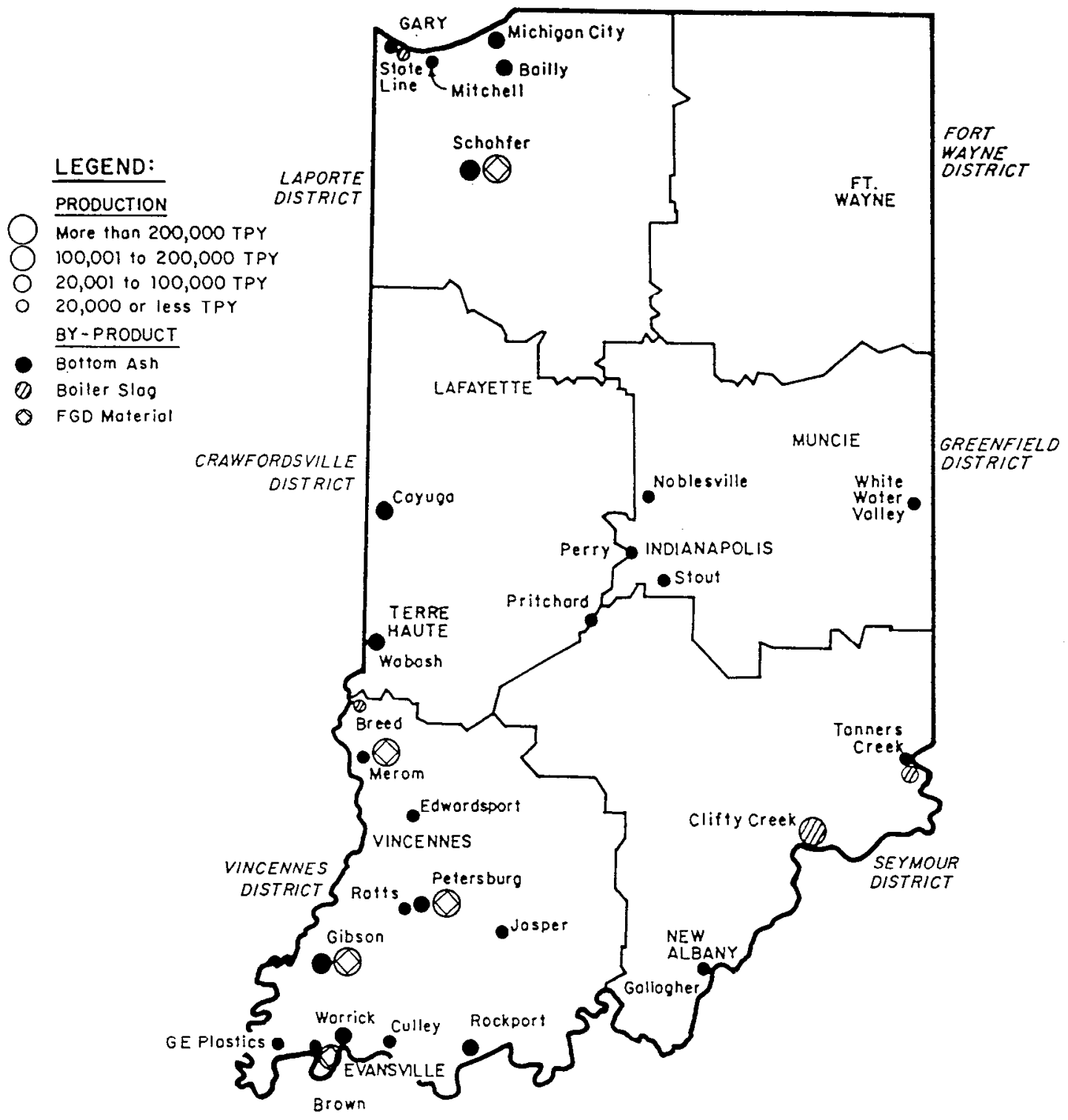

Figure 2.11 Production of Bottom Ash, Boiler Slag and FGD Material in Indiana (GAI and USIFCAU 1993). 
Table 2.2 Quantities and Types of Coal Combustion Products (CCP's) Generated by Indiana Power Plants (GAI and USIFCAU 1993).

\begin{tabular}{|c|c|c|c|c|c|c|c|c|c|c|c|}
\hline \multirow[b]{2}{*}{ Plant } & \multicolumn{2}{|c|}{ Class C Fly Ash } & \multicolumn{2}{|c|}{ Class F Fly Ash } & \multicolumn{2}{|c|}{ Bottom Ash } & \multicolumn{2}{|c|}{ Boiler Slag } & \multicolumn{2}{|c|}{ FGD Material } & \multirow{2}{*}{$\begin{array}{l}\text { Total } \\
\text { CCBP's } \\
\text { Quantity }\end{array}$} \\
\hline & Quantity & Type $^{a}$ & Quantity & Type & Quantity & Type & Quantity & Type & Quantity & Type & \\
\hline \multicolumn{12}{|c|}{ Vincennes District } \\
\hline Breed & & & 8,200 & 1 & & & 19,000 & 4 & & & 27,200 \\
\hline Rockport & 331,000 & 1 & & & 142,000 & 3 & & & & & 473,000 \\
\hline Gibson & & & 640,000 & 2 & 153,000 & 3 & & & 226,000 & 2 & $1,019,00$ \\
\hline Petersburg & & & 301,400 & NT & 75,400 & 3 & & & 456,800 & 3 & 833,600 \\
\hline Edwarsport & & & 7,900 & 2 & 1,900 & 2 & & & & & 9,800 \\
\hline Ratts & & & 50,000 & 3,4 & 12,000 & 4 & & & & & 62,000 \\
\hline Merom & & & 280,000 & 3 & 30,000 & 3,4 & & & 360,000 & 3,4 & 670,000 \\
\hline Brown & & & 88,000 & 2,3 & 22,000 & & & & 180,000 & 3 & 290,000 \\
\hline Culley & & & 88,000 & 2,3 & 22,000 & & & & & & 110,000 \\
\hline Warrick & & & 200,000 & 2,3 & 50,000 & 3 & & & & & 250,000 \\
\hline Jasper & & & & & 12,000 & 4 & & & & & 12,000 \\
\hline G.E. Plastics & & & 27,850 & 3 & 10,120 & 3 & & & & & 37,970 \\
\hline Total & 331,000 & & $1,691,350$ & & 530,420 & & 19,000 & & $1,222,000$ & & $3,794,570$ \\
\hline \multicolumn{12}{|c|}{ Crawfordsville District } \\
\hline Cayuga & & & 223,000 & 2 & 56,000 & 3 & & & & & 279,000 \\
\hline Wabash & & & 120,000 & 3 & 30,000 & 4 & & & & & 150,000 \\
\hline Total & & & 343,000 & & 86,000 & & & & & & 429,000 \\
\hline \multicolumn{12}{|l|}{ Laporte District } \\
\hline Schahfer & 10,900 & NT & 163,000 & NT & 127,800 & NT & & & 309,100 & NT & 610,800 \\
\hline Mitchell & 75,400 & NT & & & 17,400 & NT & & & & & 92,800 \\
\hline Baily & & & 41,000 & NT & 86,800 & NT & & & & & 127,800 \\
\hline Michigan City & & & 33,000 & NT & 77,100 & NT & & & & & 110,100 \\
\hline State Line & 20,000 & 3 & & & 1,200 & 3 & 9,300 & 4 & & & 30,500 \\
\hline Total & 106,300 & & 237,000 & & 310,300 & & 9,300 & & 309,100 & & 972,000 \\
\hline \multicolumn{12}{|c|}{ Seycamour District } \\
\hline Tanners Creek & & & 69,000 & NT & 10,000 & NT & 46,000 & 4 & & & 125,000 \\
\hline Gallagher & & & 76,000 & 2 & 20,000 & 3 & & & & & 96,000 \\
\hline Clifty Creek & & & 194,000 & 3 & & & 240,890 & 4 & & & 434,890 \\
\hline Total & & & 339,000 & & 30,000 & & 286,890 & & & & 655,890 \\
\hline \multicolumn{12}{|c|}{ Greenfield District } \\
\hline Pritchard & & & 17,200 & NT & 4,300 & NT & & & & & 21,500 \\
\hline Perry & & & 27,920 & NT & 6,900 & NT & & & & & 34,900 \\
\hline Stout & & & 75,000 & NT & 18,700 & NT & & & & & 93,700 \\
\hline Noblesville & & & 4,100 & 3 & 1,000 & 4 & & & & & 5,100 \\
\hline Whitewater & & & 19,500 & 2 & 4,875 & 2 & & & & & 24,375 \\
\hline Total & & & 143,720 & & 35,855 & & & & & & 179,575 \\
\hline Total & 437,300 & & $2,754,070$ & & 992,575 & & 315,190 & & $1,531,900$ & & $6,031,035$ \\
\hline
\end{tabular}

NT $=$ Not Tested. 
Table 2.3 Application Areas of CCPs and Quantities Used in Each Area During 2001 in the United States (ACAA 2001).

\begin{tabular}{lcccr}
\hline & (Thousand metric tons) & & \\
& Fly ash & $\begin{array}{l}\text { Bottom } \\
\text { ash }\end{array}$ & $\begin{array}{l}\text { Boiler } \\
\text { slag }\end{array}$ & $\begin{array}{l}\text { FGD } \\
\text { material }\end{array}$ \\
\hline \hline CCP Production & 64671 & 17331 & 2302 & 25857
\end{tabular}

$\underline{\text { CCP Use }}$

\begin{tabular}{lrrrr} 
Cement/Concrete/Grout & 12991 & 751 & 0 & 443 \\
Raw Feed for Cement Clinker & 1037 & 156 & 0 & 28 \\
Flowable Fill & 748 & 7 & 0 & 0 \\
Structural Fills & 3371 & 1084 & 14 & 172 \\
Road Base/Subbase & 1082 & 577 & 0 & 35 \\
Soil Modification & 777 & 110 & 0 & 0 \\
Mineral Filler & 111 & 8 & 11 & 1 \\
Snow and Ice Control & 0 & 814 & 17 & 0 \\
Blasting Grit/Roofing Granules & 0 & 38 & 1353 & 0 \\
Mining Applications & 836 & 113 & 0 & 127 \\
Wallboard & 0 & 0 & 0 & 5651 \\
Waste & & & & \\
Stabilization/Solidification & 1446 & 66 & 0 & 43 \\
Agriculture & 22 & 21 & 0 & 104 \\
Miscellaneous/Other & 410 & 1665 & 257 & 279 \\
Total & 22831 & 5411 & 1651 & 6884 \\
Individual Use Percentage & 35.3 & 31.2 & 71.7 & 26.6 \\
Cumulative Use Percentage & 35.3 & 34.4 & 35.5 & 33.4 \\
\hline
\end{tabular}




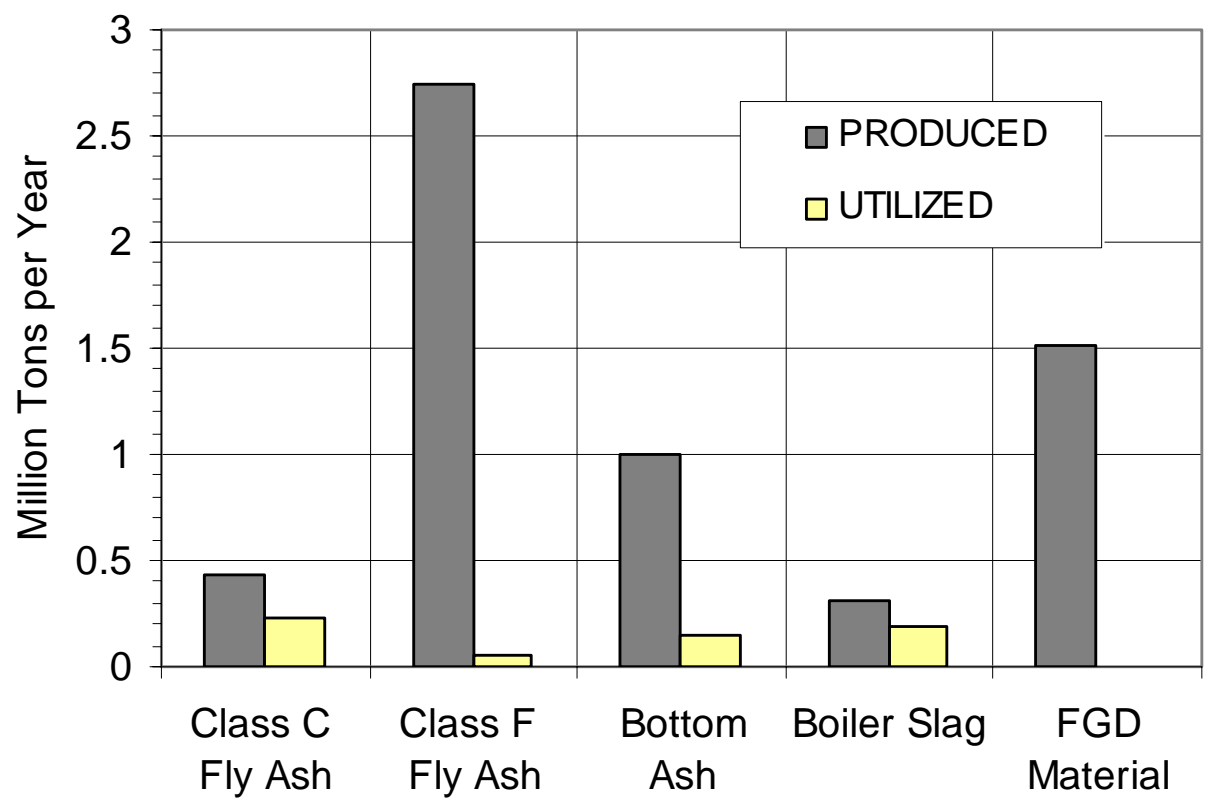

Figure 2.12 Annual Production and Utilization of Coal Combustion Products in Indiana (GAI and USIFCAU 1993). 


\subsubsection{Disposal of coal ash}

During 2001, in the United States, of a total 110 million tons of coal ash generated, about $30 \%$ of the total ash was recycled for beneficial applications, and $70 \%$ of the total, 77 millions tons of ash, was disposed (ACAA 2001). As long as the coal consumption by electric utilities increases, the amount of disposed ash will continue to increase unless either an innovative ash disposal method is developed or ash reuse is increased accordingly.

These enormous quantities of disposed ash have been a burden to the power generation industry since the cost associated with ash disposal is generally high. In the 1980 's, ash disposal costs ranged from $\$ 5$ to $\$ 10$ per ton and the total cost of ash disposal to electric utilities ranged from $\$ 375$ to $\$ 740$ million (ENR 1980). Currently, disposal costs to electric utilities are not exactly known on a national scale. However, it is obvious that the disposal cost has been continuously increasing since then, considering that coal burning by electric utilities has steadily increased. Moreover, stricter environmental requirements for ash disposal have caused an additional increase in the disposal cost. The rising costs in ash disposal will be eventually transferred to the consumers.

Typically, the disposal of coal ash is done using either the dry or wet method. In the dry method, the ash is temporarily stored dry in silos or in large piles, then, as the temporary storage area become full, hauled by trucks to an off-site user for beneficial use or to a final disposal site, a landfill. The ash landfill is normally encased with either low permeability soils such as clay or synthetic membrane to prevent a potential for leachate outflow. Most power plants in urban areas use the dry disposal method due to limited land available. The wet ash disposal method involves adding sufficient water to the dry 
ash generated dry to produce an ash slurry and transporting it to the disposal area, ponds or lagoons, where the slurry is allowed to settle. The transportation of the slurry is normally accomplished by pipelines connecting the ash hoppers used to collect the ash to the disposal area. That is, the slurry is conveyed hydraulically through the pipelines to the ponds or lagoons on site. Compared to the dry disposal, the wet disposal method has the advantage that it is simple to operate and the disposal cost is relatively low.

Most electric power utilities in the state of Indiana dispose of ash using the wet method. Table 2.4 summarizes the disposal methods used in Indiana power plants and the quantities of the disposed ash. Some power plants may dispose ash to the ponds through a single pipeline, where the separate types of collected ash are co-mingled. Other plants may have separate pipelines to discharge separate types of ash to different locations. Many power plants are running out of room for ash storage as the ponds become full and the ash landfills become overfilled.

\subsection{Properties of Coal Ash}

\subsubsection{Chemical properties}

The chemical composition of coal ash varies, depending primarily on the type of coal burned, the fineness of pulverized coal and the efficiency of the coal-burning unit. Selvig et al. (1956) and Abernethy et al. (1969) investigated the common constituents of coal ash from more than 600 ash samples from commercial coals in the United States. They found that coal ash was composed primarily of silica $\left(\mathrm{SiO}_{2}\right)$, ferric oxide $\left(\mathrm{Fe}_{2} \mathrm{O}_{3}\right)$, 
Table 2.4 CCP Disposal Rates and Methods in Indiana ${ }^{\mathrm{a}}$ (GAI and USIFCAU 1993).

\begin{tabular}{|c|c|c|c|c|}
\hline \multicolumn{5}{|c|}{ (Tons per year) } \\
\hline Plant & Bottom Ash & Ponded Ash ${ }^{\mathrm{c}}$ & $\underline{\text { Landfilled Ash }^{\mathrm{d}}}$ & $\begin{array}{l}\text { Landfilled } \\
\text { Boiler Slag }\end{array}$ \\
\hline \multicolumn{5}{|c|}{ Vincennes District } \\
\hline Breed & 0 & 0 & 8,200 & 0 \\
\hline Rockport & 121,000 & 0 & 130,000 & 0 \\
\hline Gibson & 0 & 643,000 & 0 & 0 \\
\hline Petersburg & 0 & $164,800^{\mathrm{e}}$ & 0 & 0 \\
\hline Edwardsport & 0 & 9,800 & 0 & 0 \\
\hline Ratts & 12,000 & 50,000 & 0 & 0 \\
\hline Merom & 0 & 0 & 0 & 0 \\
\hline Brown & 0 & $110,000^{\mathrm{e}}$ & 0 & 0 \\
\hline Culley & 0 & $110,000^{\mathrm{e}}$ & 0 & 0 \\
\hline Warrick & 0 & 250,000 & 0 & 0 \\
\hline Jasper & 12,000 & 0 & 0 & 0 \\
\hline G.E. Plastics & 0 & 0 & $38,000^{\mathrm{e}}$ & 0 \\
\hline Total & 145,000 & $1,337,600$ & 176,200 & 0 \\
\hline \multicolumn{5}{|c|}{ Crawfordsville District } \\
\hline Cayuga & 0 & 279,000 & 0 & 0 \\
\hline Wabash & 0 & 150,000 & 0 & 0 \\
\hline Total & 0 & 429,000 & 0 & 0 \\
\hline \multicolumn{5}{|l|}{ Laporte District } \\
\hline Schahfer & 127,800 & 0 & 0 & 0 \\
\hline Mitchell & 0 & 0 & 0 & 0 \\
\hline Bailly & 0 & 0 & 0 & 0 \\
\hline Michigan City & 26,000 & 0 & 0 & 0 \\
\hline State line & 0 & 0 & 9,200 & 0 \\
\hline Total & 153,800 & 0 & 9,200 & 0 \\
\hline \multicolumn{5}{|c|}{ Seymour District } \\
\hline Tanners Creek & 10,000 & 69,000 & 0 & 0 \\
\hline Gallagher & 0 & 96,000 & 0 & 0 \\
\hline Clifty Creek & 0 & 0 & 194,000 & 149,000 \\
\hline Total & 10,000 & 165,000 & 194,000 & 149,000 \\
\hline \multicolumn{5}{|c|}{ Greenfield District } \\
\hline Pritchard & 0 & 21,500 & 0 & 0 \\
\hline Perry & 0 & 0 & 34,900 & 0 \\
\hline Stout & 0 & 93,700 & 0 & 0 \\
\hline Noblesville & 0 & 5,100 & 0 & 0 \\
\hline Whitewater & 0 & 0 & $24,400^{\mathrm{e}}$ & 0 \\
\hline Total & 0 & 120,300 & 59,300 & \\
\hline Total & 308,800 & $2,051,900$ & 438,700 & 149,000 \\
\hline
\end{tabular}

${ }^{\mathrm{a}}$ Does not include FGD material, by-products co-disposed with FGD material, or by-products disposed of in a Type I landfill.

${ }^{\mathrm{b}}$ Bottom ash ponded or landfilled separately from fly ash.

${ }^{c}$ Fly ash ponded alone or co-ponded fly ash and bottom ash.

${ }^{\mathrm{d}}$ Fly ash landfilled separately or with bottom ash.

${ }^{\mathrm{e}}$ Assumed co-disposal of fly ash and bottom ash. 
and alumina $\left(\mathrm{Al}_{2} \mathrm{O}_{3}\right)$, with smaller quantities of calcum oxide $(\mathrm{CaO})$, potassium oxide $\left(\mathrm{K}_{2} \mathrm{O}\right)$, sodium oxide $\left(\mathrm{Na}_{2} \mathrm{O}\right)$, magnesium oxide $(\mathrm{MgO})$, titanium oxide $\left(\mathrm{TiO}_{2}\right)$, phosphorous pentoxide $\left(\mathrm{P}_{2} \mathrm{O}_{5}\right)$, and sulfur trioxide $\left(\mathrm{SO}_{3}\right)$. In bituminous coal, three major components $\left(\mathrm{SiO}_{2}, \mathrm{Fe}_{2} \mathrm{O}_{3}\right.$, and $\left.\mathrm{Al}_{2} \mathrm{O}_{3}\right)$ account for about $90 \%$ of the total components, whereas lignite and subbituminous coal ashes have relatively high percentages of $\mathrm{CaO}$ and $\mathrm{MgO}$ and, correspondingly have large amounts of sulfur (Abernethy et al. 1969). The amount of unburned carbon content in the ash is associated with the efficiency of boiler units and the fineness of pulverized coal. More efficient units produce lower carbon ash than less efficient units such as old boiler, stokers, etc. (GAI 1986).

The major chemical constituents are present in either a crystalline form or as a glass. The mineralogical analysis of coal ash shows that the crystalline components frequently detected are quartz $\left(\mathrm{SiO}_{2}\right)$, mullite $\left(2 \mathrm{SiO}_{2} \cdot 3 \mathrm{Al}_{2} \mathrm{O}_{3}\right)$, hematite $\left(\mathrm{Fe}_{2} \mathrm{O}_{3}\right)$ and magnetite $\left(\mathrm{Fe}_{3} \mathrm{O}_{4}\right)$ and the remainder being present mostly in the glassy phase. The greater portion of coal ash is glass. Typical glass contents of fly ash range from 66 to 88 percent (Watt and Thorne 1965, Barber 1970).

Diamond (1985) and Huang (1990) examined the chemical and mineralogical characteristics of Indiana fly ash and bottom ash. Diamond (1985) found that Indiana fly ash, which is mostly class F fly ash derived from burning Illinois basin bituminous coal, showed a very consistent chemical pattern. It includes high contents of combined $\mathrm{SiO}_{2}$, $\mathrm{Fe}_{2} \mathrm{O}_{3}$, and $\mathrm{Al}_{2} \mathrm{O}_{3}$, high iron oxide contents ranging from about $16 \%$ to about $24 \%$, and low $\mathrm{CaO}$ contents, typically $2 \%$ or less. The contents of unburned carbon were found to vary greatly from substantially low contents under $1 \%$ to as high as $9 \%$. Major crystalline components were quartz $\left(\mathrm{SiO}_{2}\right)$, mullite $\left(2 \mathrm{SiO}_{2} \cdot 3 \mathrm{Al}_{2} \mathrm{O}_{3}\right)$, and some magnetite $\left(\mathrm{Fe}_{3} \mathrm{O}_{4}\right)$, 
which is a typical class F fly ash assemblage of crystalline components. Indiana bottom ash also showed similar chemical and mineralogical patterns with the fly ash (Huang 1990).

\subsubsection{Physical characteristics}

\section{Appearance}

The ash particles have distinctly different physical appearances depending on the type. The differences in the appearance are primarily due to the differences in the formation of ash. Fly ash is a fine powdery material, with most of its particles barely visible to the naked eye. Most of the particles are spherical in shape. Some of the particles are hollow. The surface of the particles generally appears clean and smooth under magnification (Diamond 1985). When dry, the fly ash is easily blown away by light wind. When moistened, however, it exhibits apparent cohesion and can be formed into a ball, similar to a silty soil. The color of fly ash varies depending on the chemical composition of the ash particles, but generally ranges from brown to dark gray. Diamond (1985) reported that fly ash particles are either actually colorless or very dark. The color of the fly ash aggregate is the result of the combined effect of the various colored and colorless individual particles rather than a single color of all particles.

Both bottom ash and boiler slag are coarser than fly ash. Bottom ash is quite angular and irregular in shape, with rough surface texture. Its color ranges from gray to black and some particles, especially in smaller sizes, are black and glassy in appearance. The black glassy particles represent the molten slag from the internal surface of the boiler (Huang 1990). However, a greater portion of bottom ash formed in a dry state, not molten 
ash, is gray in color with an irregular shape.

Boiler slag (i.e. wet bottom ash) is composed of angular to subangular particles with a shiny black color and glassy surface. Its smooth surface texture is much like crushed glass. The broken glassy appearance of the boiler slag is derived from the rapid quenching as the molten slag flows from the furnace bottom into the water-filled hopper. Like bottom ash, some particles of the boiler slag are porous, which are formed as the result of trapped gas in the slag as it is tapped from the furnace (Anderson 1978).

In some power plants, the bottom ash and the boiler slags are run through a crusher to reduce their aggregate size prior to being driven through the disposal pipes. The crushing process makes the particles more angular and may produce easily breakable particles (Karim 1997).

\section{Specific Gravity}

The specific gravity of ash varies largely depending on its chemical composition and particle structure. Generally, the ashes with high iron contents will have higher specific gravities. Likewise, the ashes that have solid structures will be denser than those that are porous or hollow, and have correspondingly high specific gravities.

McLaren and DiGioia (1987) investigated the specific gravities of a total of 98 class F fly ash samples and 17 class $\mathrm{C}$ fly ash samples from separate sources in the eastern and midwestern U.S. and Canada. They showed that the specific gravities of class F fly ash range from 2.1 to 2.9 with the average of 2.4 and the average specific gravity of class $\mathrm{C}$ fly ash is 2.5 . Class $\mathrm{C}$ fly ash, formed from burning lignite coal, which has ash high in iron, tends to have high specific gravities ranging between 2.5 and 2.9 (GAI and 


\section{USIFCAU 1993).}

Normally, the specific gravities of bottom ash vary from 2.0 to 2.6 (Seals et al. 1972; Moulton 1973; Anderson et al. 1976; Majidzadeh et al. 1977). Anderson (1976), however, emphasized that the bottom ash with a dense structure may have a specific gravity as high as 2.8, whereas a poor ash with high percentages of porous and popcornlike particles, may exhibit a specific gravity as low as or even lower than 1.6. The boiler slag tends to have a higher specific gravity than bottom ash, mainly due to its denser nature. The values range from 2.6 to 2.9 with an average of about 2.75. (Seals et al. 1972; Moulton 1973; Majidzadeh et al. 1977).

In summary, the specific gravity of ash is greatly affected by its chemical properties and structure, and correspondingly exhibits high variations, but the values are generally lower than those of typical soils which range from 2.6 to 2.8 .

\section{$\underline{\text { Grain Size Distribution }}$}

The gradation characteristics of coal ash differ by type. Figure 2.13 shows typical ranges of gradation for fly ash, bottom ash, and boiler slag (GAI and USIFCAU 1993). As described earlier, fly ash is a fine, powder-like material. The grain sizes range from $0.6 \mathrm{~mm}$ (No. 40 sieve) to $0.001 \mathrm{~mm}$, which spans the range from fine sands and silt to large clay particles. In most cases, however, the fly ash is relatively uniform, falling in the range passing the No. 200 sieve $(0.075 \mathrm{~mm})$. Sheu et al. (1990) reported that most fly ash investigated passed the No. 400 sieve $(0.0325 \mathrm{~mm})$ with only $6 \%$ of fly ash being retained on the No. 200 sieve $(0.075 \mathrm{~mm})$. Accordingly, the grain size analysis of fly ash is typically performed using the sedimentation method. The sedimentation method is 


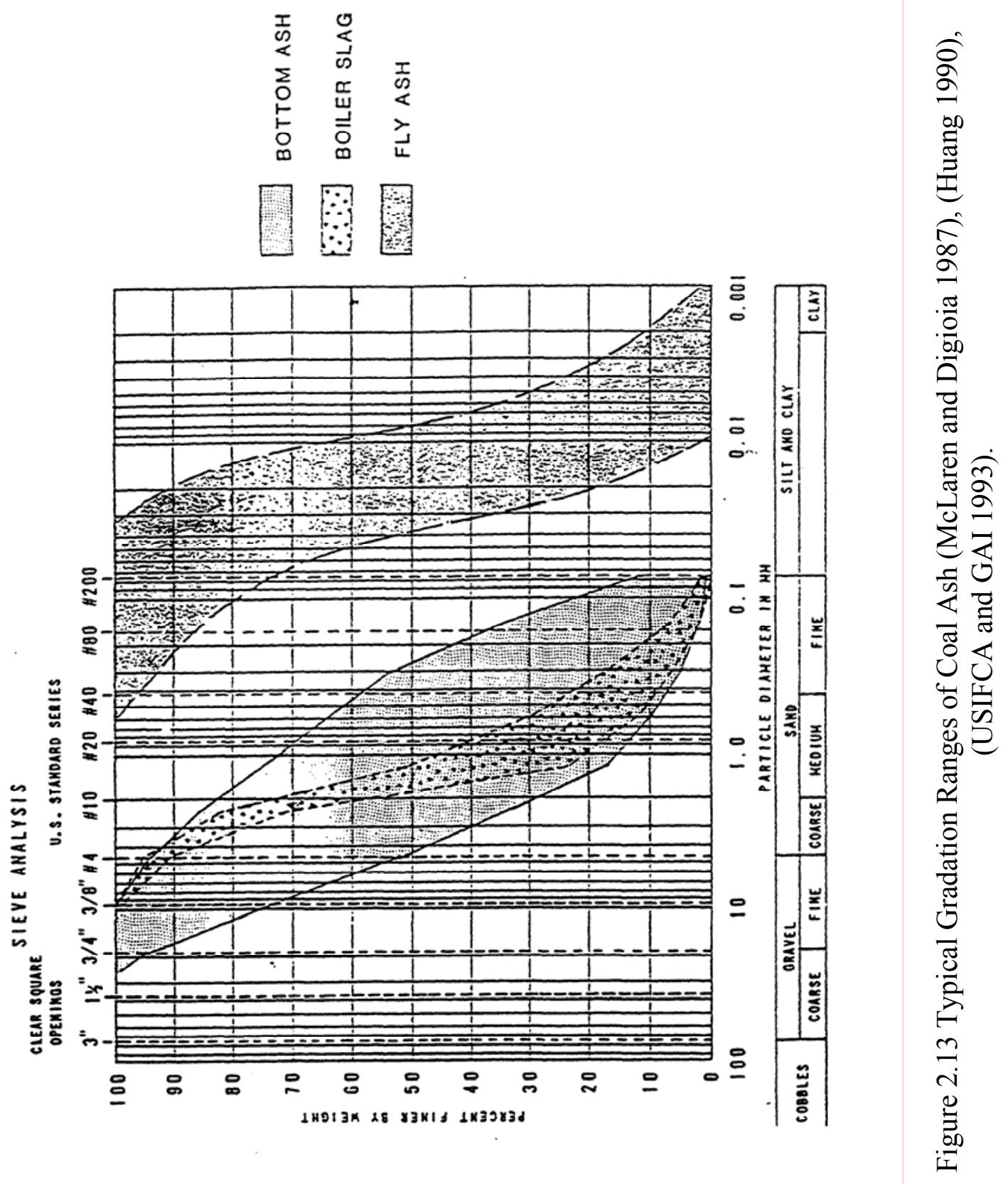


based on the idea that large particles in suspension in a liquid settle more quickly than small particles, assuming similar densities and spherical shapes for the particles. The assumption of the spherical shape of the particles may be a quite good approximation for fly ash, whereas possible different densities between the hollow and the solid fly ash particles may result in misleading interpretation of the grain size distribution.

Bottom ash is coarse and relatively well graded. The particle sizes typically vary from 1 inch $(25.5 \mathrm{~mm})$ to the No. 200 sieve $(75 \mu \mathrm{m})$, which corresponds to the sizes of medium gravel to fine sand. Some fines passing the No.200 sieve $(0.075 \mathrm{~mm})$ may exist in the bottom ash, normally accounting for 0 to $10 \%$ of the ash by weight. They are essentially coarse, non-plastic fly ash (Huang 1990).

Compared with bottom ash, boiler slag exhibits a quite uniform grain size distribution. Most particles fall in a narrow range from the No. $4(4.75 \mathrm{~mm})$ to the No.30 $(600 \mu \mathrm{m})$ sieve (Huang 1990).

\subsubsection{Mechanical properties}

\section{Compaction Characteristics}

Compaction is the densification of a material by the application of loads, through rolling, tamping, or vibration, with the goal of increasing the dry density of the material. It has long been recognized, empirically and scientifically, that soil compaction changes the physical properties of soil, which are greatly affected by the degree of density (Hilf 1991). The principal aim of compaction is to ensure the stability of the soil mass by changing the properties of the soil. The properties sought differ from structure to 
structure. When it is used as a construction material, the most important engineering properties of soil are its shear strength, its compressibility and its permeability. The compaction of soil, in general, increases its shear strength and decreases its compressibility and its permeability. In the case of an embankment, compaction is desired to improve the stability of the slope and to prevent detrimental settlement.

The compaction of soil is achieved through the expulsion of air from the soil mass, which consists of the soil particles, water and air, without a significant change in water content. This reduction in air volume leads to a corresponding reduction in the volume of the soil mass. The compaction is influenced by various factors. The primary factors are: a) the water content of the soil, b) the type of soil, c) the type and the level of compactive effort. Other influencing factors, to a lesser extent, are: a) the temperature of the soil and $b$ ) the amount of manipulation given the soil during the compaction process (Highway Research Board 1952).

When considering the compaction of soils, two broad classification of soils are discussed separately: 1) cohesive soils, and 2) cohesionless soils. Commonly, a compaction characteristic for soil is expressed by its moisture-density curve, which is also referred to as a compaction curve. Figure 2.14 represents the moisture-density relationship for a typical cohesive soil. The compaction curve is obtained when a soil is compacted at various water contents with a given compactive effort. It clearly shows that the dry densities obtained vary largely with the compaction water contents at the given compaction energy. At low water contents, the soil particles are surrounded by a thin film of water, which tends to keep the particles apart even when compacted, resulting in low dry density. As the water content increases, the additional water develops the water films 


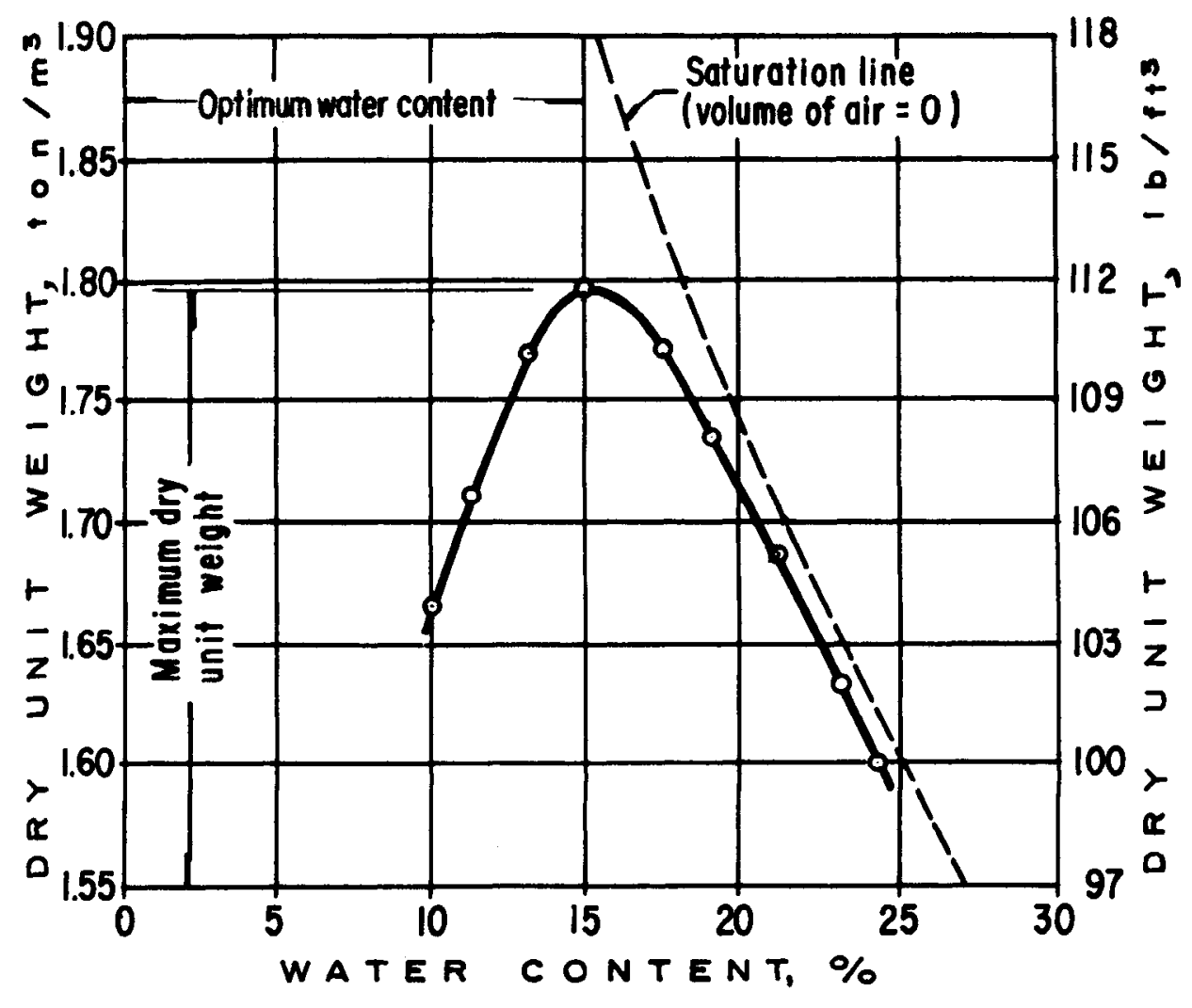

Figure 2.14 Typical Compaction Curve (Rodriguez et al. 1988). 
around the particles to be larger, which tends to lubricate the particles and enables the particles to be more easily compacted together. At a certain point of water content, the particles become as closely packed together as they can be (i.e. maximum dry density). More water beyond this point, however, decreases the dry density since the excess water starts to push the particles apart (Head 1980; Holtz and Kovacs 1981). Consequently, the compaction curve presents a peak in density. The water content that results in the maximum dry density or state of compactness is referred to as the optimum water content. Any state in range of the water contents less than the optimum water content is said to be dry of optimum. Any state with water contents greater than the optimum water content is said to be wet of optimum.

Although there are several laboratory compaction standards and many different types of compactive efforts used in construction of compacted fills, the effect of water content of the soil on the resulting dry density is similar for all methods (Hilf 1991). If another soil is compacted at various water contents, but with a different compactive effort, the compaction curve produced will also have a peaked shape but with a different optimum water content and maximum dry density. Normally, the greater the compactive effort applied, the higher the maximum density and the lower the optimum water content obtained.

The compaction behavior of cohesionless soils is different from that of cohesive soils. Cohesionless soils are relatively pervious even when compacted, thus they are not significantly affected by the water content. Consequently, the peaked shape of the moisture-density curve that is characteristic of cohesive soils is not well defined in cohesionless soils. Figure 2.15 represents the typical compaction curve of a cohesionless 
soil. For a given compactive effort on the soil, the dry density obtained is high when the soil is completely dry and high when the soil is saturated, with somewhat lower densities occurring when the soil has intermediate amounts of water. This phenomenon is known as bulking (Foster 1962; Lambe and Whitman 1979; Hilf 1991). The bulking phenomenon is caused by the small capillary stresses developed between soil particles when the soil is partly saturated. The capillary stresses produce a shear strengh in the soil that tends to resist the rearrangement of the particles by the compactive effort. As more water is added, however, the capillary stresses gradually decrease and, in turn, the dry density increases until the soil is saturated with water. Beyond the point of saturation, the density begins to decrease again since the excess water resists the compactive effort. In this case, however, the decrease in density may be much smaller than that in cohesive soils because the excess water is easily drained during compaction.

The compaction characteristic of fly ash exhibits a similar trend to that of low plasticity cohesive soil (Karim 1997). Typical moisture-density curves have a mound shape. Available data on the compaction characteristics of fly ash show somewhat wide variations in both optimum water content and maximum dry density. Figure 2.16 and Figure 2.17 show the typical compaction curves for Western Pennsylvania class F fly ash and Western United States class C fly ash (DiGioia et al. 1986). The maximum dry density and the optimum water content for Western Pennsylvania fly ash typically ranges from 11.9 to $18.7 \mathrm{kN} / \mathrm{m}^{3}$ and from 13 to $32 \%$, respectively. For Western United States fly ash, the values vary from 13.0 to $18.7 \mathrm{kN} / \mathrm{m}^{3}$ in the maximum dry density, and from 11 to $19 \%$ in optimum water content. DiGioia et al. (1986) reported that nationwide values for the optimum water content and maximum dry density cover an extremely wide 


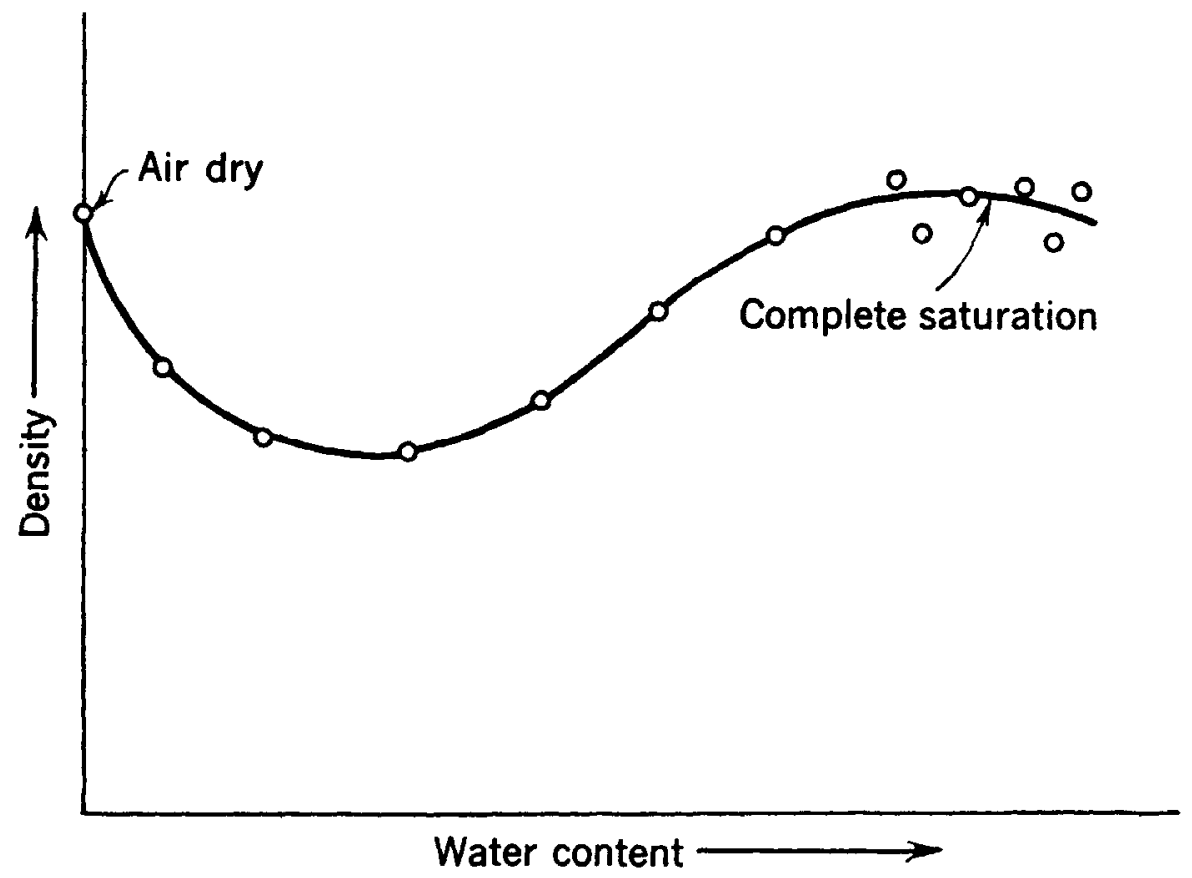

Figure 2.15 Typical Compaction Curve for Cohesionless Soils (Foster 1962). 


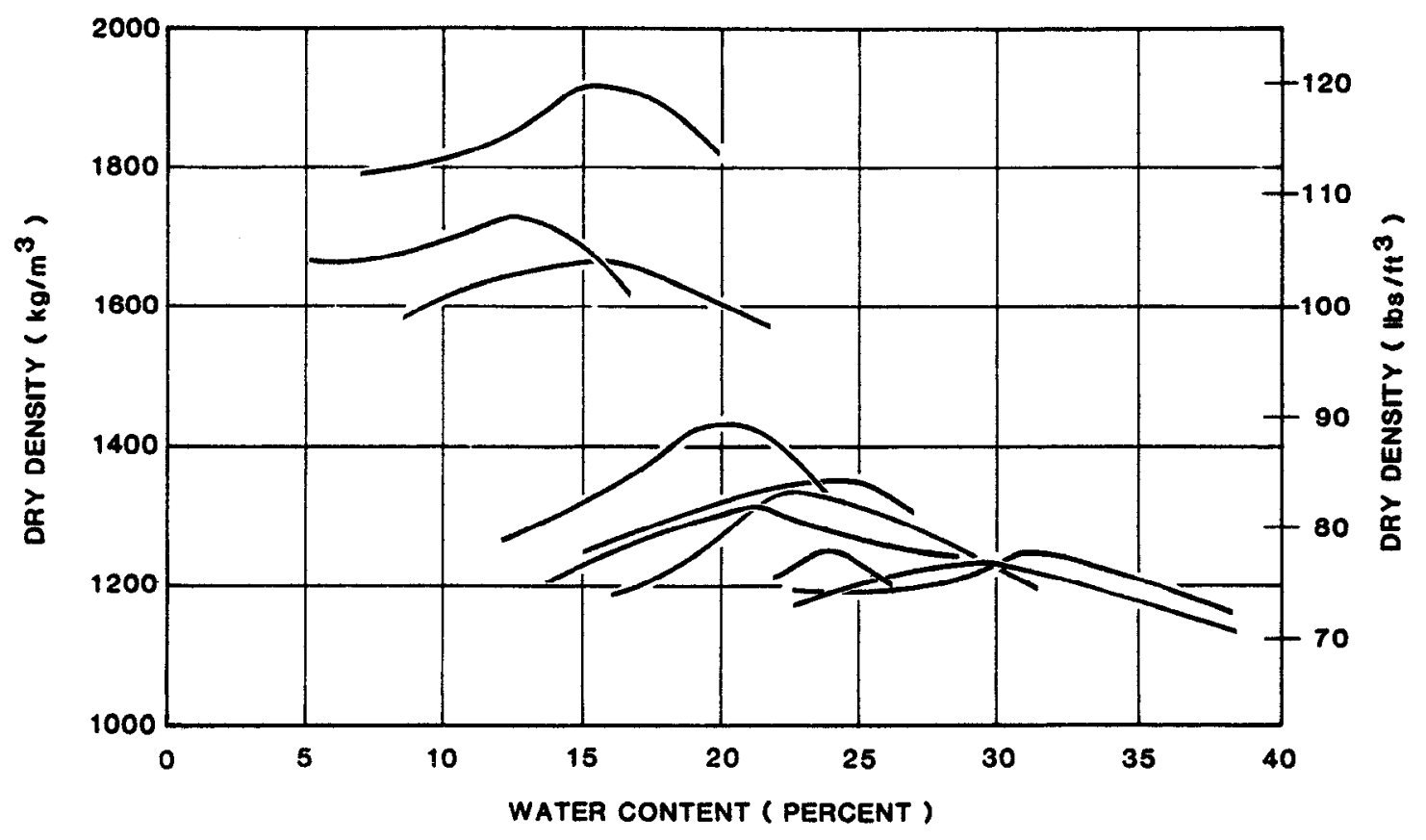

Figure 2.16 Typical Compaction Curves for Western Pennsylvania Bituminous Fly Ashes (DiGioia et al. 1986) 


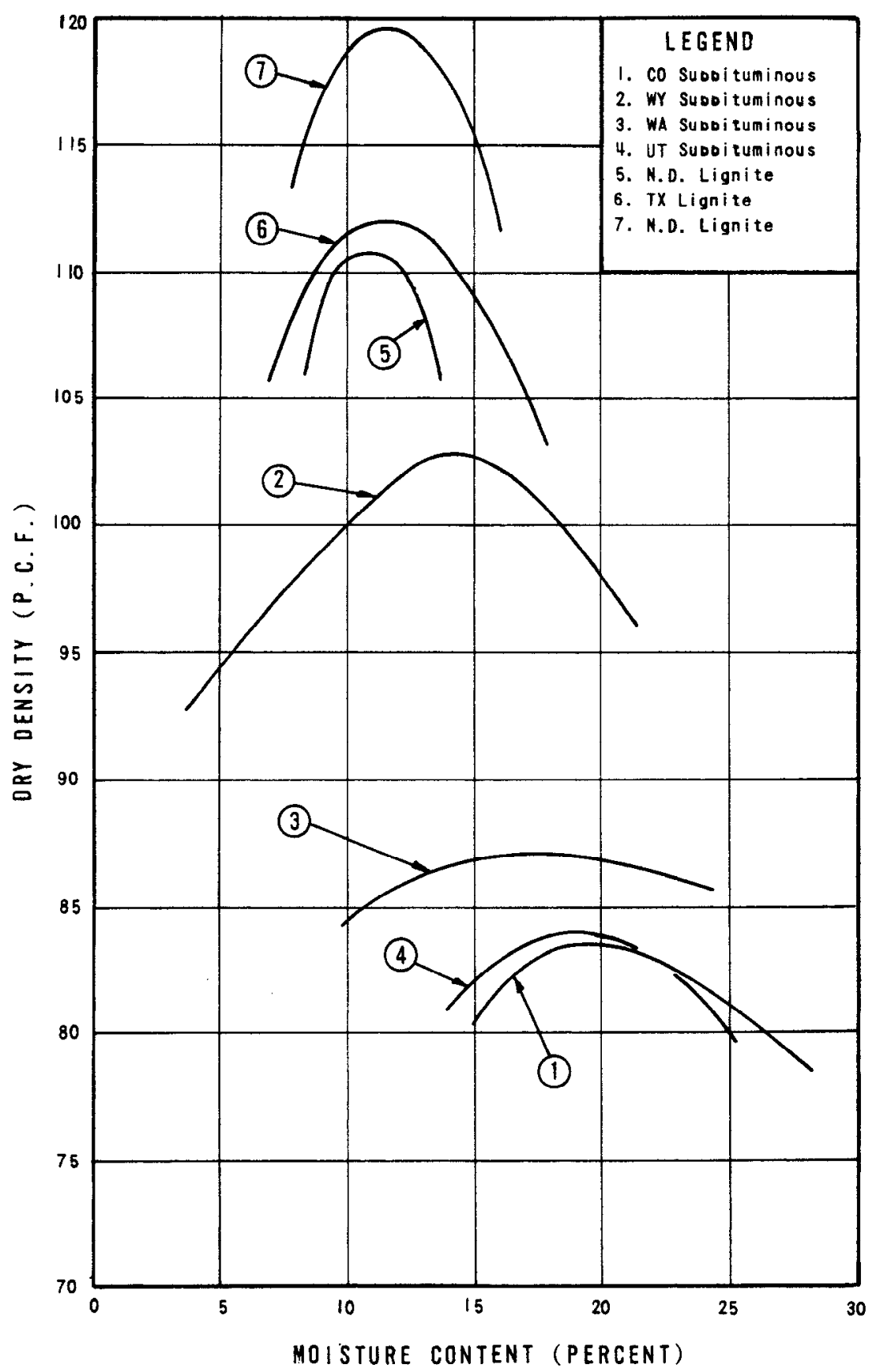

Figure 2.17 Typical Compaction Curves for Western United States Lignite and Subbituminous Fly Ash (DiGioia et al. 1986). 
range. The large variations in the values are mainly due to the variation of fly ash itself, which exhibits different chemical and physical characteristics depending on factors such as the source of coal and the condition of coal combustion.

The bottom ash response in compaction is mostly similar to that of cohesionless soil since it is relatively pervious. Figure 2.18 shows the moisture-density curve obtained from bottom ash from one Indiana power plant. Huang (1990) reported, however, that the variations in the moisture-density relation are high between the different sources of bottom ash. Seals et al. (1972) and Usmen (1977) presented data obtained from West Virginia bottom ash. The standard proctor maximum densities varied between 11.6 and $18.4 \mathrm{kN} / \mathrm{m}^{3}$; the optimum water contents ranged from 12 to $34 \%$. Majidzadeh et al. (1977) reported that the optimum water content of each ash actually occurred within a zone rather than exhibiting a clear optimum value.

\section{$\underline{\text { Shear Strength }}$}

In soil mechanics, shear strength is the fundamental characteristic that determines the ability of soils to resist loading without failing (Rodriguez et al. 1988). The evaluation of the shear strength is important for the stability assessment of all soil structures including embankment slopes, foundations, and soil retaining structures. The shear strength of the soil system is usually expressed by the Mohr-Coulomb failure criterion.

$$
S=c+\sigma \tan \phi
$$

where $S=$ shear strength; $c=$ cohesion intercept; $\phi=$ angle of internal friction; and $\sigma=$ normal stress on the shear plane. For a cohesive soil, the shear strength is primarily 


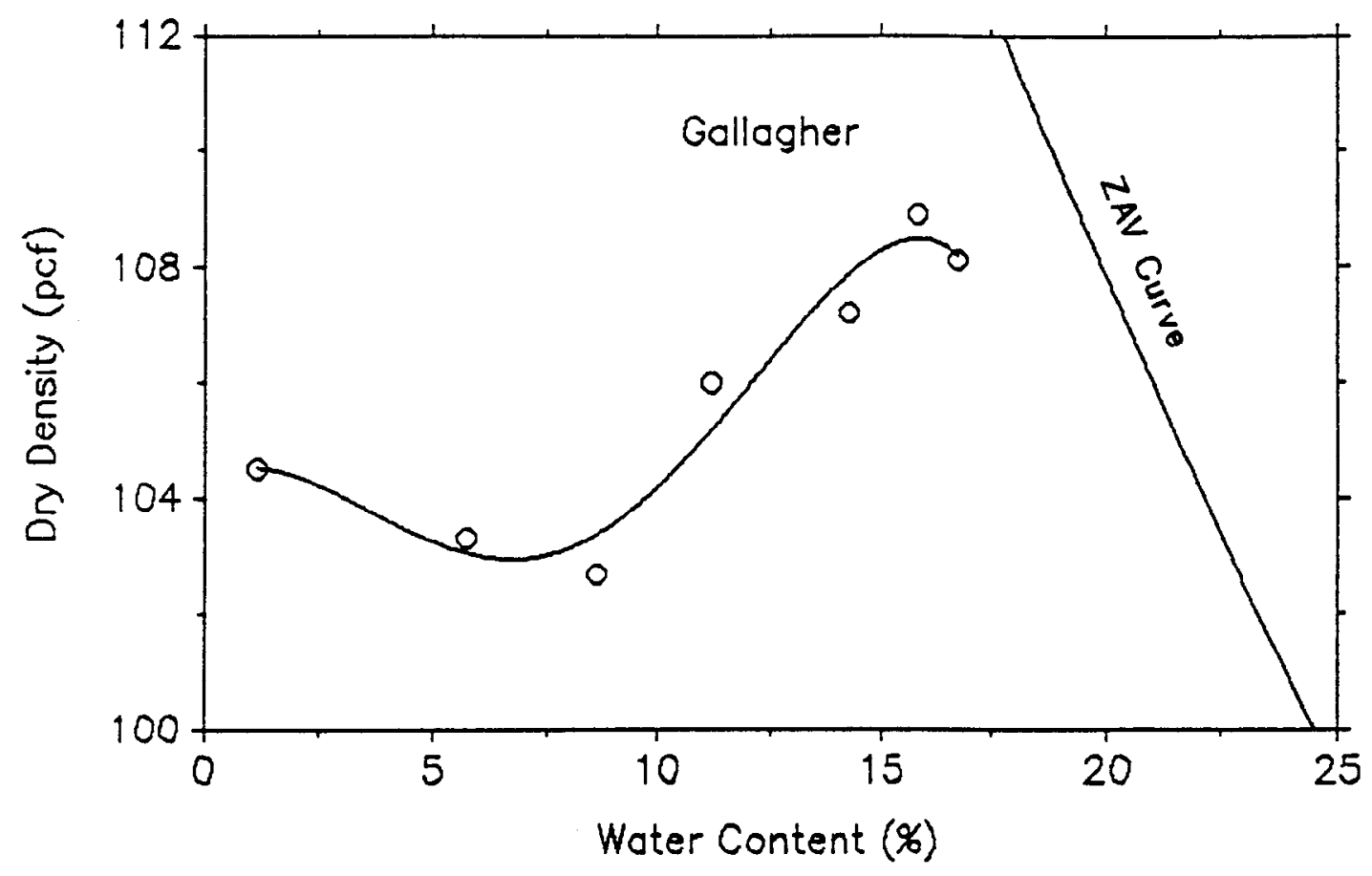

Figure 2.18 Compaction Curve for Bottom Ash from Gallagher Power Plant, Indiana (Huang 1990). 
represented by the cohesion intercept, whereas the shear strength of a cohesionless soil results from the friction angle and the normal stress. The strength parameters $\mathrm{c}$ and $\phi$ are determined in the laboratory or in the field.

Class F fly ash, bottom ash and boiler slag are basically only frictional materials. The class F fly ash may develop an apparent cohesion due to capillary tension when it becomes wet. However, the effect is completely lost when it is either dried or saturated. In contrast to this behavior, class $\mathrm{C}$ fly ash can exhibit considerable cohesive strength due to cementitious reactions, which is the dominant source of shear strength of class $\mathrm{C}$ fly ash (McLaren and DiGioia 1987).

In a frictional soil, the shear resistance is developed from the sliding friction and the interlocking of the particles. There are many factors affecting the shear strength of granular soil. These factors may be divided into two groups. The first group consists of soil state variables, such as relative density of the soil, the effective stress state, and the fabric. The other group includes factors related to the nature of the soil, such as particle shape, particle size distribution, particle surface characteristics, and mineralogy. The factors related to the latter group are referred to as intrinsic variables (Been et al. 1991; Salgado et al. 1997a, b).

The higher the relative density and the effective stress, the more tightly the soil grains are held together, resulting in higher shear strength of the soil. Soil with wellgraded particle distributions and soil with angular particle shapes exhibit generally higher shear strength than uniformly distributed soil and soil with rounded particle shapes, since more particle interlocking occurs in the soil with the former characteristics. Particle size affects the shearing strength by influencing the amount of shearing displacement required 
to overcome interlocking and to bring the grains to a free sliding position (Hough 1969). Accordingly, a coarser material will exhibit greater shear strength than a finer material because larger particles need more effort to overcome interlocking than smaller particles. Mineral composition of the soil particles also affect the shear strength since it has an effect on the crushing of the particle. For example, it was reported that for well graded quartz, a good fit for Mohr's failure envelope as a straight line may be obtained for stresses up $1000 \mathrm{kPa}$, whereas for calcareous sand, a good straight-line fit may be only obtained for stresses up to $500 \mathrm{kPa}$, which indicates that calcareous sands start crushing at a lower stress. Particle crushing results in a loss of dilatatancy and the shear strength derived from it. It is known that the stresses causing considerable particle crushing are low for large, angular and weak particles. Loose uniform soils usually reach crushing faster than dense well-graded soils of the same mineral composition.

The friction angles of compacted class $\mathrm{F}$ fly ash reported in the literature range from $25^{\circ}$ to $40^{\circ}$ (GAI and USIFCAU 1993). McLaren and DiGioia (1987) reported that, from 51 class $\mathrm{F}$ fly ash samples investigated, the average friction angle was $34^{\circ}$ with standard deviation of $3.3^{\circ}$ and coefficient of variation $9.8 \%$. The friction angles of bottom ash and boiler slag are slightly higher than fly ash. The reported values typically range from $32^{\circ}$ to $44^{\circ}$ for bottom ash and $37^{\circ}$ to $46^{\circ}$ (McLaren and DiGioia 1987; GAI and USIFCAU 1993). Huang (1990) investigated the shear strength of Indiana bottom ash and boiler slag in different densities using direct shear testing. The values vary from $35^{\circ}$ to $55^{\circ}$ (Table 2.5). Bottom ash and boiler slag are generally angular to subangular in particle shape. The angularity of the particles provides more interlocking, and hence greater friction angles than those of fly ash, which is mostly spherical in particle shape. 
Larger particle size may also be a reason for higher friction angles in bottom ash and boiler slag. Huang (1990) reported, however, that the larger the particles, the more porous the particles in bottom ash, and generally bottom ash may be more fragile than natural sand. Consequently, bottom ash may undergo particle crushing at relatively low confining stresses.

Table 2.5 Results of Direct Shear Tests on Indiana Bottom Ashes (Huang 1990).

\begin{tabular}{lcc}
\hline \multirow{2}{*}{ Power Plant } & Loose & Dense \\
\cline { 2 - 3 } & Values of $\phi^{\prime}$, deg & Values of $\phi^{\prime}$, deg \\
\hline \hline Schahfer & 35.1 & 46.3 \\
Unit 14 & 39.2 & 47.7 \\
Unit 17 & 44.8 & 55.0 \\
Gibson & 41.3 & 51.6 \\
Gallagher & 41.5 & 50.6 \\
Perry & $32-34$ & $44-46$ \\
\hline Medium sand, angular & 34 & 45 \\
Sand and gravel & & 45 \\
Well graded, angular sand $^{\mathrm{c}}$ & 39 & 40 \\
Well graded, rounded sand $^{\mathrm{c}}$ & 34 & \\
\hline
\end{tabular}

\footnotetext{
${ }^{\text {a }}$ Wet bottom ash

${ }^{\mathrm{b}}$ From Leonards (1962)

${ }^{\mathrm{c}}$ From Sowers (1979)
}

As discussed earlier, some fly ash particles are hollow. The hollow fly ash particles may appear to be very crushable compared to solid fly ash particles. There is no information available in the literature on the crushing characteristics of fly ash by shearing. However, knowledge of approximate ranges for the compressive strength of the 
hollow fly ash particles may help understanding of the crushing tendency of the fly ash under shearing. Besides the field of construction, the fly ash material has been given great attention in the field of material science. For example, fly ash material has been studied for use as a filler or a reinforcement material in metal composites and as an insulating material. Guo et al. (1996) investigated compaction characteristics of aluminum-fly ash powder mixtures, where he observed that hollow fly ash particles start collapsing at compaction pressures of the order of $345 \mathrm{MPa}$. Dry (1995) reported that the compressive strengths of hollow fly ash particles range from $5 \mathrm{MPa}$ to $7 \mathrm{MPa}$. Considering that the approximate compressive strength of common rocks such as quartz, feldspar and shale vary from 40 to $280 \mathrm{MPa}$, depending on the geological conditions, the compressive strength of the hollow fly ash particles may be lower than that of natural granular soils. Nevertheless, under the practical range of the loads considered in the design and construction of geotechnical structures, especially highway embankments, the crushing of hollow fly ash particles appears to be a remote possibility.

\section{Hydraulic Conductivity}

Hydraulic conductivity of a soil is a measure of its ability to allow the flow of water through it. Soils consist of solid particles with voids between them. Generally, the voids in soils are interconnected, which enables water to pass through them. Accordingly, the hydraulic conductivity of a soil is dependent on the nature of the void system. There are a number of factors that affect the soil void system. Primary influencing factors may be particle size distribution, particle size, particle shape and texture, void ratio, and mineralogical composition. 
The smaller the particles, the smaller the voids between them, and therefore the resistance to flow of water increases with decreasing particle size. Consequently, the hydraulic conductivity decreases. Elongated or irregular particles create flow paths which are more tortuous than those around rounded or spherical particles. Also, particles with a rough surface texture provide more frictional resistance to flow than do smooth-textured particles. In clays, different types of minerals hold on to different thickness of adsorbed water, which affects the hydraulic conductivity by varying the effective pore sizes. Void ratio has a significant effect on the hydraulic conductivity because it may change considerably depending on how a soil is placed or compacted (Head 1982).

In general, the range of the hydraulic conductivity for soils is very wide. It is known that the values vary from $1 \times 10^{-9} \mathrm{~cm} / \mathrm{sec}$ to $1 \times 10^{2} \mathrm{~cm} / \mathrm{sec}$ depending on the type of soil. For compacted fly ash, a typical normal range for hydraulic conductivity is between $1 \times 10^{-4} \mathrm{~cm} / \mathrm{sec}$ and $1 \times 10^{-6} \mathrm{~cm} / \mathrm{sec}$ (GAI and USIFCAU 1993). McLaren and DiGioia (1987) reported that a mean value of the hydraulic conductivities for 41 compacted class F fly ash samples was $1.32 \times 10^{-5} \mathrm{~cm} / \mathrm{sec}$ and for 10 class C fly ash samples, a mean value was $1.13 \times 10^{-5} \mathrm{~cm} / \mathrm{sec}$. Wayne et al. (1991) conducted a series of hydraulic conductivity tests on class F fly ash. They concluded that a hydraulic conductivity of $3.2 \times 10^{-5} \mathrm{~cm} / \mathrm{sec}$ could be reached for the samples compacted at $90 \%$ of standard Proctor effort. The hydraulic conductivity of bottom ash and boiler slag is greater than fly ash primarily due to larger particle sizes. The reported values range from $5 \times 10^{-3} \mathrm{~cm} / \mathrm{sec}$ to $1 \times 10^{-1} \mathrm{~cm} / \mathrm{sec}$ (Huang 1990; GAI and USIFCAU 1993). 


\section{Compressibility}

The compressibility of a soil determines the vertical deformation that occurs at its surface when the load on the surface increases. The mechanism under which soils are compressed differs depending on the type of soil. For a granular soil, the deformation undergone is the result of deformation in the particles themselves and relative interparticle movement. In contrast, the deformation in a fine-grained, cohesive soil occurs as water and air are squeezed out from between the particles. Since the voids between the particles are so small and hence the hydraulic conductivity is very low, the deformation can take much longer than that of the granular soil. Bottom ash and boiler slag are considered as free-draining, granular materials. Fly ash is a fine-grained material and less permeable than bottom ash, but it is more permeable than compacted cohesive soils. Consequently, the deformation behavior is likely to be similar to that of a granular soil.

In granular soils, deformation is caused by distortion and crushing of individual particles, and relative motion between particles as the result of sliding or rolling (Lambe and Whitman 1979). While the sliding between the particles occurs at all stress levels, the crushing and fracturing of particles begins in a minor way at very low stresses, but becomes evident when some critical stress is reached (Roberts and DeSouza 1958). Lambe and Whitman (1979) present data on the behavior of initially compacted, uniform, medium and coarse quartz sands. When tested in a consolidometer, they showed yielding at stresses of about $150 \mathrm{MN} / \mathrm{m}^{2}$. Beyond this level, the behavior was plastic due to the fracturing of the individual particles, which permits large relative motions between particles. The critical stress is dependent on the particle size, particle size distribution, the 
angularity of the particles, and the strength of the individual particles.

Roberts and DeSouza (1958), Schultze and Moussa (1961), Hendron (1963), and Lee and Farhoomand (1967) published their works on sand compression. They concluded that in general, a uniformly graded soil compresses more than a well-graded soil; and an angular sand is more compressible than a rounded sand. Roberts and DeSouza (1958) observed that at moderately low pressures, angular sands crushed and compressed more than rounded sands, but at very high pressures the compression behavior of angular and rounded soil is very similar. Lee and Farhoomand (1967) found that coarse soils compressed more and showed more particle fracturing than fine soils. Seals et al. (1972) performed a series of one-dimensional compression tests on West Virginia bottom ash. They reported that at low stress levels, the compressibility of bottom ash is comparable to natural granular soils placed at the same relative density (Figure 2.19). Huang (1990) investigated the compression characteristics of Indiana bottom ashes. He concluded that the bottom ash is slightly more compressible than a typical sand due primarily to two reasons: angularity and rough surface texture of bottom ash particles; and the presence of weak and popcornlike particles which break at relatively low stress levels (Figure 2.20). McLaren and DiGioia (1987) reported values of the compression index, $\mathrm{C}_{\mathrm{c}}$, for fly ash. The average value presented for $C_{c}$ was equal to 0.13 with a standard deviation of 0.088 and coefficient of variation of $67.1 \%$. Seals et al. (1977) and Leonard and Bailey (1982) investigated the compressibility of compacted fly ash fill. They found that the fly ash fill was less compressible than indicated by $\mathrm{C}_{\mathrm{c}}$ values determined in laboratory tests. However, the fly ash can undergo large deformations unless it is well compacted. Fly ash is a fine grained material, but still coarser and more permeable than clay, so that when 


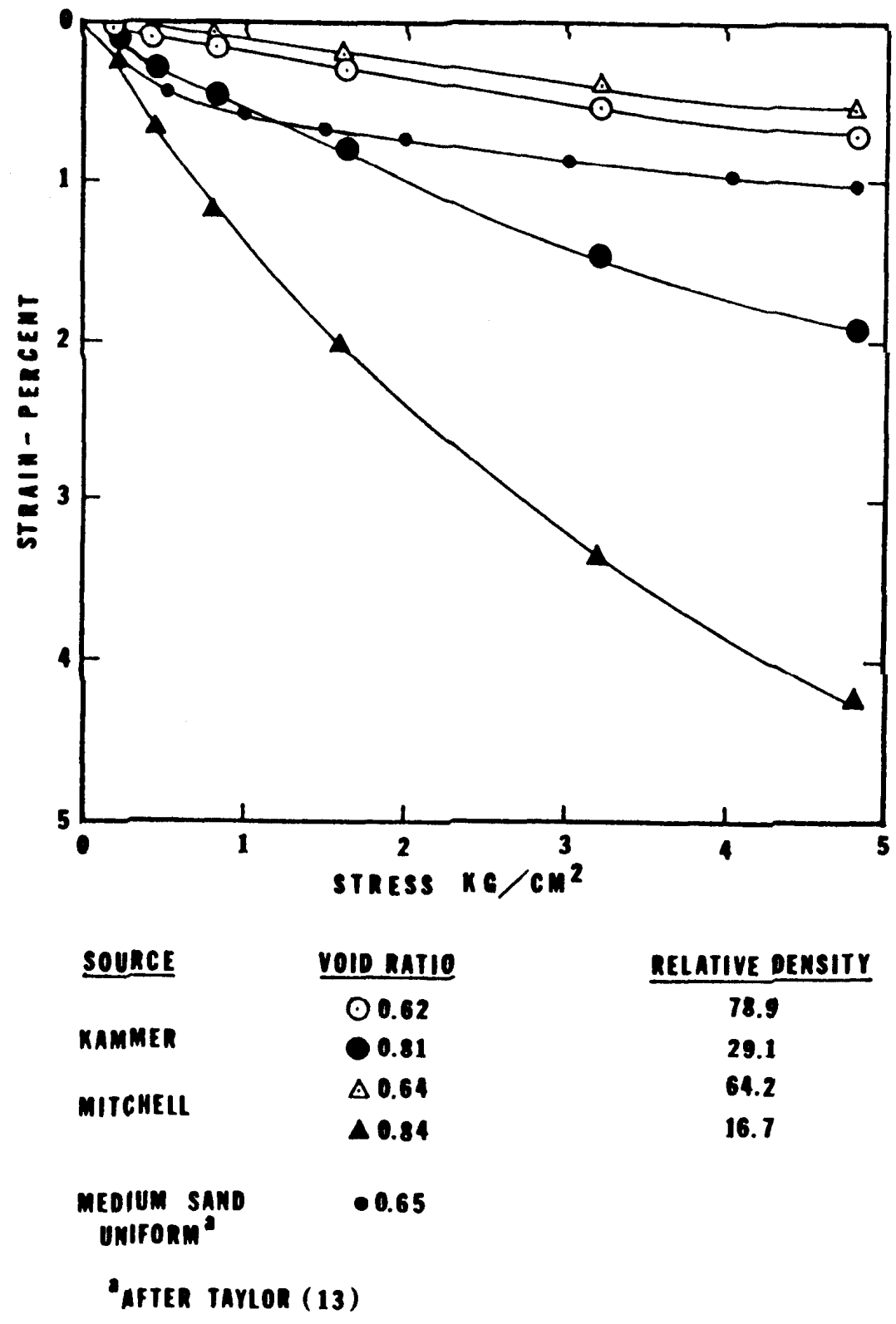

Figure 2.19 One-Dimensional Compression Curves of West Virginia Bottom Ash (Seals et al. 1972). 


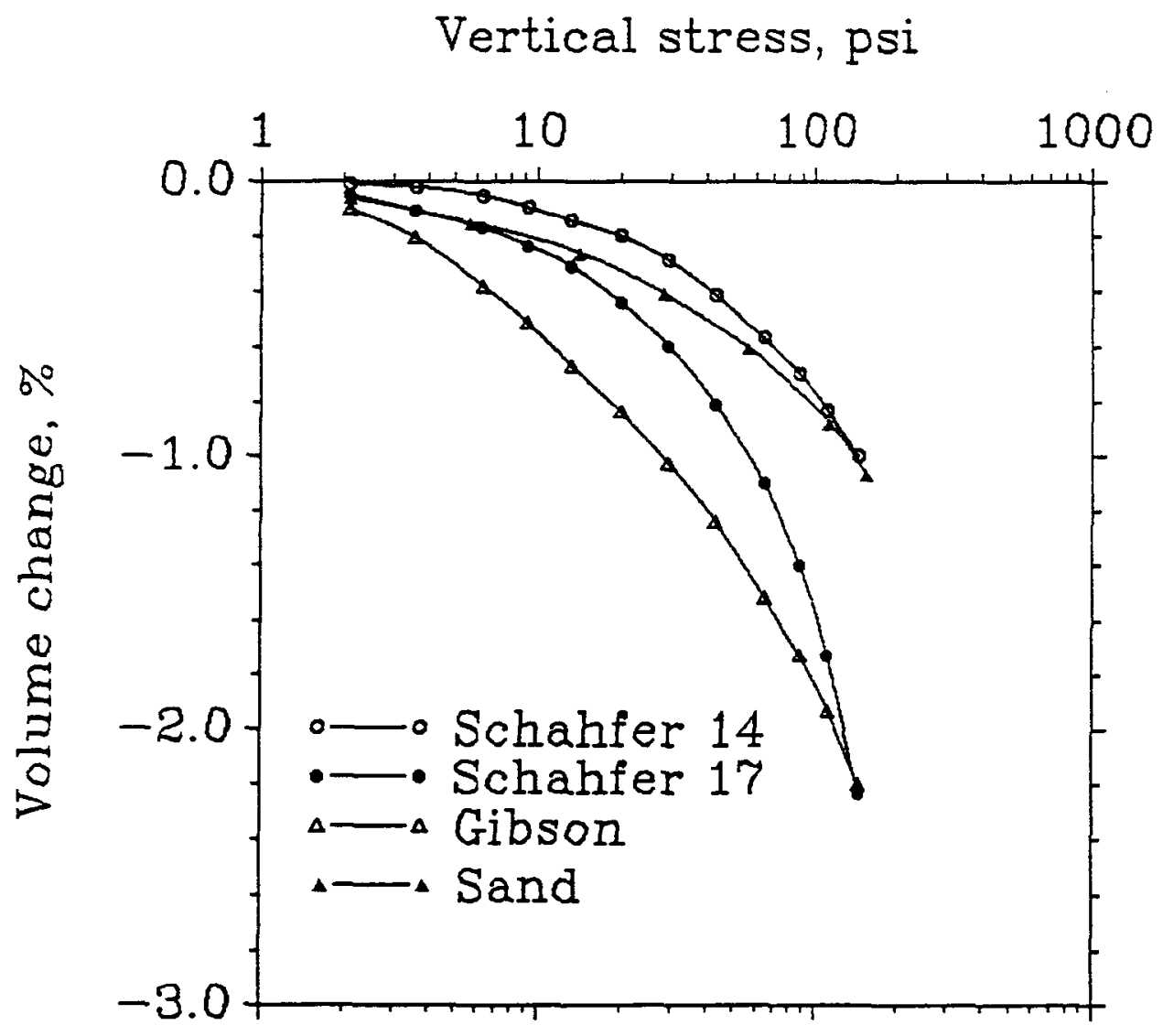

Figure 2.20 One-Dimensional Compression Curves of Indiana Bottom Ash (Huang 1990). 
used in a structural fill, most of the defomations are likely to be completed during the construction period.

\subsection{Utilization of Coal Ash in Highway Embankment}

Coal-fired power plants produce millions of tons of coal ash annually, but only a small fraction is productively used and most ash is just disposed. The costs associated with ash disposal are generally high, which has been a pressure on power industry. On the other hand, construction of a highway embankment requires a large amount of natural soils as fill materials. Typically, in developed urban and industrial areas, where power plants are usually located, natural borrow sources may be scarce, expensive or sometimes inaccessible. Therefore, the use of coal ash as an alternative fill material to soils would result in a substantial savings of ash disposal costs and great savings in construction fill costs. Moreover, coal ash has typically a lower unit weight than that of most soils. In view of embankment performance, it can provide an advantage over typical soils since the loads on foundation soils can be decreased. When the embankment is built on weak soils, the property can be very useful.

There are, however, some concerns regarding ash utilization. Primary concerns would be associated with the environmental impacts of construction uses of ash and the mechanical behavior of ash, especially mixed fly ash and bottom ash. The principal environmental concern is the possible leaching of toxic substances or other potentially harmful constituents from the ash and the possibility of groundwater degradation as a result of such leaching. The environmental issues will be further addressed in the next 
section. Single types of ash have been utilized successfully in several demonstration projects. However, highway embankments constructed with ash mixtures have not yet been reported. Moreover, the mechanical characteristics of ash mixtures, especially with varying mixture proportions, are still uncertain. They will be the focus of upcoming chapters.

2.7.1 Current practices of coal ash utilization in highway construction

The utility industry has demonstrated the technical and economic advantages of coal ash utilization in its internal construction projects. These materials are effectively and routinely used in plant road construction and maintenance. The internal utilization of these materials also includes construction of dams, dikes, and berms, and as foundation materials for stacks, cooling towers, and other structures (GAI and USIFCAU 1993). The technical and economic advantages of coal ash utilization have attracted the interest of the Federal Highway Administration and many state transportation departments. The Federal Highway Administration has approved several demonstration projects (EPRI 1987 and 1989; Glogowski 1989; Srivastava and Collins 1989). Currently, coal ash is used in a variety of highway applications nationwide. Table 2.6 lists current uses for coal ash in highway construction.

\subsubsection{Environmental aspects}

The environmental impact of waste utilization is a function of both waste type and waste use. For ash utilization in highway embankments, the major environmental impacts 
Table 2.6 Uses of Coal Combustion Products in Highway Applications

(GAI and USIFCAU 1993).

\section{$\underline{\text { Uses of Fly Ash }}$}

- Raw material in Portland cement

- Replacement for cement in concrete

- Cement replacement in precast concrete products

- Ingredient in aerated concrete

- Mineral filler in asphaltic concrete

- Stabilization of highway subgrades

- Raw material in the manufacture of lightweight aggregates

- Material for structural fill

- Material for flowable fill or backfill

- Ingredient in grouting

- Stabilized fly ash base course without aggregate

- Stabilized fly ash-aggregate base course

$\underline{\text { Use of Bottom Ash }}$

- Aggregate in asphalt

- Ingredient in bituminous stabilized bases for highways

- Aggregate in Portland cement stabilized bases for highways

- Snow and ice abrasive

- Structural fill

- Unstabilized road base

\section{$\underline{\text { Uses of Boiler Slag }}$}

- Snow and ice abrasive

- Road base aggregate

- Ingredient in anti-skid bituminous wearing course

- Sand blasting grit

Note: FGD materials are presently not widely used in highway construction. 
would be erosion and leaching. Erosion includes wind erosion, causing airborne contamination, and runoff erosion resulting in surface water contamination. It is known that unprotected, compacted fly ash is erodible when subjected to surface runoff or high winds. Therefore, permanent measures should be taken to protect fly ash surfaces which are not covered by a pavement or understructure. The erosion control during and after construction will be addressed later in this section.

The principal environmental concern with leaching is possible groundwater contamination as a result of such leaching. Leachate is produced when water comes into contact with a solid material and incorporates its soluble constituents. Coal ash, like the coals from which it is produced, may contain trace elements in very small proportions. These traces are found as compounds of barium, nickel, arsenic, silver, cadmium, lead, mercury, and other potentially harmful elements. (GAI and USIFCAU 1993). If these trace elements (heavy metals) are released in sufficient concentrations, it may be harmful to the environment. These contaminants can be leached out and carried along with infiltrating precipitation, possibly penetrating groundwater and surface water.

In general, leaching occurs very slowly in the environment. Therefore, it is important that a test method should accurately predict long-term leaching behavior in the field. Numerous laboratory methods for leachabilty were developed. Representative tests are the U.S. Environmental Protection Agency's (EPA's) extraction procedure (EP) test and the U.S. EPA's toxicity characteristics leaching procedure (TCLP). Column-leaching methods have also been employed to simulate long-term leachate characteristics (GAI and USIFCAU 1993). The main objectives of these tests are to find the concentrations of the deleterious elements in the leachates and to define if the ash is hazardous or not. 
Under EPA's Resource Conservation and Restoration Act (RCRA) regulations, solid wastes are classified as hazardous if they exhibit one of the following properties: a) ignitability; b) reactivity; c) corrosivity; and d) toxicity as determined by the toxicity characteristic leaching procedure (TCLP). Coal ash is not ignitable or reactive, but it may be corrosive. Huang and Lovell (1993) examined the corrosivity of Indiana bottom ash and concluded that most of samples tested were found to be potentially corrosive. They recommended that adequate protection must be provided to any metal structure placed within the vicinity of a potentially corrosive ash. The corrosivity of the ash will be described in later chapters. For toxicity of an inorganic material such as coal ash, RCRA regulations define it as TCLP toxic if a standardized extraction procedure produces a leachate from the waste that contains any one of eight metallic elements at levels equaling or exceeding the concentrations listed on Table 2.7. These concentrations are 100 times the allowable concentrations for these elements under the National Primary Drinking Water Standards.

Repeated laboratory studies performed by the EPA, Department of Energy, Electric Power Research Institute and utility companies to analyze the presence of trace metals in leachates from fly ash have consistently demonstrated that heavy metals and other elements have a very low potential of leaching from coal combustion products (CCPs) (Valley Forge Laboratories 1984). There are very limited data available for bottom ash. The Radian Corporation for the U.S. Department of Energy analyzed seven bottom ash samples. They found that none of the concentrations has exceeded the RCRA toxicity standards. Only four analyses on trace elements, out of a possible 56 analyses, were in excess of the primary drinking water standards, and all of these excesses were 
Table 2.7 EPA Hazardous Waste Criteria ${ }^{a}$.

(Title 40, Code of Federal Regulations, Part 261)

\begin{tabular}{lc}
\hline Contaminant & Concentration $(\mathrm{mg} / \mathrm{L})$ \\
\hline \hline Arsenic & 5.0 \\
Barium & 100.0 \\
Cadmium & 1.0 \\
Chromium & 5.0 \\
Lead & 5.0 \\
Mercury & 0.2 \\
Selenium & 1.0 \\
Silver & 5.0
\end{tabular}

${ }^{\mathrm{a}}$ The EPA list of contaminants also includes organic compounds, which are generally not present in coal combustion wastes.

less than ten times the drinking water standard limits (Radian Corporation 1985). Mason and Carlile (1986) reported the results of TCLP tests on CCPs. Table 2.8 illustrates the means and the coefficients of variation $\left(\mathrm{C}_{\mathrm{V}}\right)$ for TCLP analysis of 14 constituents in seven CCPs as measured using several analytical techniques. Fly ash leachate rarely exceeds RCRA hazardous waste criteria. None of the mean values on Table 2.8 exceed RCRA limits.

When the ashes are used for embankment construction, they are usually moistened and compacted, which results in reducing the hydraulic conductivity. Additionally, embankments are normally designed to limit infiltration of both surface and groundwater. Moreover, it was shown that laboratory leachate tests do not account for 
Table 2.8 TCLP Results of Coal Combustion Products (mg/L) (Mason and Carlile 1986).

\begin{tabular}{|c|c|c|c|c|c|c|c|c|c|c|c|c|c|c|c|}
\hline \multirow[t]{2}{*}{ Element } & \multirow[t]{2}{*}{$\begin{array}{l}\text { Analysis } \\
\text { Method }\end{array}$} & \multicolumn{2}{|c|}{$\begin{array}{l}\text { Alkaline } \\
\text { Fly Ash }\end{array}$} & \multicolumn{2}{|c|}{$\begin{array}{l}\text { Acidic } \\
\text { Fly Ash }\end{array}$} & \multicolumn{2}{|c|}{$\begin{array}{l}\text { Neutral } \\
\text { Fly Ash }\end{array}$} & \multicolumn{2}{|c|}{$\begin{array}{c}\text { Alkaline } \\
\text { Bottom Ash }\end{array}$} & \multicolumn{2}{|c|}{$\begin{array}{c}\text { Neutral } \\
\text { Bottom Ash }\end{array}$} & \multicolumn{2}{|c|}{$\begin{array}{c}\text { Forced } \\
\text { Oxidized FGD } \\
\text { Material } \\
\end{array}$} & \multicolumn{2}{|c|}{ FGD Material } \\
\hline & & Mean & $\overline{\mathrm{C}_{\mathrm{V}}}$ & Mean & $\overline{\mathrm{C}_{\mathrm{V}}}$ & Mean & $\mathrm{C}_{\mathrm{V}}$ & Mean & $\overline{\mathrm{C}_{\mathrm{V}}}$ & Mean & $\mathrm{C}_{\mathrm{V}}$ & Mean & $\mathrm{C}_{\mathrm{V}}$ & Mean & $\mathrm{C}_{\mathrm{V}}$ \\
\hline Silver & GFAA & BDL & & BDL & & BDL & & BDL & & BDL & & BDL & & BDL & \\
\hline \multirow[t]{2}{*}{ Arsenic } & GFAA & .009 & 38 & .317 & 72 & .149 & 14 & .005 & 75 & .005 & 74 & .006 & 69 & .010 & 20 \\
\hline & ICAP & .403 & 52 & BDL & & BDL & & BDL & & BDL & & BDL & & BDL & \\
\hline Barium & ICAP & .327 & 45 & .098 & 43 & .446 & 31 & .819 & 41 & .287 & 105 & .121 & 57 & .209 & 54 \\
\hline Boron & ICAP & 17.72 & 8 & 44.85 & 6 & 1.233 & 12 & 1.591 & 18 & .271 & 45 & .918 & 29 & 1.890 & 29 \\
\hline \multirow[t]{2}{*}{ Cadmium } & GFAA & .016 & 25 & .244 & 16 & .006 & 32 & BDL & & .004 & 358 & .028 & 17 & .004 & 38 \\
\hline & ICAP & .022 & 46 & .233 & 43 & BDL & & BDL & & BDL & & .030 & 41 & BDL & \\
\hline \multirow[t]{2}{*}{ Chromium } & GFAA & .352 & 27 & .860 & 50 & .059 & 30 & .010 & 46 & .004 & 55 & .042 & 86 & .013 & 116 \\
\hline & ICAP & .470 & 15 & .921 & 44 & $\mathrm{BDL}$ & & .040 & 68 & BDL & & BDL & & BDL & \\
\hline Fluoride & ISE & .315 & 72 & 1.500 & 45 & 1.481 & 14 & .092 & 92 & BDL & & 8.331 & 33 & 2.016 & 17 \\
\hline Mercury & CVAA & BDL & & BDL & & BDL & & BDL & & BDL & & $\mathrm{BDL}$ & & BDL & \\
\hline Lead & GFAA & BDL & & .181 & 67 & BDL & & BDL & & BDL & & BDL & & BDL & \\
\hline \multirow[t]{2}{*}{ Manganese } & FAA & 4.804 & 12 & 3.999 & 8 & .158 & 32 & .621 & 12 & .027 & 47 & 1.507 & 5 & 1.934 & 6 \\
\hline & ICAP & 4.518 & 10 & 3.793 & 4 & .170 & 6 & .614 & 11 & .032 & 17 & 1.517 & 8 & 1.926 & 8 \\
\hline Selenium & GFAA & BDL & & BDL & & .135 & 27 & BDL & & BDL & & BDL & & $\mathrm{BDL}$ & \\
\hline Sulfate & $\mathrm{IC}$ & 874.1 & 84 & 3396 & 33 & 427.1 & 113 & 339.7 & 173 & 135.6 & 233 & 1451 & 57 & 1389 & 36 \\
\hline \multirow[t]{2}{*}{ Vanadium } & GFAA & .072 & 25 & .664 & 71 & .206 & 12 & BDL & & BDL & & BDL & & .113 & 18 \\
\hline & ICAP & BDL & & .545 & 81 & .210 & 10 & BDL & & BDL & & BDL & & .127 & 84 \\
\hline \multirow[t]{2}{*}{ Zinc } & FAA & .238 & 72 & 5.369 & 7 & .234 & 60 & .164 & 106 & .175 & 96 & 1.607 & 14 & .306 & 91 \\
\hline & ICAP & .228 & 79 & 5.364 & 6 & .261 & 59 & .176 & 101 & .201 & 87 & 1.481 & 23 & .255 & 56 \\
\hline
\end{tabular}

$\mathrm{C}_{\mathrm{V}}=$ Coefficient of variation; GFAA = Graphite Furnace Atomic Absorption; BDL = Below Detection Limit;

ICAP = Inductively Coupled Argon Plasma Spectroscopy; ISE = Ion Specific Electrode; CVAA = Cold Vapor Atomic Absorption;

$\mathrm{FAA}=$ Flame Atomic Absorption, IC = Ion Chromatography. 
attenuation mechanisms, such as precipitation, adsorption, dilution and dispersion (Huang 1990). Consequently, the leaching level at construction sites may be lower than that at disposal sites. Valley Forge Laboratories summarized the groundwater monitoring data from two fly ash highway embankments and two fly ash structural fills. The levels of contaminants in samples from monitoring wells showed either no noticeable change or insignificant increases compared to pre-operational conditions (Valley Forge Laboratories 1984).

In Indiana, CCPs which are placed in disposal sites are usually tested to determine the proper restricted waste site type based on the various parameter concentrations of laboratory leachates. Table 2.9 presents the waste site types and parameter levels defined by the Indiana Administrative Code, 329 IAC 2-9-3 (the values included in Table 2.9 may be changed in the future). Four waste types are specified in order of increasing leachate parameter concentrations. Type IV criteria indicate the lowest leachate concentrations which meets the National Primary Drinking Water Standards and Secondary Drinking Water Standards for most parameters. Type I criteria represent leachate concentrations up to near hazardous levels. The majority of fly ash in Indiana is Type II or III. Bottom ash and boiler slag generally have lower leachate levels since they have a lower ratio of surface area to volume than fly ash (GAI and USIFCAU 1993). The majority of Indiana bottom ash is Type III, while all of the boiler slag is Type IV. Huang (1990) performed the EP toxicity tests and the Indiana neutral leachate tests on bottom ashes from four Indiana power plants. He reported that the bottom ash from only one site failed to meet the Type IV criteria. 
Table 2.9 Indiana Administrative Code Restricted Waste Site Type Criteria (Indiana Administrative Code, 329 IAC 2-9-3).

\begin{tabular}{lllll}
\hline Parameter & \multicolumn{4}{c}{ Concentrations (milligrams per liter) } \\
\hline \hline & \multicolumn{1}{c}{ Type IV } & Type III & Type II & Type I \\
\cline { 2 - 5 } (1) For Parameters Using the EP Toxicity Test: & & \\
Arsenic & $\leq 0.05$ & $\leq 0.5$ & $\leq 1.25$ & $\leq 5.0$ \\
Barium & $\leq 1$ & $\leq 10$ & $\leq 25$ & $\leq 100$ \\
Cadmium & $\leq 0.01$ & $\leq 0.1$ & $\leq 0.25$ & $\leq 1.0$ \\
Chromium & $\leq 0.05$ & $\leq 0.5$ & $\leq 1.25$ & $\leq 5.0$ \\
Lead & $\leq 0.05$ & $\leq 0.5$ & $\leq 1.25$ & $\leq 5.0$ \\
Mercury & $\leq 0.002$ & $\leq 0.02$ & $\leq 0.05$ & $\leq 0.2$ \\
Selenium & $\leq 0.01$ & $\leq 0.1$ & $\leq 0.25$ & $\leq 1.0$ \\
Silver & $\leq 0.05$ & $\leq 0.5$ & $\leq 1.25$ & $\leq 5.0$ \\
(2) For Parameters Using the Leaching Method Test: & & \\
Barium & $\leq 1$ & $\leq 10$ & $\leq 25$ & $\mathrm{~b}$ \\
Boron & $\leq 2$ & $\leq 20$ & $\leq 50$ & $\mathrm{~b}$ \\
Chlorides & $\leq 250$ & $\leq 2,500$ & $\leq 6,250$ & $\mathrm{~b}$ \\
Copper & $\leq 0.25$ & $\leq 2.5$ & $\leq 6.25$ & $\mathrm{~b}$ \\
Cyanide, Total & $\leq 0.2$ & $\leq 2$ & $\leq 5$ & $\mathrm{~b}$ \\
Fluoride & $\leq 1.4$ & $\leq 14$ & $\leq 35$ & $\mathrm{~b}$ \\
Iron & $\leq 1.5$ & $\leq 15$ & $\mathrm{~b}$ & $\mathrm{~b}$ \\
Manganese & $\leq 0.05$ & $\leq 0.5$ & $\mathrm{~b}$ & $\mathrm{~b}$ \\
Nickel & $\leq 0.2$ & $\leq 2$ & $\leq 5$ & $\mathrm{~b}$ \\
Phenols & $\leq 0.3$ & $\leq 3$ & $\leq 7.5$ & $\mathrm{~b}$ \\
Sodium & $\leq 250$ & $\leq 2,500$ & $\leq 6,250$ & $\mathrm{~b}$ \\
Sulfate & $\leq 250$ & $\leq 2,500$ & $\leq 6,250$ & $\mathrm{~b}$ \\
Sulfide, Total & $\leq 1^{\mathrm{c}}$ & $\leq 5$ & $\leq 12.5$ & $\mathrm{~b}$ \\
Total Dissolved Solids & $\leq 500$ & $\leq 5,000$ & $\leq 12,500$ & $\mathrm{~b}$ \\
Zinc & $\leq 2.5$ & $\leq 25$ & $\leq 62.5$ & $\mathrm{~b}$ \\
pH (Standard Units) & $6-9$ & $5-10$ & $4-11$ & $\mathrm{~b}$ \\
\hline
\end{tabular}

${ }^{a}$ IDEM allows EP toxicity test or TCLP test.

${ }^{\mathrm{b}}$ Testing is not required.

${ }^{\mathrm{c}}$ If detection limit problems exist, please consult the Office of Solid and Hazardous Waste for guidance. 
2.7.3 Design and construction considerations for highway embankment constructed using coal ash

Design and construction procedures for coal ash would be similar to those normally followed for natural soils. Due to its origin as a by-product, however, there may be some considerations that should be given in designing and constructing an embankment. In this section, a review of key design and construction considerations particular to ash use for highway embankments is described.

\section{$\underline{\text { Design Considerations }}$}

In general, the design of embankment involves a series of steps, 1) conceptual design; 2) characterization of site and materials; 3) detailed design. The whole design process is iterative.

The purpose of the conceptual design phase is to assess project goals and develop a general scheme to achieve the desired purpose. This stage normally involves developing conceptual plans which satisfy site needs such as providing a sufficient area of usable land, while at the same time considering design requirements pertaining to slope stability, bearing capacity, settlement, and drainage. Next, for characterization, detailed information about the site conditions, proposed fill materials, and other factors pertinent to the design, construction, and performance of the embankment are collected. The information obtained in this stage provides the design parameters for the conceptual and final design. The detailed design phase includes analyses for establishing final site geometry and for predicting the performance of the embankment (DiGioia and Brendel 1992). 
The ash fill must have sufficient strength to safely support its own weight plus the loads imposed upon it without excessive settlements. Consequently, slope stability and settlement analysis are essential to confirm a stable ash fill design. Stable slopes and acceptable compressibility are directly related to the mechanical properties of the material such as the shear strength and the stiffness. When ash mixtures are used as a fill material, the mechanical behavior of the ash mixtures may be dependent on the mixture proportions. Accordingly, characterizations should be made with consideration to the mixture proportions of the ash fill material.

Detailed design considerations pertinent to ash embankments would include drainage, capillary action, corrosion protection, leaching and erosion control and their preventions. Drains must be designed to allow the passage of surface water and groundwater but prevent the migration of fine particles. This can be accomplished by using pipe drains, blanket drains of properly sized and graded material, or a combination drain type of the blanket drain and pipe drain systems. Capillary action may occur in compacted fly ash, which can commonly cause water rise through the fly ash, resulting in a saturated, unstable zone (Smith 1962). Ash saturation may lead to frost susceptibility or liquefaction problems in addition to the environmental problems due to leaching (DiGioia 1994). A properly designed protective granular underdrain would minimize the capillary action. The chemical constituents in ash may cause corrosion of pipes and structural members embedded in the ash fill. If necessary, any steel structure made of non-corrosion resistant materials can be protected from corrosion by methods such as applying protective coating, cathodic protection or using inhibitors. Alternatively, use of fiberglass or PVC may be considered to avoid corrosion. A primary concern regarding leachate is 
the contamination of ground and surface waters in the vicinity of the ash embankment. This problem can be minimized by controlling the amount of water which infiltrates or runs onto the ash embankment. This control can be accomplished by compacting and proofrolling the ash and by diverting the water around the embankment (DiGioia and Brendel 1992). Using barriers of compacted soils that have low hydraulic conductivity or geosynthetic liners would help prevent the physical contact and the migration of leachates. Additionally, properly benched and graded slopes prevent the erosion of ash particles. Runoff from pavement surfaces should be collected and discharged into a pipe drainage system.

\section{Construction Considerations}

Construction using coal ash in place of conventional material follows the same generally accepted construction practices as conventional construction (DiGioia and Brendel 1992). It is crucial that the desired degree of compaction is achieved so that the ash will possess the strength and deformation characteristics which were used in the embankment design. Field tests to be used for quality control purposes are advisable to, at a minimum, monitor moisture content and density. The use of test strips can help in developing compaction method specifications for the construction of the fill. Field experience on each project, however, may provide some unique insights that will tailor site-specific construction procedures. Detailed specifications for construction using fly ash have been reported by several authors (DiGioia et al. 1986; Brendel et al. 1988; DiGioia and Brendel 1992; DiGioia 1994). 


\section{a. Ash sources}

When using dry ash directly from the storage silo at the power plant, the ash should be conditioned. Ideally, the ash should be conditioned to a moisture content within the range of several percent dry of optimum up to the optimum moisture content as determined from moisture-density tests (Smith 1962). Dry ash may present a dust problem during transport.

Typically, lagoon ash or ponded ash is in an extremely wet condition. Therefore, it is necessary to reduce their moisture contents to a range suitable for handling and placement. The gradation of lagoon ash may vary significantly from one location to another in the pond. Accordingly, it is often necessary to perform a series of moisturedensity tests on samples collected from different areas of the pond for characterization.

Stockpiled ash can vary greatly in character and moisture content depending on its location in the stockpile and on how long the ash was stockpiled. Some adjustment of moisture content may be necessary prior to compaction (DiGioia and Brendel 1992).

\section{b. Site preparation}

Surface drainage onto the site from off-site sources should be diverted to prevent excess water from entering the site during construction. All seeps and springs encountered during site preparation must be evaluated for drainage. Depending on flow rates, trenches or perforated pipes can be used. Trenches filled with granular material wrapped in a geotextile are effective for low to moderate flow. For higher flows, the installation of perforated pipes within the granular material will increase the capacity of the drain. In those cases, filter criteria should be considered to prevent migration of soil 
or ash into the drain (DiGioia and Brendel 1992).

\section{c. Delivery and on-site storage of ash}

As previously mentioned, dry ash from hoppers or silos must be conditioned with water at the power plants before delivery to the site to prevent a dusting problem. Ponded ash or stockpiled ash will generally contain enough moisture to prevent dusting. Ash may need to be temporarily stockpiled on-site if the rate at which the ash can be supplied to the site is less than the contractor's demand for an efficient rate of placement. In this case it will be necessary to begin storing ash at the construction site prior to the start of construction.

\section{d. Fill Placement and Compaction}

Coal ash is typically spread by a bulldozer in loose lifts of 200 to $300 \mathrm{~mm}$ (8-12 inch). It was reported that the most efficient and satisfactory compaction performance for coal ash has been achieved with either self-propelled or towed, padfoot or smooth drum, vibratory rollers. Regardless of the equipment used, the ash should be compacted immediately after placing. If the material is dry, the layer should be moistened with water before compaction. If the material is wet, discing or blading may be appropriate (DiGioia et al. 1986; Brendel et al. 1988; Brendel and Glogowski 1989; DiGioia and Brendel 1992; DiGioia 1994).

\section{e. Erosion and Dusting Control}

All ash surfaces should be graded and sloped at the end of each working day to 
control drainage and to prevent the ponding of water. Uncontrolled runoff can erode slopes and produce sediment problems in surface waters of the area. Benches may be used to prevent the formation of runoff channels. Compacted ash slopes must be protected after final grading to avoid severe erosion of the slopes. A typical method for protection is to cover the slopes with a layer of soil which is then fertilized and seeded. Also, when compacted ash is subjected to drying weather, high winds, or traffic for any substantial length of time, the surface will become dry and dusting will occur. Accordingly, during conditions which may cause dusting, the surface of the ash should be kept continuously moist. Alternatively, it may be useful to cover the surface with a thin layer of soil or other materials which are not subject to dusting (DiGioia and Brendel 1992). 


\section{CHAPTER 3 EXPERIMENTAL PROGRAM}

\subsection{Overview}

This chapter introduces the experimental program followed in the present study. The main objective of this program is to evaluate the mechanical characteristics of the fly/bottom ash mixtures. The experimental program is designed to first characterize the ash materials (class F fly ash and bottom ash) sampled from three Indiana power plants and then investigate various mechanical properties of the mixtures of the fly ash and the bottom ash characterized.

For material characterization, the fly and the bottom ash are subjected to a series of characterization tests, consisting of grain size analysis, specific gravity test, and microscopic examination. Extensive engineering property tests, including compaction, permeability, shear strength, stiffness, compressibility and collapsibility, are then performed on the fly/bottom ash mixtures for the evaluation of their mechanical behaviors. Additionally, as an environmental factor affecting highway construction, the corrosion potential to metal structures is examined by conducting corrosivity tests.

In this chapter, a detailed description of the testing materials, the testing methods, and the procedures is presented. 


\section{$\underline{3.2 \text { Testing Materials }}$}

\subsubsection{Ash sources}

Coal ash samples used in this study were extracted from three power plants in Indiana. All of the three power plants produce class F fly ash and bottom ash as byproducts with a general production ratio of $80 \%$ fly ash and $20 \%$ bottom ash. The first power plant was the Wabash River power plant, located in Vigo county, central Indiana and owned by the Cinergy Co.. At the Wabash River power plant, fly ash and bottom ash are co-disposed, existing in the form of mixtures at the disposal sites. The second and third power plants are the A.B. Brown and F.B. Culley power plants, respectively, which are owned by Vectren Co.. They are located on the Ohio River in southeastern Indiana (Posey county and Warrick county, respectively). At the A.B. Brown plant, fly ash and bottom ash are disposed separately, whereas at the F.B. Culley power plant they are disposed of both separately and together as co-mingled mixtures.

\subsubsection{Ash generation and disposal procedures in ash sources}

The Wabash River plant uses pulverized coal burning units. Class F fly ash and bottom ash are produced from burning bituminous coal. The fly ash is separated from the emitted hot gases using electrically charged precipitators, then collected into hoppers. It is slurried using water jets and pumped through pipes to a discharge point close to a disposal pond. The bottom ash is collected in a hopper, crushed, and pumped through pipes to be discharged at the same location as the fly ash disposal. The fly ash and the 
bottom ash thus become mingled at the discharge location.

Similar to Wabash River power plant, at the A.B. Brown power plant all ash generated is ponded. However, the fly ash and the bottom ash collected are conveyed separately through two separate pipelines and discharged into separate locations within a disposal pond. As a result, the disposal pond is for the most part split into a section of fly ash, and a section of bottom ash with little to no commingling of the two ashes.

The F.B. Culley power plant has three power generating units. Unit 1 has $50 \mathrm{MW}$ output and is unscrubbed. Unit 2 has $100 \mathrm{MW}$ output and is scrubbed except during upset conditions in which it then bypasses the scrubber stack. Unit 3 (300 MW) is fully scrubbed. The ashes from Unit 2 during normal operation and Unit 3 are sent to a common area. Dry fly ash is sent to a conveyor and into a dry ash silo, while the bottom ash goes to the East pond. The ash from Unit 1 and Unit 2 during upset conditions are commingled and sent to the West pond. Accordingly, the majority of ash in East pond is bottom ash, whereas the West pond has commingled fly and bottom ash.

\subsubsection{Ash sampling}

\section{$\underline{\text { Sampling from Wabash River Power Plant }}$}

Fly ash samples were directly obtained from electro-static precipitators where fly ash is collected prior to being sent to ash hoppers. They were completely dry, powdery and light tan-colored materials. Bottom ash samples were extracted from the discharge point and the margins of the disposal pond using a back-hoe. Since the coarse part of the ash tends to settle out immediately after being discharged from the pipe, the ashes near 
the discharge point were mostly gravel size materials. On the other hand, the finer the ash particles, the farther they drift along the pond. As a result, the ashes near the end of ash pond channel were mostly very fine materials.

Both the fly ash and the bottom ash samples were stored in two 50-gallon lined plastic drums each (about $250 \mathrm{~kg}$ each) (four drums total) and transported to Purdue University. Unlike the fly ash, the bottom ash samples were in an extremely wet condition since they were taken from the pond. No natural soil was encountered in the samples.

$\underline{\text { Sampling from A.B. Brown and F.B. Culley Power Plant }}$

Sampling from the A.B. Brown power plant was accomplished in a similar manner to bottom ash sampling from Wabash River power plant. Since in the A.B. Brown plant fly ash and bottom ash are discharged separately through separate pipelines, the fly ash and bottom ash samples were extracted from near their respective discharge locations and the margins of the disposal pond using a back-hoe. They were both in highly moist conditions. Fly ash and bottom ash samples were stored in four and two 30gallon lined plastic drums, respectively and transported to Purdue University.

Additionally, from the F.B. Culley power plant, a large sample of class F fly ash (about $200 \mathrm{~kg}$ ) was extracted in a dry condition from a storage silo and delivered inside a sealed 30-gallon drum to Purdue University. 


\section{$\underline{3.3 \text { Ash Characterization Tests }}$}

\subsubsection{Grain size analysis}

The gradation of the ash samples was determined by ASTM D 422, which is designed for soils. The test was performed on fly ash, bottom ash, and fly/bottom ash mixtures. Mixture proportions of fly ash contents of $50 \%$ and $75 \%$ were used. The bottom ash samples extracted from the Wabash River plant contained a small percentage of fines although they were extracted from the discharge point. The fine fraction of the samples was considered as fly ash, discharged together with bottom ash. Hence, the bottom ash samples were first sieved to exclude the fine portion in the samples prior to testing and only the particles retained on \#200 sieve $(0.075 \mathrm{~mm})$ were used as bottom ash in the analysis.

The distribution of grain sizes for fly ash and fly/bottom mixtures were determined by both sieving and a sedimentation process using a hydrometer. All sieves used were U.S. standard sieves conforming to ASTM E 11 specifications.

\subsubsection{Microscopic examination}

Fly ash and bottom ash samples were subjected to microscopic examination in order to characterize their particle shape, angularity, and surface texture. This examination was performed with the use of a scanning electron microscope (manufactured by Electro-Scan, Model 2020) and a light microscope (manufactured by Nikon). Scanning electron microscopy (SEM) was utilized to examine fly ash particles. 
Porous silver membrane filters were used in the sample preparation to avoid charging difficulties and permits imaging of close packed fields of representative particles. Lovell and Diamond (1986) describe the detailed sample preparation procedures for the SEM. The images were captured on photomicrographs in addition to digitized files. Bottom ash particles display a relatively wide range of particle sizes. The shapes and surface textures of large bottom ash particles (size \#8 and larger) could be identified with the naked eye. The light microscope was used to examine smaller bottom ash particles. The magnified images were captured on photomicrographs using a polaroid camera.

\subsubsection{Specific gravity}

The specific gravity of fly ash and bottom ash was determined by means of a water pycnometer as described by ASTM D 854-00 (Method A). The method involved determining the mass of the sample by weighing on an analytical balance, and then determining the apparent solid volume of the particles in the sample. This is done by measuring the amount of fluid (water) that was displaced by the particles in a vessel of known total volume. Only the particles passing the $4.75-\mathrm{mm}$ sieve were used in the test.

De-airing can be done either by using a vacuum pump or by heating. The application of a vacuum, however, may result in the removal of the fly ash particles of lower specific gravity in addition to the entrapped air in the pycnometer. Hence, de-airing was done by very slow heating. 


\subsection{Engineering Property Tests of Coal Ash Mixtures}

The engineering property tests included in this experimental program aim to evaluate the mechanical characteristics of ash mixtures with different, high fly ash contents by applying typical geotechnical testing procedures. Therefore, all the tests were performed on the fly/bottom ash mixtures with fly ash contents of $50 \%, 75 \%$, and $100 \%$. As described in section 3.3.1, the bottom ash samples extracted from disposal ponds were first sieved prior to being tested in order to remove the fine fraction of the samples and thus only the particles coarser than the $\# 200$ sieve were used for bottom ash when forming a mixture.

Most of the methods used were the standard ASTM tests. Some of the tests were conducted with modifications of the ASTM procedure. The tests with modifications will be discussed in greater detail.

\subsubsection{Compaction}

The compaction tests, as described by the ASTM D 698-00a, were performed on the ash mixtures to establish the moisture density relations. To form a mixture of known fly ash content, a specific quantity of fly ash was mixed with a predefined quantity of bottom ash (i.e. by weight). The fly ash and bottom ash were mixed slowly by hand at first and then a specified water quantity was sprayed on gradually while the mixing was continued in a mortar mixer. The ash mixture is then compacted in a 4-in. diameter mold using the standard proctor effort. The tests were performed on seven ash mixtures from three power plants. The moisture-dry density curves were obtained for each mixture 
using at least five compaction tests.

\subsubsection{Maximum and minimum density}

The maximum and the minimum density tests were performed on dry samples of ash mixtures. Saturated samples were liquefied due to positive pore pressures generated from vibrations for obtaining maximum densities. Oven-dried samples were carefully mixed by hand to provide an even distribution of particle sizes, having as little segregation as possible. The minimum density was obtained by pouring ash mixture into a standard mold with a volume of $2830 \mathrm{~cm}^{3}$ using a thin-wall cylindrical tube, as described in the ASTM D 4254-00. The use of respiratory protection equipment was necessary during the sample preparations and the tests. The maximum density was determined based on the ASTM D 4253-00. An electromagnetic, vertically vibrating table with a frequency of $60 \mathrm{~Hz}$ was used to increase the density of dry sample in the mold. From several trials, it was noticed that a great amount of fines is lost through the gap between the mold and the surcharge base-plate during vibration of the mold, causing erratic results. In order to avoid the loss of fines under the vibration, a filter paper, sized slightly larger than the mold diameter, was placed on top of the sample in the mold before vibration. Additionally, the surcharge base-plate was wound along the rim by electrical tape to reduce the gap between the base plate and the mold while allowing up and down movement of the plate. Using the filter paper and the electrical tape reduced significantly the amount of fines lost. The fines collected on the surfaces of the surcharge base plate after vibration were less than $0.6 \%$ of the total mass of the sample for all the ash mixtures tested. Dust raised during vibration was minimal. The respiratory protection 
equipment was a good precaution, but ultimately not necessary.

\subsubsection{Hydraulic conductivity}

The hydraulic conductivity of the ash mixtures were measured by falling head tests using a rigid-wall, compaction-mold permeameter, as described by ASTM D 585695. The permeameter had a $100 \mathrm{~mm}$ (4 in.) inside diameter and an $117 \mathrm{~mm}$ (4.6 in.) height. Each ash mixture was formed as described in section 3.4.1 and compacted in the mold permeameter to $95 \%$ of the maximum density obtained from the standard compaction test specified by ASTM D 698 (i.e. Relative compaction R =95\%). The compaction moisture content was maintained at approximately optimum for the standard effort. A period of time of about 24 hours was then allowed for permeating water to flow downward through the test specimen for saturation prior to the test. The head loss across the test specimen during permeation was measured and recorded until steady values of hydraulic conductivity were obtained.

\subsubsection{One-dimensional compression test}

One-dimensional compression tests were performed on the ash mixtures. The objective of this test was to evaluate the compressibility and the collapsibility of the compacted ash mixtures.

For compressibility, the tests were conducted on the specimens divided into two groups. The first group of specimens was intended for investigation of the effect of mixture composition on the compressibility of the compacted ash mixtures. For that 
purpose, each ash mixture sample was molded at its optimum water content and compacted to a relative compaction level of $95 \%(\mathrm{R}=95 \%)$. The compacted specimens were then soaked for 24 hours before compression. The tests, therefore, were conducted according to the normal consolidation test procedure as described by ASTM D 2435-96. The second group of specimens was prepared to examine the effect of compaction water contents (molding water contents) on the compressibility of the compacted ash mixtures. The tests were performed on the ash mixtures with fly ash content of $50 \%$ and $100 \%$. For the ash mixture with a given mixture composition, two samples were prepared to be compacted to the same dry densities, but molded with different water contents, dry of optimum and wet of optimum, respectively. The values of the densities and the water contents were determined from the compaction curves obtained from the compaction tests (ASTM D 698) on the ash mixtures. The compacted samples were then onedimensionally compressed without soaking through all incremental loadings.

Collapsibility tests were performed on the ash mixtures with fly ash contents of $50 \%$ and $100 \%$. The samples were compacted at dry of optimum and loaded initially without soaking. For a specified vertical stress, however, the specimens were subject to a sudden inundation to induce potential collapse in the specimen. A vertical stress of 100 $\mathrm{kPa}$ was used as the inundation stress. A total of 29 samples was tested for both compressibility and collapsibility tests.

\section{$\underline{\text { Procedure }}$}

An ash mixture molded with a known water content was compacted in a split mold with a diameter of $7.2 \mathrm{~cm}$ (2.8 in.) and a height of $5.5 \mathrm{~cm}(2.2 \mathrm{in}$.$) . A standard$ 
manual rammer conforming to ASTM D 698 was used in the compaction of the mixture sample. To achieve a specified density, the number of blows was determined by trials.

The compacted sample was carefully trimmed using a knife and a wire saw and inserted into a consolidation ring in a lathe. Extreme care was taken in this process to minimize any disturbance in the sample. The consolidation ring was $6.4 \mathrm{~cm}(2.5 \mathrm{in}$.$) in$ diameter and $2.5 \mathrm{~cm}$ (1.0 in.) in height.

The specimen was placed in a consolidometer and a small seating load was applied to record the initial zero reading. The specimen was then loaded incrementally until a maximum vertical stress of $1600 \mathrm{kPa}$ was applied (Figure 3.1). The specimen deformation by incremental loads was measured by a LVDT positioned on the loading frame which changes together as the specimen height changes. A data acquisition system (the TestNet-GP data acquisition system, manufactured by Trautwein Soil Testing Equipment Co.) was used for the LVDT data readings.

\section{a. Soaked specimen}

Prior to the incremental loadings, the specimen was soaked under a small seating pressure of 2 or $3 \mathrm{kPa}$. The seating load was increased as specimen swelling was observed. Seating pressures ranging from $5 \mathrm{kPa}$ to $15 \mathrm{kPa}$ were required to prevent swelling. Upon the initial zero reading, the specimen was loaded according to the standard loading schedule as described by ASTM D 2435. Each incremental load was maintained until no further deformation was observed. 


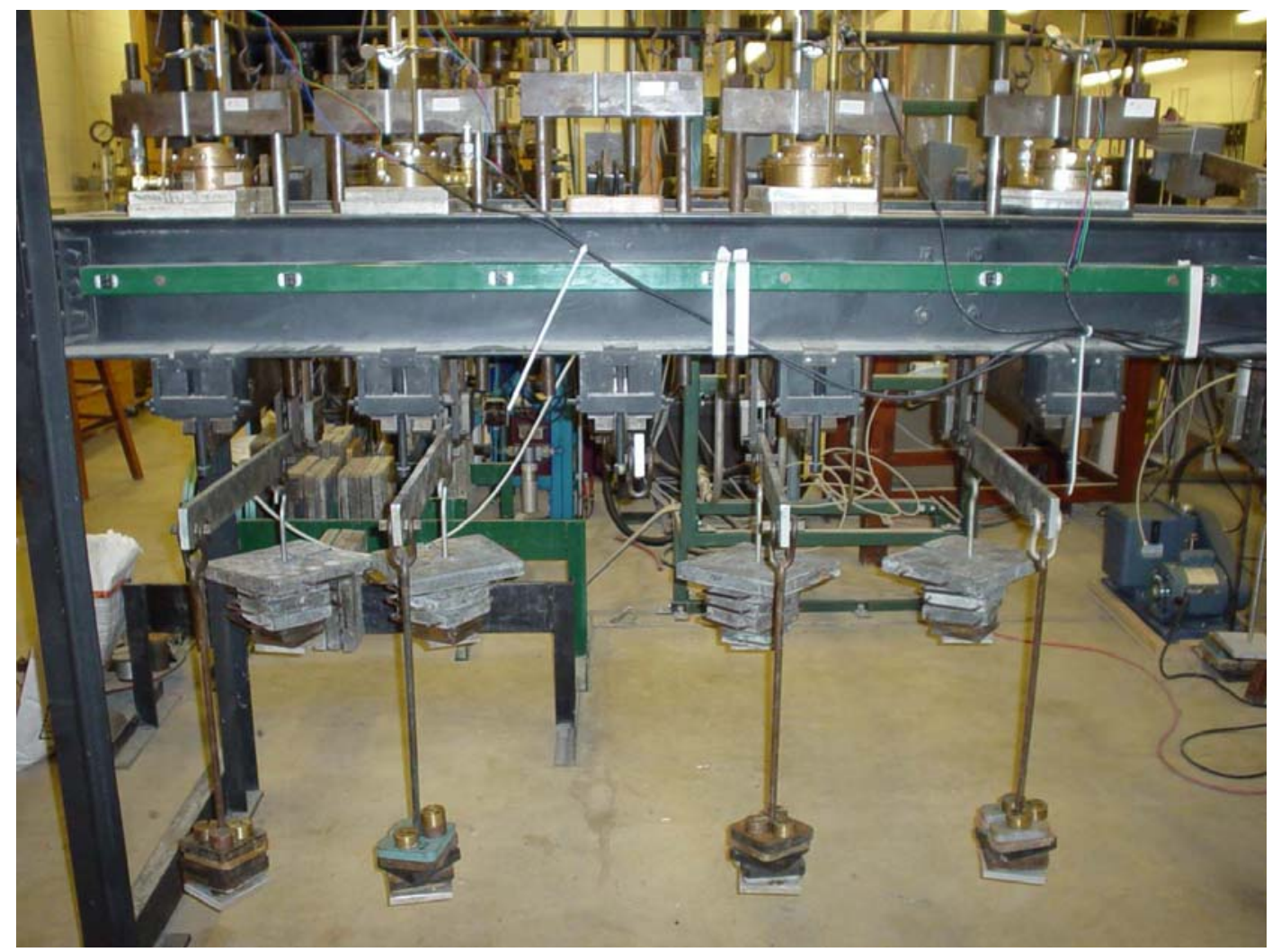

Figure 3.1 One-Dimensional Compression Tests for Compressibility and Collapsibility of Ash Mixtures. 


\section{b. As-compacted specimen}

Immediately after the application of seating loads $(2-3 \mathrm{kPa})$ and the zero reading, the incremental loadings on the specimen were begun. The consolidometer was covered with a damp tissue and the duration between the load increments was limited to one hour to prevent excessive evaporation of moisture from the specimen. It was observed for most specimens that under each incremental load, the specimen deformation was completed within this period of time.

\section{c. Specimen for collapsibility}

The specimen was prepared and loaded initially in the same manner as the ascompacted specimen. When the deformation under the vertical stress of $100 \mathrm{kPa}$ was completed, the specimen was inundated without allowing any change in the vertical stress. Upon completion of the deformation due to the inundation, the next load increment was added to the soaked specimen.

\subsubsection{Direct shear test}

Direct shear tests were performed on ash mixture samples as specified by ASTM D 3080-98. The test was intended to investigate the effects of compaction water content (i.e. molding water content) and saturation on the shear strength of the compacted ash mixtures. To examine the effect of compaction water content, two samples were compacted to the same dry densities, but molded with different water contents (i.e. dry of optimum and wet of optimum). Each ash mixture was prepared and tested for a specified fly ash content, similar to the compressibility tests conducted on the as-compacted 
specimens. In addition to the as-compacted samples, soaked samples, which were initially compacted dry of optimum, were tested for the purpose of examining the influence of saturation on the shear strength. The shear strength of the soaked samples was then compared to those of the as-compacted samples.

In a shear box, a sample of ash mixture was compacted by tamping until the total mass of the sample placed was compacted to a known volume by adjusting the number of layers and the number of tamps per layer. Upon completion of the sample preparation, a specified normal stress was applied on the sample. The soaked sample was prepared by immersing the shear box for 24 hours while a normal stress is applied (Figure 3.2). The sample was then sheared at a slow displacement rate to ensure drained conditions during shearing. Pilot tests showed that the peak shear stresses remained essentially constant when the displacement rate was less than $0.5 \mathrm{~mm} / \mathrm{min}$ for the soaked samples and 2.0 $\mathrm{mm} / \mathrm{min}$ for the as-compacted samples, respectively. Hence, the displacement rates of 0.4 $\mathrm{mm} / \mathrm{min}$ and $1.0 \mathrm{~mm} / \mathrm{min}$ were selected as the displacement rates for the shearing of the soaked samples and the as-compacted samples, respectively.

The test equipment used was the ELE Direct/Residual Shear Apparatus using a microprocessor controlled drive system. The direct shear box had a diameter of $64 \mathrm{~mm}$ (2.5 in.) and a height of $38 \mathrm{~mm}$ (1.5 in.). Three normal stresses, $50 \mathrm{kPa}(7.3 \mathrm{psi}), 100 \mathrm{kPa}$ (14.5 psi), and $200 \mathrm{kPa}(29 \mathrm{psi})$ were used in the test.

\subsubsection{Consolidated drained triaxial tests}

In order to study stress-strain and volumetric behaviors of compacted ash mixtures under shearing and to determine their shear strength, consolidated isotropically, 


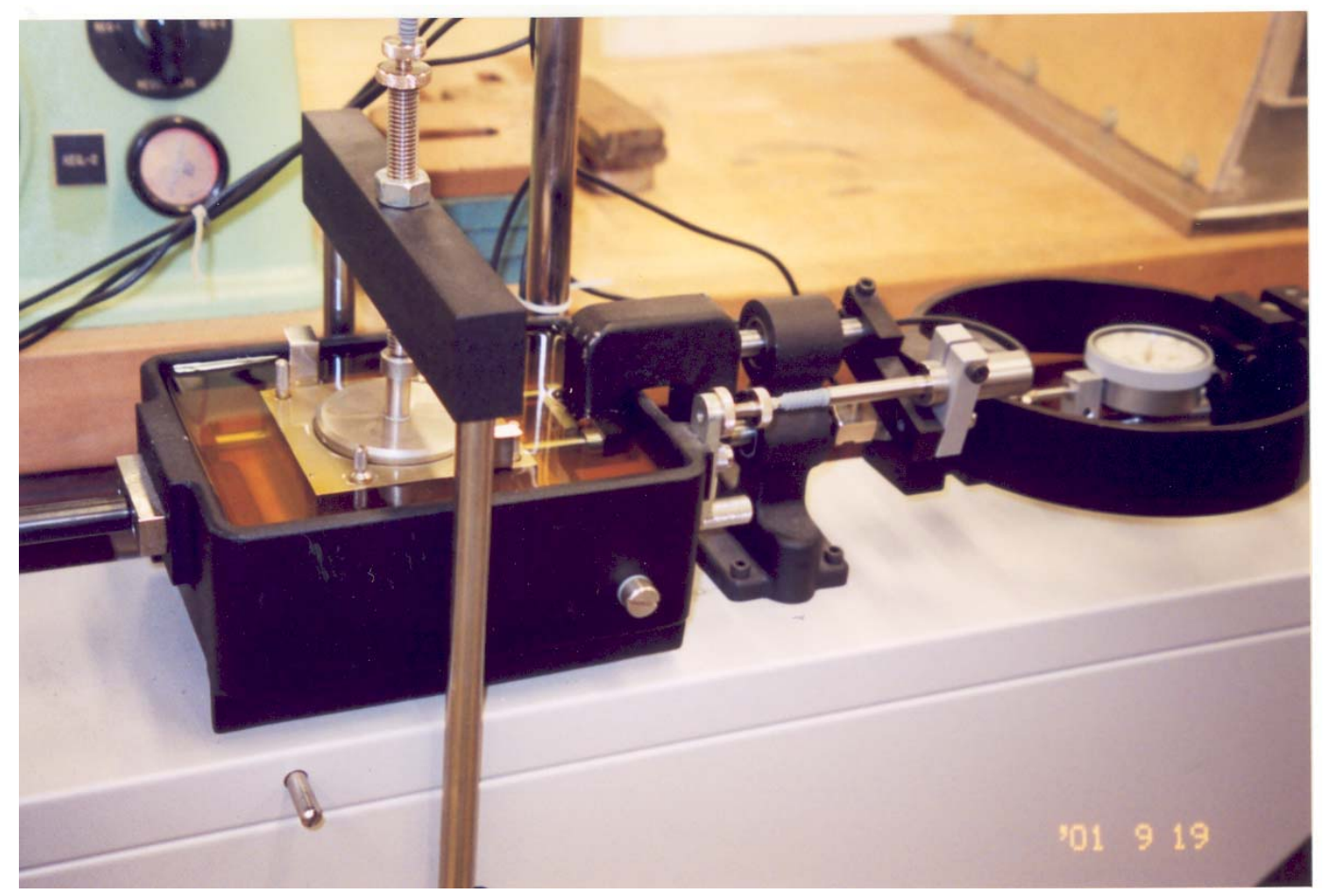

Figure 3.2 Soaked Specimen for Direct Shear Test. 
drained (CID) triaxial tests were performed on compacted ash mixture samples. The test objectives were to investigate the effects of mixture compositions, compaction levels, and confining stresses on the behavior and shear strength of ash mixtures. Class F fly ash has negligible cementing properties and hence can be considered a frictional and dilatational material rather than a cohesive one. A focus, therefore, was placed on obtaining the friction angles of the compacted ash mixture samples.

A total of 42 samples of ash mixtures were tested. The ash mixtures were formed and compacted as described in Section 3.4.1. The compacted ash mixtures were then saturated, consolidated, and sheared under drained conditions. Two levels of relative compaction $(\mathrm{R}=90 \%$ and $95 \%)$ were used per mixture. At each compaction level, three tests were performed, each at a specific confining stress level $(50 \mathrm{kPa}, 100 \mathrm{kPa}$, and 200 $\mathrm{kPa}$, respectively). A summary of the testing program is given in Table 3.1.

Table 3.1 CID Triaxial Compression Tests on Ash Mixtures.

\begin{tabular}{|c|c|c|c|}
\hline \multirow{2}{*}{ Ash source } & Fly ash content (\%) & $\begin{array}{c}\text { Relative } \\
\text { compaction (R) }\end{array}$ & $\begin{array}{c}\text { Confining pressure } \\
\sigma^{\prime}{ }_{3}(\mathrm{kPa})\end{array}$ \\
\hline \hline \multirow{2}{*}{ Wabash River Plant } & 50 & 95,90 & $50,100,200$ \\
\cline { 2 - 4 } & 75 & 95,90 & $50,100,200$ \\
\cline { 2 - 4 } & 100 & 95,90 & $50,100,200$ \\
\cline { 2 - 4 } A.B. Brown Plant & 50 & 95,90 & $50,100,200$ \\
\cline { 2 - 4 } & 75 & 95,90 & $50,100,200$ \\
\hline F.B. Culley Plant & 100 & 95,90 & $50,100,200$ \\
\hline
\end{tabular}




\section{Equipment}

The equipment used in the tests was the CKC automatic triaxial testing system. The system includes a loading frame, a triaxial cell, a load piston, a volume- measuring device with three pressure transducers, a dual channel pneumatic loading unit, a signalconditioning unit, a process interface unit, a personal computer and a printer. Additionally, a $\mathrm{CO}_{2}$ gas cylinder equipped with pressure regulators was used during sample saturation. Figure 3.3 shows the test equipment used.

The testing apparatus uses a pneumatic pressure loading system. The axial loading is applied through a double-acting oil piston, $139.7 \mathrm{~mm}$ in diameter. The axial load is measured with a load cell and the axial deformation with a linear variable differential transformer (LVDT). The three pressure transducers measure the chamber pressure, the effective pressure, and the volume change. The test is computer-controlled, and the stress-strain histories are recorded automatically.

\section{$\underline{\text { Procedure }}$}

The ash mixture sample was compacted in six layers in a split mold with a collar using a standard manual sleeve compaction rammer. The split mold had a diameter of 72 $\mathrm{mm}$ (2.8 in.) and a height of $163 \mathrm{~mm}$ (6.4 in.), which was equal to the specimen size. To achieve a known density of the specimen, blows per layer were determined by several trials for each mixture. Following compaction of the last layer and trimming the top of the compacted sample, the split mold was carefully removed. The sample was then mounted on the triaxial cell base. A membrane was applied to the sample using a membrane expander and the cell chamber was assembled. The pressure line was 


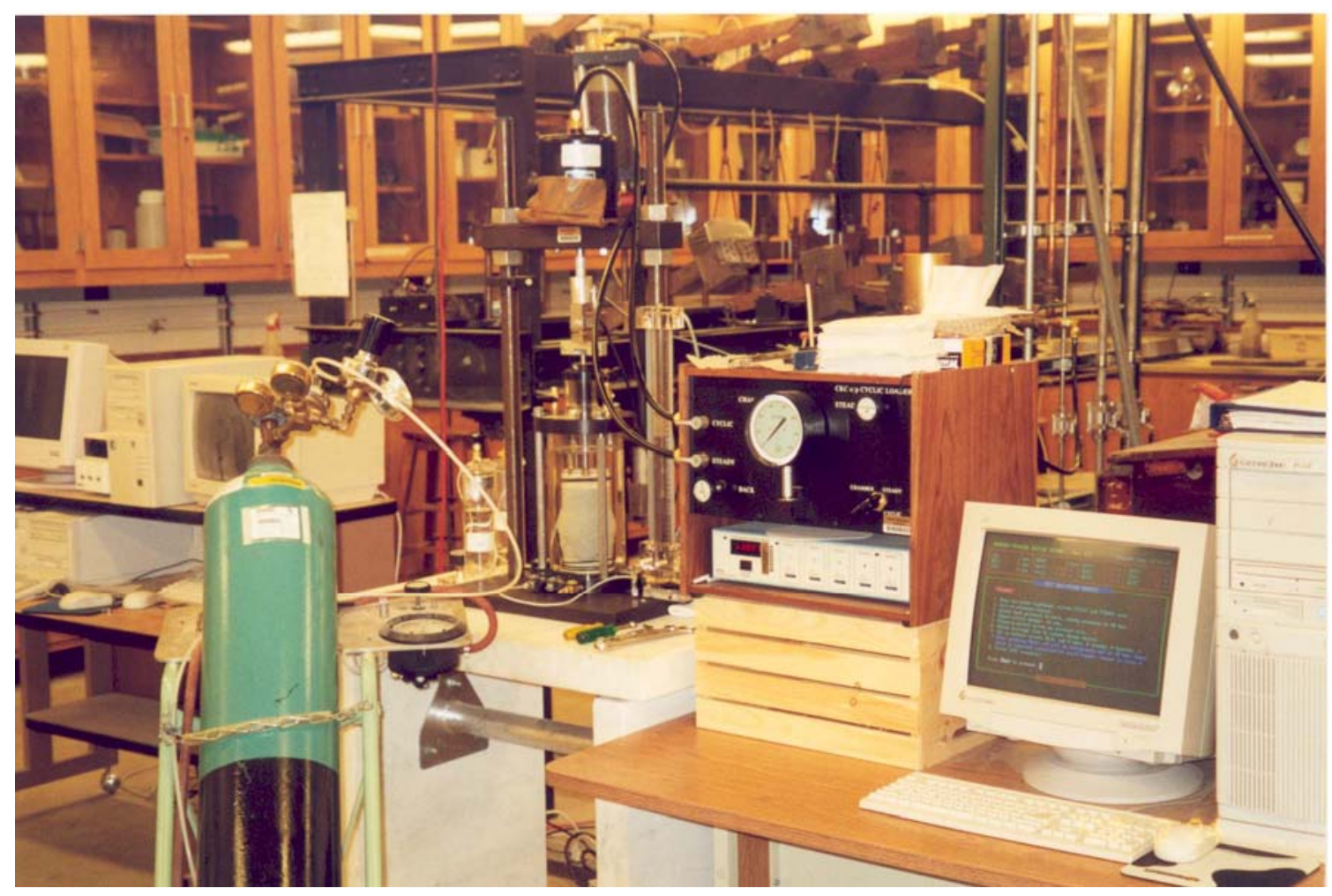

Figure 3.3 CKC Triaxial Testing System Including $\mathrm{CO}_{2}$ Percolation Equipment. 
connected to the chamber top valve, and upon turning on the pressure source, a confining stress of the order of $25 \mathrm{kPa}$ was automatically applied by the CKC system.

The $\mathrm{CO}_{2}$ was percolated at an entrance pressure of less than $20 \mathrm{kPa}(3 \mathrm{psi})$ for about 60 minutes. The objective of $\mathrm{CO}_{2}$ percolation was to replace the majority of the air bubbles in the specimen's pores by $\mathrm{CO}_{2}$ gas bubbles. The $\mathrm{CO}_{2}$ line was then replaced by the bottom platen line. De-aired water was allowed to percolate very slowly under the partial vacuum plus a small elevation head (about $50 \mathrm{~cm}$ ), until no more gas bubbles pass through the top platen. The water percolation was usually completed in 45 to 90 minutes depending on the mixture composition and the degree of compaction. The percolation lines were then switched to the transducer lines from the volume change device for backpressure saturation. The backpressure was increased simultaneously with the cell pressure to keep the effective pressure on the sample at about $35 \mathrm{kPa}$. The pressure was increased slowly in about 30 to 50 minutes (about $10 \mathrm{kPa}$ per minute). A period of time was then allowed for the gas bubbles to dissolve in the pressurized fluid, while the sample was allowed to absorb more de-aired water. The backpressure saturation was continued until a B-value higher than 0.95 is achieved.

Upon completion of the back pressure saturation, the specimens were isotropically consolidated by applying the desired effective confining stresses $(50 \mathrm{kPa}$, $100 \mathrm{kPa}$, and $200 \mathrm{kPa}$ ) and a period of time ranging from 180 minutes (for the specimen at $\mathrm{R}=95 \%$ and low confining stress) to 360 minutes (for the specimen at $\mathrm{R}=90 \%$ and high confining stress) was allowed for the specimens to have enough time to fully dissipate the generated pore pressure and reach primary consolidation, as revealed by the on-screen plot generated as the testing proceeds. 
Triaxial compression (shearing) was performed on the saturated specimens previously consolidated to a given effective confining stress under strain-controlled conditions. Typically, specimen shearing was completed in 7 to 9 hours. The CKC system recorded automatically the axial and volumetric strains, the total confining stress, pore pressure, and deviator stress at each pre-set time interval. On-screen plots were generated as the testing proceeds to help the user evaluate the test at any stage during the shearing.

\subsection{Corrosivity Tests}

Corrosion is defined as the deterioration of a material, usually a metal, which is normally caused by chemical or electrochemical interaction with the surrounding environment or media. Corrosivity is the characteristics of a material (or an environment) indicating the likelihood of its causing the corrosion of a contacted metal. In highway construction, metal structures such as culverts, rebars in concrete, steel piles used in retaining walls, and reinforcing steel strips in reinforced earth are often included (Ke and Lovell 1992). The corrosivity of coal ash is a concern to potential ash users and may result in limiting its extensive use in highway construction unless potential interactions between the ash and such metal structures are well understood and designed against.

The corrosivity of Indiana bottom ash was studied by Ke and Lovell (1992). As described in previous chapters, however, a potential fill material for highway embankments is a fly/bottom ash mixture involving a high proportion of fly ash or pure fly ash itself, and yet little research has been done on the corrosivity of ash mixtures or 
fly ash. This has been a motivation for examining the corrosivity of the ash mixtures in this study.

The method adopted in this study to evaluate the corrosivity of the ash mixture was a correlation method that involves measuring two corrosivity parameters: electrical resistivity $(\mathrm{R})$ and $\mathrm{pH}$. To obtain the corrosivity parameters, electrical resistivity tests were performed on ash mixtures with fly ash contents of $50 \%, 75 \%$, and $100 \%$. Two values of electrical resistivity were measured for each specimen: as-compacted and saturated. Following measurements of electrical resistivity, the saturated specimens were subjected to $\mathrm{pH}$ measurements.

\subsubsection{Electrical resistivity test}

The electrical resistivity test is a simple method used in estimating the corrosivity of a material and has been widely used for the evaluation of soil corrosivity. The test is also known as the soil resistivity test. This test uses the principle that the corrosion of metals in a material is affected by the variation in potential that exists at different points or areas on the surface of the metal (Chaker 1996). The resistivity in this test is defined as the electrical resistance between opposite faces of a unit cube of material, which is obtained by measuring the potential drop between metal electrodes placed in the material. Since resistivity is an electrical quantity and thus is related to current flow by Ohm's law, it is most often considered indicative of material corrosivity (Fitzgerald III 1993). ASTM G 57-95a standardizes the resistivity test. The evaluation criteria for corrosivity based on resistivity are normally available.

The equipment used for the tests in this study consist of a soil box, four insulated 
soil box test leads (electrodes) (manufactured by Mc Miller Co.), and an electrical resistivity tester (Nilsson Model 400, manufactured by Nilsson Electrical Laboratory Inc.).

The ash mixture was formed and compacted in layers in the soil box by tamping to adjust the desired density (Relative compaction $\mathrm{R}=95 \%$ ). Two inner electrodes were then carefully inserted into the compacted ash mixtures. When all the connections between the inner/outer electrodes and the resistivity meter were complete, the resistivity was read from the meter in ohm-centimeters (Figure 3.4). Following the resistivity reading for the as-compacted ash mixture, the soil box was immersed for 24 hours to make the specimen saturated. Then the resistivity reading was taken again for the saturated specimen.

\section{$3.5 .2 \mathrm{pH}$ test}

$\mathrm{pH}$ measurements were performed on the saturated specimen in the soil box according to the ASTM G 51 (1995) procedure (Figure 3.5). This $\mathrm{pH}$ test was to supplement the resistivity measurements. $\mathrm{pH}$ can be used as a parameter aiding evaluation of the ash mixture corrosivity. 


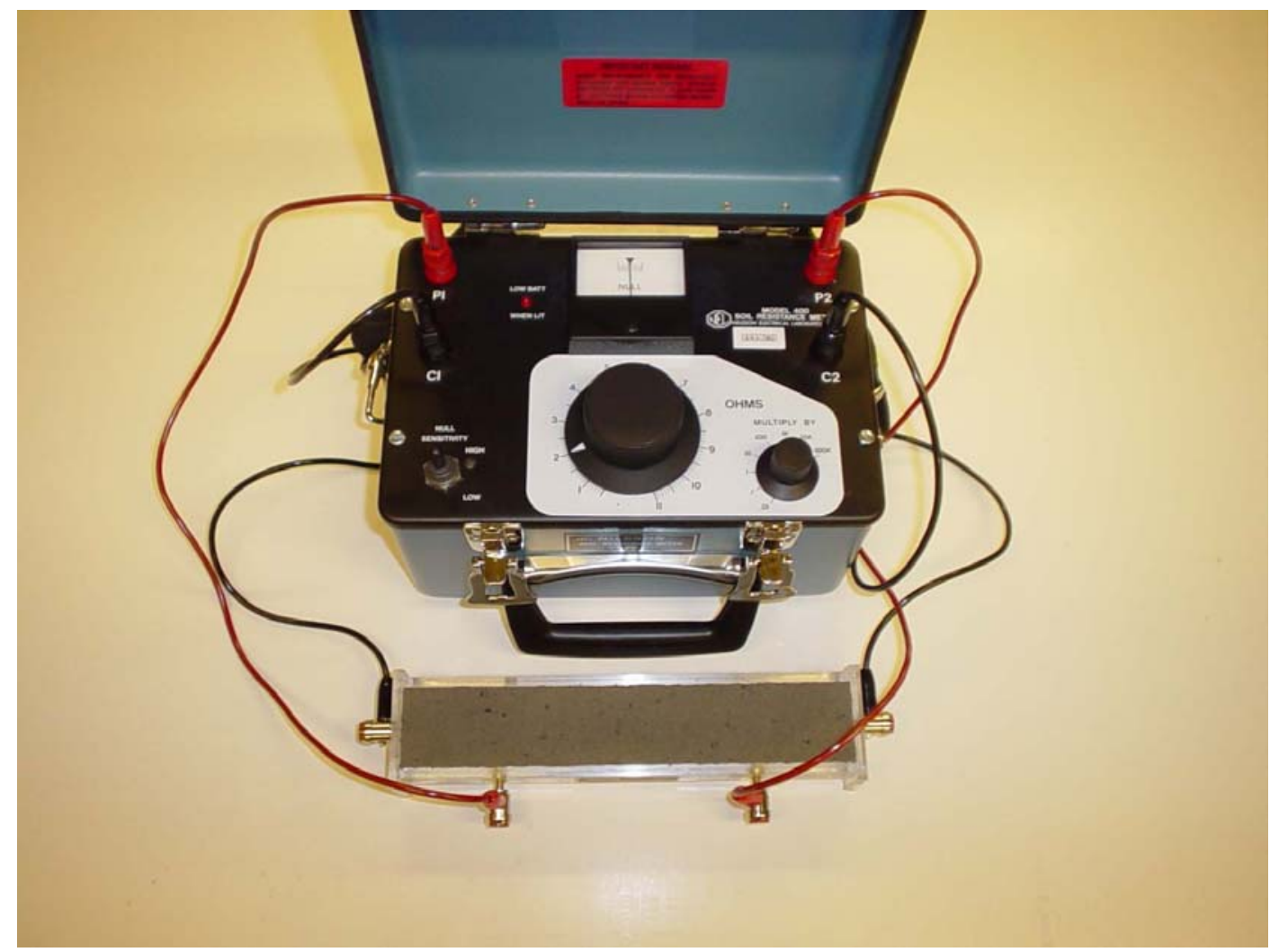

Figure 3.4 Electrical Resistivity Test on Ash Mixture 


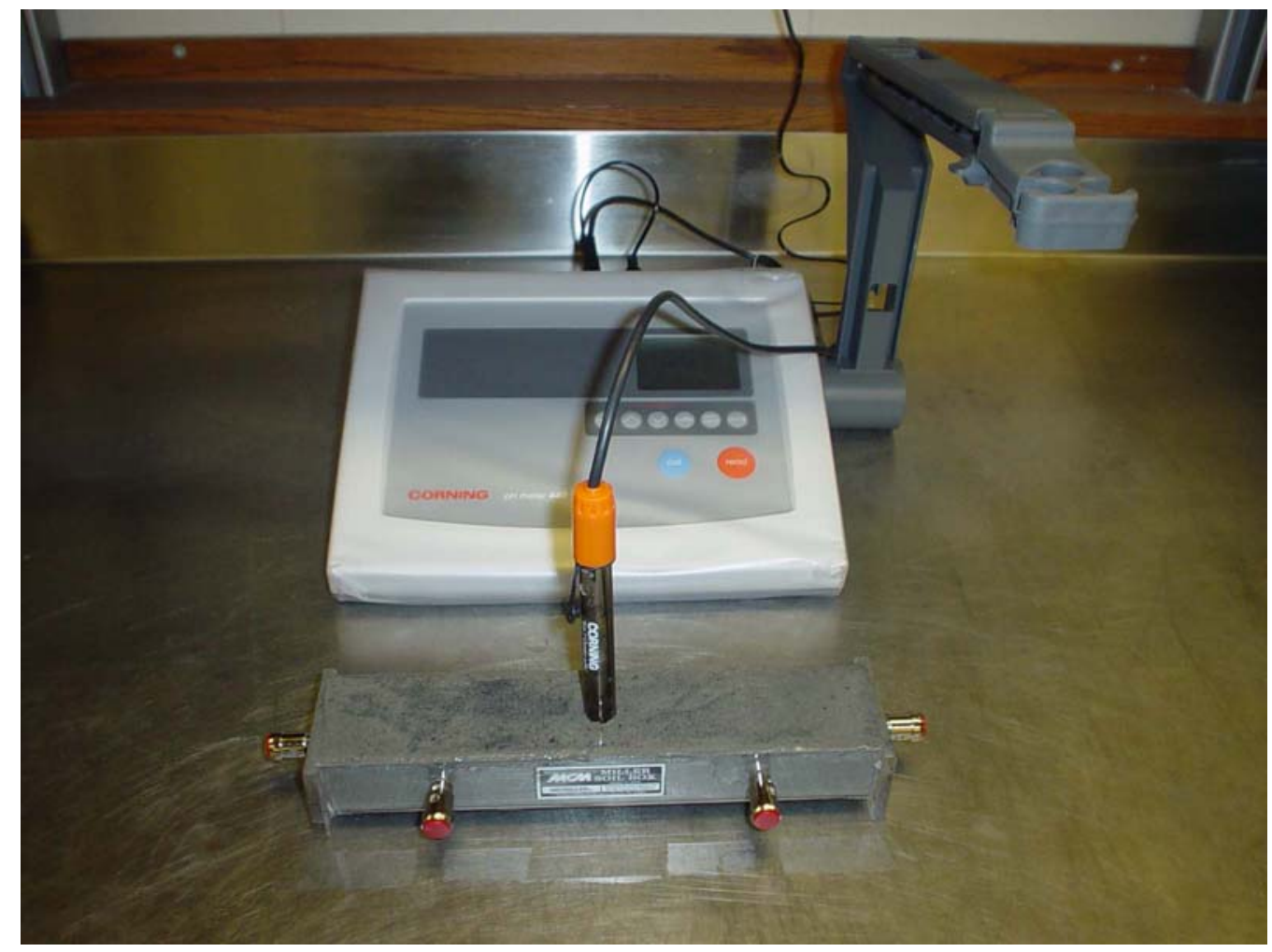

Figure $3.5 \mathrm{pH}$ Measurement of Ash Mixture 


\section{CHAPTER 4 RESULTS AND DISCUSSION}

\subsection{Overview}

This chapter presents the results and discussion of laboratory experiments performed on fly ash, bottom ash, and mixtures of fly and bottom ash. Fly ash and bottom ash samples were characterized through a series of characterization tests including particle size analysis, microscopic examination, and specific gravity. Discussions focus on distinct features between fly ash and bottom ash and between ashes from different sources.

Mechanical properties of fly/bottom ash mixtures with fly ash contents of $50 \%$, $75 \%$, and $100 \%$ were extensively investigated and test results are presented in the following sequence:

- compaction behavior;

- maximum and minimum density;

- hydraulic conductivity;

- compressibility and collapsibility;

- shear strength.

The effects of fly ash content on the mechanical behavior of ash mixtures are extensively discussed. Also, influences of compaction water content and saturation on the 
compressibility and shear strength of the ash mixtures are examined. The test results are compared with those of typical granular materials.

Finally, corrosion test results of ash mixtures are analyzed and their corrosivities are evaluated.

\section{$\underline{4.2 \text { Grain Size Distribution }}$}

Gradations of fly ash, bottom ash and fly/bottom ash mixtures were investigated by performing sieve analyses and hydrometer tests. Grain size distribution analyses of fly and bottom ash were performed first and the gradations of ash mixtures were then determined based on their grain sizes. Although samples were taken mostly near the discharge point in which the coarse fraction of discharged ash exists, since the bottom ash samples from the Wabash River power plant were extracted from the pond where fly ash

and bottom ash become commingled, a representative bottom ash sample was needed to be separated from the samples by investigating the gradations of ponded ash.

Figure 4.1 displays the grain size distributions of the ashes sampled from two extreme locations at the ash pond of the Wabash river plant. For comparison, the grain size distribution of the fly ash sampled from an electro-static precipitator from the same plant is also plotted. The ponded ash obtained from the end of the pond channel consists of very fine materials and its gradation is similar to that of fly ash sampled from a precipitator. Hence, the pond ash near the end of the pond channel appears to be essentially fly ash. Conversely, the ash near the discharge point is much coarser than the fly ash, and its grading curve is similar to that of a well graded sand. Nevertheless, it 


\section{Wabash River Plant Ash}

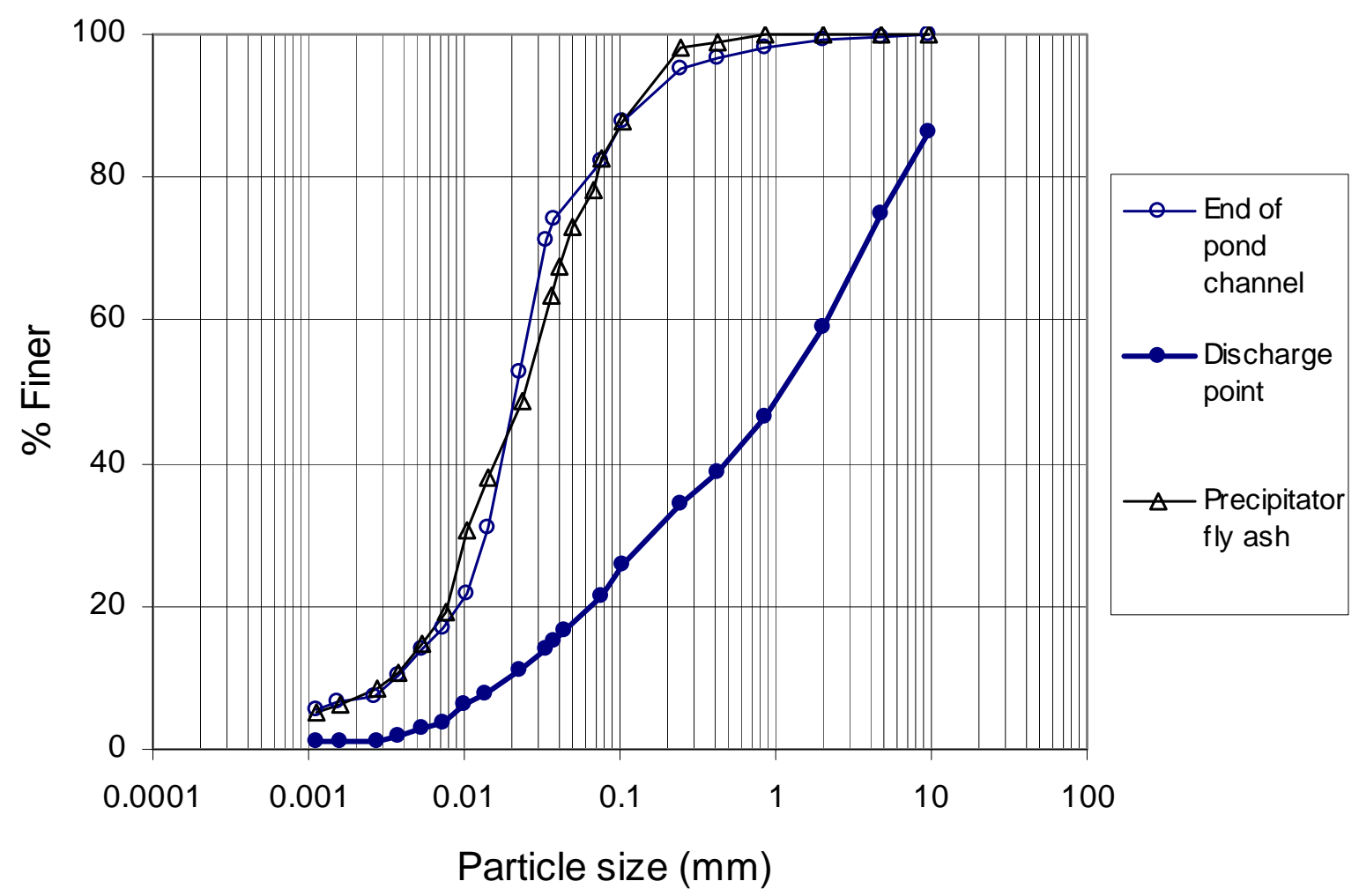

Figure 4.1 Particle Size Distributions of the Wabash River Plant Ash. 
contains a relatively a large portion of fines in it. It is believed that the fines consist of fly ash which settled down near the discharge point together with bottom ash. Accordingly, the fines (material passing the \#200 sieve) were excluded from the bottom ash sample by sieving prior to forming a mixture of fly ash and bottom ash with a specified mixture ratio. Except for the bottom ash sample from the Wabash River plant, fly ash and bottom ash samples were collected from separate sources of fly ash and bottom ash, and thus it was considered that they were representative of each type of ash.

Figure 4.2 through Figure 4.4 show the grain size distribution curves of fly ash, bottom ash, and fly/bottom ash mixtures with fly ash contents of 50\%, 75\%, and 100\% from different power plants. Generally, fly ashes exhibit well-graded size distribution ranging from mostly silt to fine sand sizes. A majority of the sizes occurs in a range between $0.001 \mathrm{~mm}$ and $0.075 \mathrm{~mm}$. From the gradation curves, it appears that the Wabash plant fly ash has more silt size particles than Brown plant and Culley plant fly ash. Bottom ash gradations are quite similar between two bottom ashes from the Wabash river plant and A.B. Brown plant. Their sizes range from sands to small-size gravels. The shapes of the gradation curves indicate that the size distributions become better graded with increasing bottom ash content in the ash mixtures.

Attempts were made to perform Atterberg limit tests on the fly ash passing the \#200 sieve. However, it was not possible to establish either a liquid limit or a plastic limit. Fly ash samples generally crumbled quickly by squeezing and rolling at both a low and high range of water contents (plastic limit tests). Also, at a low to moderate range of water contents, the samples generally slid on the surface of the brass cup of the Casagrande liquid limit device, but further increase in the water contents turned them 


\section{Wabash River Plant Ash}

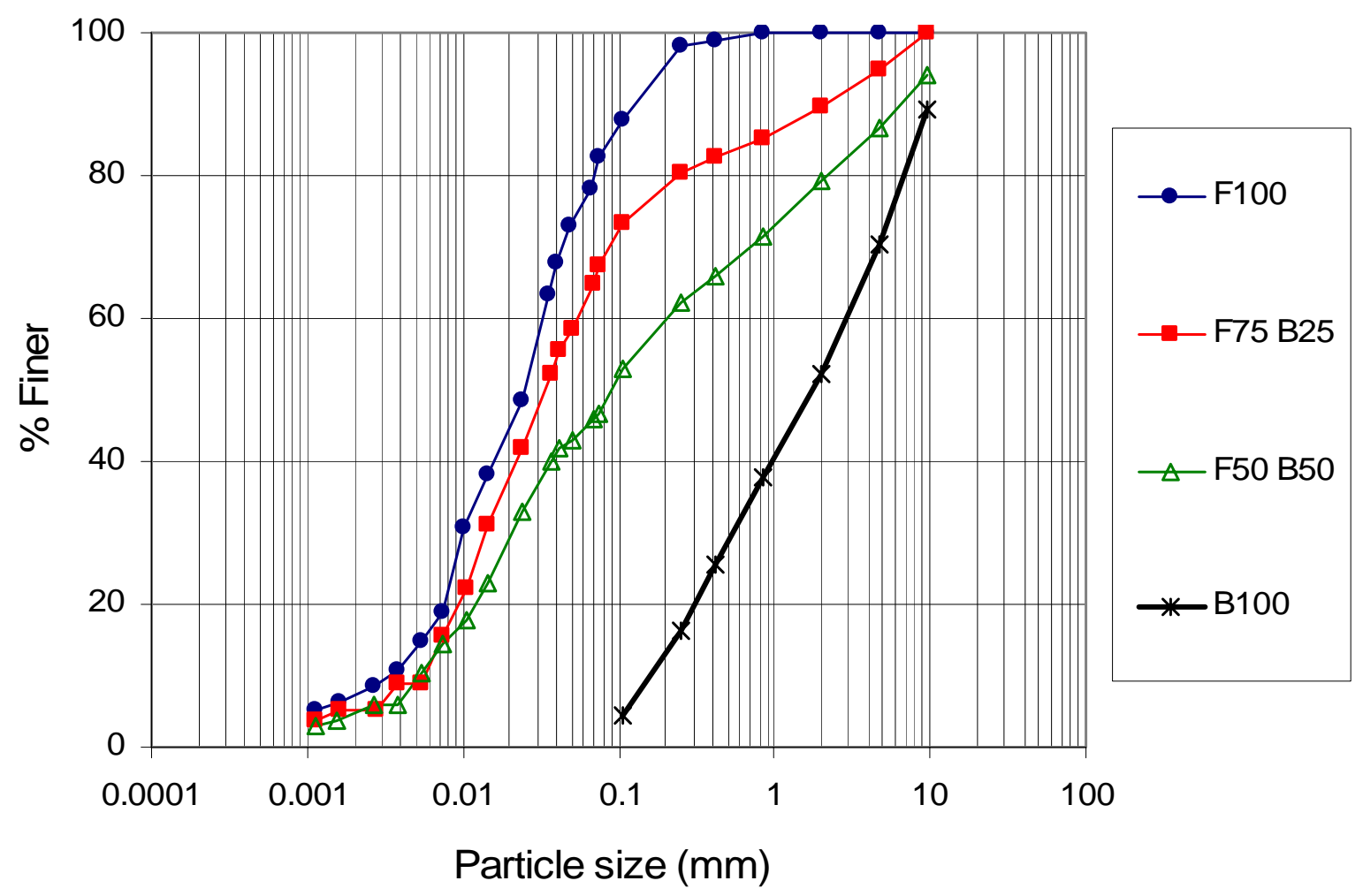

Figure 4.2 Particle Size Distributions of the Wabash River Plant Fly Ash, Bottom Ash, and Fly/Bottom Ash Mixtures. 


\section{A.B. Brown Plant Ash}

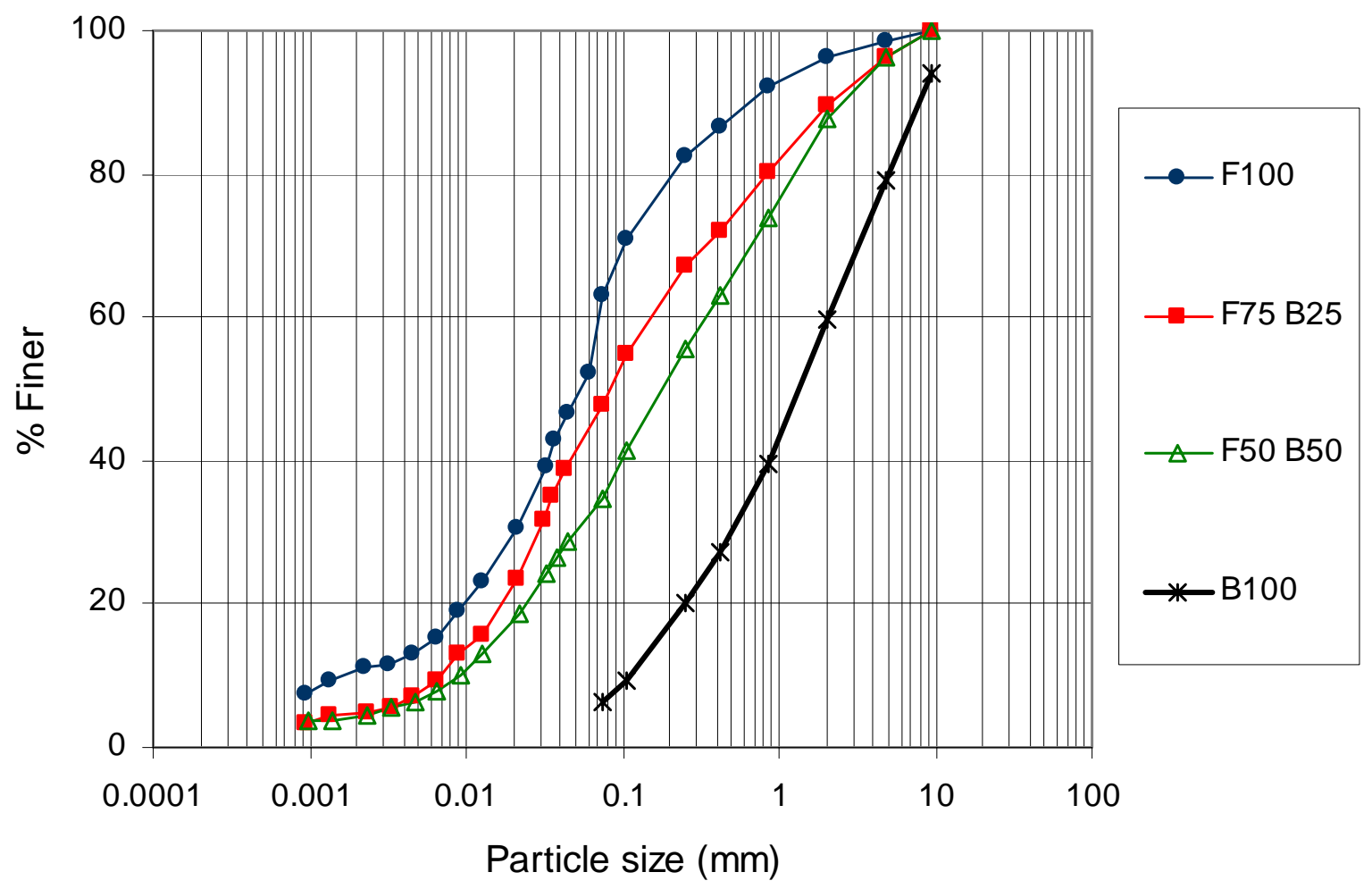

Figure 4.3 Particle Size Distributions of the A.B.Brown Plant Fly Ash, Bottom Ash, and Fly/Bottom Ash Mixtures. 


\section{F.B. Culley Plant Fly Ash}

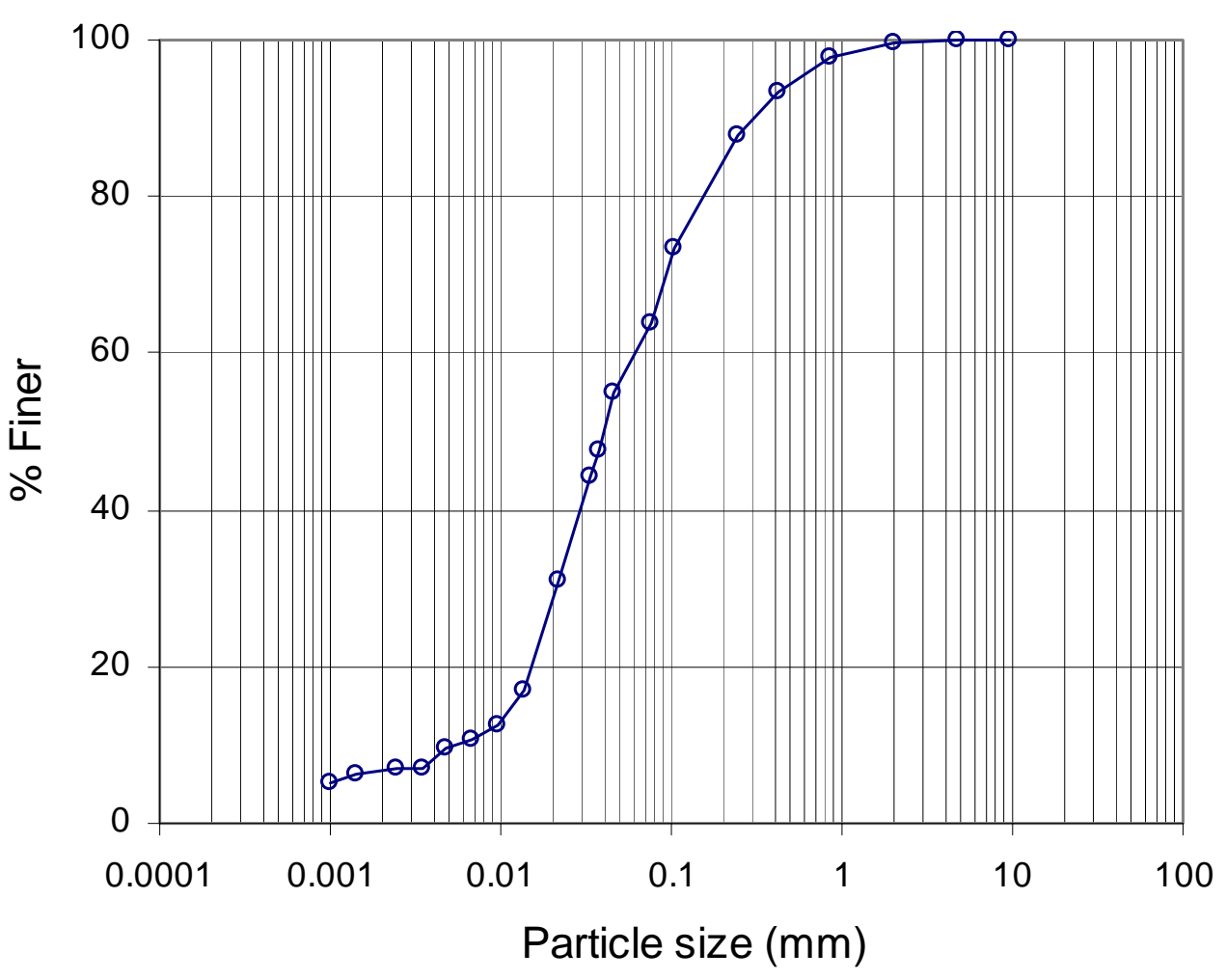

Figure 4.4 Particle Size Distributions of the F.B.Culley Plant Fly Ash. 
quickly into slurry, making it difficult to form a groove. Therefore, it was considered that the tested fly ashes (class F fly ash) are non-plastic.

\section{$\underline{4.3 \text { Microscopic Characterization }}$}

In order to characterize the particle shapes and surface textures of fly and bottom ash particles, and to gain some insight of the behavior of ash materials during testing, microscopic examinations were conducted on the samples of fly ash and bottom ash using the scanning electron microscope (SEM) and the light microscope (LM).

Observed under the naked eye, fly ash appears to be composed of powder-like particles with color that varies little from plant to plant. Wabash river plant fly ash was light tan, whereas Brown plant fly ash and Culley plant fly ash were light and dark gray, respectively. Figure 4.5 through Figure 4.7 are SEM photomicrographs of the fly ash particles under different magnifications. There did not appear to be a large morphological difference between different plants. In general, fly ash particles were well-rounded, spherical in shape and their surfaces appeared to be very smooth. Some particles were very small (less than $1 \mu \mathrm{m})$. Some particles were approximately hollow spheres with thin walls. Figure 4.5 (b), Figure 4.6 (a), and Figure 4.7 (a) show broken hollow fly ash particles containing numerous smaller particles within them. A distinct morphological difference observed between fly ashes from different plants appears to be the extent of the agglomeration of particles. As shown in Figure 4.6 (b) and (c), the agglomerates of particles are more evident in the Brown plant fly ash, compared with the fly ashes from other plants. The agglomerates of particles may be separated into finer particles under 


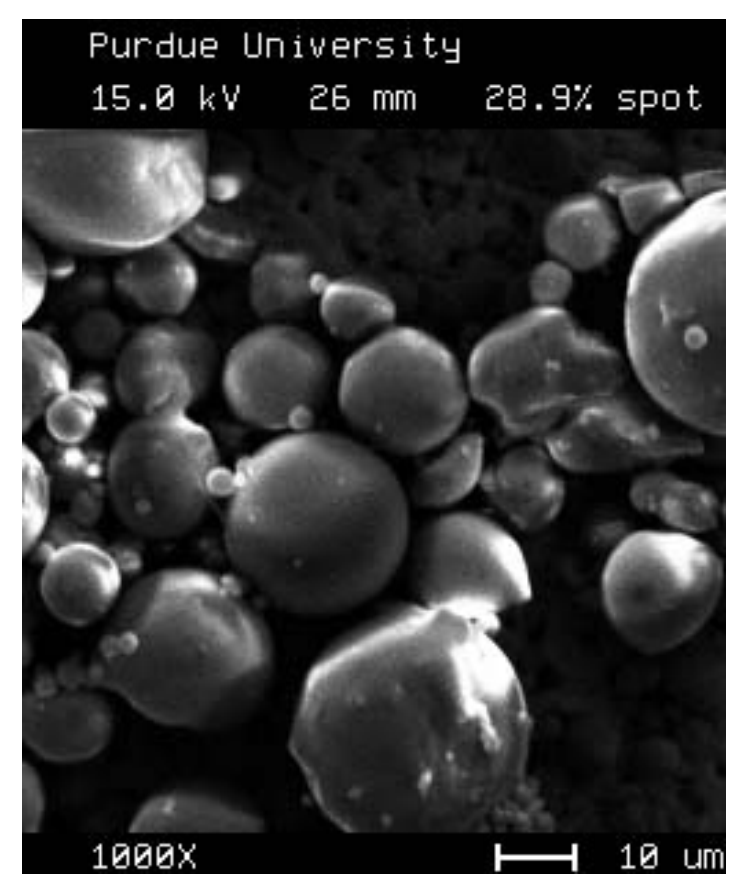

(a)

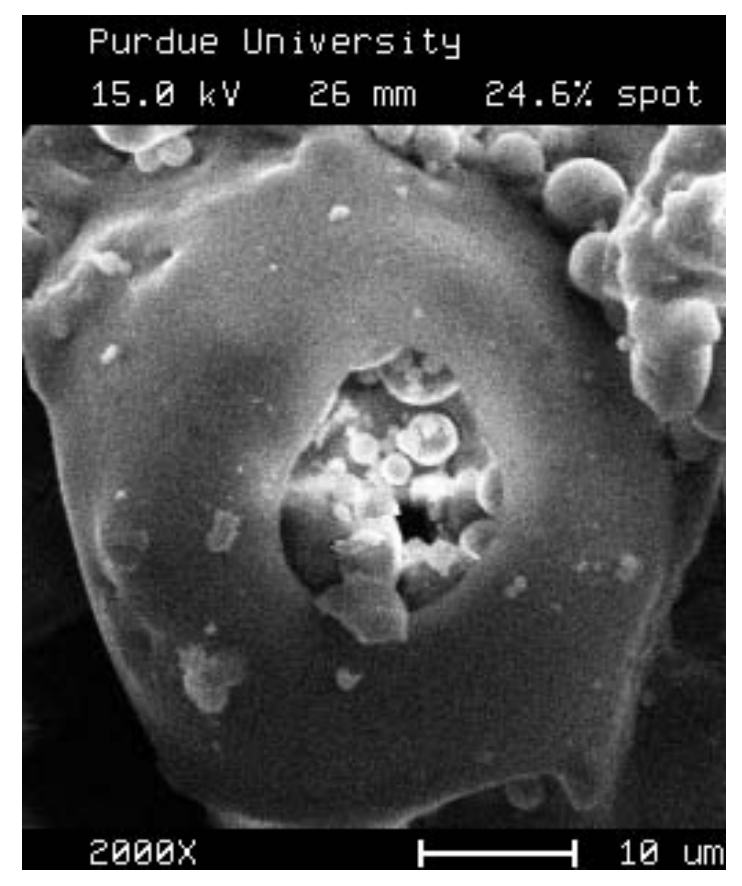

(b)

Figure 4.5 SEM Micrograph of Fly Ash Particles from the Wabash River Plant: (a) Magnification $\times 1000$ (b) Magnification $\times 2000$. 


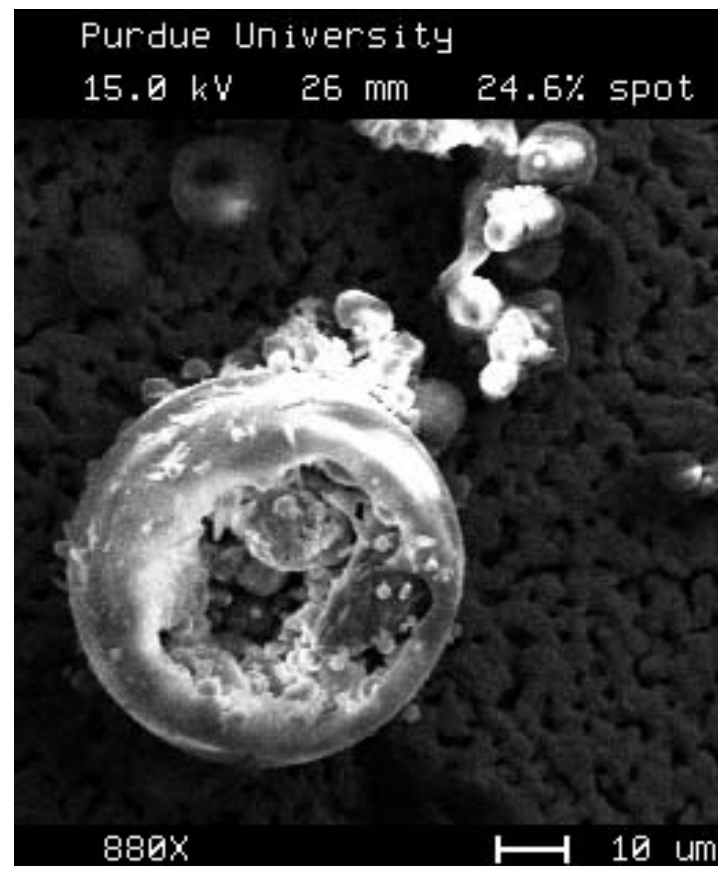

(a)

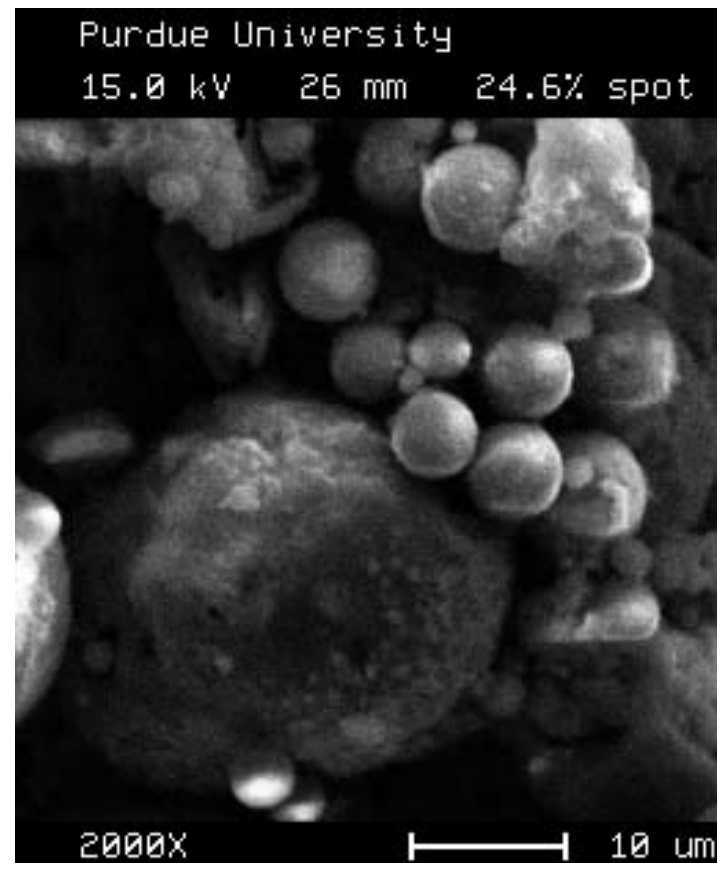

(b)

Figure 4.6 SEM Micrograph of Fly Ash Particles from the A.B.Brown Plant: (a) Magnification $\times 880$ (b) Magnification $\times 2000$ (c) Magnification $\times 2000$. 


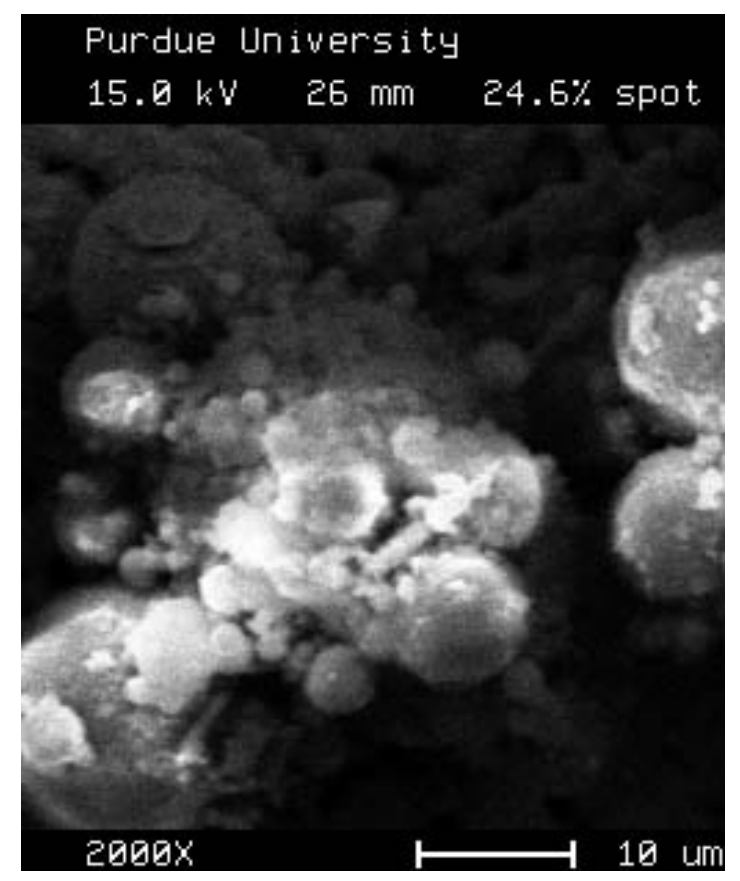

(c)

Figure 4.6 [Continued] 


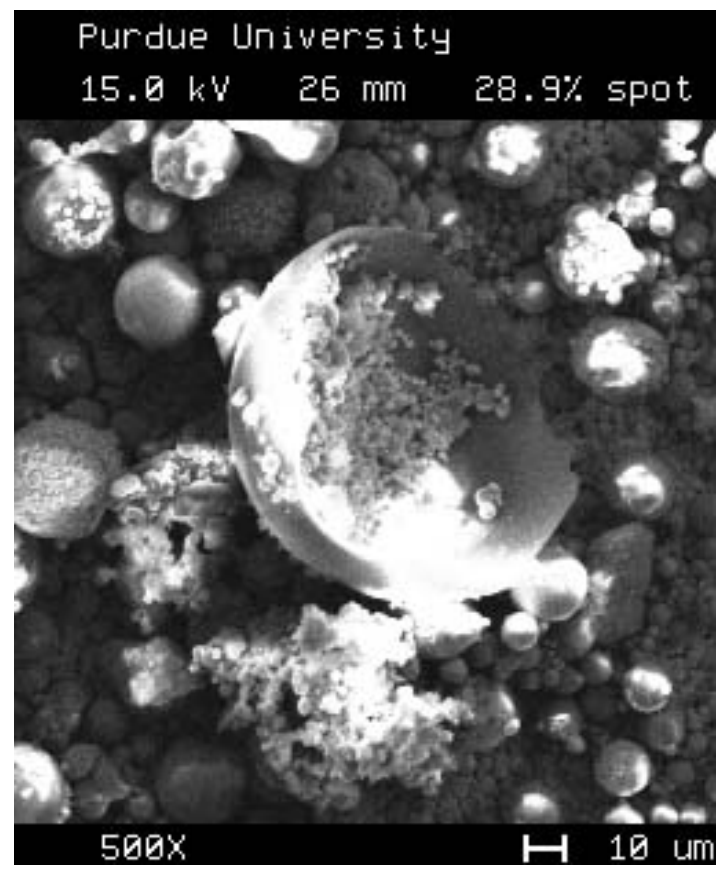

(a)

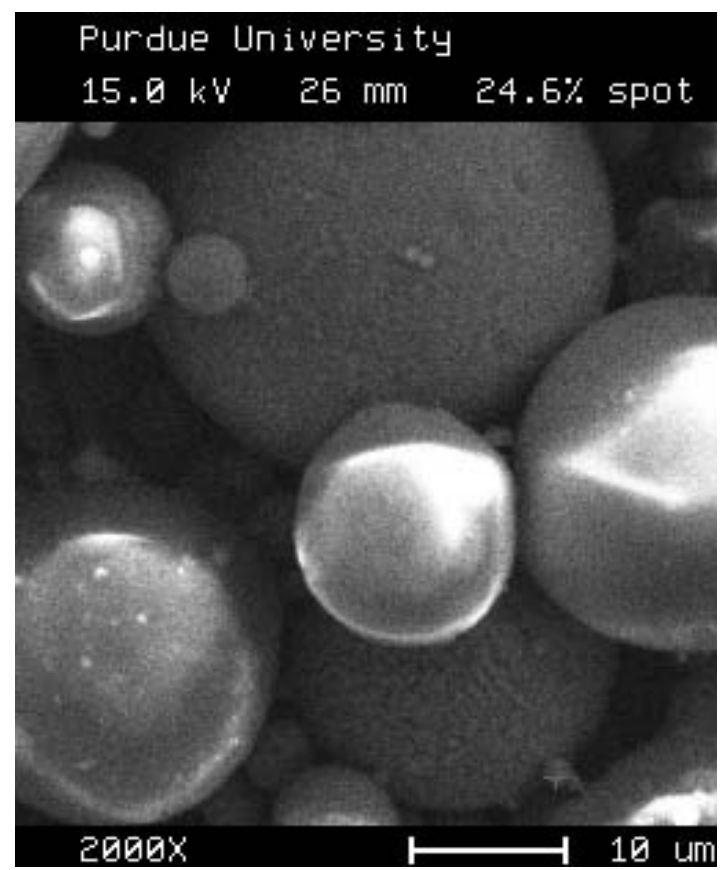

(b)

Figure 4.7 SEM Micrograph of Fly Ash Particles from the F.B.Culley Plant: (a) Magnification $\times 500$ (b) Magnification $\times 2000$. 
elevated pressures.

In terms of the shape and surface characteristic of the particles, bottom ash is quite different from fly ash. Figure 4.8 and Figure 4.9 show the photomicrographs of bottom ash particles taken at the magnifications of 20 and 50, respectively, using a light microscope. Bottom ash particles are angular and irregular in shape and have rough, gritty surface textures (as was commonly observed in both Wabash plant and Brown plant bottom ash). They are usually light gray to black in color. The surfaces of the particles were observed to be essentially free of dust, clean and shiny. Some large particles were both internally and externally porous, which appeared to result from air or gas inclusion during combustion. The internal porosity of the particles makes them more crushable. Some of the popcorn-like particles were crushed even under finger pressure. Particle agglomerations were also observed in bottom ashes. Some bottom ash particles appeared to be combined with fly ash particles. Brown plant bottom ash had many of the agglomerates of bottom ash particles alone or both bottom ash particles and fly ash particles, compared with Wabash plant bottom ash. Some of these agglomerates appeared to be lightly cemented, and some, strongly bonded. The weakly bonded particles may undergo complete crushing during compaction. The agglomerates of strongly bonded particles may also be subject to separation with increasing pressures.

\subsection{Specific Gravity}

The specific gravity of fly ash and bottom ash, as determined by the test method applicable to soils (ASTM D 854), is tabulated in Table 4.1. As can be seen from the 


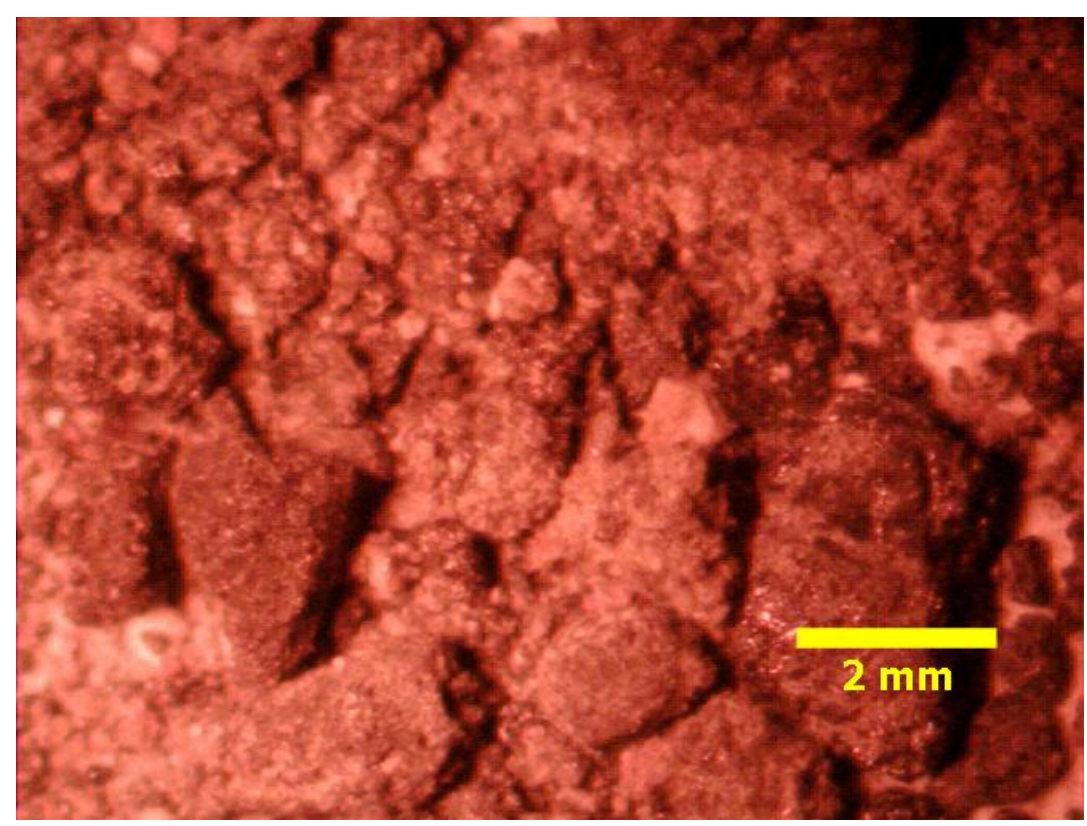

(a)

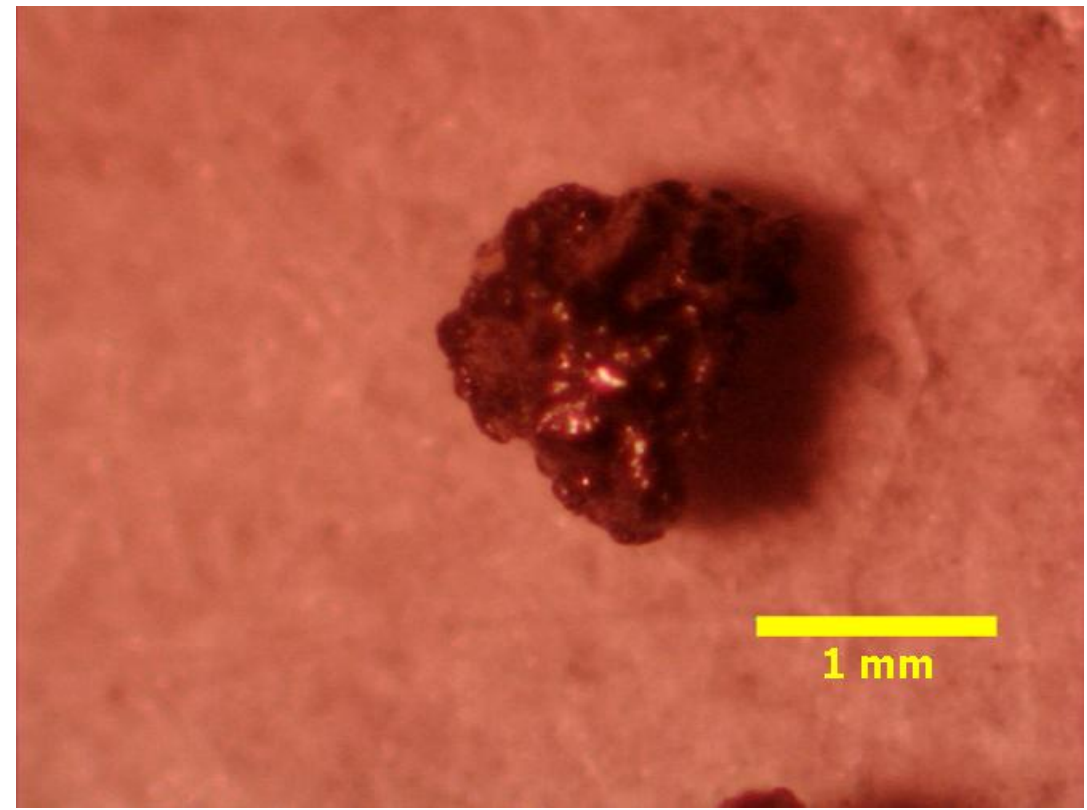

(b)

Figure 4.8 LM Micrograph of Bottom Ash Particles from the Wabash River Plant: (a) Magnification $\times 20$, Several Particles (b) Magnification $\times 50$, A Single Particle (c) Magnification $\times 50$, A Large, Porous Particle. 


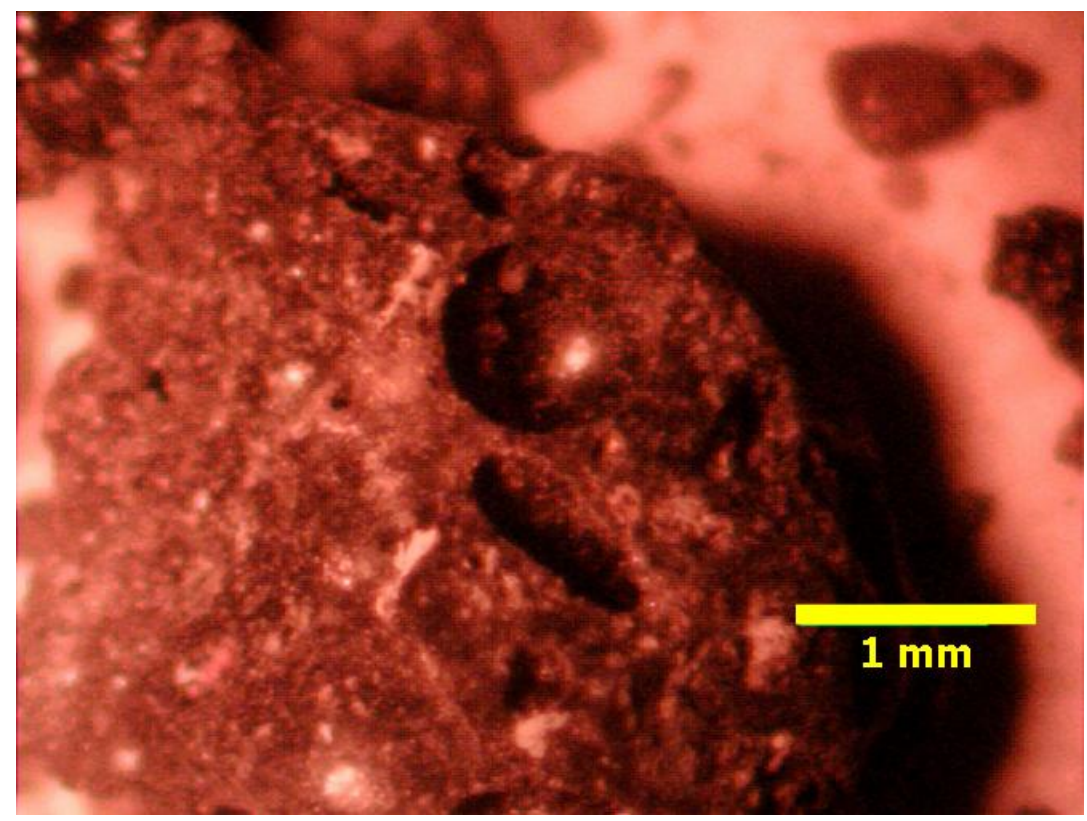

(c)

Figure 4.8 [Continued] 


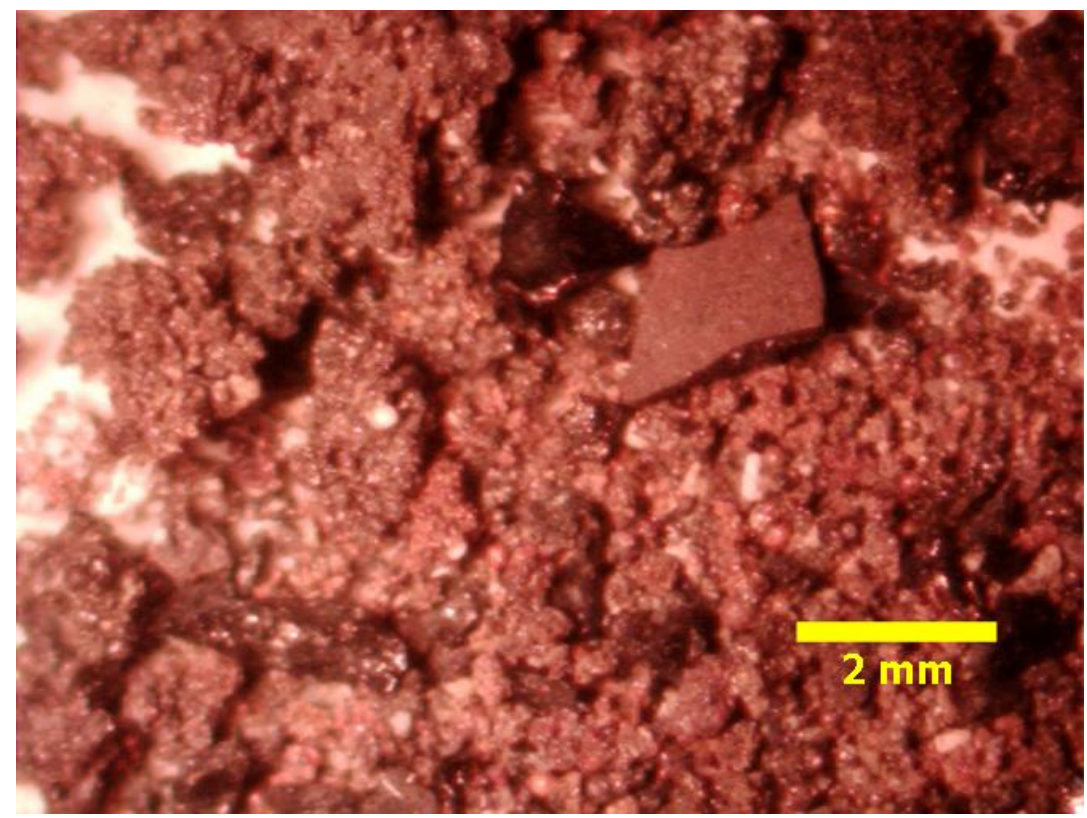

(a)

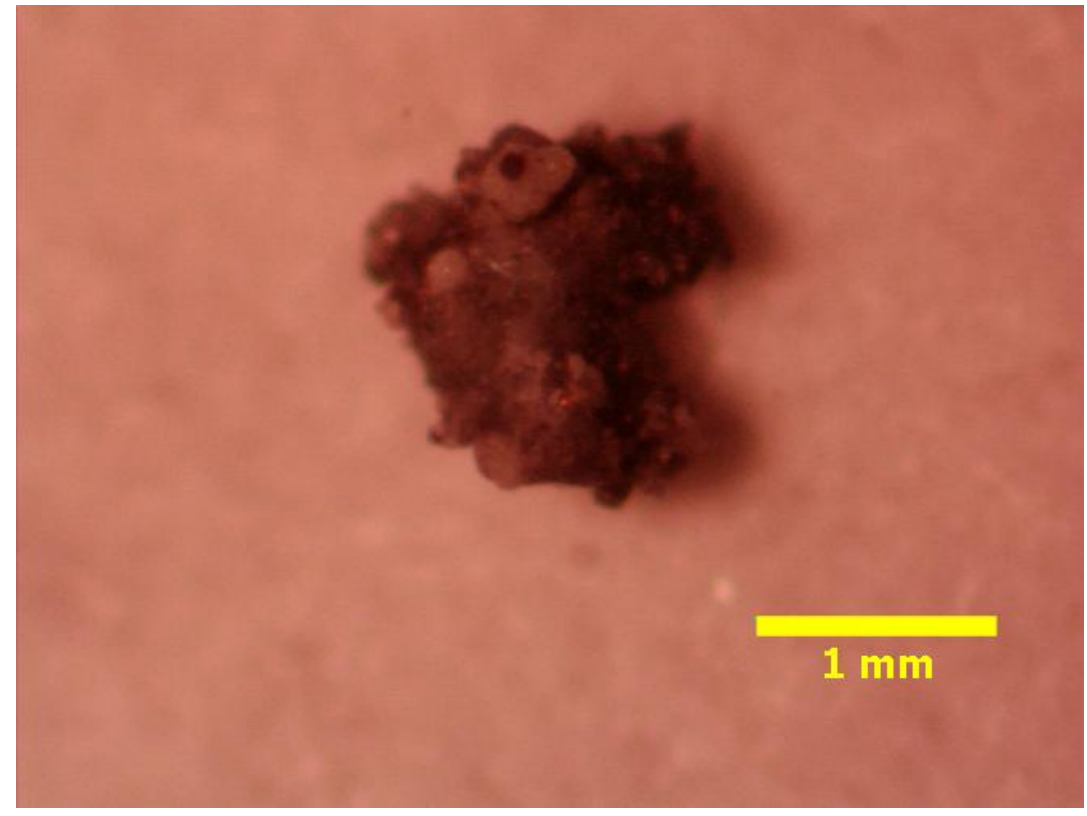

(b)

Figure 4.9 LM Micrograph of Bottom Ash Particles from the A.B.Brown Plant: (a) Magnification $\times 20$, Several Particles (b) Magnification $\times 50$, A Single Particle. 
Table 4.1 Specific Gravities of Fly and Bottom Ash.

\begin{tabular}{ccc}
\hline Ash Source & Fly Ash & Bottom Ash \\
\hline \hline Wabash River Plant & 2.30 & 2.32 \\
A.B. Brown Plant & 2.81 & 2.62 \\
F.B. Culley Plant & 2.61 & \\
\hline
\end{tabular}

table, the specific gravities of fly and bottom ash range from 2.30 to 2.81 - a wide range compared with that of typical soils. The relatively large variations in specific gravity between different sources of fly ashes (or bottom ashes) can be attributed to two factors: 1) chemical composition, and 2) presence of hollow fly ash particles or particles of bottom ash with porous or vesicular textures. Thus, the low specific gravities of Wabash plant fly and bottom ash are explained by their low iron oxide contents and, conversely, the high specific gravities of Brown plant fly and bottom ash by their high iron oxide contents (Table 4.2). Different amounts of hollow particles present in fly ash also cause the variation in specific gravity. Obviously, a fly ash containing a high percentage of hollow particles would have lower specific gravity than that with mostly solid particles. In fact, the two factors affecting the specific gravity of fly ash may be related. Guo et al. (1996) examined the chemical compositions of hollow and solid fly ash particles separately, and the data revealed that hollow-particle fly ash had significantly lower iron content (4.5\%) than solid-particle fly ash (25.1\%).

Bottom ash particles with high porosity would affect the specific gravity. Comparing the specific gravities between fly ash and bottom ash from the Brown plant, 
Table 4.2 Chemical Compositions of Fly and Bottom Ash.

\begin{tabular}{|c|c|c|c|}
\hline Ash Source & $\begin{array}{l}\text { Chemical } \\
\text { Composition }\end{array}$ & Fly Ash & Bottom Ash \\
\hline \multirow{5}{*}{ Wabash River Plant } & $\% \mathrm{SiO}_{2}$ & $52.7^{\mathrm{a}}, \quad 51.1^{\mathrm{c}}$ & $53.7^{\mathrm{b}}, \quad 39.6^{\mathrm{c}}$ \\
\hline & $\% \mathrm{Al}_{2} \mathrm{O}_{3}$ & $21.9^{\mathrm{a}}, \quad 22.9^{\mathrm{c}}$ & $15.2^{\mathrm{b}}, \quad 15.1^{\mathrm{c}}$ \\
\hline & $\% \mathrm{Fe}_{2} \mathrm{O}_{3}$ & $16.4^{\mathrm{a}}, \quad 12.2^{\mathrm{c}}$ & $22.3^{\mathrm{b}}, \quad 15.0^{\mathrm{c}}$ \\
\hline & $\%$ Total & $91.0^{\mathrm{a}}, \quad 86.2^{\mathrm{c}}$ & $91.2^{b}, \quad 69.7^{c}$ \\
\hline & $\mathrm{G}_{\mathrm{s}}$ & 2.30 & 2.32 \\
\hline \multirow{5}{*}{ A.B. Brown Plant } & $\% \mathrm{SiO}_{2}$ & $39.7^{\mathrm{a}}$ & $43.3^{\mathrm{b}}$ \\
\hline & $\% \mathrm{Al}_{2} \mathrm{O}_{3}$ & $27.3^{\mathrm{a}}$ & $13.0^{\mathrm{b}}$ \\
\hline & $\% \mathrm{Fe}_{2} \mathrm{O}_{3}$ & $25.5^{\mathrm{a}}$ & $32.8^{\mathrm{b}}$ \\
\hline & $\%$ Total & $92.5^{\mathrm{a}}$ & $89.1^{\mathrm{b}}$ \\
\hline & $\mathrm{G}_{\mathrm{s}}$ & 2.81 & 2.62 \\
\hline \multirow{5}{*}{ F.B. Culley Plant } & $\% \mathrm{SiO}_{2}$ & $39.9^{\mathrm{a}}$ & \\
\hline & $\% \mathrm{Al}_{2} \mathrm{O}_{3}$ & $26.4^{\mathrm{a}}$ & \\
\hline & $\% \mathrm{Fe}_{2} \mathrm{O}_{3}$ & $24.1^{\mathrm{a}}$ & \\
\hline & $\%$ Total & $90.4^{\mathrm{a}}$ & \\
\hline & $\mathrm{G}_{\mathrm{s}}$ & 2.61 & \\
\hline
\end{tabular}

${ }^{\mathrm{a}}$ Diamond (1985), ${ }^{\mathrm{b}} \mathrm{Huang}(1990),{ }^{\mathrm{c}} \mathrm{C} \mathrm{C} \& \mathrm{E}$ Environmental Services Inc. (2001)

the bottom ash has lower specific gravity than fly ash, although Table 4.2 indicates slightly higher iron content may be present in the bottom ash. This may be due to the presence of highly porous, popcornlike bottom ash particles.

\section{$\underline{4.5 \text { Compaction Behavior }}$}

Seven ash mixtures were prepared and tested by the standard proctor compaction 
procedure. The compacted dry unit weight versus the water content curves of the ash mixtures are displayed in Figure 4.10, 4.11, and 4.12. The values of maximum dry unit weight and corresponding optimum water content are tabulated in Table 4.3. The test results show that, as the fly ash content increases from $50 \%$ to $100 \%$, the maximum dry unit weight $\left(\gamma_{\mathrm{d}, \mathrm{max}}\right)$ decreases, while the optimum water content $\left(w_{\mathrm{opt}}\right)$ increases.

The studies of silty sands have revealed that in low silt contents ranging from zero to about $25 \%$, both the $\gamma_{\mathrm{d} \text {,max }}$ and $\gamma_{\mathrm{d} \text {,min }}$ of a silty sand increase with increasing fines content because the fines occupy the voids between sand particles, whereas further increase in the fines, exceeding about $25 \%$, causes the fines to begin to separate adjacent sand particles, resulting in a decrease in $\gamma_{\mathrm{d}, \max }$ and $\gamma_{\mathrm{d}, \min }$ (Kuerbis et al. 1988; Lade and Yamamuro 1997; Salgado et al. 2000). Similarly, in the ash mixtures with high fly ash content (i.e. F $>50 \%$ ), bottom ash particles can be separated by fly ash particles and are not, on average, in contact. At a certain level of fly ash content, the bottom ash particles may be completely separated, floating in a fly ash matrix. As a result, further increase of fly ash content up to $100 \%$ causes the decrease in the $\gamma_{\mathrm{d}, \max }$. The behavior of a material with a floating fabric may be quite different from one in which the bottom ash particles are in contact. Salgado et al. (2000) discussed the floating fabric in their study for silty sands.

From another perspective, the gradations of the ash mixtures varying with different mixture ratios also explain the change in dry unit weight. The addition of bottom ash to fly ash leads to increasingly more well-graded size distributions (see section 4.2), which allows the fly and bottom ash particles to pack more closely, resulting in the increase in $\gamma_{\mathrm{d} \text {,max }}$. 
Compaction Curves

(Wabash River Plant)

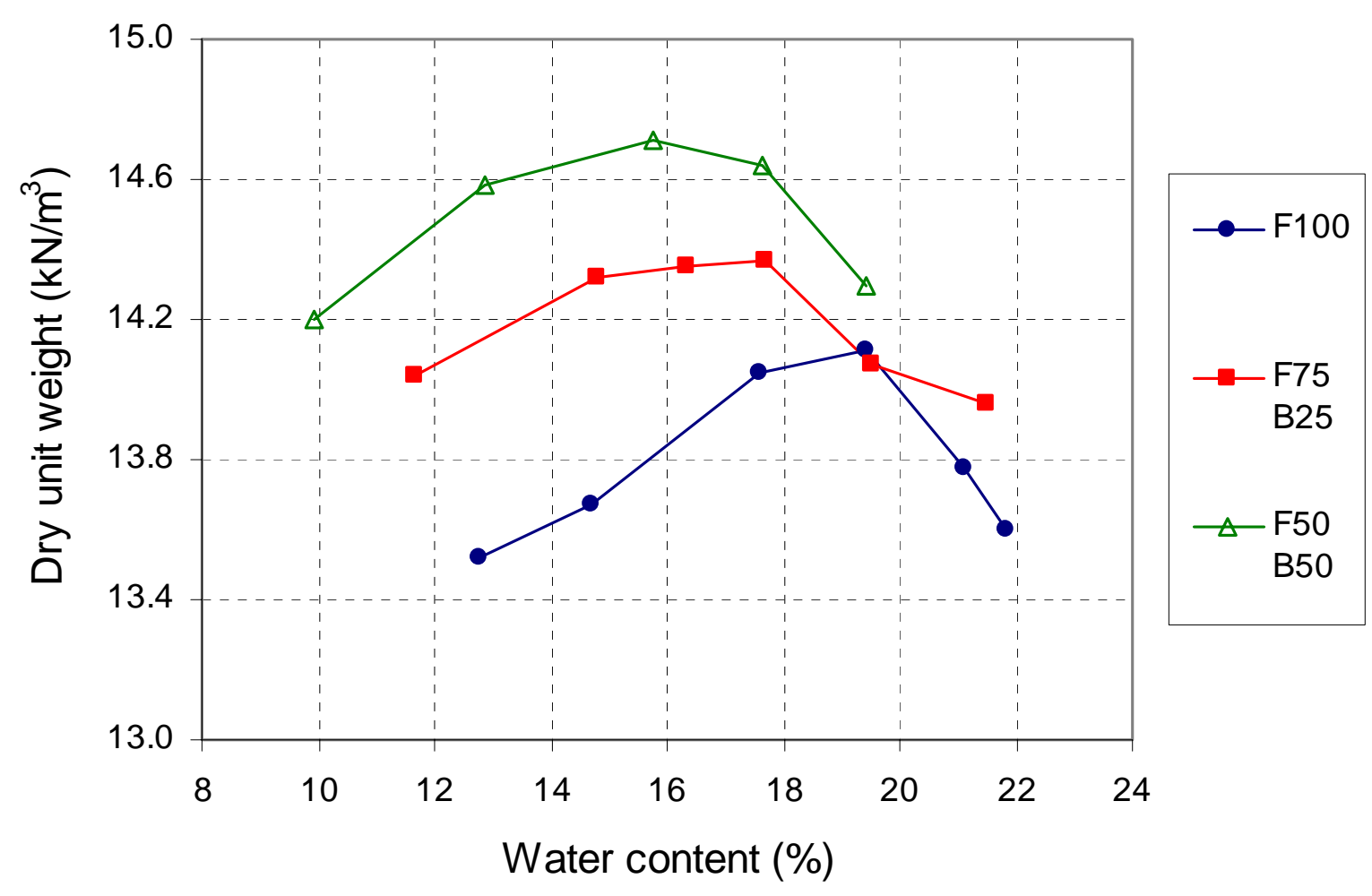

Figure 4.10 Compaction Curves of Fly Ash and Bottom Ash Mixtures from the Wabash River Plant. 
Compaction Curves

(A.B. Brown Plant)

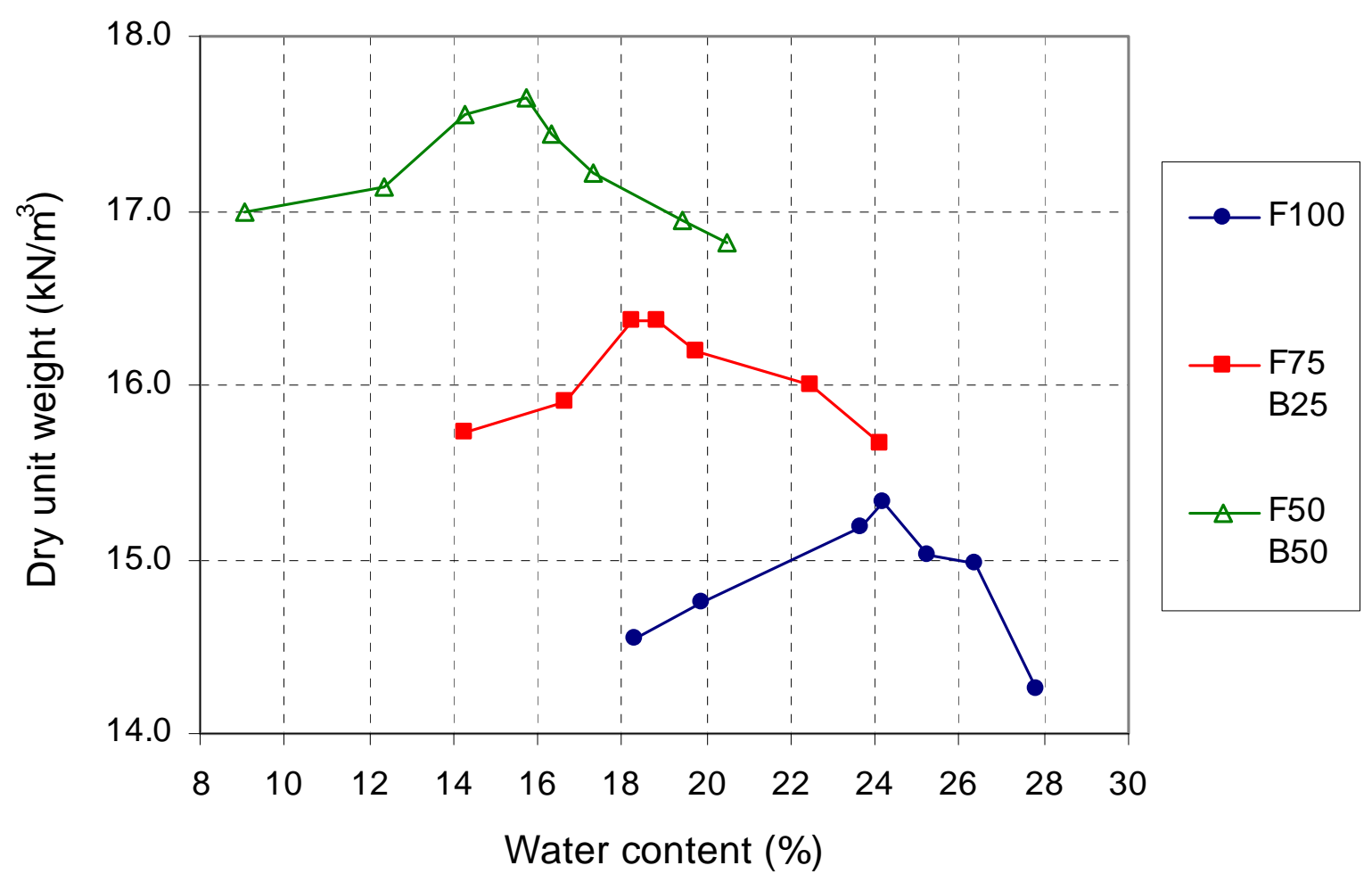

Figure 4.11 Compaction Curves of Fly Ash and Bottom Ash Mixtures from the A.B.Brown Plant. 
Compaction Curve

(F.B. Culley Plant)

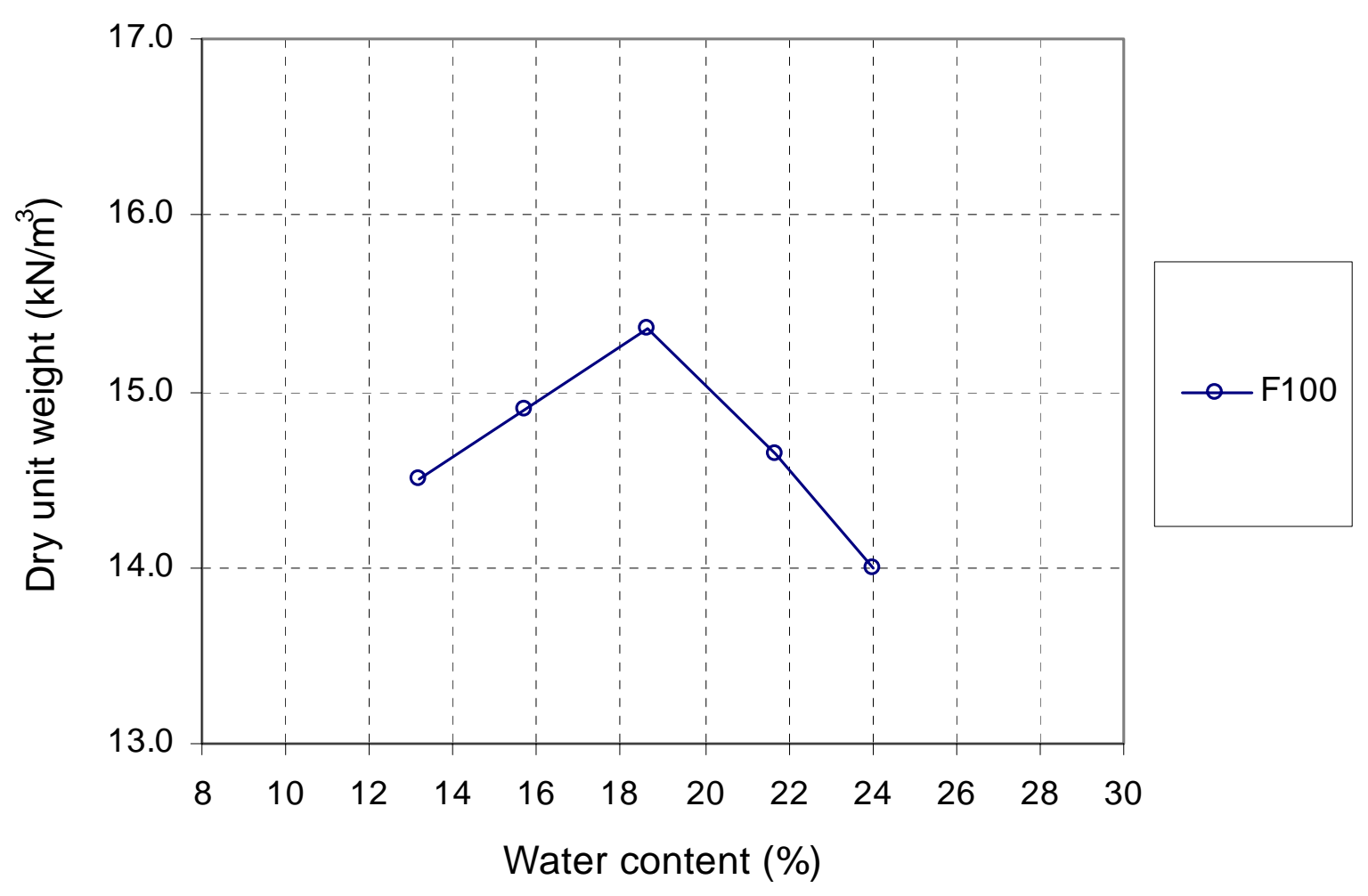

Figure 4.12 Compaction Curves of Fly Ash from the F.B.Culley Plant. 
Table 4.3 Compaction Properties of Ash Mixtures.

\begin{tabular}{lccc}
\hline Ash Source & $\begin{array}{c}\text { Mixture } \\
\text { Composition }\end{array}$ & $\begin{array}{c}\text { Optimum } \\
\text { Water Content } \\
(\%)\end{array}$ & $\begin{array}{c}\text { Max. } \\
\text { Dry Density } \\
\left(\mathrm{kN} / \mathrm{m}^{3}\right)\end{array}$ \\
\hline Wabash River & F100 & 19.0 & 14.12 \\
& F75 B25 & 17.4 & 14.38 \\
& F50 B50 & 16.0 & 14.72 \\
\hline \multirow{2}{*}{ A.B. Brown Plant } & F100 & 24.1 & 15.33 \\
& F75 B25 & 18.5 & 16.40 \\
\hline F.B. Culley Plant & F100 B50 & 15.5 & 17.65 \\
\hline
\end{tabular}

The increase in $w_{\text {opt }}$ with increasing fly ash content is needed to release the capillary tension from the greater exposed surface of the fine fly ash particles.

Although the same trends were observed in the $w_{\mathrm{opt}}$ and $\gamma_{\mathrm{d}, \max }$ relation with increasing fly ash contents, the values of $\gamma_{\mathrm{d}, \max }$ of the ash mixtures exhibit relatively large differences between different ash sources. The differences appear to be primarily due to large variations in the specific gravities between the ash mixtures from different ash sources. Thus, the Brown plant ash mixtures, whose specific gravities are much higher than those of the Wabash river plant ash mixtures, exhibit higher $\gamma_{\mathrm{d}, \max }$ values. It was also often observed, especially in the Brown plant ash mixtures, that some weak large bottom ash particles were broken down into finer particles by compaction. The bottom ash particles subject to crushing during compaction may contribute to the increase in the $\gamma_{\mathrm{d}, \max }$ of ash mixtures. Accordingly, it appears that relatively large $\gamma_{\mathrm{d}, \max }$ increments with increasing bottom ash content in the Brown plant ash mixtures compared to the Wabash 
plant ash mixtures are ascribed to the crushed bottom ash particles as well as their higher specific gravities.

Compared with the $\gamma_{\mathrm{d} \text {,max }}$ of compacted soils, however, the $\gamma_{\mathrm{d}, \max }$ values of ash mixtures tend to be lower than those of soils - which range typically from 17 to 20 $\mathrm{kN} / \mathrm{m}^{3}$ (NAVFAC DM-7 1971).

\section{$\underline{4.6 \text { Maximum and Minimum Density }}$}

Since both fly and bottom ash are basically granular-type materials, parameters to define physical states of granular soils can also be used for coal ash mixtures. The maximum and minimum densities were investigated for ash mixtures with fly ash contents of $50 \%, 75 \%$ and $100 \%$. Tests were basically performed after ASTM procedures (ASTM D 4253 and D 4254). In obtaining the maximum densities, however, slight modifications were made in order to avoid losing excessive fines during vibration as described in Section 3.4.2., which led to significant reductions in the loss of fines (i.e. less than $0.6 \%$ ).

Table 4.4 shows the values of maximum and minimum density obtained for ash mixtures. Both the maximum and minimum densities decrease as fly ash content increases from $50 \%$ to $100 \%$. A comparison between the maximum densities achieved by vibration and impact compaction (ASTM 698 procedure) indicates that the vibration procedure provides slightly higher dry unit weights than ASTM D 698. The implication is that the vibration was more effective than the impact compaction in densification. It can be seen that for the Wabash plant ash mixtures, vibration becomes more effective as 
Table 4.4 Maximum and Minimum Densities of Ash Mixtures.

\begin{tabular}{cccc}
\hline Ash Source & $\begin{array}{c}\text { Mixture } \\
\text { Composition }\end{array}$ & $\begin{array}{c}\text { Max. Density } \\
\left(\mathrm{kN} / \mathrm{m}^{3}\right)\end{array}$ & $\begin{array}{c}\text { Min. Density } \\
\left(\mathrm{kN} / \mathrm{m}^{3}\right)\end{array}$ \\
\hline \hline $\begin{array}{c}\text { Wabash River } \\
\text { Plant }\end{array}$ & F100 & $14.64(14.12)$ & 10.99 \\
& F75 B25 & $14.91(14.38)$ & 11.52 \\
& F50 B50 & $15.50(14.72)$ & 12.42 \\
\hline F.B. Brown Plant & F75 B25 & $15.69(15.33)$ & 12.10 \\
& F50 B50 & $16.71(16.40)$ & 13.48 \\
\hline F.B. Culley Plant & F100 & $15.91(17.65)$ & 14.44 \\
\hline
\end{tabular}

( ) The values produced by impact compaction (ASTM D 698 procedure)

bottom ash content increases (i.e. with decreasing fly ash content), whereas the Brown plant ash mixtures exhibit a similar rate of increase in the maximum densities with increasing bottom ash content between two procedures (i.e. vibration and compaction). This may be because during the impact compaction, in which particle breakdown is more significant than in vibration, larger amounts of weak bottom ash particle crushing occurred in the Brown plant ash mixtures, resulting in an increase of dry unit weights.

Although extreme care was taken to obtain both maximum and minimum density values as accurately as possible, there may have been sources of error in the tests. One significant source of error, the fines loss during sample vibration for maximum density, appeared to be removed by making some modifications to the test procedure. Nevertheless, there was a possibly unsolved problem, which is particle segregation. The segregation of particles, in general, occurs when particles have different sizes and densities. It is expected that especially during maximum density tests for ash mixtures 
with fly ash content $50 \%$ and $75 \%$, the particle segregations could be significant, since the vibration of the sample may have caused small fly ash particles to fall through voids toward bottom of mold. Accordingly, obtained values of the maximum density may be lower than true values of the maximum density to a certain extent.

The maximum and minimum density are used in computing relative density of a granular material, which is a measure of the relative compactness with respect to the densest and loosest possible states for the granular material. The relative density can be used to control field compaction. Similarly, relative compaction (R), defined as the ratio of a compacted dry unit weight to the maximum dry unit weight obtained from a standard laboratory compaction test (ASTM D 698), can also be used as an alternative to relative density for controlling compaction. Selig and Ladd (1973) evaluated relative density and its applications and discussed the method's limitations, sources of errors, and advantages of the method. They concluded that relative density can be a suitable control method for granular material compaction. However, they left the choice of using either the relative density or alternative method to the project engineer. They emphasized the considerable care that needs to be practiced during the maximum and minimum density determinations in addition to the field density measurements.

The present study uses relative compaction (R) as a method to control the densities of testing samples because ash mixtures showed relatively well-defined moisture-density relations in the laboratory compaction tests and thus desired levels of relative compaction may be easily achieved. In contrast, possible sources of error inherent in the maximum and minimum density tests, especially when a material contains a high percentage of fines (as mentioned the above), may lead to difficulty in obtaining 
reliable values of the maximum and minimum density and, accordingly, reasonably reproducible relative densities for the ash mixtures.

The density of a granular material at a certain level of relative compaction can be expressed in terms of the relative density if the maximum and minimum density are known for the material. It was believed that while the maximum and minimum density values obtained may not represent exact values due to difficulties in eliminating all sources of errors present in the test, they can be used to provide at least approximate relations between the relative compaction and the relative density, and thus an insight to the physical states of ash mixtures at different relative compaction levels. Table 4.5 displays the values of relative density calculated for ash mixtures at three different percent relative compactions. For all ash mixtures, the relative density ranges from $56 \%$ to $76 \%$ for $95 \%$ relative compaction and from $32 \%$ to $54 \%$ for $90 \%$ relative compaction, respectively. In terms of classifications based on relative density range, therefore, it appears that ash mixtures compacted to $95 \%$ relative compaction exist in medium to dense states, whereas ash mixtures compacted to $90 \%$ relative compaction exist in loose to medium states. 
Table 4.5 Relative Density (R.D.) vs. Relative Compaction (R).

\begin{tabular}{ccccc}
\hline & Mixture & \multicolumn{3}{c}{ Relative Density (\%) } \\
\cline { 3 - 5 } Ash Source & Composition & $\mathrm{R}=100 \%$ & $\mathrm{R}=95 \%$ & $\mathrm{R}=90 \%$ \\
\hline \hline & F100 & 89 & 72 & 54 \\
Wabash River & F75 B25 & 87 & 69 & 48 \\
Plant & F50 B50 & 79 & 56 & 32 \\
\hline $\begin{array}{c}\text { A.B. Brown } \\
\text { Plant }\end{array}$ & F100 & 92 & 74 & 54 \\
\hline $\begin{array}{c}\text { F.B. Culley } \\
\text { Plant }\end{array}$ & F50 B50 & 92 & 70 & 45 \\
\hline
\end{tabular}




\subsection{Hydraulic Conductivity}

Hydraulic conductivity was measured for ash mixtures at $95 \%$ relative compaction level by conducting falling head permeability tests (ASTM D 5856). Table 4.6 and Figure 4.13 display the values of hydraulic conductivity for compacted ash mixtures with fly ash contents of $50 \%, 75 \%$, and $100 \%$. Measured hydraulic conductivities decrease as fly ash contents increase from $50 \%$ to $100 \%$. The ranges of hydraulic conductivity varying with fly ash content are relatively small and essentially the same for both the Wabash river plant and the Brown plant ash mixtures. The values range from $3 \times 10^{-8}$ to $1 \times 10^{-7} \mathrm{~m} / \mathrm{sec}$ for the Wabash plant ash and from $2 \times 10^{-8}$ to $1 \times 10^{-7}$ $\mathrm{m} / \mathrm{sec}$ for the Brown and the Culley plant ash mixtures.

Table 4.6 Hydraulic Conductivities of Ash Mixtures.

\begin{tabular}{ccc}
\hline Ash Source & $\begin{array}{c}\text { Mixture } \\
\text { Composition }\end{array}$ & $\begin{array}{c}\text { Hydraulic Conductivity } \\
(\mathrm{m} / \mathrm{sec})\end{array}$ \\
\hline \hline Wabash River Plant & F100 & $3 \times 10^{-8}$ \\
& F75 B25 & $6 \times 10^{-8}$ \\
& F50 B50 & $1 \times 10^{-7}$ \\
\hline A.B. Brown Plant & F100 & $6 \times 10^{-8}$ \\
& F75 B25 & $9 \times 10^{-8}$ \\
& F50 B50 & $1 \times 10^{-7}$ \\
\hline F.B. Culley Plant & F100 & $2 \times 10^{-8}$ \\
\hline
\end{tabular}


Wabash River Plant

Hydraulic Conductivity

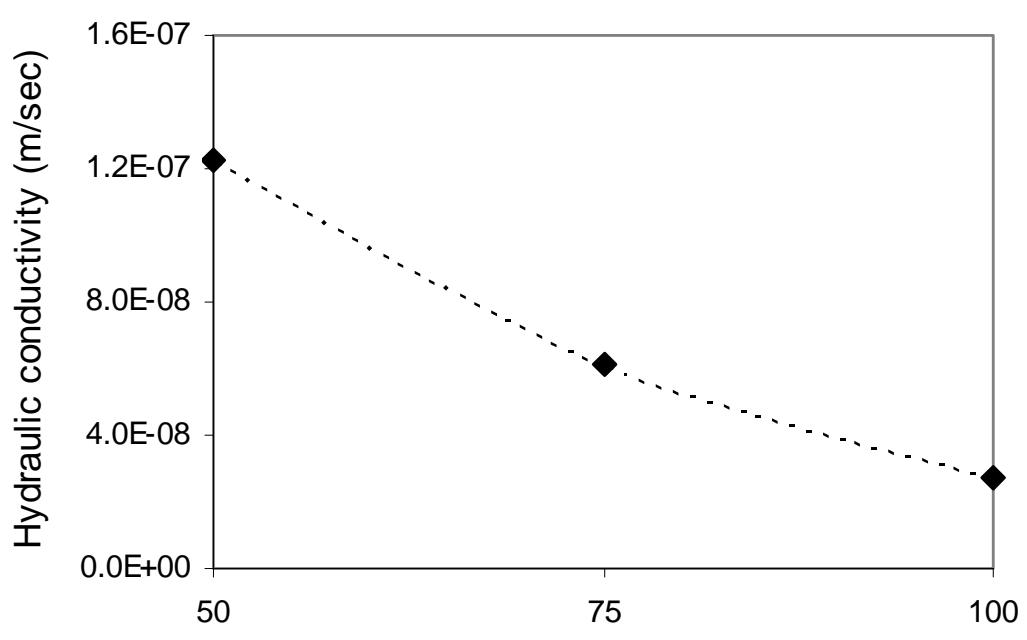

Fly ash content (\%)

(a)

A.B. Brown Plant

Hydraulic Conductivity

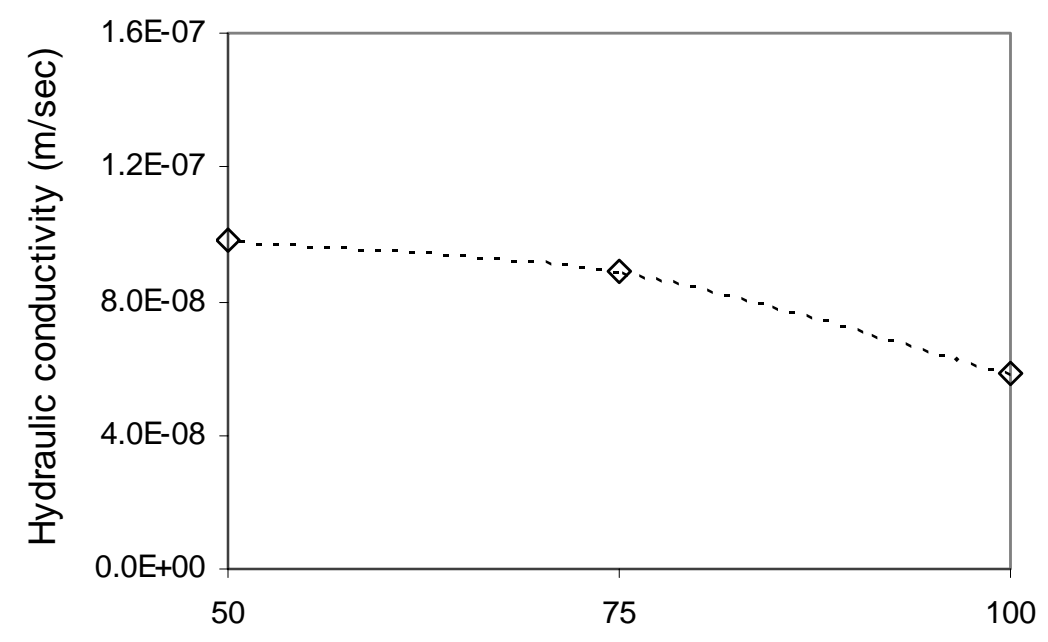

Fly ash content (\%)

(b)

Figure 4.13 Results of Hydraulic Conductivity Tests: (a) Wabash River Plant Ash Mixyures (b) A.B.Brown Plant Ash Mixtures. 
It appears that the fineness of fly ash caused the hydraulic conductivities of the ash mixtures to decrease with increasing fly ash content. As explained in chapter 2, hydraulic conductivity is primarily influenced by the nature of the void system between particles. Fine fly ash particles have voids much smaller than the bottom ash particles. Larger specific surfaces of fly ash would cause more resistance to flow of water through the voids. Huang (1990) did a series of hydraulic conductivity tests on Indiana bottom ashes. He observed that the fines included in bottom ash had a predominant effect on the permeability and thus the hydraulic conductivities decreased as the fine contents increased.

Table 4.7 shows the hydraulic conductivities for typical soils, which indicate the compacted ash mixtures with high fly ash contents exhibit the permeability approximately corresponding to that of the fine sand/silt mixture or silt. 
Table 4.7 Hydraulic Conductivities of Typical Soils (Terzaghi et al. 1996).

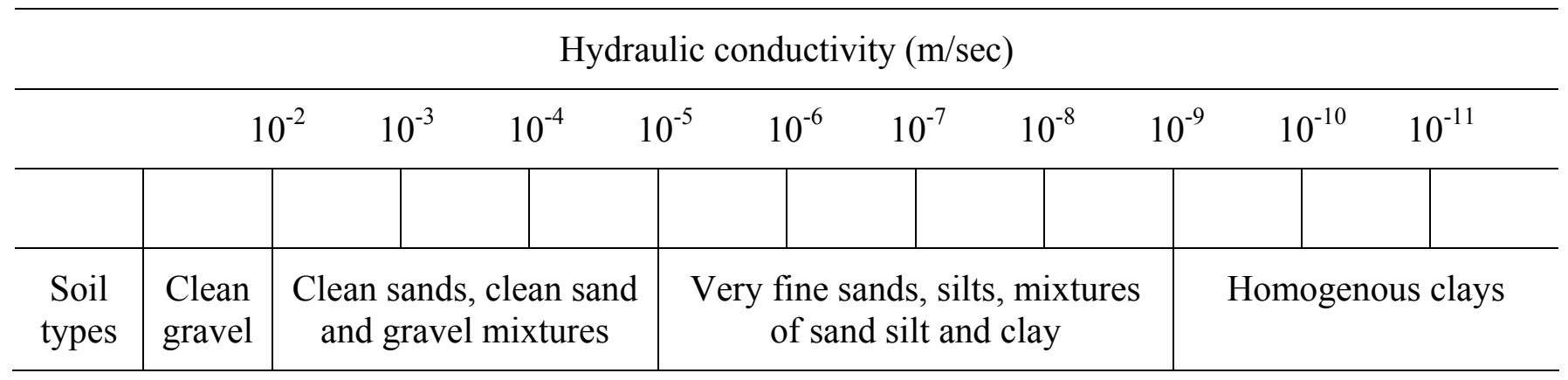




\subsection{Compressibility and Collapsibility}

\subsubsection{Compressibility}

The compacted ash mixture samples were one-dimensionally compressed in the consolidometers (ASTM 2435). This test was intended to investigate the effect of the mixture composition on the compressibility of compacted ash mixtures. Each sample was compacted to $95 \%$ of relative compaction at the optimum compaction water content. A total of seven incremental loadings was used in the compression so that the vertical stress on each sample increased from zero to $1600 \mathrm{kPa}$. The compression curve of each sample was generated by plotting the vertical strains induced against the logarithm of the vertical stress applied.

Figure 4.14 (a), (b), and (c) show the compression curves (i.e. vertical stressstrain relationships) of the compacted ash mixture samples with fly ash content of $50 \%$, $75 \%$ and $100 \%$ from three ash sources. Regardless of the ash sources, a general observed trend is that as the fly ash content decreases from $100 \%$ to $50 \%$ (i.e. as the bottom ash content increases from zero to 50\%), the ash samples become slightly more compressible. When comparing ash sources, the Wabash plant and the Culley plant ash samples are stiffer than the Brown plant ash samples. Table 4.8 displays the vertical strains of the ash mixture samples at various stress levels. For comparison, the values for typical compacted sands were included. From Table 4.8, it appears that the ash mixtures are slightly more compressible than sands.

Two possible mechanisms can explain the increasing compressibility with decreasing fly ash content (i.e. increasing bottom ash content): 1) angularity and porous 
Wabash River Plant

(Compression Curves)

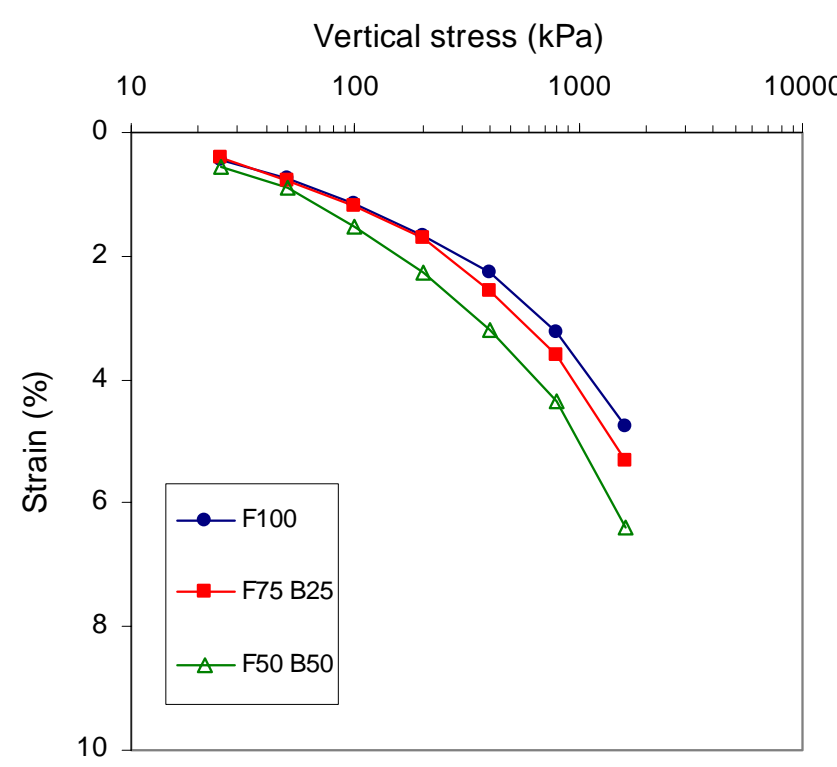

(a)

A.B. Brown Plant

(Compression Curves)

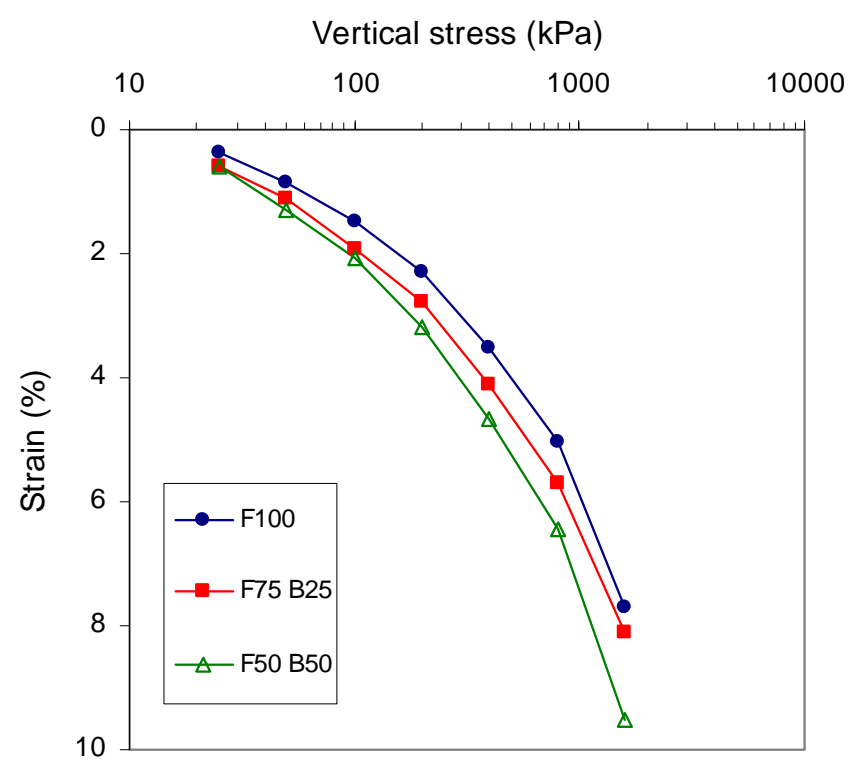

(b)

Figure 4.14 One-Dimensional Compression Curves of Ash Mixtures: (a) Wabash River Plant (b) A.B.Brown Plant (c) F.B.Culley Plant. 


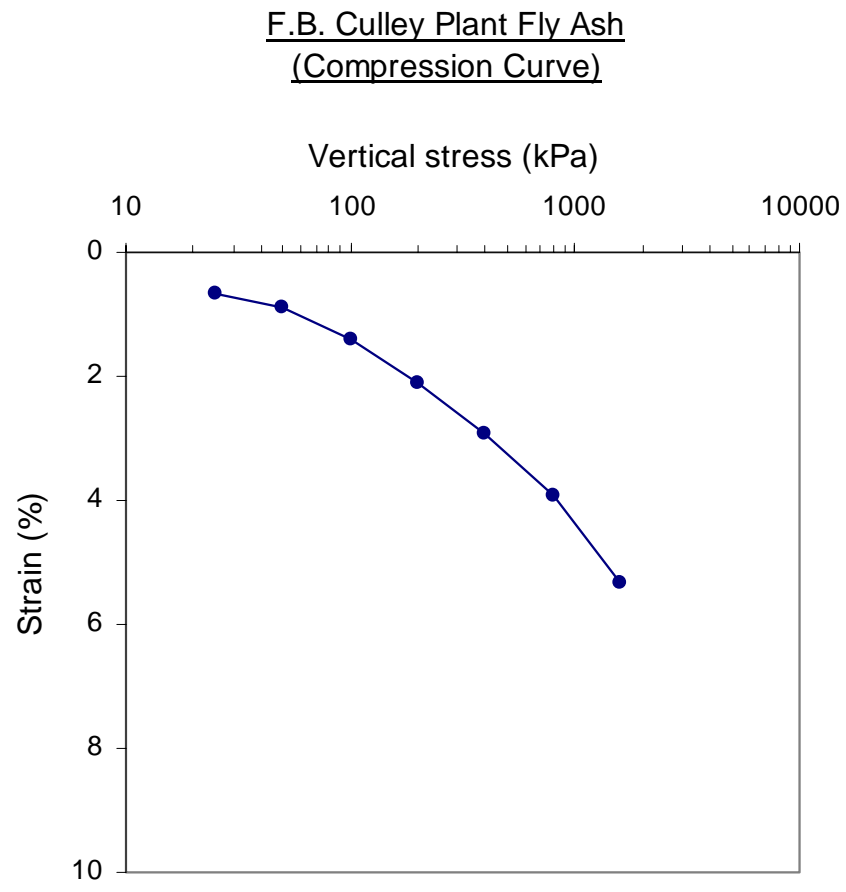

(c)

Figure 4.14 [Continued] 
Table 4.8 Vertical Strains of Ash Mixtures at Various Stress Levels.

\begin{tabular}{|c|c|c|c|c|c|c|}
\hline \multirow[b]{2}{*}{ Ash Source } & \multirow[b]{2}{*}{$\begin{array}{c}\text { Mixture } \\
\text { Composition }\end{array}$} & \multicolumn{5}{|c|}{ Vertical Strain $(\%)$} \\
\hline & & At $50 \mathrm{kPa}$ & At $100 \mathrm{kPa}$ & At $200 \mathrm{kPa}$ & At $400 \mathrm{kPa}$ & At $1600 \mathrm{kPa}$ \\
\hline \multirow{3}{*}{$\begin{array}{c}\text { Wabash } \\
\text { River Plant }\end{array}$} & F100 & 0.74 & 1.15 & 1.66 & 2.28 & 4.75 \\
\hline & F75 B25 & 0.77 & 1.20 & 1.69 & 2.55 & 5.33 \\
\hline & F50 B50 & 0.90 & 1.53 & 2.25 & 3.18 & 6.41 \\
\hline \multirow{3}{*}{$\begin{array}{l}\text { A.B. Brown } \\
\text { Plant }\end{array}$} & F100 & 0.86 & 1.48 & 2.30 & 3.50 & 7.72 \\
\hline & F75 B25 & 1.12 & 1.91 & 2.79 & 4.12 & 8.11 \\
\hline & F50 B50 & 1.29 & 2.09 & 3.17 & 4.68 & 9.51 \\
\hline $\begin{array}{c}\text { F.B. Culley } \\
\text { Plant }\end{array}$ & F100 & 0.89 & 1.41 & 2.12 & 2.92 & 5.34 \\
\hline \multirow{2}{*}{\multicolumn{2}{|c|}{ Slightly Silty Sand ${ }^{\mathrm{a}}$}} & \multicolumn{5}{|c|}{$\underline{\text { At } 27 \mathrm{kPa}} \underline{\text { At } 54 \mathrm{kPa}} \underline{\text { At } 110 \mathrm{kPa}}$} \\
\hline & & $0.25-0.91$ & $0.35-1.43 \quad 0.48$ & 2.25 & & \\
\hline \multirow{2}{*}{\multicolumn{2}{|c|}{ Clean Sand ${ }^{\mathrm{b}}$}} & \multicolumn{5}{|c|}{$\underline{\text { At } 138 \mathrm{kPa}(20 \mathrm{psi})}$ At $345 \mathrm{kPa}(50 \mathrm{psi})$} \\
\hline & & \multicolumn{5}{|c|}{$0.6-0.8$} \\
\hline
\end{tabular}

${ }^{\mathrm{a}}$ From Carrier III, W.D. (2000)

${ }^{\mathrm{b}}$ From NAVFAC DM-7 (1971) 
surface texture of bottom ash particles and 2) particle crushing. Granular soils with angular particles are typically more compressible than those with well-rounded particles because the sharp edges in the angular particles tend to be overstressed during movement and reorientation of the particles, and thus break to allow compression (Roberts and DeSouza 1958; Schultze and Moussa 1961). Furthermore, it is believed that fine fly ash particles adjacent to or filled in the external pores of bottom ash particles may be squeezed gradually through or in the pores with increasing vertical stress, resulting in an increase in deformation. On the other hand, particle crushing can also play a role in increasing the deformation. Particularly weak bottom ash particles, which in most cases have internal pores, can break at relatively low stress levels as discussed by Huang (1990).

When comparing the compressibility of different ash sources, the Brown plant ash mixture samples exhibit greater compressibility than the Wabash plant ash mixture samples. The difference in the compressibility appears to be mainly due to different compressibility between fly ashes rather than bottom ashes, because the increasing rate in the compressibility with increasing bottom ash content are similar between two ash sources (i.e. Wabash plant and Brown plant). Relatively high compressibility in the Brown plant fly ash may be attributed to breakages occurring in the agglomerations of particles, which are more abundant in the Brown plant fly ash (i.e. compared to the Wabash plant and Culley plant). The agglomerates may be subject to separations into finer particles with increasing stress, which causes the deformation to increase. Hollow fly ash particles, especially those with cracks or openings, may be more crushable than solid fly ash particles. As discussed in Section 2.6.3, however, typical hollow fly ash 
particles have high compressive strength (i.e. $>5 \mathrm{MPa}$ ) and moreover, the particle size of fly ash is generally very small. Accordingly, it appears that crushing of fly ash particles themselves was not a likely factor affecting the compressibility.

When ash mixtures are to be used as fill materials, the settlement of the ash layer may be estimated using elastic theory. Moreover, the compression behavior of the ash layer in an embankment of large lateral extent can be considered one-dimensional. The constrained modulus is the parameter used in estimating settlement under onedimensional compression (i.e. confined compression). It is defined as the vertical stress change necessary to cause a unit increase in the vertical strain under conditions of zero lateral strain. It can be expressed as:

$$
M=\frac{\Delta \sigma_{V}}{\Delta \varepsilon_{V}}=\frac{\sigma_{V 2}-\sigma_{V 1}}{\varepsilon_{V 2}-\varepsilon_{V 1}}
$$

where $M=$ constrained modulus

$$
\begin{aligned}
& \varepsilon_{v 1}=\text { vertical strain at a stress of } \sigma_{\mathrm{v} 1} \\
& \varepsilon_{v 2}=\text { vertical strain at a stress of } \sigma_{\mathrm{v} 2}
\end{aligned}
$$

In order to find the tangent constrained modulus at any vertical stress, power functions were curve-fitted to each data series of the measured vertical stress-strain curves and then differentiated. Figure 4.15 presents the calculated tangent constrained moduli for all the ash mixture samples tested for vertical stresses ranging from zero to $200 \mathrm{kPa}$, which may be the range of the stress levels expected in highway embankments commonly found in practice. The values for a compacted sand at different densities were plotted together for comparison. As can be seen in Figure 4.15, the constrained moduli of sand at $99 \%$ and $85 \%$ relative compaction span those of all ash mixtures, such that the 


\section{Constrained Modulus vs. Vertical Stress}

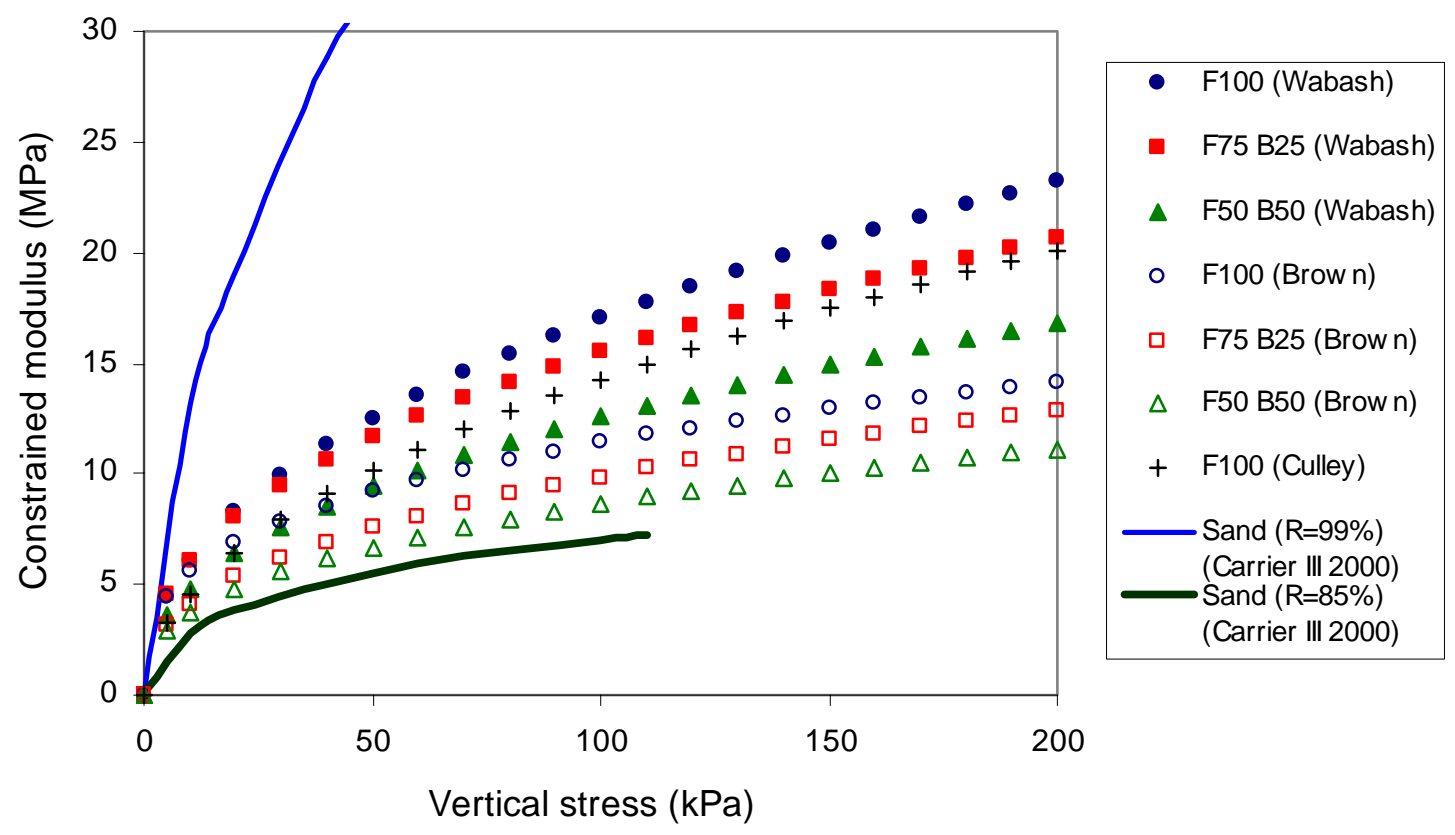

Figure 4.15 Constrained Moduli of Ash Mixtures and Sands. 
values for the ash mixtures lie near the lower end of the sand moduli range. This suggests again that for the same compaction levels, the ash mixtures are slightly more compressible than sand.

\subsubsection{Effect of compaction water content on compressibility}

The compression tests were also performed to examine the effect of compaction water contents on the compressibility of the compacted ash mixtures with fly ash contents of $100 \%$ and $50 \%$ (i.e. $\mathrm{F}=100 \%$ and $\mathrm{F}=50 \%, \mathrm{~B}=50 \%$ ). For each ash mixture with a given fly ash content, two samples were compacted to the same dry densities, but molded with different water contents (i.e. dry of optimum and wet of optimum). The values of the density and water content were determined from the compaction test result for each ash mixture sample. Table 4.9 displays the tested samples and sample conditions, including compaction water content and relative compaction levels. Figure 4.16 (a), (b), (c) and the Figure 4.17 (a), (b) show the compression curves for the tested samples.

The overall trend observed for both $\mathrm{F}=100 \%$ and $\mathrm{F}=50 \%$ is that the samples compacted dry of optimum are slightly stiffer than those compacted wet of optimum at low to moderate stress levels. As the vertical stress increases further, however, the dry side samples become more compressible and at high stress levels the deformations become similar between the dry and wet side samples. The trend is most prominent in the Culley plant fly ash (i.e. $F=100 \%$ ) and the least in the Brown plant fly ash. Except for the Culley plant fly ash, however, the difference in compressibility is generally very small for both $\mathrm{F}=100 \%$ and $\mathrm{F}=50 \%$. Table 4.10 shows the total vertical strains induced at low, moderate and high vertical stresses. 
Table 4.9 Relative Compaction Levels and Compaction Water Contents of Samples (One Dimensional Compression Test).

\begin{tabular}{cccccc}
\hline & & \multicolumn{2}{c}{ Dry of Optimum } & \multicolumn{2}{c}{ Wet of Optimum } \\
\cline { 3 - 6 } Ash Source & $\begin{array}{c}\text { Mixture } \\
\text { Composition }\end{array}$ & $\begin{array}{c}\text { Relative } \\
\text { Compaction } \\
(\%)\end{array}$ & $\begin{array}{c}\text { W/C } \\
\text { (from opt.) } \\
(\%)\end{array}$ & $\begin{array}{c}\text { Relative } \\
\text { Compaction } \\
(\%)\end{array}$ & $\begin{array}{c}\text { W/C } \\
\text { (from opt.) } \\
(\%)\end{array}$ \\
\hline \hline $\begin{array}{c}\text { Wabash River } \\
\text { Plant }\end{array}$ & F100 & 96 & -5.0 & 96 & +2.8 \\
\hline $\begin{array}{c}\text { A.B. Brown } \\
\text { Plant }\end{array}$ & F50 B50 & 97 & -5.0 & 97 & +3.2 \\
\hline $\begin{array}{c}\text { F.B. Culley } \\
\text { Plant }\end{array}$ & F50 B50 & 96 & -4.6 & 96 & +2.9 \\
\hline
\end{tabular}


Wabash River Plant

(Compression Curves of F100)

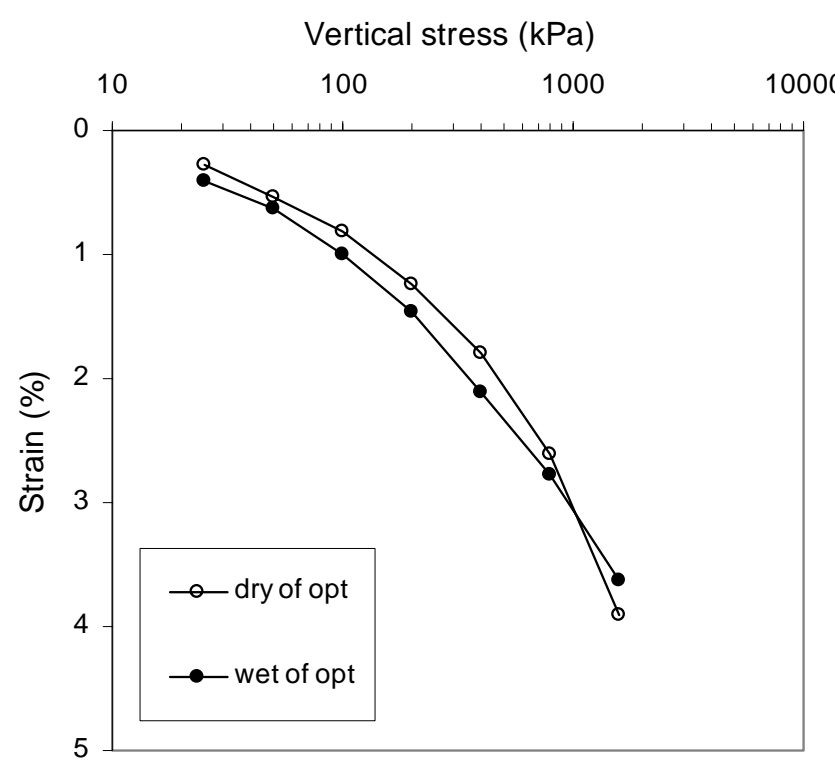

(a)

A.B. Brown Plant

(Compression Curves of F100)

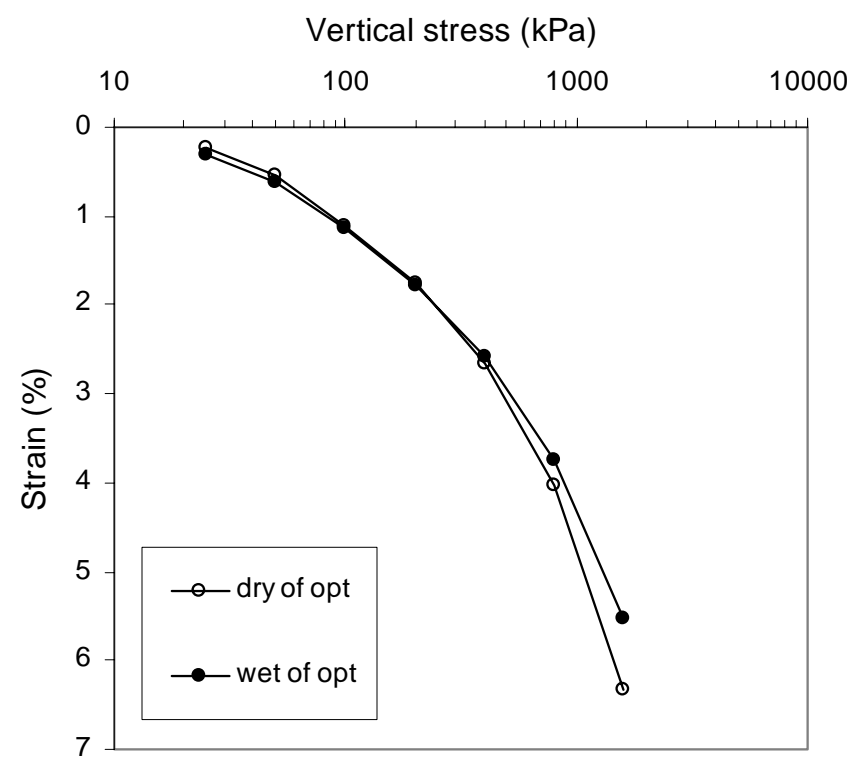

(b)

Figure 4.16 One-Dimensional Compression Curves of Fly Ashes Compacted Dry of Optimum and Wet of Optimum: (a) Wabash River Plant (b) A.B.Brown Plant (c) F.B.Culley Plant. 


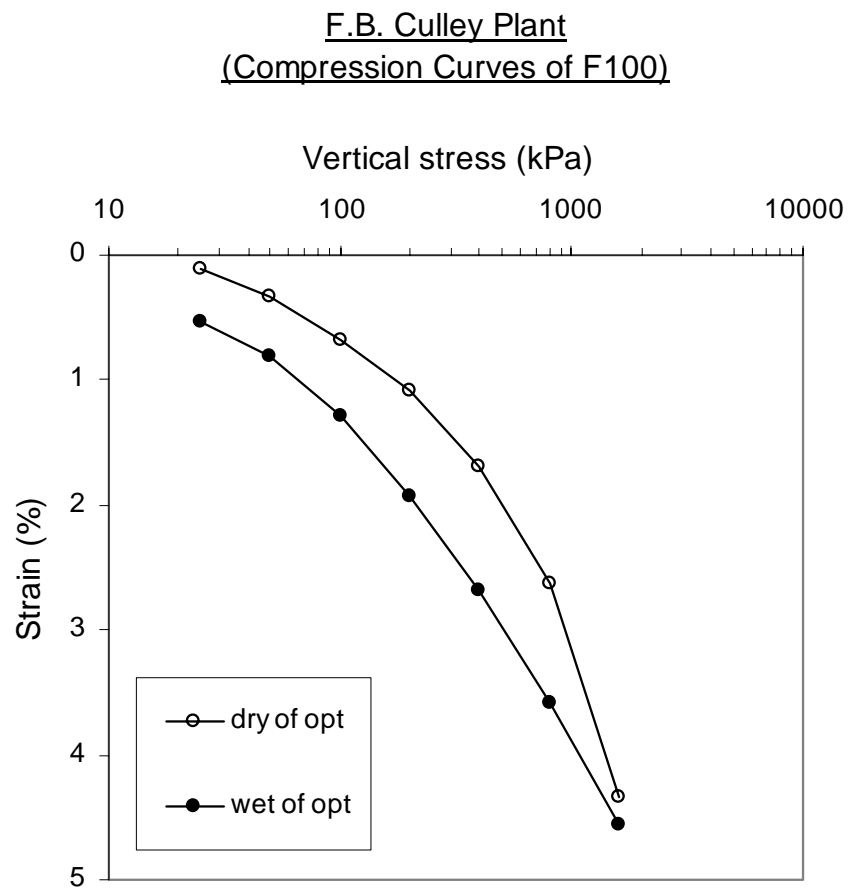

(c)

Figure 4.16 [Continued] 
Wabash River Plant

(Compression Curves of F50B50)

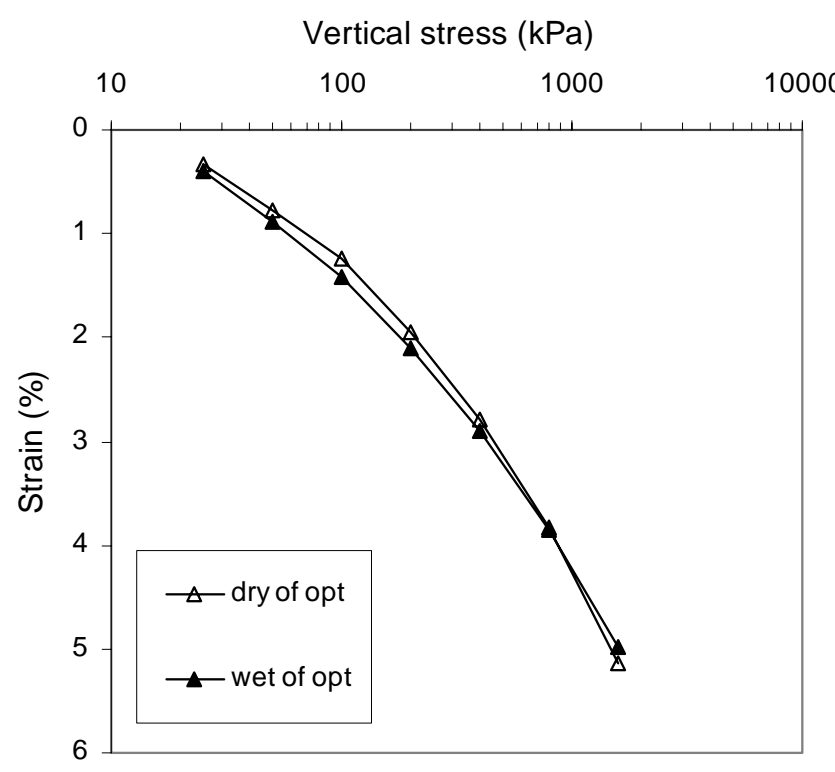

(a)

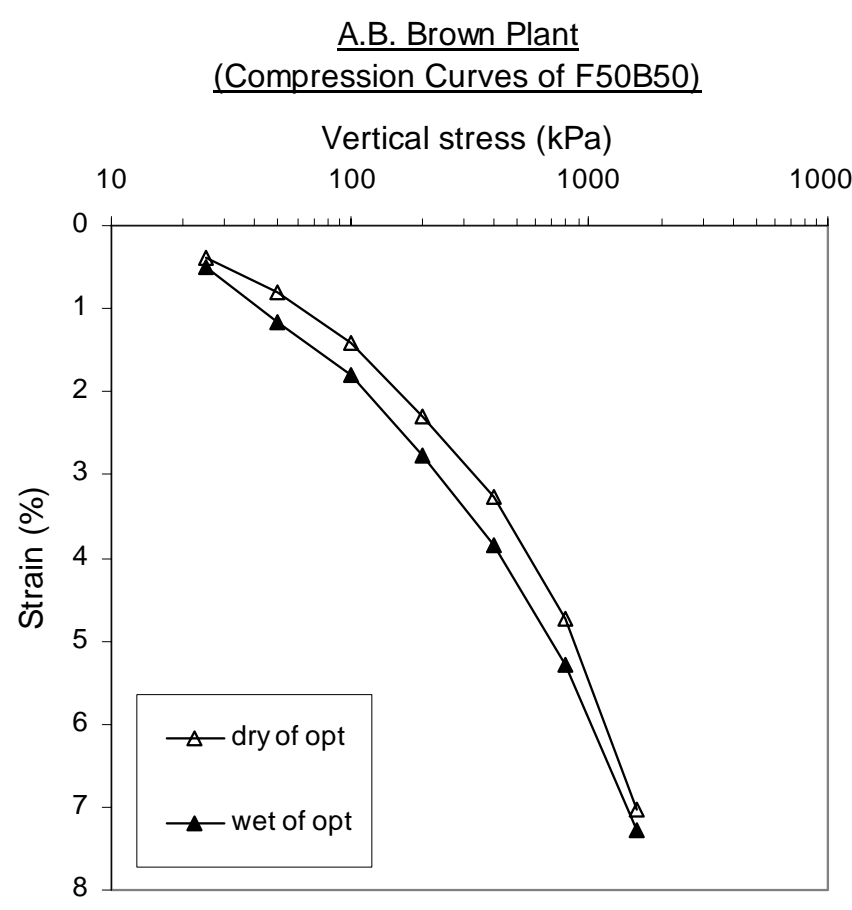

(b)

Figure 4.17 One-Dimensional Compression Curves of Ash Mixtures ( $\mathrm{F}=50 \%, \mathrm{~B}=50 \%)$ Compacted Dry of Optimum and Wet of Optimum: (a) Wabash River Plant (b) A.B.Brown Plant. 
Table 4.10 Vertical Strains at Various Vertical Stresses for Ash Mixtures Compacted Dry and Wet of Optimum.

\begin{tabular}{cccccccccccc}
\hline & & \multicolumn{10}{c}{ Vertical Strain (\%) } \\
\cline { 3 - 11 } Ash Source & $\begin{array}{c}\text { Mixture } \\
\text { Ratio }\end{array}$ & At 25 kPa & At $100 \mathrm{kPa}$ & At $200 \mathrm{kPa}$ & At $800 \mathrm{kPa}$ & At $1600 \mathrm{kPa}$ \\
\cline { 3 - 11 } & F100 & 0.27 & 0.41 & 0.82 & 1.0 & 1.23 & 1.46 & 2.61 & 2.78 & 3.91 & 3.64 \\
$\begin{array}{c}\text { Wabash } \\
\text { River Plant }\end{array}$ & F50 B50 & 0.32 & 0.39 & 1.24 & 1.41 & 1.95 & 2.11 & 3.82 & 3.85 & 5.13 & 4.97 \\
\hline \hline $\begin{array}{c}\text { A.B. Brown } \\
\text { Plant }\end{array}$ & F100 & 0.24 & 0.31 & 1.10 & 1.14 & 1.74 & 1.78 & 4.03 & 3.75 & 6.34 & 5.52 \\
\hline $\begin{array}{c}\text { F.B. Culley } \\
\text { Plant }\end{array}$ & F50 B50 & 0.38 & 0.50 & 1.40 & 1.80 & 2.30 & 2.77 & 4.73 & 5.29 & 7.02 & 7.28 \\
\hline
\end{tabular}


The slight difference between the deformations observed in the dry and wet side samples at low to moderate stress levels may be primarily due to lubricating effects of water. As compared to dry-side samples, wet-side samples may contain more water that is not retained by capillary tension between particles. The extra water will lubricate interparticle contacts, facilitating particle rolling and sliding under loading, resulting in an increase in relative motion between particles. However, the effect of water may disappear gradually with further increasing stress and the deformation would occur primarily by particle crushing. As a result, at very high stress levels, the deformations observed in both dry and wet side samples will be identical if both samples were the same except for their initial water contents. The tangent constrained moduli were calculated for the tested dry and wet side samples and shown in Figure 4.18 (a), (b), and (c) and Figure 4.19 (a) and (b). 
Wabash River Plant (F100)

(Constrained Modulus vs. Vertical Stress)

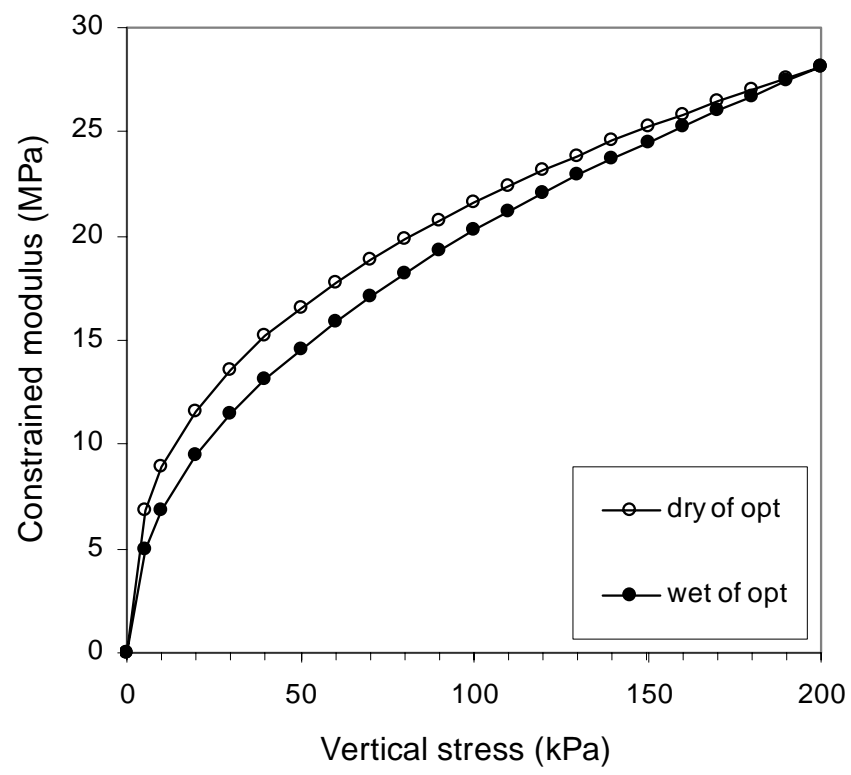

(a)

A.B. Brown Plant (F100)

(Constrained Modulus vs. Vertical Stress)

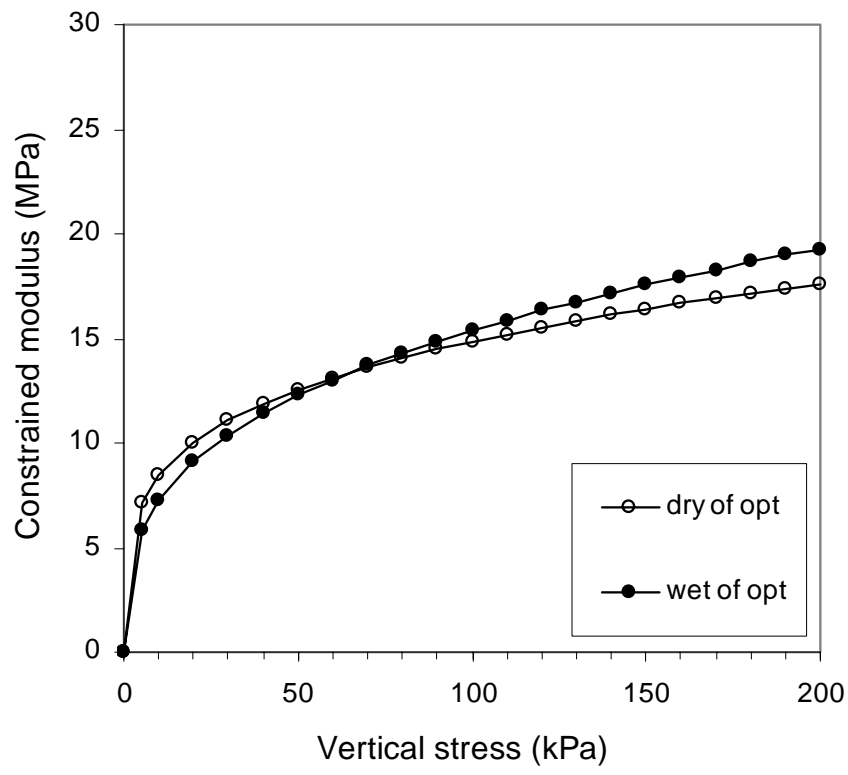

(b)

Figure 4.18 Constrained Moduli of Fly Ashes Compacted Dry of Optimum and Wet of Optimum: (a) Wabash River Plant (b) A.B.Brown Plant (c) F.B.Culley Plant. 
F.B. Culley Plant (F100)

(Constrained Modulus vs. Vertical Stress)

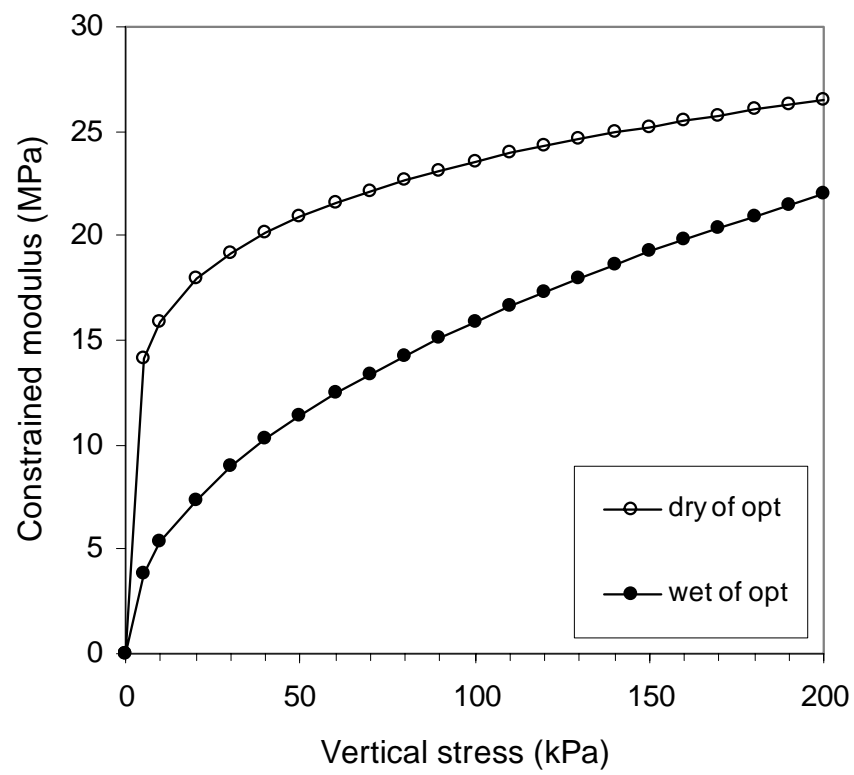

(c)

Figure 4.18 [Continued] 
Wabash River Plant (F50 B50)

(Constrained Modulus vs. Vertical Stress)

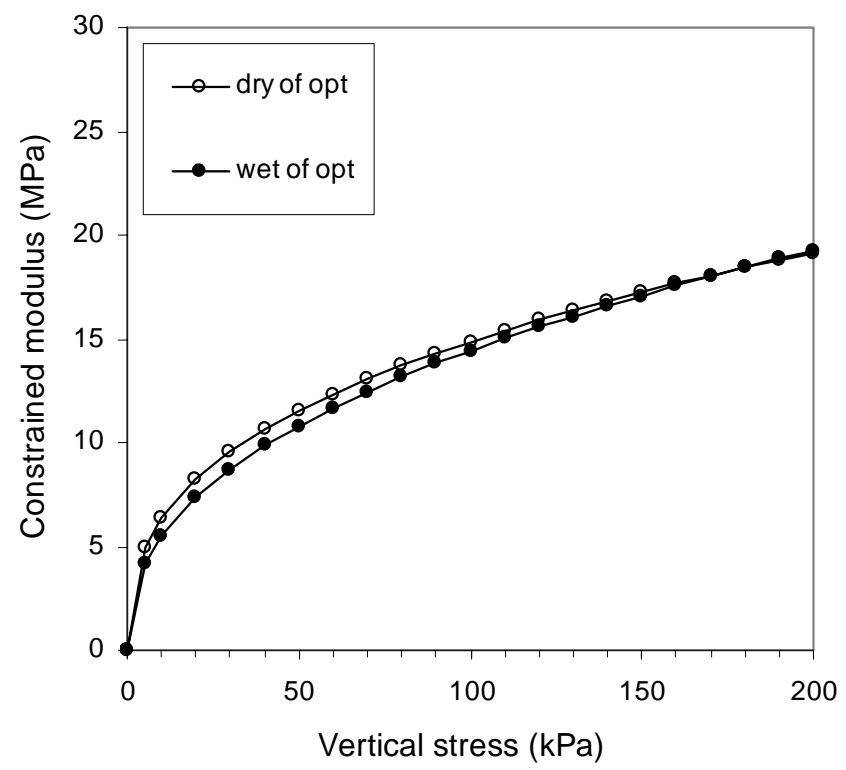

(a)

A.B. Brown Plant (F50 B50)

(Constrained Modulus vs. Vertical Stress)

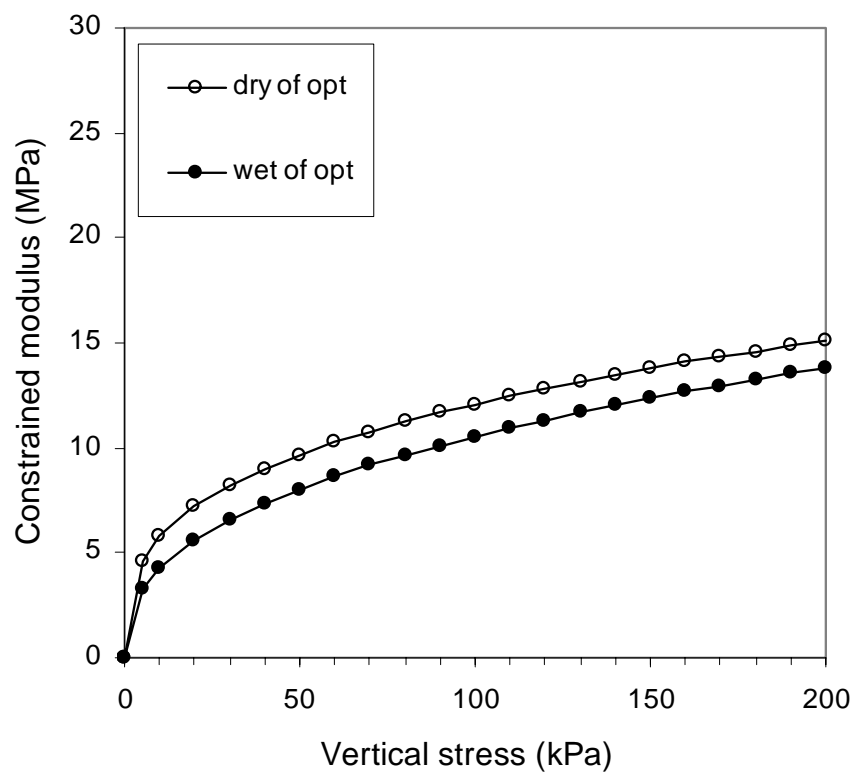

(b)

Figure 4.19 Constrained Moduli of Ash Mixtures ( $\mathrm{F}=50 \%, \mathrm{~B}=50 \%)$ Compacted Dry of Optimum and Wet of Optimum: (a) Wabash River Plant (b) A.B.Brown Plant. 


\subsubsection{Collapsibility}

In order to evaluate the collapse potential of ash mixtures, collapsibility tests were conducted on mixture samples with fly ash contents of $50 \%$ and $100 \%$. The collapse potential is defined as the volume decrease induced by water permeation under a constant stress. In a one-dimensional oedometer test, therefore, the collapse potential can be calculated using;

$$
I_{C}=\left(\frac{\Delta h}{h_{0}}\right) \cdot 100 \%=\left(\frac{\Delta e}{1+e_{0}}\right) \cdot 100 \%
$$

where $I_{C}=$ collapse potential;

$\Delta h$ and $\Delta e=$ change of specimen height and void ratio resulting from wetting, respectively;

$h_{0}$ and $e_{0}=$ initial specimen height and initial void ratio, respectively.

The collapse potential can be measured at any stress level which is of interest, depending on the field conditions. This way, the predicted collapse potential can be used to estimate the settlement that occurs in an ash layer at a particular site. In the test for the present study, a vertical stress of $100 \mathrm{kPa}$, which may be reasonably representative of the stress levels expected for typical highway embankments, was used for determining the collapse potentials. The degree of observed collapse has been related to the collapse potential as presented in Table 4.11. The term "collapse index" refers to the collapse potential determined at the vertical stress of $200 \mathrm{kPa}$. Although the collapse potentials for the ash samples were measured at a stress lower than $200 \mathrm{kPa}$, the approximate degree of collapse can be evaluated through the comparison with the values shown in Table 4.11. 
Table 4.11 Classification of Collapse Potential (ASTM D 5333-92).

\begin{tabular}{cc}
\hline Degree of Collapse & Collapse Index (\%) \\
\hline \hline None & 0 \\
Slight & $0.1-2.0$ \\
Moderate & $2.1-6.0$ \\
Moderately Severe & $6.1-10.0$ \\
Severe & $>10.0$ \\
\hline
\end{tabular}

Each ash sample was compacted at moisture contents dry of optimum and then loaded incrementally in a consolidometer until the vertical stress of $100 \mathrm{kPa}$ was reached. When the specimen reached equilibrium under that pressure (i.e. when no further deformation was observed), water was added to the specimen for inundation and the deformation caused by the inundation was recorded until no further deformation is observed. Figure 4.20 (a), (b), and (c) show the vertical stress-strain curves obtained for the tested samples. The calculated collapse potentials are tabulated in Table 4.12.

Table 4.12 Collapse Potentials of Ash Mixtures at Vertical Stress of $100 \mathrm{kPa}$.

\begin{tabular}{ccc}
\hline Ash Source & Mixture Composition & Collapse Potential (\%) \\
\hline \hline Wabash River Plant & F100 & 0.99 \\
& F50 B50 & 2.18 \\
\hline A.B. Brown Plant & F100 & 1.07 \\
F.B. Culley Plant & F50 B50 & 1.46 \\
\hline
\end{tabular}


The measured collapse potentials range from $0.42 \%$ to $2.18 \%$. Comparison with Table 4.11 indicates that the obtained values fall mostly into the slightly collapsible range. The results also suggest that the collapse potential increases slightly with decreasing fly ash content (i.e. increasing the bottom ash content).

The observed collapse in the ash mixtures can be explained similarly as for soils. The wetting-induced collapse has been of particular concern for naturally deposited soils and thus most studies regarding the collapse have focused on naturally deposited soils. Lawton (1986), however, found through a series of collapsibility tests on various compacted soils that nearly all types of compacted soils can be subject to wetting-induced collapse by similar mechanisms to those in naturally deposited soils. In general, four factors are considered necessary for collapse to occur in soil (Barden et al. 1973; Mitchell 1976; Lawton et al. 1992): 1) An open, partially unstable, partially saturated fabric; 2) A high enough total stress that the structure is metastable; 3) A bonding or cementing agent that stabilizes the soil in the partially saturated condition; 4) The addition of water to the soil, which causes the bonding or cementing agent to be reduced and the interaggregate or intergranular contacts to fail in shear, resulting in a reduction in total volume of the soil mass. It is known that the collapse potential tends to increase with decreasing water content, decreasing density, and increasing vertical stress (Lawton et al. 1992).

Class F fly ash and bottom ash are all cohesionless materials and, therefore, in the compacted fly/bottom ash mixtures, the metastable bonding may be provided by capillary suction. The capillary suction will disappear upon wetting. Furthermore, in pure fly ash (i.e. $\mathrm{F}=100 \%$ ), very fine fly ash particles adjacent to large fly ash particles may act as a bridge or binder between the large fly ash particles. Similarly, in mixtures of fly ash and 
Wabash River Plant

Compression Curves of Collapse Potential Test

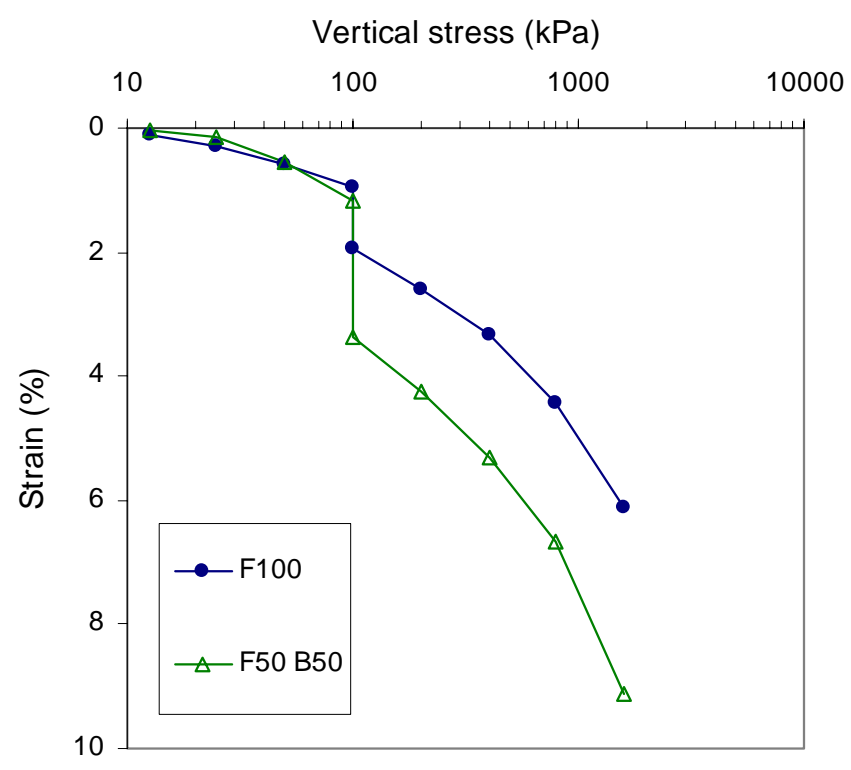

(a)

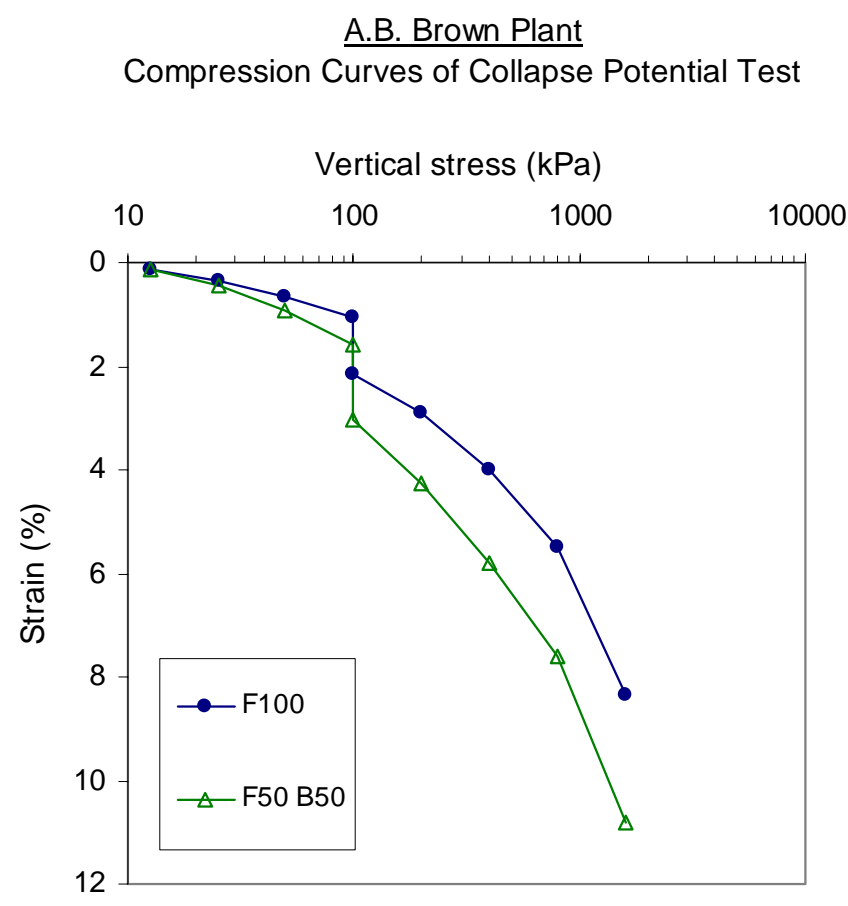

(b)

Figure 4.20 Results of Collapsibility Tests: (a) Wabash River Plant (b) A.B.Brown Plant (c) F.B.Culley Plant. 


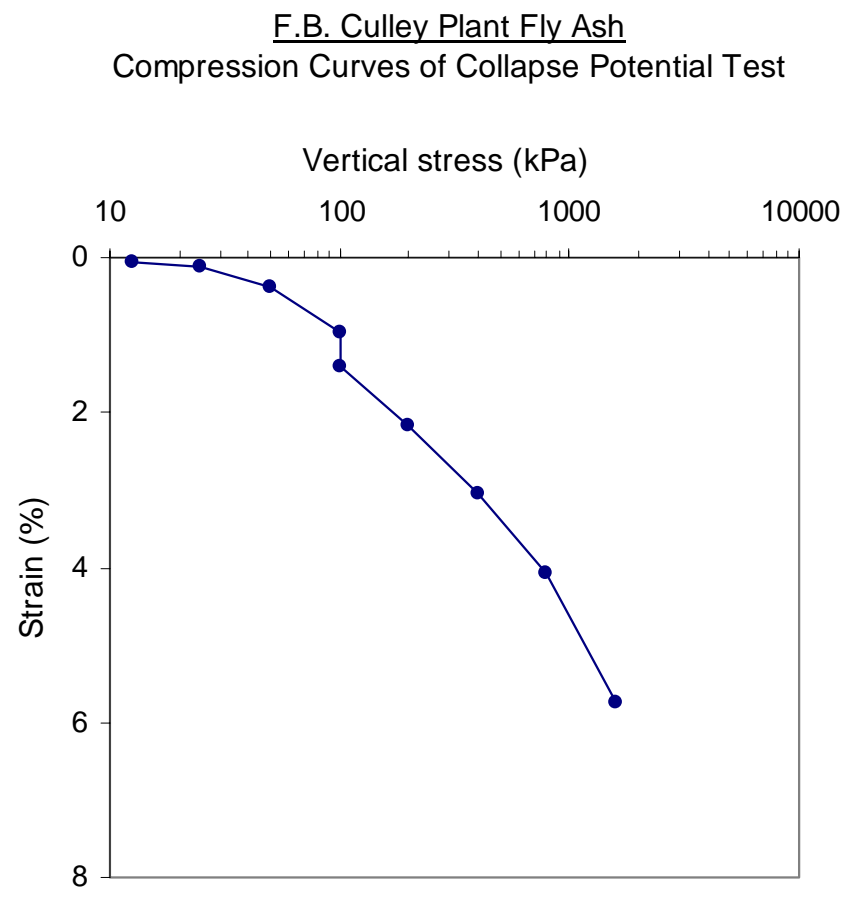

(c)

Figure 4.20 [Continued] 
bottom ash (i.e. $\mathrm{F}=50 \%, \mathrm{~B}=50 \%$ ), fly ash particles can serve as bridges between bottom ash particles. The infiltrated water will cause the bridges to become soft, "lubricating" interparticle contacts. The relative displacement between particles would be larger between bottom ash particles than between fly ash particles, which may have resulted in higher collapse deformation in $\mathrm{F}=50 \%$ than in $\mathrm{F}=100 \%$.

\subsection{Shear Strength}

\subsubsection{Effect of compaction water content and saturation}

This section presents the results and discussion of direct shear tests conducted on the compacted ash mixture samples. The purpose of the tests was to examine the influence of compaction water content and saturation on the shear strength of compacted ash mixtures since the ash mixtures may exhibit different strength characteristics depending on the water contents at which they are compacted. Furthermore, they may undergo a decrease in the strength upon saturation after compaction. To investigate the effect of compaction water content, two samples were prepared and tested in identical conditions with only a difference in their compaction water contents (i.e. dry of optimum and wet of optimum) for each mixture with a given fly ash content. Similarly, an evaluation of the effect of saturation was made by comparing the strengths between ascompacted samples and soaked samples, which were compacted under essentially the same conditions. The tested samples and sample conditions, including compaction water content and compaction level, are tabulated in Table 4.13. To obtain shear strength 
Table 4.13 Relative Compaction Levels and Compaction Water Contents of Samples (Direct Shear Test).

\begin{tabular}{|c|c|c|c|c|c|c|c|}
\hline \multirow[b]{3}{*}{ Ash Source } & \multirow[b]{3}{*}{$\begin{array}{l}\text { Mixture } \\
\text { Ratio }\end{array}$} & \multicolumn{4}{|c|}{ As-Compacted } & \multirow{2}{*}{\multicolumn{2}{|c|}{$\frac{\text { Soaked }}{\text { Dry of Optimum }}$}} \\
\hline & & \multicolumn{2}{|c|}{ Dry of Optimum } & \multicolumn{2}{|c|}{ Wet of Optimum } & & \\
\hline & & $\begin{array}{c}\text { Relative } \\
\text { Compaction } \\
(\%) \\
\end{array}$ & $\begin{array}{c}\mathrm{W} / \mathrm{C} \\
\text { (from opt.) } \\
(\%) \\
\end{array}$ & $\begin{array}{c}\text { Relative } \\
\text { Compaction } \\
(\%) \\
\end{array}$ & $\begin{array}{c}\mathrm{W} / \mathrm{C} \\
\text { (from opt.) } \\
(\%) \\
\end{array}$ & $\begin{array}{c}\text { Relative } \\
\text { Compaction } \\
(\%) \\
\end{array}$ & $\begin{array}{c}\mathrm{W} / \mathrm{C} \\
\text { (from opt.) } \\
(\%) \\
\end{array}$ \\
\hline \multirow{3}{*}{$\begin{array}{c}\text { Wabash } \\
\text { River Plant }\end{array}$} & F100 & 91 & -5.0 & 91 & +2.8 & 91 & -5.0 \\
\hline & F75 B25 & 92 & -5.1 & 92 & +1.8 & 92 & -5.1 \\
\hline & F50 B50 & 92 & -5.0 & 92 & +3.2 & 92 & -5.0 \\
\hline \multirow{3}{*}{$\begin{array}{l}\text { A.B. Brown } \\
\text { Plant }\end{array}$} & F100 & 91 & -4.6 & 91 & +2.9 & 91 & -4.6 \\
\hline & F75 B25 & 91 & -3.5 & 91 & +5.1 & 91 & -3.5 \\
\hline & F50 B50 & 92 & -4.5 & 92 & +3.0 & 92 & -4.5 \\
\hline $\begin{array}{c}\text { F.B. Culley } \\
\text { Plant }\end{array}$ & F100 & 91 & -4.7 & 91 & +3.2 & 91 & -4.7 \\
\hline
\end{tabular}


parameters (i.e. peak friction angle and cohesion intercept), the peak shear stresses were plotted against the normal stresses and then a straight line was fitted through the data of the peak shear stresses and the normal stresses to form a Mohr-Coulomb failure envelope (Figure 4.21(a),(b),(c), and Figure 4.22 (a),(b),(c),(d)).

Table 4.14 and 4.15 show the values of the strength parameters (i.e. $\phi$, and c) obtained for the ash mixture samples. When comparing the as-compacted samples, the observed trend indicates that the samples compacted dry of optimum exhibit generally higher shear strength than those compacted wet of optimum. However, the overall difference appears to be quite small. The peak friction angles decreased by only about 1 to $2^{\circ}$ (Table 4.14 and Figure 4.23 ). The values of the cohesion intercept also differ by only about $1.6 \mathrm{kPa}$ on average (i.e. higher for the dry side samples). The relatively high values of the cohesion intercept for the as-compacted samples compared to the soaked samples may suggest that they exhibit apparent cohesion due to capillary stresses. In fact, both class F fly ash and bottom ash exhibit no cohesive property when they are saturated. On the other hand, it should be noted that due to the presence of the capillary suction, the peak friction angles obtained for the as-compacted samples should be also different from their effective peak friction angles, which can be measured under saturated conditions. Normally, the capillary suction (i.e. negative pore pressure), which results from the combined effects of pore air pressure, pore water pressure and surface tension, contributes to the increase in the effective stress by pulling particles towards one another and thus increasing interparticle contact force. For unsaturated granular soils, in general, the capillary suction increases as water content decreases and particle size decreases (Likos and Lu 2002). As a result, the slightly higher strength observed for the dry side 
$\underline{\text { Wabash River Plant }}$

(F100)

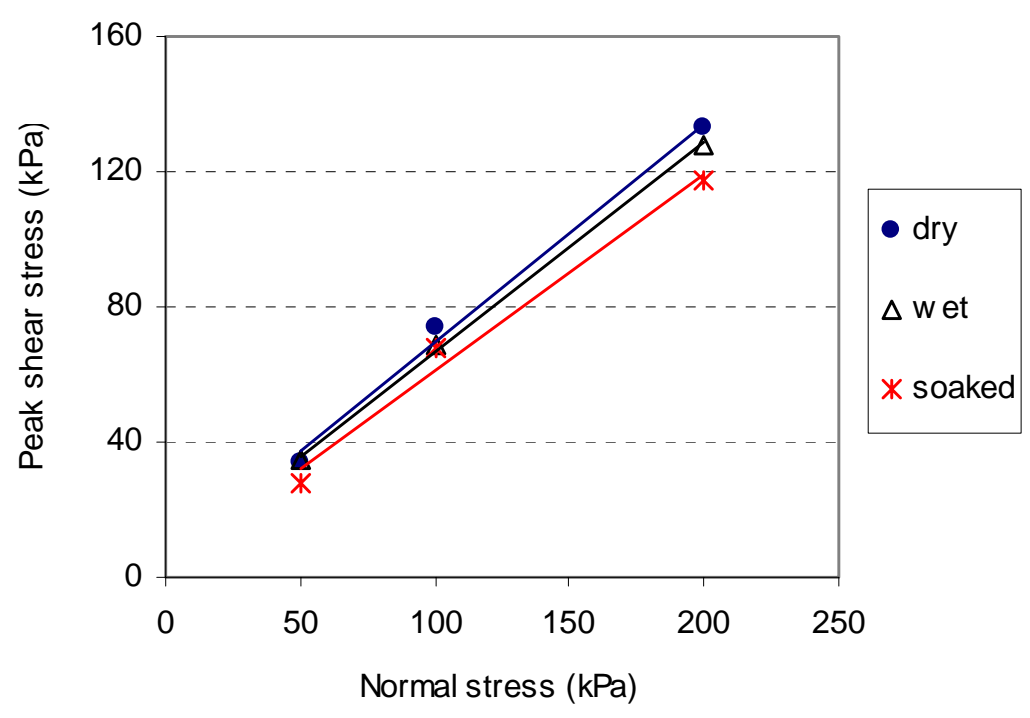

(a)

Wabash River Plant

(F75 B25)

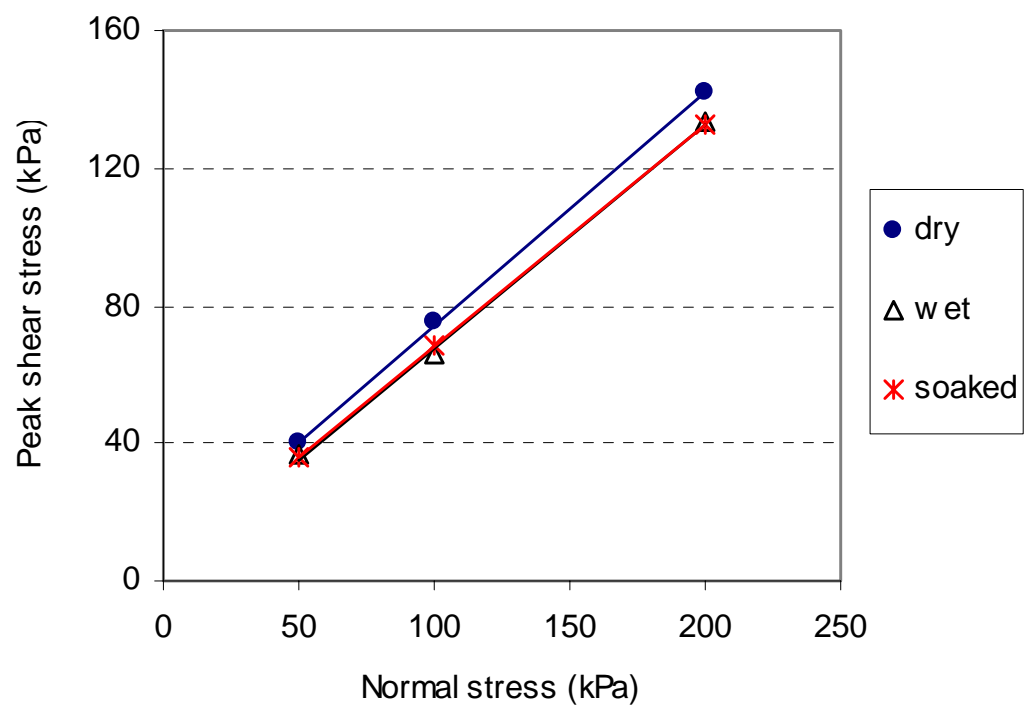

(b)

Figure 4.21 Results of Direct Shear Tests on Samples from the Wabash River Plant Ash Mixtures: (a) $\mathrm{F}=100 \%$ (b) $\mathrm{F}=75 \%, \mathrm{~B}=25 \%$ (c) $\mathrm{F}=50 \%, \mathrm{~B}=50 \%$. 
Wabash River Plant

(F50 B50)

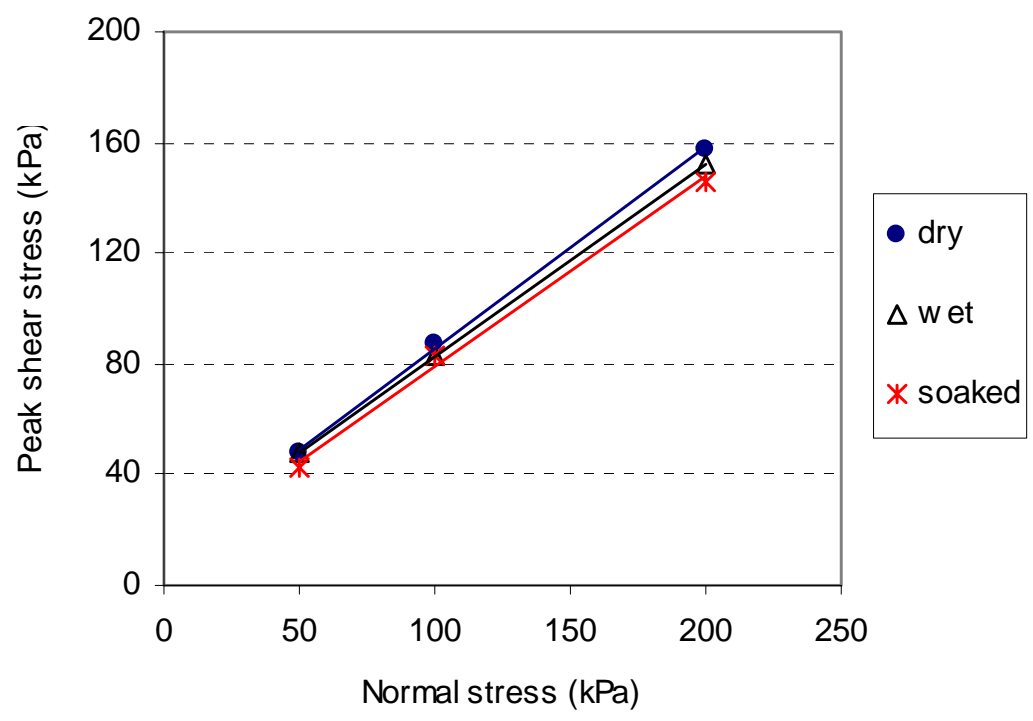

(c)

Figure 4.21 [Continued] 
A.B. Brown Plant

(F100)

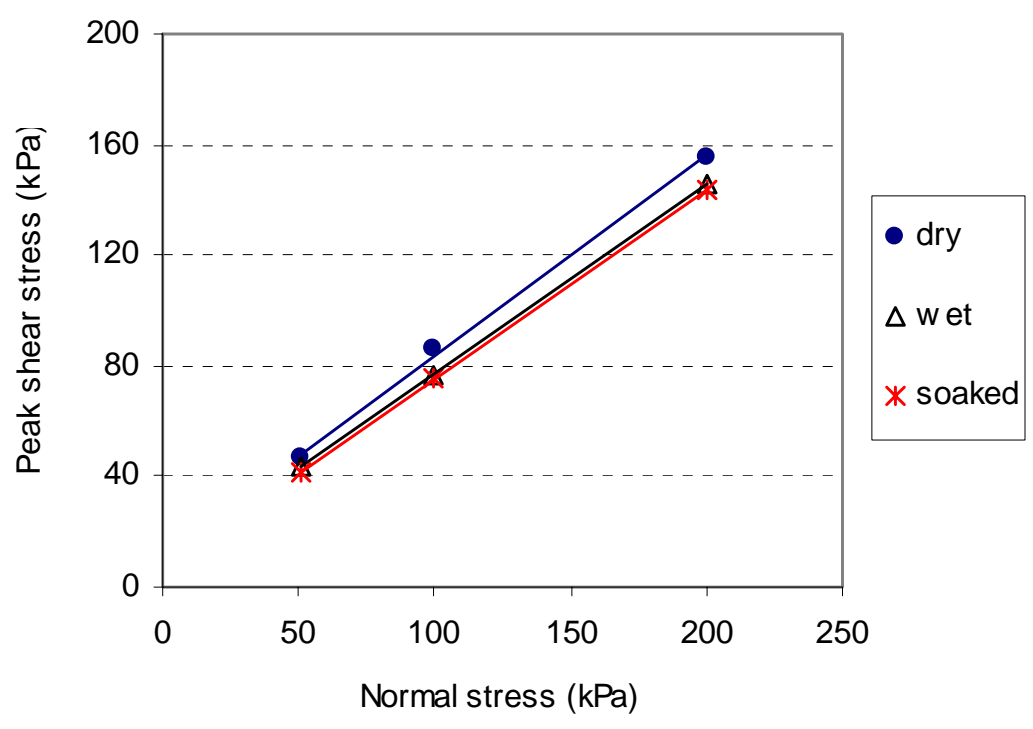

(a)

A.B. Brown Plant (F75 B25)

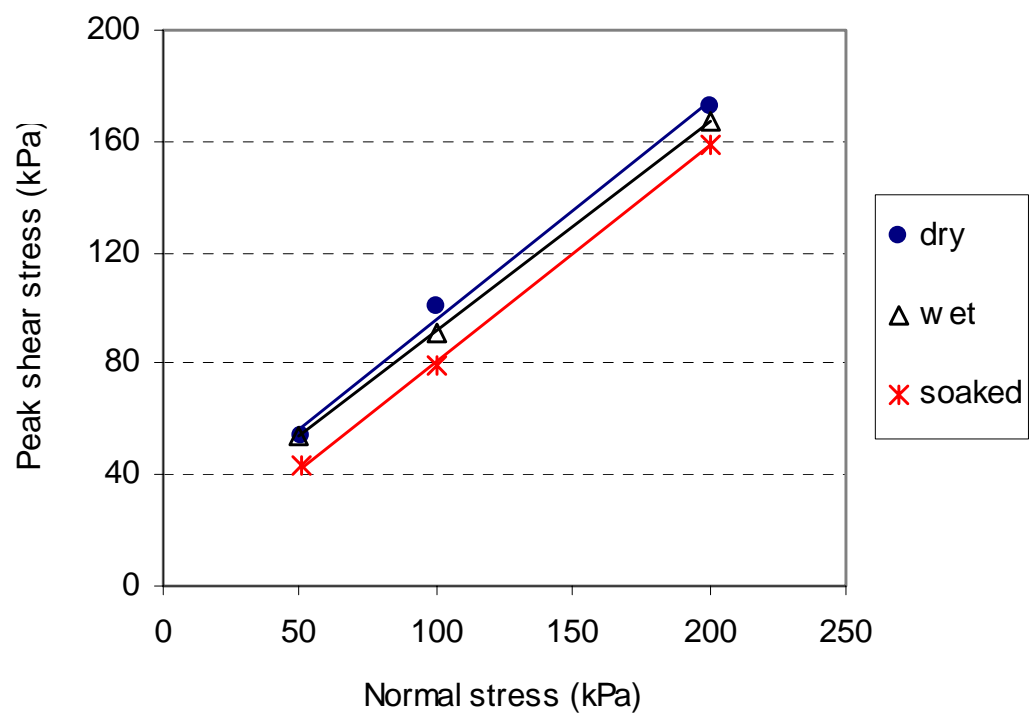

(b)

Figure 4.22 Results of Direct Shear Tests on Samples from the A.B.Brown Plant and F.B.Culley Plant: (a) $F=100 \%$ (b) $F=75 \%, B=25 \%$ (c) $F=50 \%, B=50 \%$ (d) $F=$ $100 \%$ (F.B.Culley Plant). 
A.B. Brown Plant

(F50 B50)

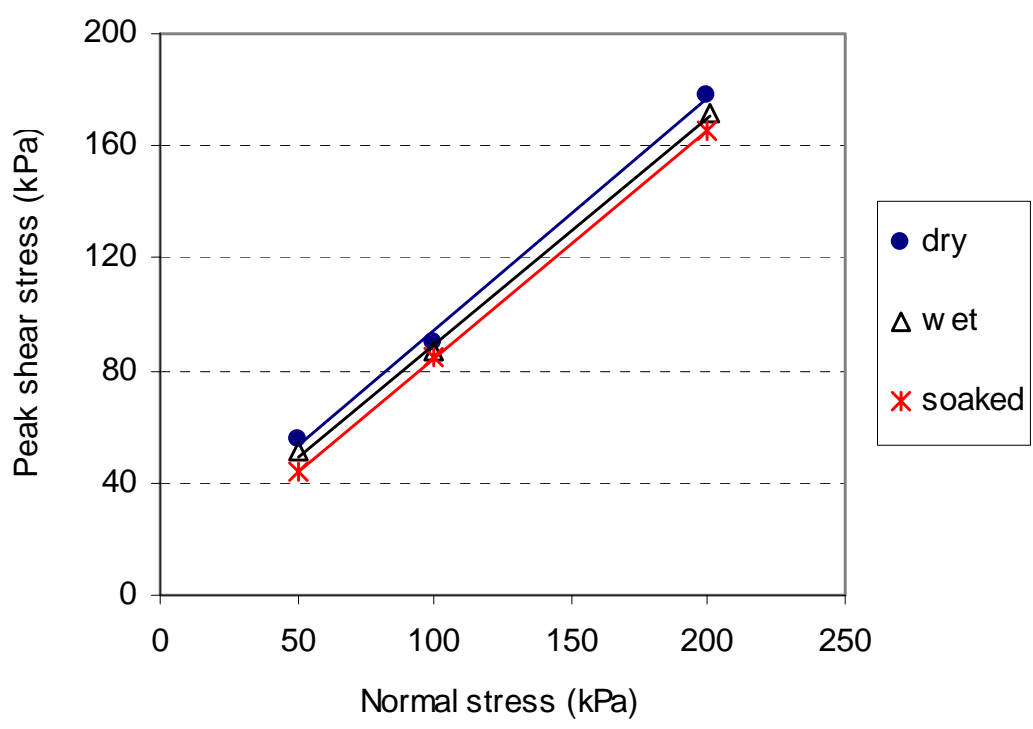

(c)

F.B. Culley Plant Fly Ash

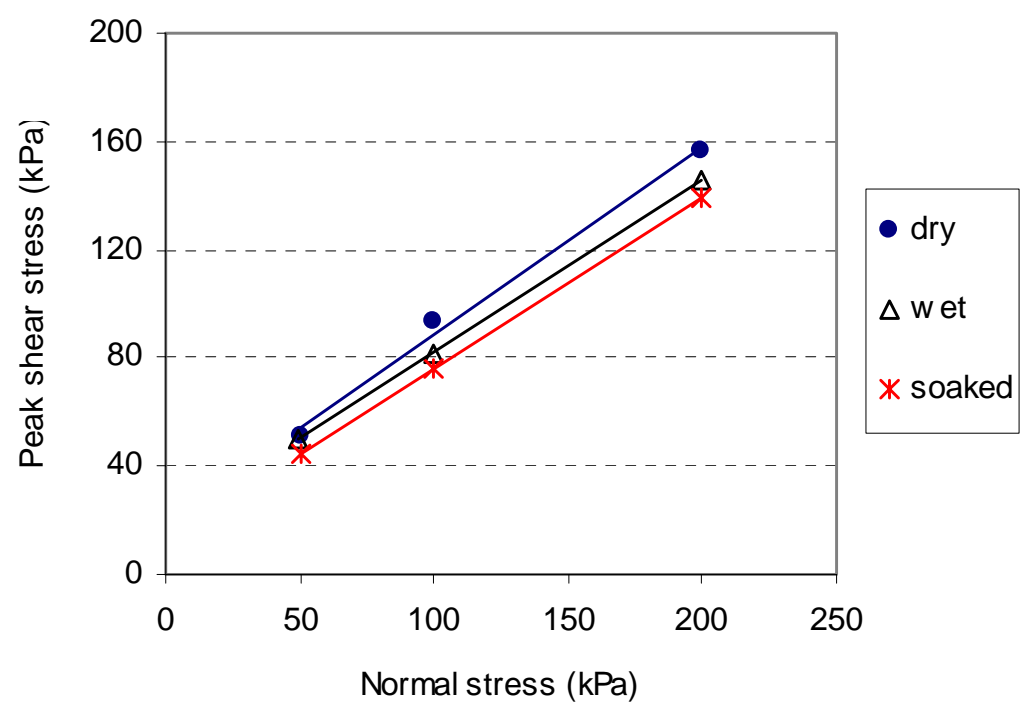

(d)

Figure 4.22 [Continued] 
Table 4.14 Results of Direct Shear Tests (Peak Friction Angle).

\begin{tabular}{ccccc}
\hline & & \multicolumn{3}{c}{ Peak Friction Angle (degree) } \\
\cline { 3 - 4 } Ash Source & Mixture & Ratio & As-Compacted & Soaked \\
\cline { 3 - 4 } \cline { 5 - 5 } & & Dry of Optimum & Wet of Optimum & Dry of Optimum \\
\hline \hline W100 & 32.9 & 31.7 & 30.2 \\
River Plant & F75 B25 & 34.2 & 32.9 & 32.9 \\
& F50 B50 & 36.0 & 34.7 & 34.4 \\
\hline A.B. Brown & F100 & 35.8 & 34.4 & 34.5 \\
Plant & F75 B25 & 38.0 & 37.3 & 37.9 \\
\hline F.B. Culley & F50 B50 & 39.6 & 38.9 & 39.1 \\
\hline Plant & F100 & 34.7 & 32.5 & 32.2 \\
\hline
\end{tabular}

Table 4.15 Results of Direct Shear Tests (Cohesion Intercept).

\begin{tabular}{|c|c|c|c|c|}
\hline \multirow{3}{*}{ Ash Source } & \multirow{3}{*}{$\begin{array}{l}\text { Mixture } \\
\text { Ratio }\end{array}$} & \multicolumn{3}{|c|}{ Cohesion Intercept (kPa) } \\
\hline & & \multicolumn{2}{|c|}{ As-Compacted } & \multirow{2}{*}{$\begin{array}{c}\text { Soaked } \\
\text { Dry of Optimum }\end{array}$} \\
\hline & & Dry of Optimum & Wet of Optimum & \\
\hline \multirow{3}{*}{$\begin{array}{l}\text { Wabash } \\
\text { River Plant }\end{array}$} & F100 & 4.8 & 5.0 & 2.8 \\
\hline & F75 B25 & 6.3 & 3.2 & 3.5 \\
\hline & F50 B50 & 12.9 & 13.5 & 10.4 \\
\hline \multirow{3}{*}{$\begin{array}{l}\text { A.B. Brown } \\
\text { Plant }\end{array}$} & F100 & 12.0 & 9.2 & 6.4 \\
\hline & F75 B25 & 17.7 & 15.4 & 3.1 \\
\hline & F50 B50 & 11.5 & 8.9 & 3.2 \\
\hline $\begin{array}{l}\text { F.B. Culley } \\
\text { Plant }\end{array}$ & F100 & 19.3 & 18.2 & 13.2 \\
\hline
\end{tabular}


Wabash River Plant

Direct shear test results

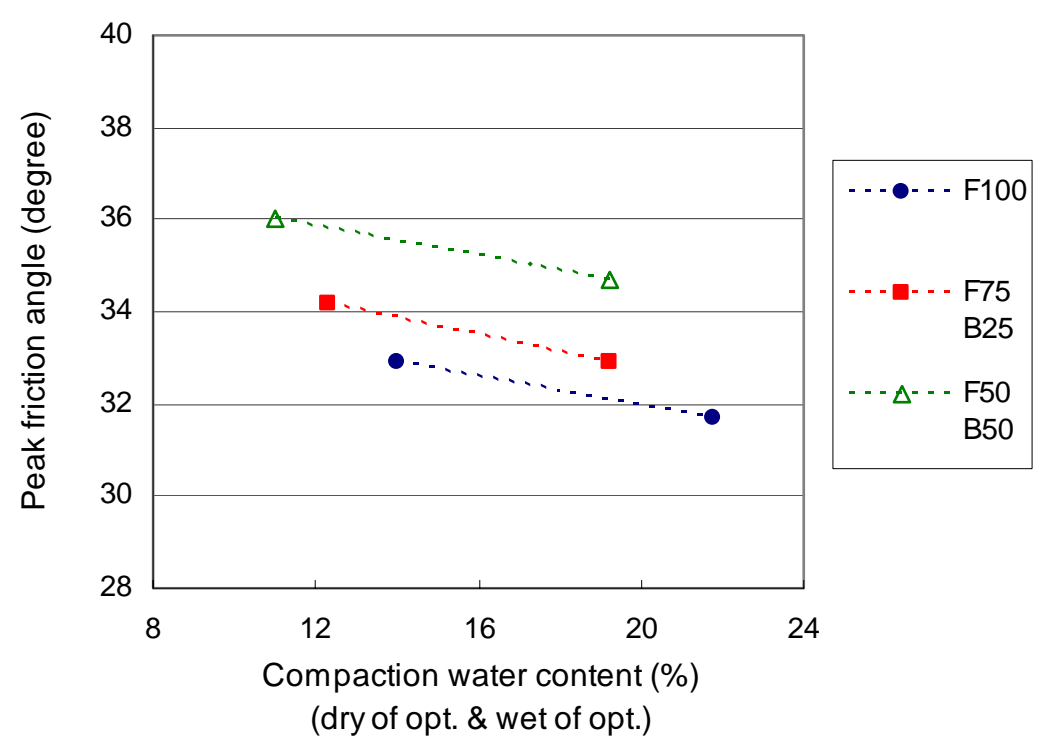

(a)

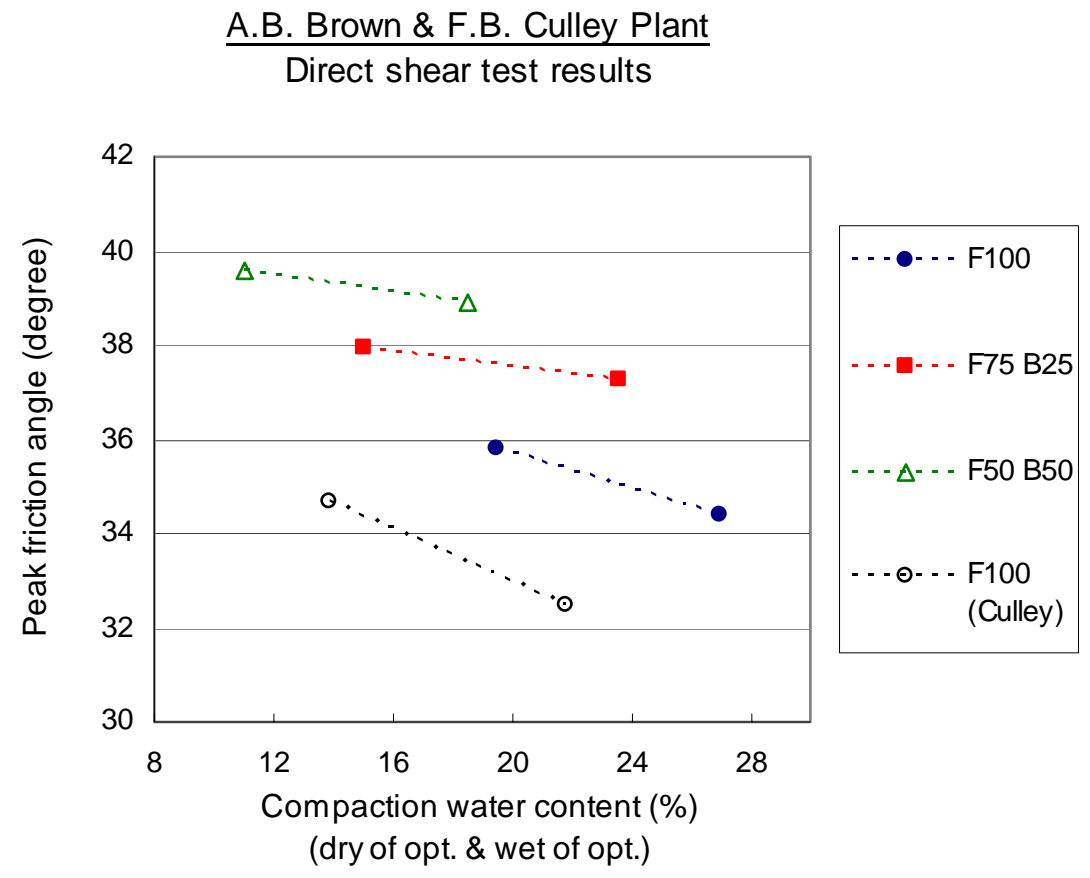

(b)

Figure 4.23 Peak Friction Angles of Ash Mixtures Compacted Dry of Optimum and Wet of Optimum (Results of Direct Shear Tests): (a) Wabash River Plant (b) A.B.Brown Plant and F.B.Culley Plant. 
Wabash River Plant

Direct shear test results

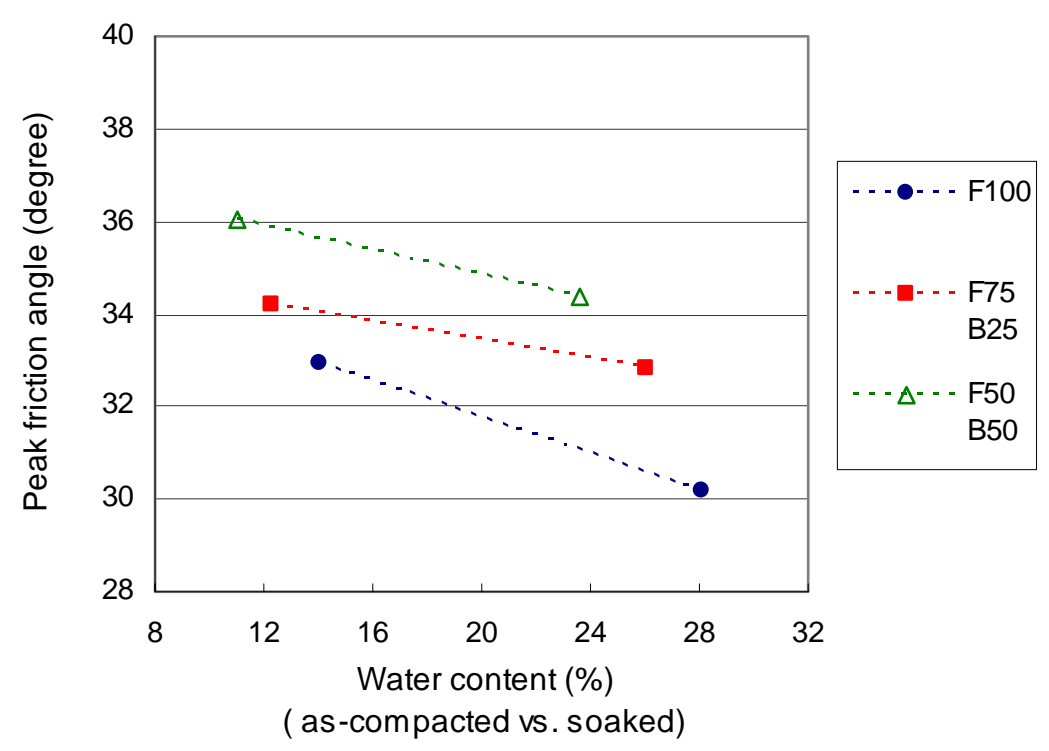

(a)

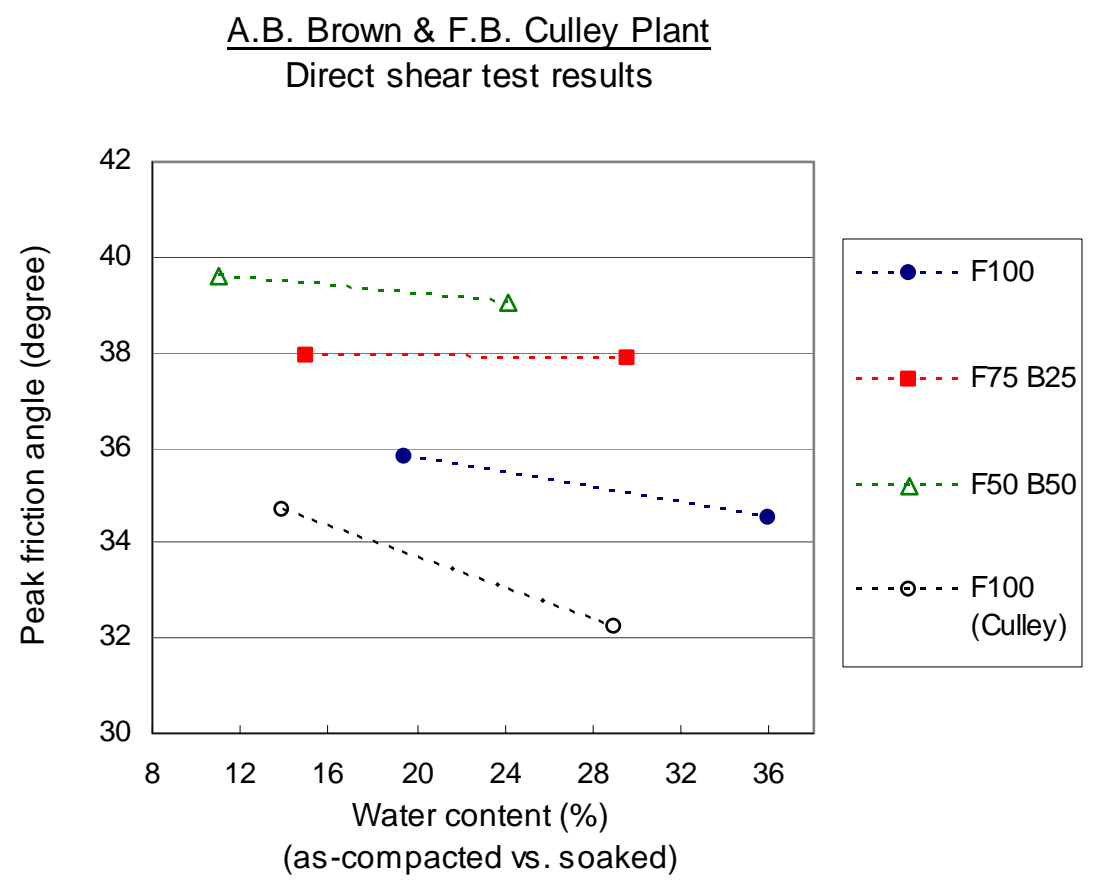

(b)

Figure 4.24 Peak Friction Angles of As-Compacted and Soaked Samples (Results of Direct Shear Tests): (a) Wabash River Plant (b) A.B.Brown Plant and F.B.Culley Plant. 
samples may be primarily attributed to slightly higher capillary suction developed in the dry side samples.

As mentioned earlier, the capillary suction disappears upon saturation. Comparisons between the as-compacted and soaked samples suggest that the shear strength drops upon saturation due to the vanished capillary stress. The decrease in the strength, however, was generally small. The reduction in the peak friction angle is about $2^{\circ}$ (Table 4.14 and Figure 4.24). The difference in the cohesion intercepts is about $6 \mathrm{kPa}$ on average (Table 4.15). It should be noted that for the soaked samples, the positive values of the cohesion intercepts do not mean that the mixtures have cohesion. The cohesion intercept is simply the result of a curve fit to the data, and reflect higher dilatancy at low effective confining stresses.

4.9.2 Stress-strain and volumetric behaviors of ash mixtures and their shear strength

In order to study the behavior of compacted ash mixtures in shearing and to determine their shear strength, isotropically consolidated, drained (CID) triaxial compression tests were performed. This section presents the results and discussion of the triaxial experimental program, which includes the testing of ash mixtures with fly ash contents of 50\%, 75\%, and 100\% from the Wabash River and A.B. Brown plants, and fly ash (i.e. $100 \%$ fly ash content) from F.B. Culley plant. Six samples were formed from each mixture and divided into two groups, three samples each. The first group of samples was compacted to a relative compaction $\mathrm{R}=95 \%$, and the second group to $\mathrm{R}=90 \%$. Three levels of effective confining pressure $\left(\sigma^{\prime}{ }_{3}=50,100\right.$, and $\left.200 \mathrm{kPa}\right)$ were used per 
group. The mixture composition, compaction level $\mathrm{R}$, and confining pressures of each sample were presented in Chapter 3 (Table 3.1).

The results of the shear tests using the triaxial procedures are discussed and analyzed in the following sequence: for each mixture at a given relative compaction (R), the deviatoric stress $\left(\sigma^{\prime}{ }_{\mathrm{d}}\right)$ and volumetric strain $\left(\varepsilon_{\mathrm{v}}\right)$ were plotted versus axial strain $\left(\varepsilon_{\mathrm{a}}\right)$ at three levels of confining pressure $\left(\sigma_{3}^{\prime}\right)$. The stress-strain and volumetric behaviors during shear are discussed. For the different mixtures and relative compactions, the effective peak friction angle $\phi_{p}^{\prime}=\sin ^{-1}\left[\left(\sigma^{\prime}{ }_{1}-\sigma^{\prime}{ }_{3}\right) /\left(\sigma^{\prime}{ }_{1}+\sigma^{\prime}{ }_{3}\right)\right]_{\max }$ was calculated from the values of $\sigma_{1}^{\prime}$ and $\sigma_{3}^{\prime}$ at peak stress and plotted against the fly ash content. Critical state friction angle $\phi_{c}^{\prime}=\sin ^{-1}\left[\left(\sigma^{\prime}{ }_{1}-\sigma^{\prime}{ }_{3}\right) /\left(\sigma^{\prime}{ }_{1}+\sigma^{\prime}{ }_{3}\right)\right]_{\text {critical }}$ was also estimated for each ash mixture with a given fly ash content and comparisons are made with those for typical sands. Additionally, for the fly ash (i.e. $\mathrm{F}=100 \%$ ), an attempt was made to apply the Bolton (1986) correlation for predicting the relationship between $\phi_{p}^{\prime}$ and $\phi_{c}^{\prime}$ based on the mean effective stress and relative density. The obtained correlation parameters $\mathrm{Q}$ and $\mathrm{R}$ are compared with those for sands.

\section{$\underline{\text { Stress-Strain and Volumetric Behaviors }}$}

As a sample was deforming axially at a constant rate, the vertical load was automatically measured and recorded simultaneously with the axial deformation. The volume change due to the deviatoric stress $\left(\sigma^{\prime}{ }_{d}=\sigma^{\prime}{ }_{1}-\sigma_{3}^{\prime}\right)$ was also monitored and recorded. The deviatoric stress $\left(\sigma^{\prime}{ }_{1}-\sigma^{\prime}{ }_{3}\right)$ and volumetric strain $\left(\varepsilon_{\mathrm{v}}\right)$ were calculated and plotted against the axial strain $\left(\varepsilon_{\mathrm{a}}\right)$. As the axial strain $\left(\varepsilon_{\mathrm{a}}\right)$ increased, the sample deformed 
gradually and failure occurred. Figure 4.25 and 4.26 (a) and (b) display two typical failure patterns observed for ash mixtures. A clearly identifiable shear plane occurred in the dilatant stiff sample. A bulging pattern was commonly observed for contractive loose sample. Some samples exhibited a more complex pattern, that is, a combined pattern of the two (Figure 4.27). For a given relative compaction $\mathrm{R}$, the characteristics of both stress-strain and volume change behaviors were similar between the samples from different ash sources.

a. Ash mixtures compacted at $\mathrm{R}=95 \%$

Figure 4.28 through Figure 4.30 show the stress-stain and volume change behavior of fly ash specimens (i.e. $\mathrm{F}=100 \%, \mathrm{~B}=0 \%$ ) compacted at $\mathrm{R}=95 \%$ for different confining stresses (i.e. $\sigma_{3}^{\prime}=50,100$, and $200 \mathrm{kPa}$ ). The observed stress-strain and volumetric behavior of fly ash was typically similar to that of a granular soil in a dense state. Initially, the deviatoric stress increases up to a peak (i.e. peak shear strength) with axial strain. After the peak, the stress drops and gradually approaches a plateau as the axial strain increases further. As can be seen in the Figures (i.e. Figure 4.28 through Figure 4.30), the increase in the deviatoric stress is associated with a slight initial volumetric contraction, followed by a gradually increasing rate of volume expansion (dilation). The peak strength occurs when the rate $\mathrm{d} \varepsilon_{\mathrm{v}} / \mathrm{d} \varepsilon_{\mathrm{a}}$ of volume expansion with respect to axial strain reaches the maximum. The post-peak reduction in deviatoric stress is associated with a decreased rate of dilation until the stress state reaches the critical state with a constant stress and volume. The dilation is a function of both initial relative density and confining stress. That is, for a higher relative density and lower confining 


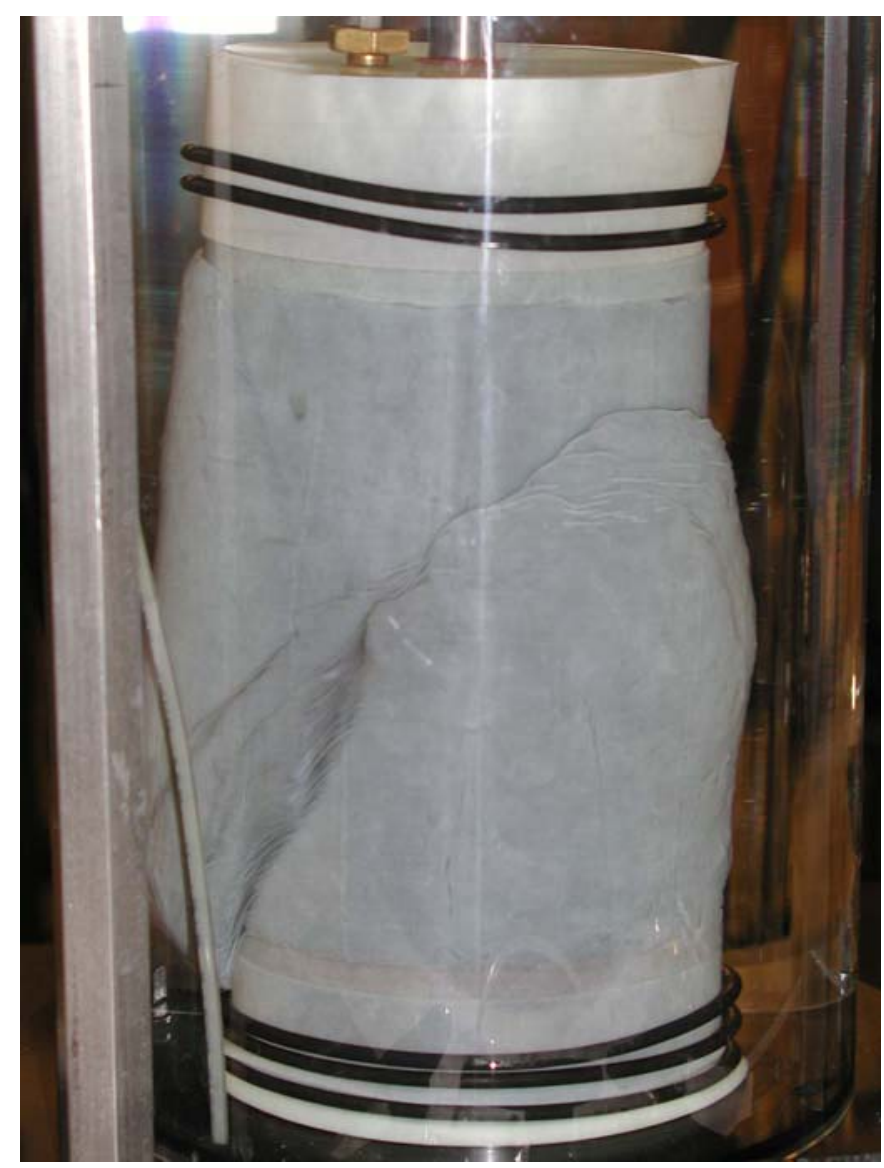

Figure 4.25 Triaxial Sample: Failure with Shear Plane. 


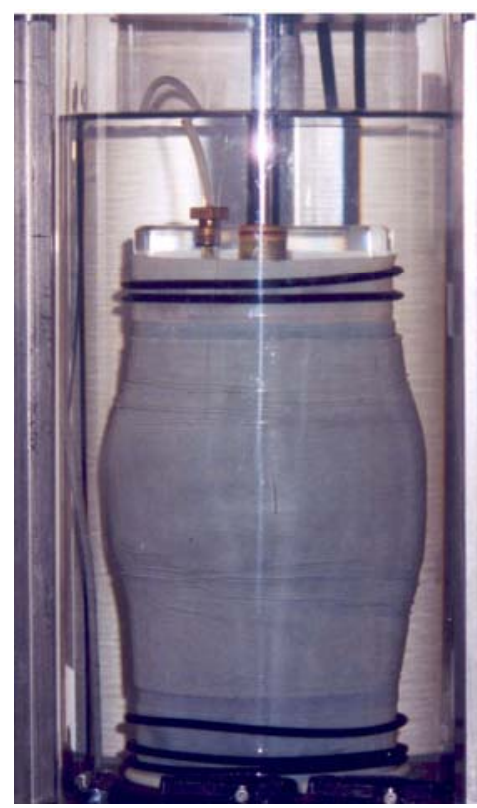

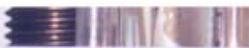

$\underline{\text { CD Triaxial Test }}$

Wabash River Station

$100 \%$ Fly ash

Compacted@90\% (ASTM 698)

Effective Confining Stress $=\mathbf{5 0} \mathbf{~ k P a}$

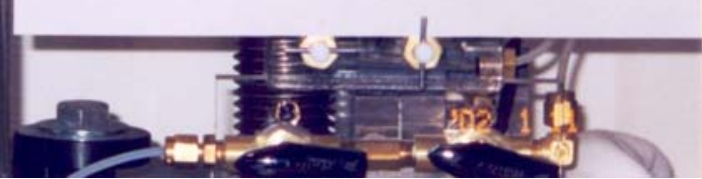

(a)

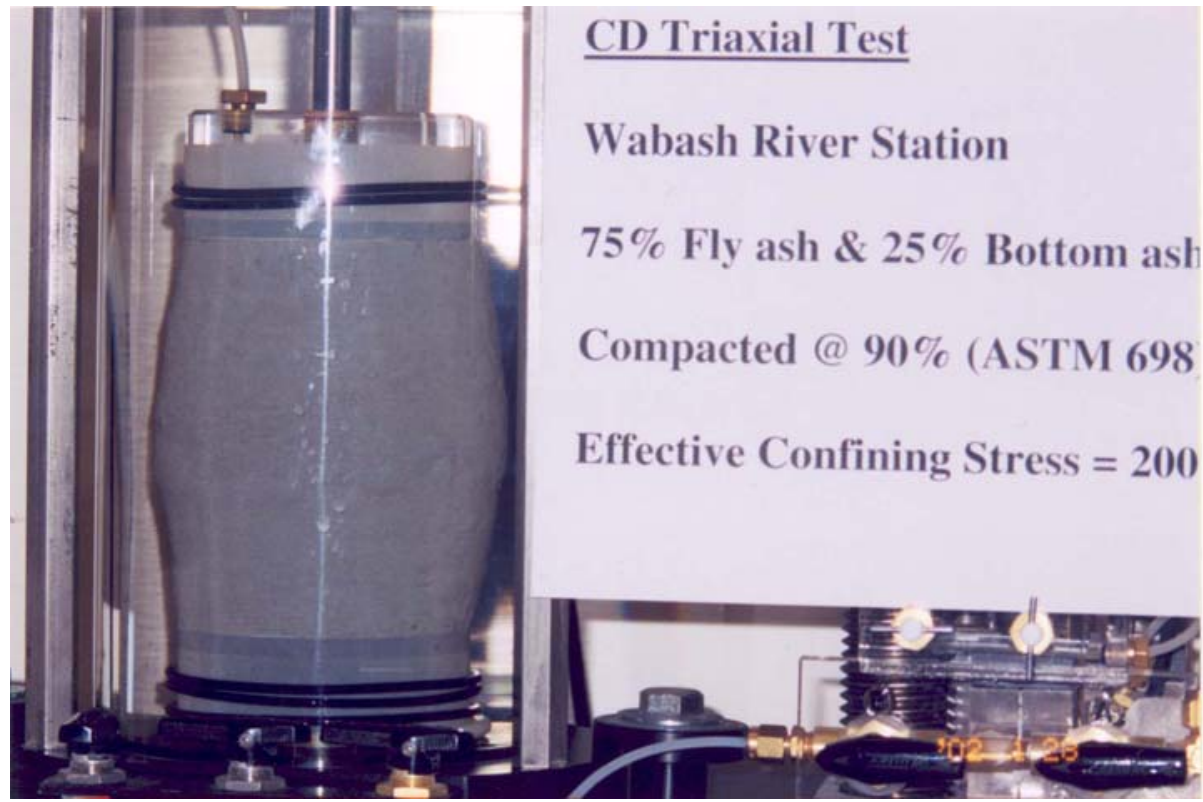

(b)

Figure 4.26 Triaxial Samples: Bulging Failures. 


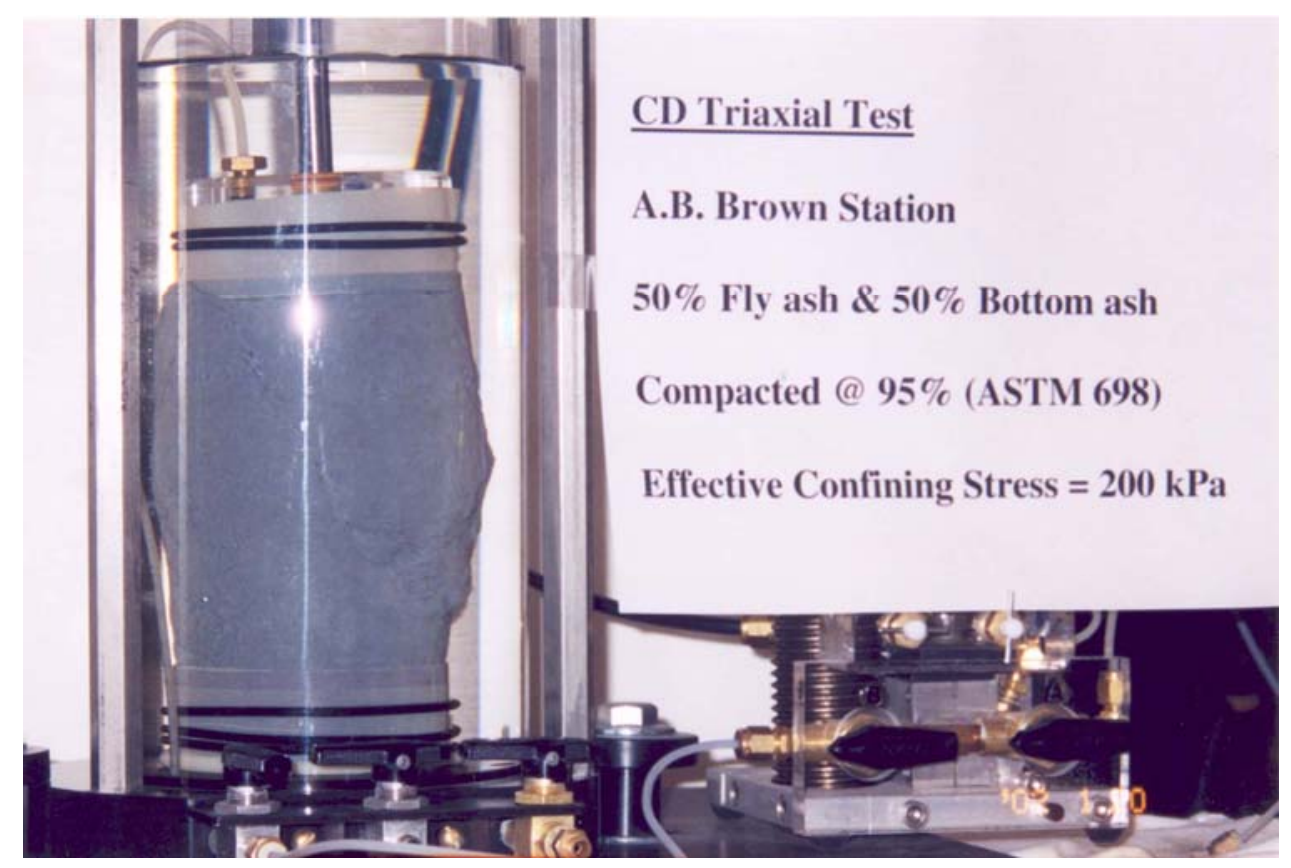

Figure 4.27 Triaxial Sample: Combined Pattern of Shear Banding and Bulging. 
stress, there is higher dilatancy. It is observed that dilation decreases gradually as the confining stress $\sigma_{3}^{\prime}$ increases from 50 to $200 \mathrm{kPa}$.

Figure 4.31 and Figure 4.32 display the stress-strain and volumetric behavior of ash mixtures with a fly ash content of $75 \%$ (i.e. $F=75 \%, B=25 \%$ ). At this level of fly ash content, fly ash particles float bottom ash particles and the behavior of the mixture is controlled by the fly ash. The peak deviatoric stresses increased slightly. The axial strains required for the mobilization of the peak deviatoric stress were practically the same as those observed in pure fly ash. However, both the maximum rate of dilation and the maximum dilation decreased somewhat with a change in the fly ash content. The difference in the degree of dilation may be partly due to different initial relative densities between the ash mixtures with fly ash contents of $100 \%$ and $75 \%$ although both were at the same relative compaction. The confining stress also affects the dilation. Dilation decreases with increasing confining stress. At $\sigma_{3}^{\prime}=200 \mathrm{kPa}$, the Brown plant ash mixture exhibits contractive behavior throughout shearing.

As the fly ash content decreases from $75 \%$ to $50 \%$ (i.e. $F=50 \%, B=50 \%$ ), further reduction in dilation is observed (Figure 4.33 and Figure 4.34). The peak deviatoric stresses changed slightly. For this mixture ratio, fly ash particles would still float bottom ash particles and bottom ash particles may not be, on average, in contact. At low to moderate confining stress levels (i.e. $\sigma_{3}^{\prime}=50$ and $100 \mathrm{kPa}$ ), the volumetric behavior is clearly a combined pattern of dilation and contraction. Slight dilation was observed at relatively small strains, but is not developed further and the volume becomes contractive as the axial strain increases further. The shift from dilation to contraction may be because particles break while they climb over each other. At a higher confining stress 
Wabash River Plant

CID Triaxial ( $F=100 \%, R=95 \%)$

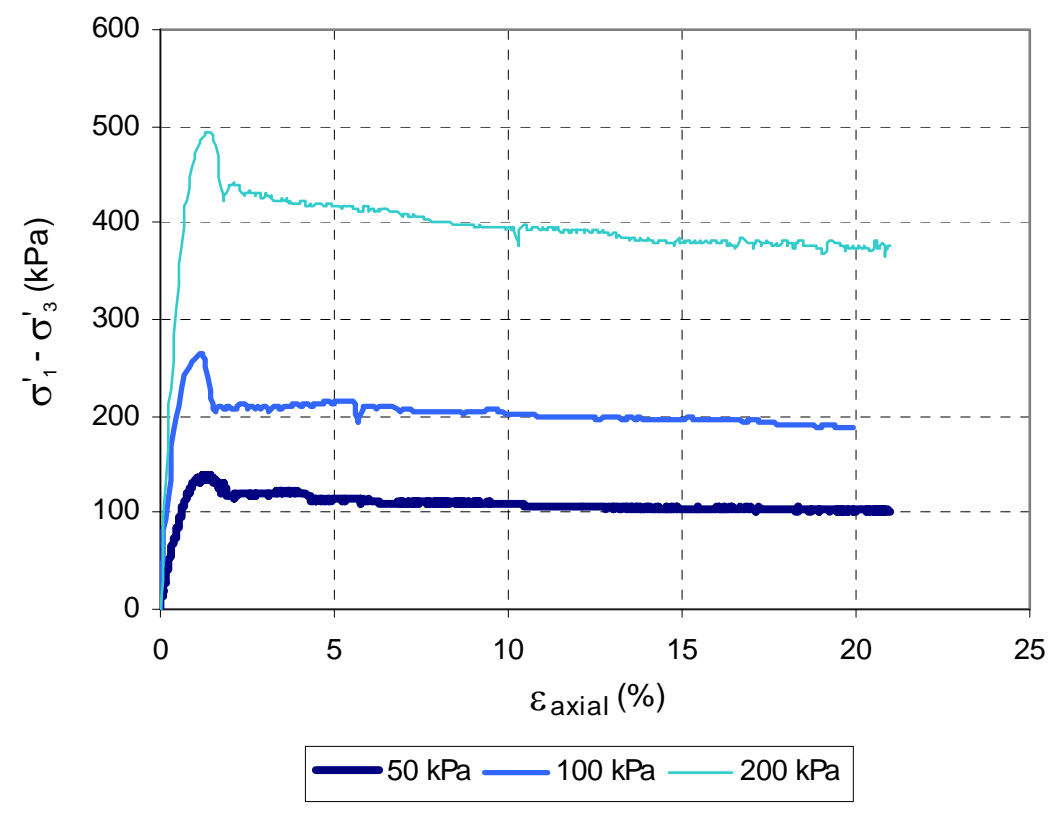

(a)

Wabash River Plant

CID Triaxial ( $F=100 \%, R=95 \%)$

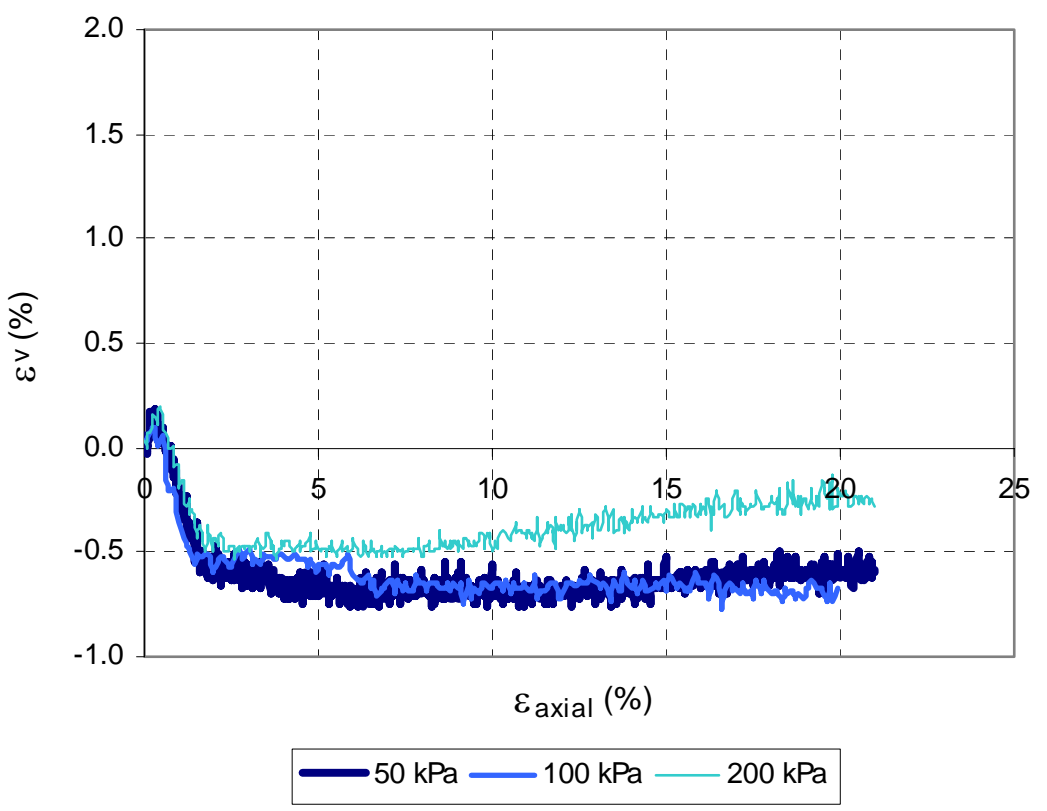

(b)

Figure 4.28 CID Triaxial Tests on $F=100 \%$ from the Wabash River Plant ( $R=95 \%$ ): (a) Deviatoric Stress vs. Axial Strain (b) Volumetric Strain vs. Axial Strain. 
A.B. Brown Plant

CID Triaxial $(F=100 \%, R=95 \%)$

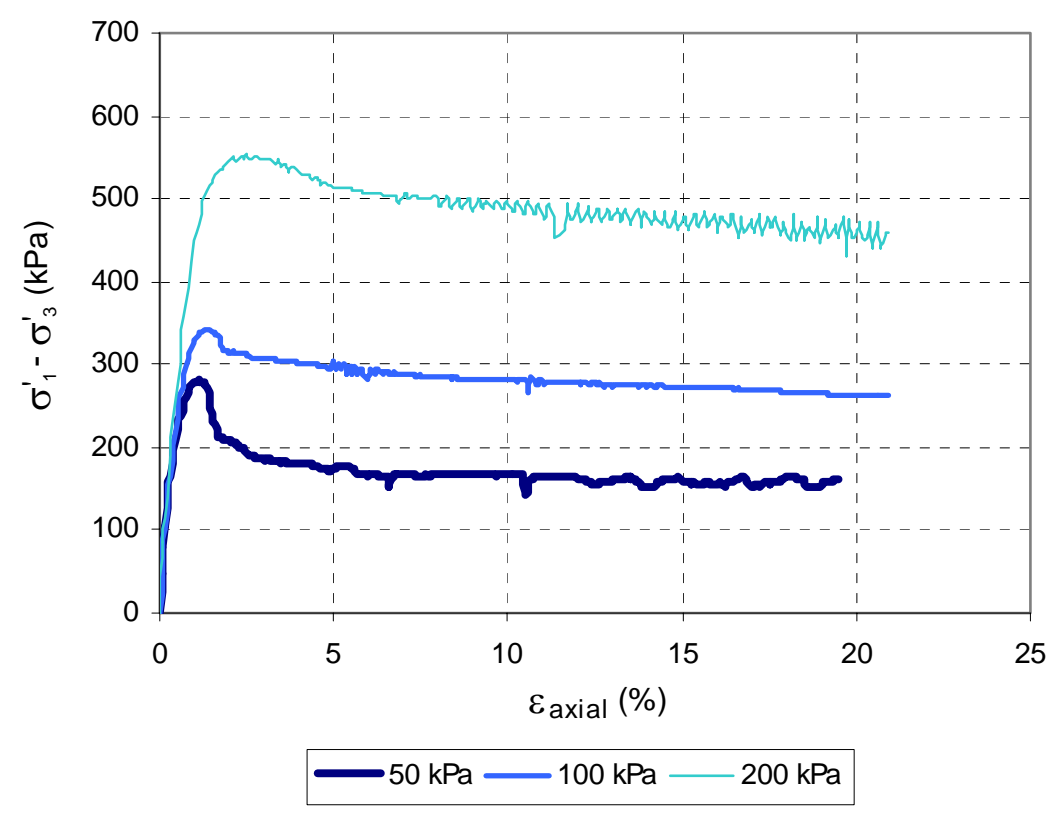

(a)

A.B. Brown Plant

CID Triaxial $(\mathrm{F}=100 \%, \mathrm{R}=95 \%)$

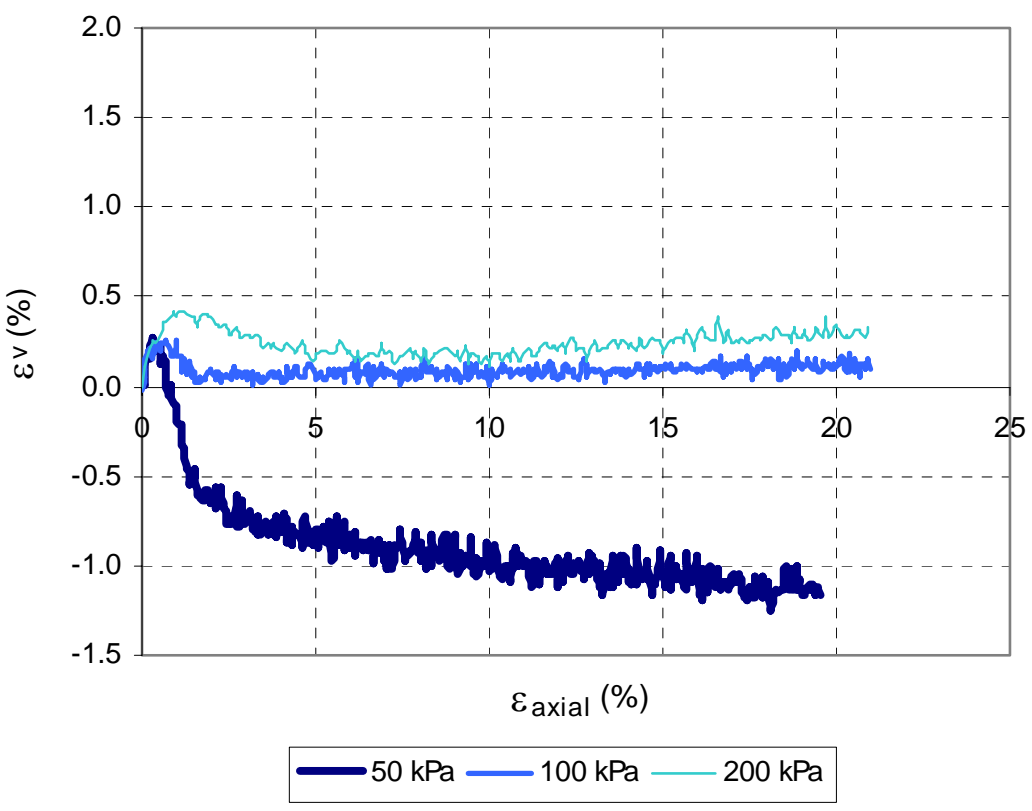

(b)

Figure 4.29 CID Triaxial Tests on $\mathrm{F}=100 \%$ from the A.B.Brown Plant ( $\mathrm{R}=95 \%$ ): (a) Deviatoric Stress vs. Axial Strain (b) Volumetric Strain vs. Axial Strain. 
F.B. Culley Plant

CID Triaxial $(F=100 \%, R=95 \%)$

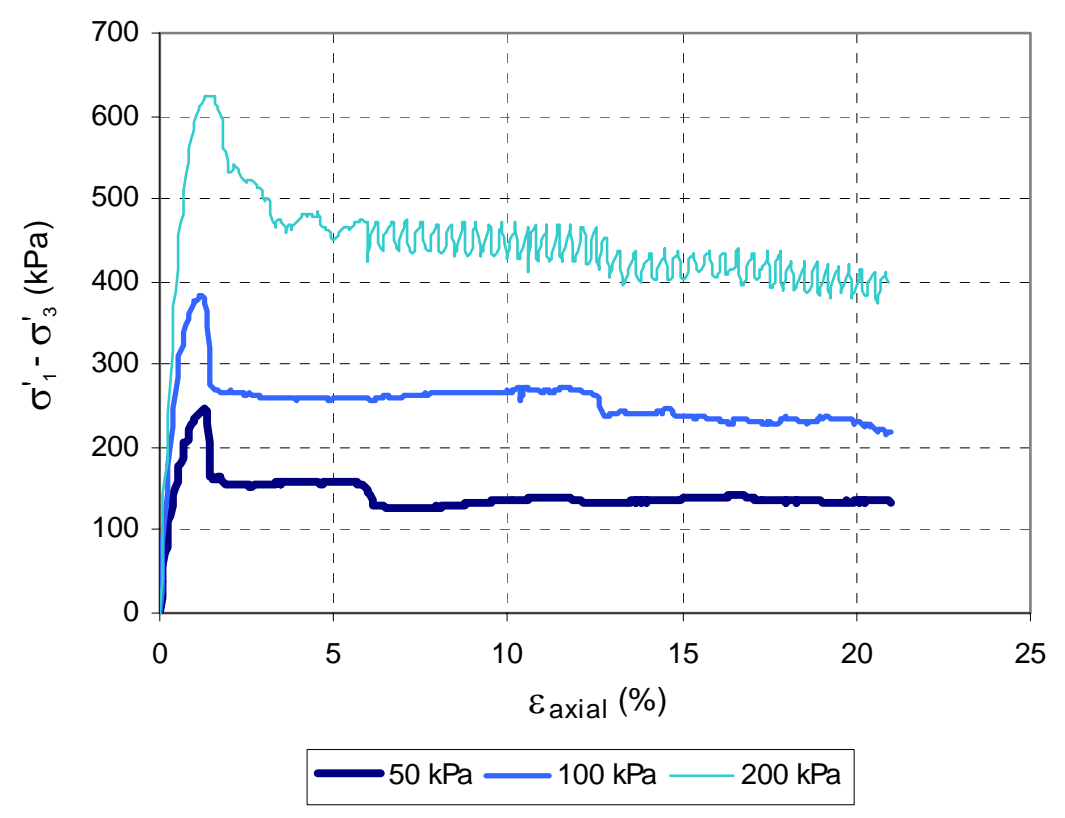

(a)

F.B. Culley Plant

CID Triaxial $(\mathrm{F}=100 \%, \mathrm{R}=95 \%)$

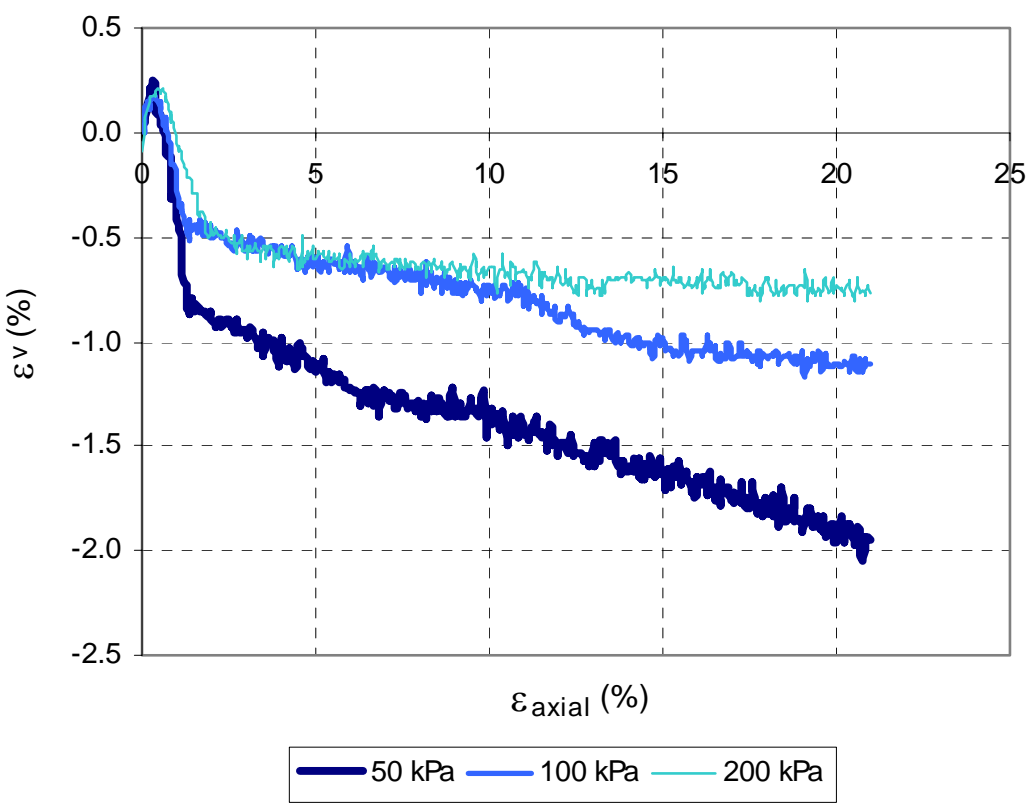

(b)

Figure 4.30 CID Triaxial Tests on $F=100 \%$ from the F.B.Culley Plant ( $R=95 \%$ ): (a) Deviatoric Stress vs. Axial Strain (b) Volumetric Strain vs. Axial Strain. 


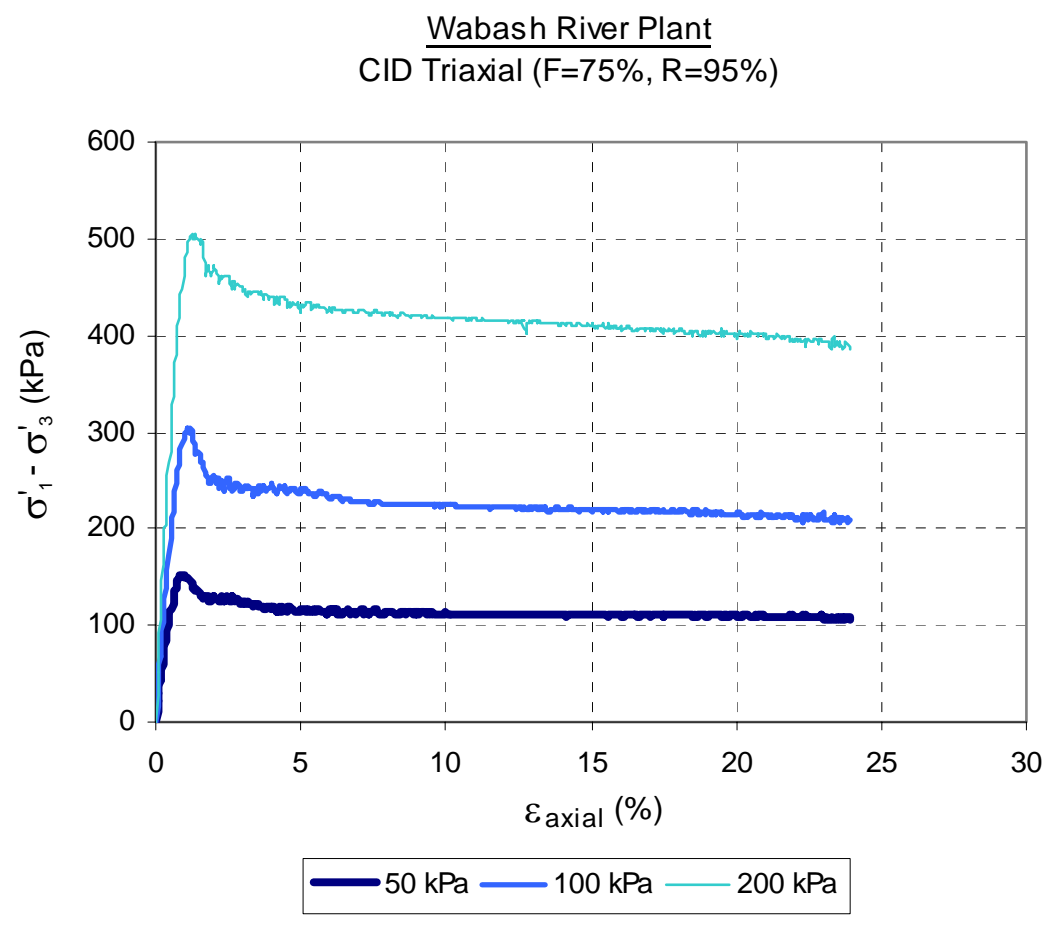

(a)

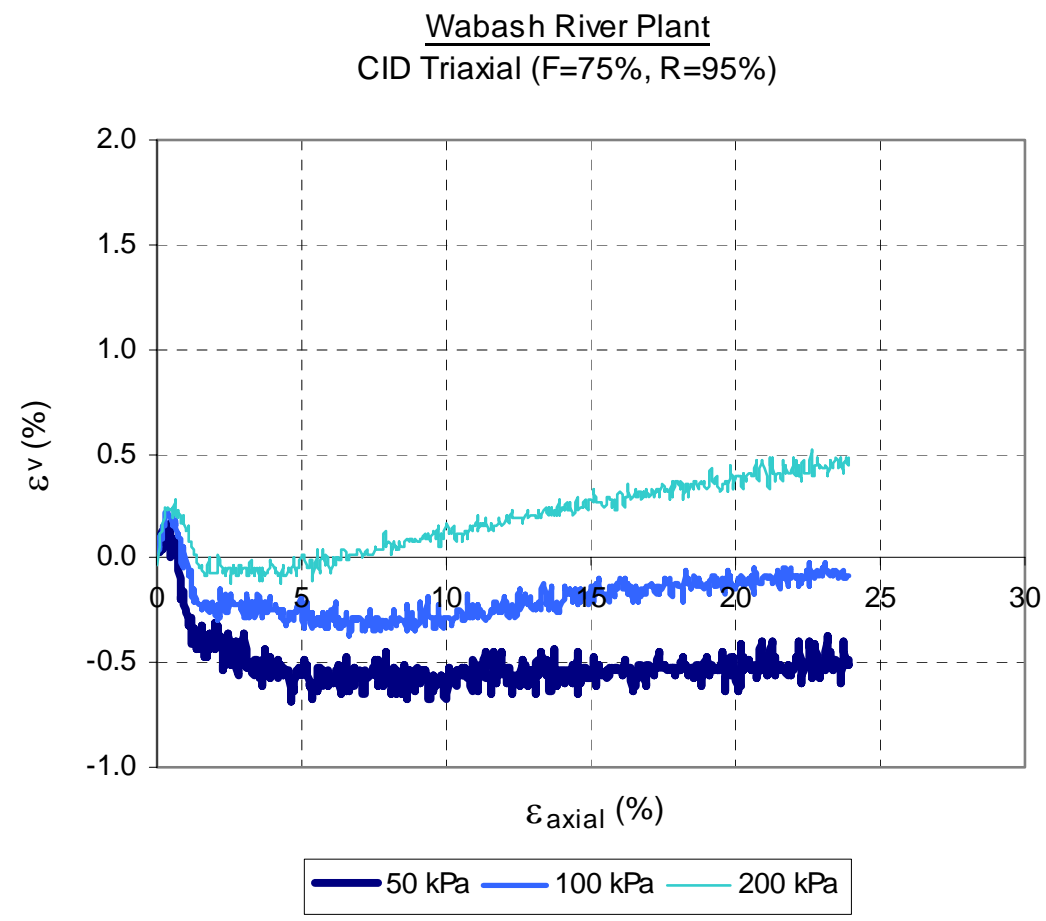

(b)

Figure 4.31 CID Triaxial Tests on $\mathrm{F}=75 \%, \mathrm{~B}=25 \%$ from the Wabash River Plant $(\mathrm{R}=$ 95\%): (a) Deviatoric Stress vs. Axial Strain (b) Volumetric Strain vs. Axial Strain. 
A.B. Brown Plant

CID Triaxial $(F=75 \%, R=95 \%)$

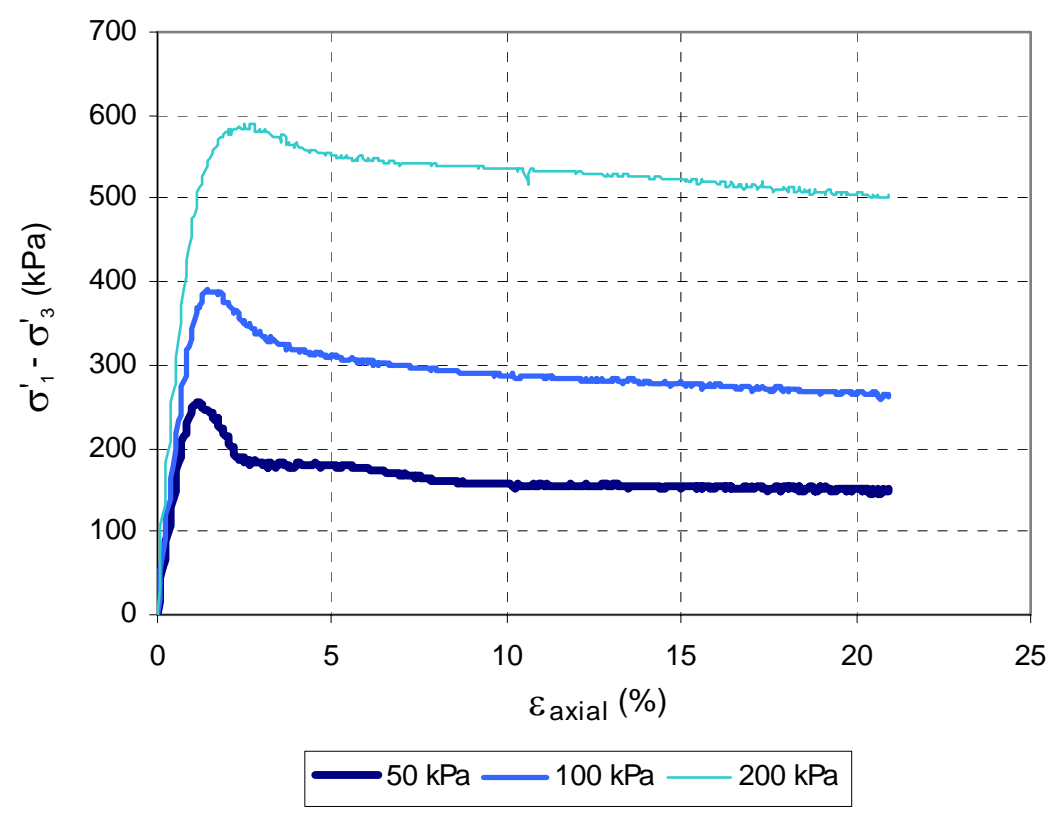

(a)

A.B. Brown Plant

CID Triaxial $(F=75 \%, R=95 \%)$

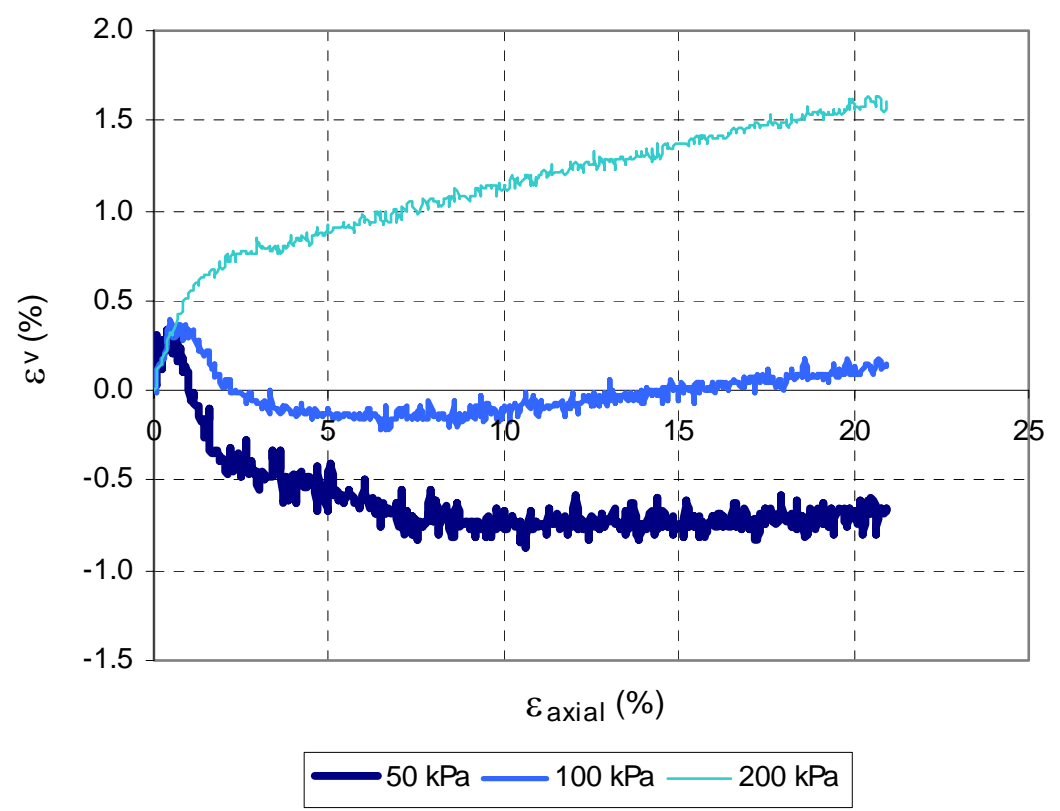

(b)

Figure 4.32 CID Triaxial Tests on $\mathrm{F}=75 \%, \mathrm{~B}=25 \%$ from the A.B.Brown Plant $(\mathrm{R}=$ 95\%): (a) Deviatoric Stress vs. Axial Strain (b) Volumetric Strain vs. Axial Strain. 
Wabash River Plant

CID Triaxial $(F=50 \%, R=95 \%)$

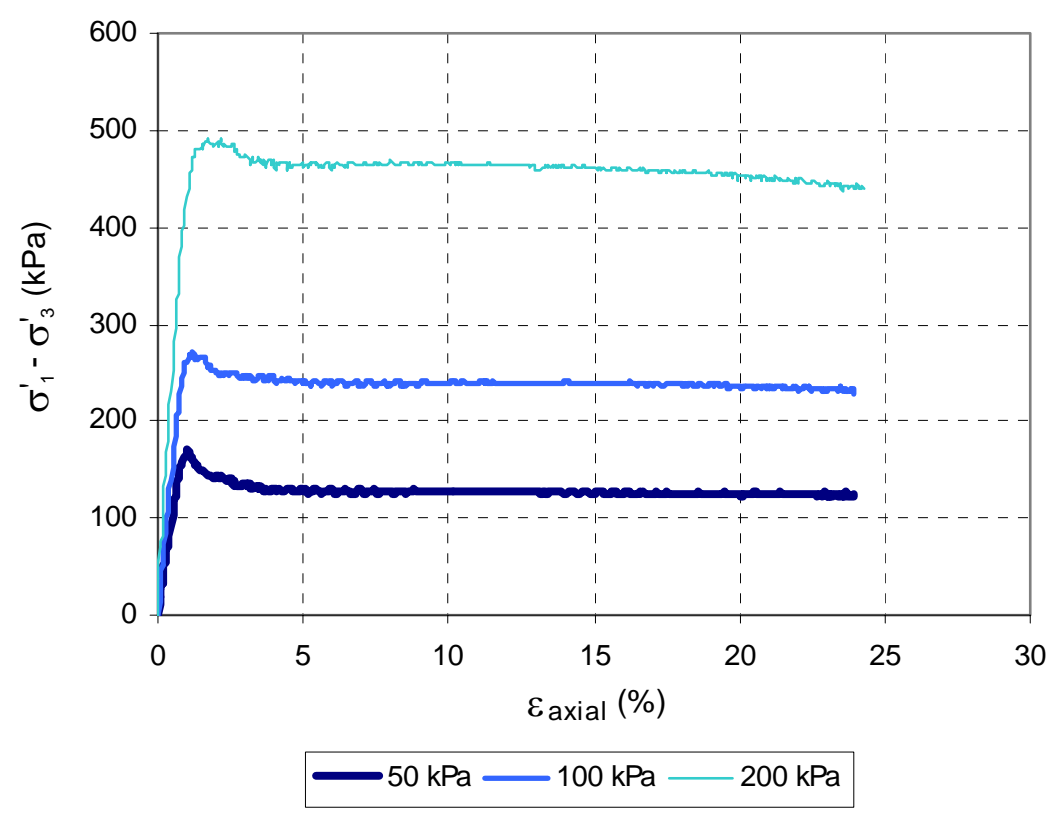

(a)

Wabash River Plant

CID Triaxial ( $F=50 \%, R=95 \%)$

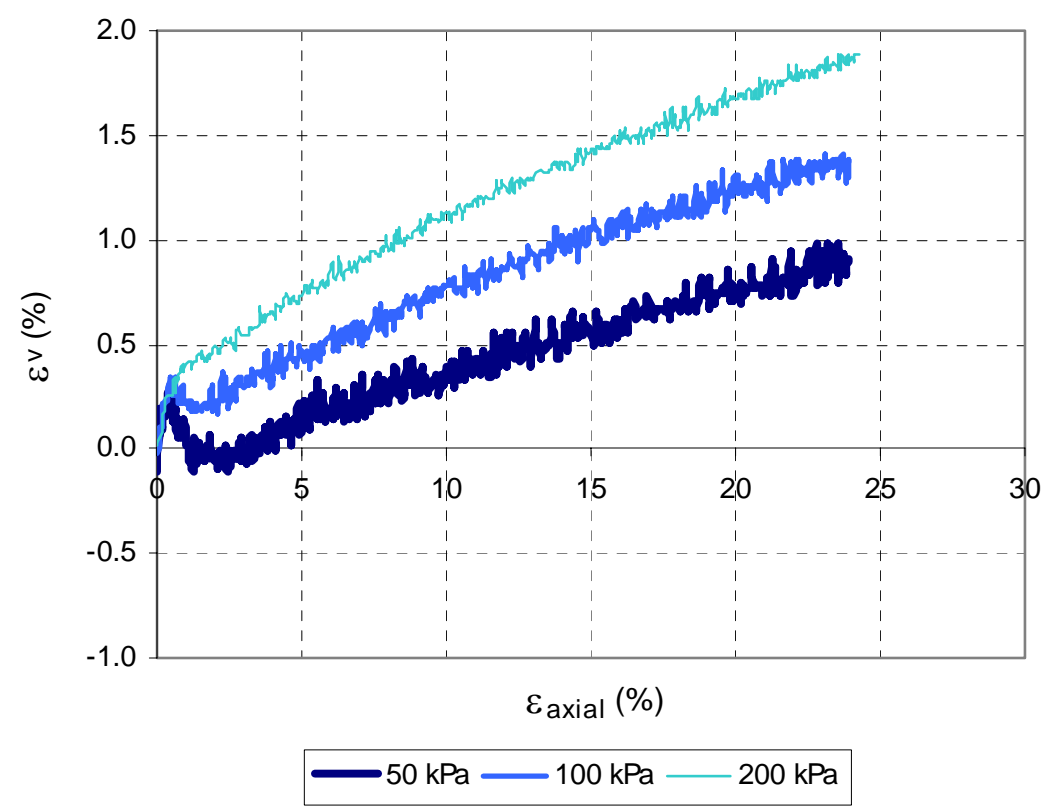

(b)

Figure 4.33 CID Triaxial Tests on $\mathrm{F}=50 \%, \mathrm{~B}=50 \%$ from the Wabash River Plant $(\mathrm{R}=$ 95\%): (a) Deviatoric Stress vs. Axial Strain (b) Volumetric Strain vs. Axial Strain. 
A.B. Brown Plant

CID Triaxial $(F=50 \%, R=95 \%)$

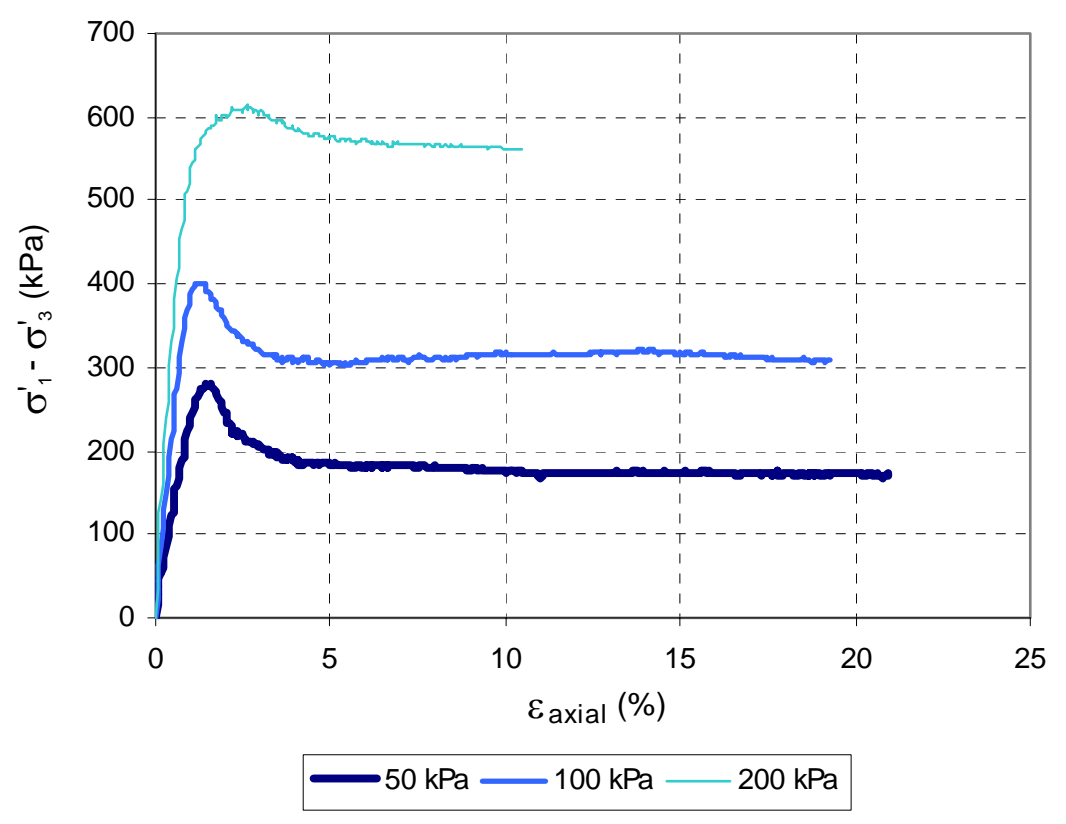

(a)

A.B. Brown Plant

CID Triaxial $(F=50 \%, R=95 \%)$

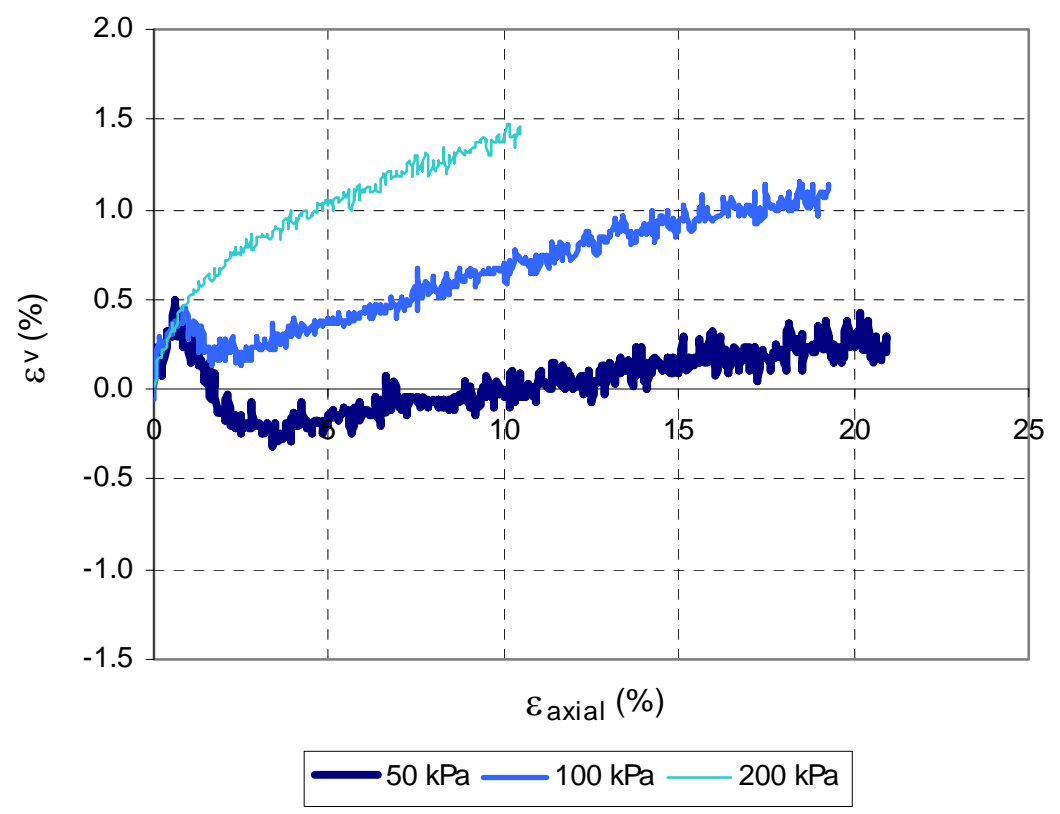

(b)

Figure 4.34 CID Triaxial Tests on $\mathrm{F}=50 \%, \mathrm{~B}=50 \%$ from the A.B.Brown Plant $(\mathrm{R}=$ 95\%): (a) Deviatoric Stress vs. Axial Strain (b) Volumetric Strain vs. Axial Strain. 
(i.e. $\sigma_{3}^{\prime}=200 \mathrm{kPa}$ ), dilatancy is completely suppressed and thus contraction occurs throughout shearing. In fact, the combined behavior (i.e. dilative initially and contractive afterward) was observed to a less extent for the ash mixtures with higher fly ash content (i.e. lower bottom ash content), particularly at moderate to high confining stress. Accordingly, it appears that bottom ash plays a role in the transition from dilative to contractive behavior, which is likely associated with the fact that bottom ash is highly crushable in shearing.

b. Ash mixtures compacted at $\mathrm{R}=90 \%$

The ash mixtures compacted at $\mathrm{R}=90 \%$ show distinct characteristics in both the stress-strain and volume change behavior from those at $\mathrm{R}=95 \%$. Figure 4.35 through 4.37 display the stress-strain and volumetric versus axial strain curves for fly ash samples $(\mathrm{F}=100 \%)$. As shown in the Figures, the overall behavior is similar to that of a granular soil in a loose state. The volumetric strains are contractive throughout shearing. The deviatoric stress increases gradually up to a peak level and then stays practically unchanged with increasing axial strain. For some samples tested at low confining stress, slight dilation and an accordingly small post-peak reduction in the deviatoric stress is observed (Figure 4.36 and Figure 4.37). The magnitudes of the peak deviatoric stress, however, are significantly less in comparison with those achieved at $\mathrm{R}=95 \%$. The decrease in volume increases as confining stress increases. Brown plant fly ash exhibits a relatively large volume decrease with increasing confining stress as compared with fly ashes from other plants. As discussed in Section 4.8.1, this may be because the 
agglomeration of particles rich in the Brown plant fly ash undergoes crushing, contributing to the volume decrease.

As the fly ash content decreases to $75 \%(\mathrm{~F}=75 \%, \mathrm{~B}=25 \%)$ and $50 \%(\mathrm{~F}=50 \%$, $\mathrm{B}=50 \%$ ) (Figure 4.38 through 4.41 ), the behavior of ash mixtures becomes slightly less stiff. The trend is more noticeable in the Wabash river plant ash. Initial slopes of the stress-strain curves decrease gradually and contractive volumetric strains increase as the fly ash content decreases (Figure 4.35, 4.38, and 4.40). However, the peak deviatoric stresses changed increasingly with changing the fly ash content. Volumetric behaviors were contractive at all three levels of confining stress and, at the higher confining stresses, larger volume reductions were observed.

\section{$\underline{\text { Peak Friction Angle } \phi_{\text {peak }}^{\prime}}$}

The peak friction angle $\phi_{p}^{\prime}$ is a measure of the maximum shear strength that the material can develop. For dilative behavior, $\phi_{p}^{\prime}$ is associated with the maximum rate of dilation, which normally develops at relatively small strains (Wood 1990, Salgado et al. 2000). On the other hand, for an ideal contractive behavior, $\phi_{p}^{\prime}$ coincides with $\phi_{c}^{\prime}$, occurring at large strains.

As indicated in Table 4.16 and 4.17, the peak friction angle $\phi_{p}^{\prime}$ for ash mixtures is a function of the relative compaction $\mathrm{R}$, the confining pressure, and the fly ash content $\mathrm{F}$, in order of decreasing significance. The reduction of relative compaction from $95 \%$ to $90 \%$ decreases $\phi_{p}^{\prime}$ significantly. Also, $\phi_{p}^{\prime}$ decreases as the confining stress increases from $50 \mathrm{kPa}$ to $200 \mathrm{kPa}$. The samples at $\mathrm{R}=95 \%$ display notable reductions in $\phi_{p}^{\prime}$ with 
Wabash River Plant

CID Triaxial ( $F=100 \%, R=90 \%)$

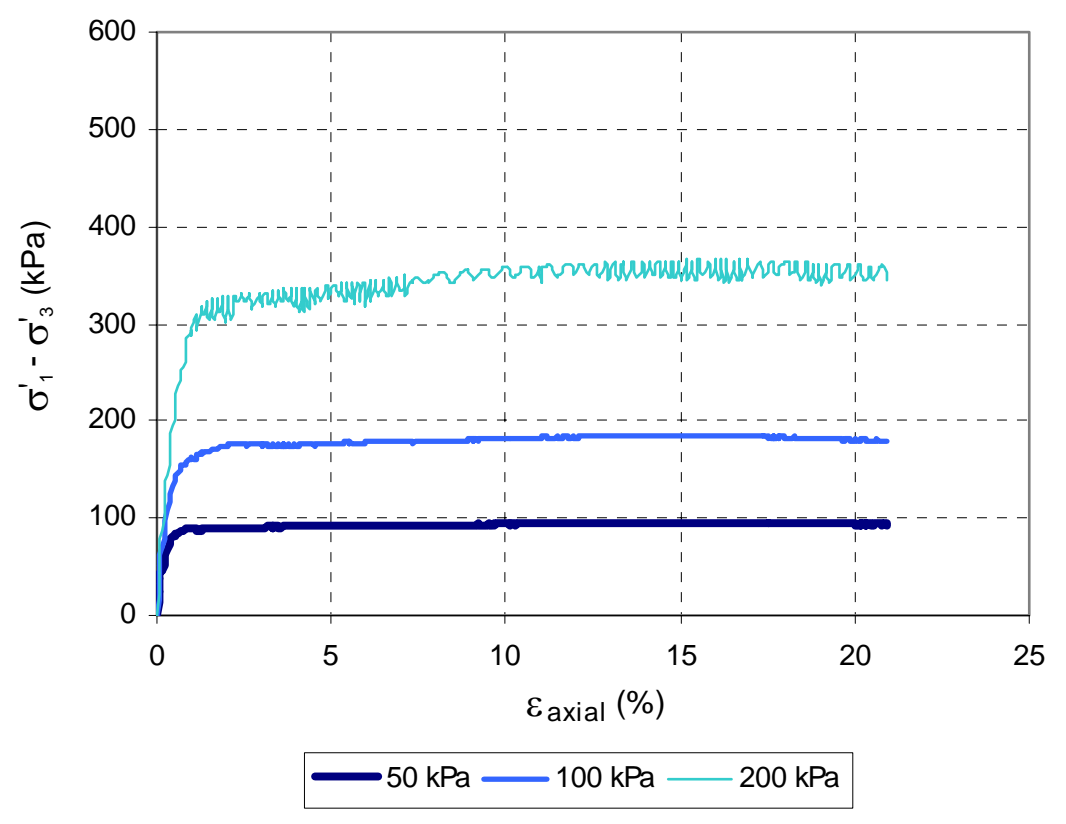

(a)

Wabash River Plant

CID Triaxial (F=100\%, $\mathrm{R}=90 \%)$

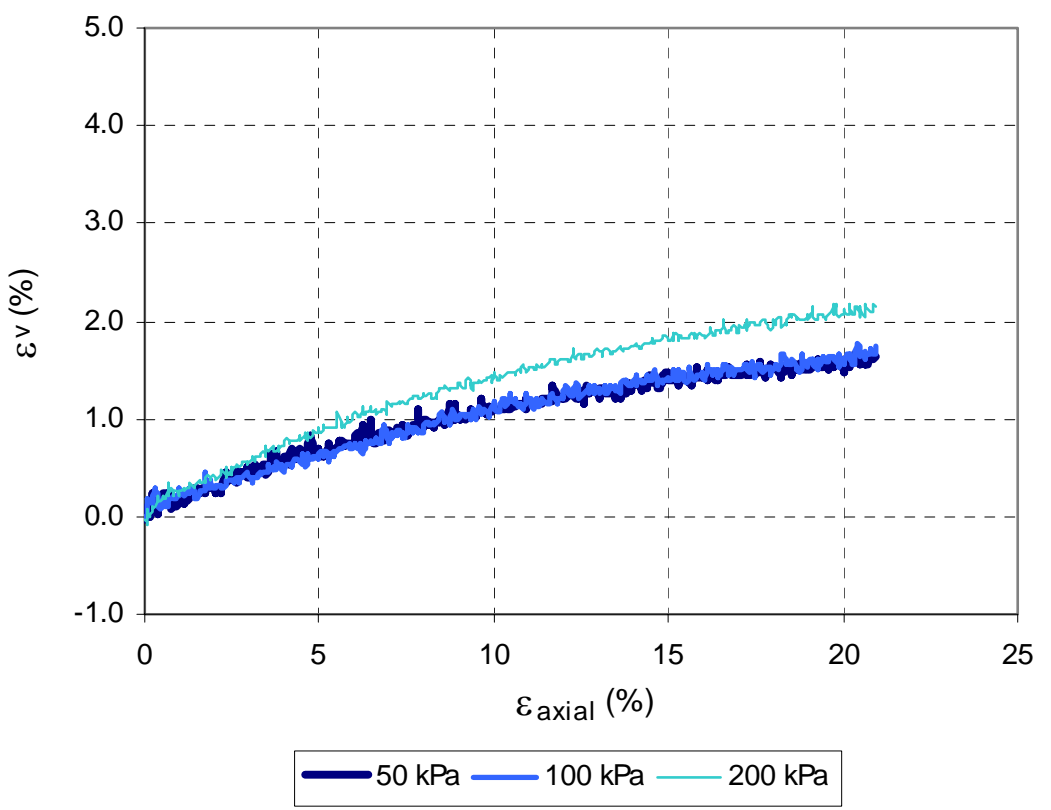

(b)

Figure 4.35 CID Triaxial Tests on $\mathrm{F}=100 \%$ from the Wabash River Plant $(\mathrm{R}=90 \%)$ : (a) Deviatoric Stress vs. Axial Strain (b) Volumetric Strain vs. Axial Strain. 
A.B. Brown Plant

CID Triaxial $(F=100 \%, R=90 \%)$

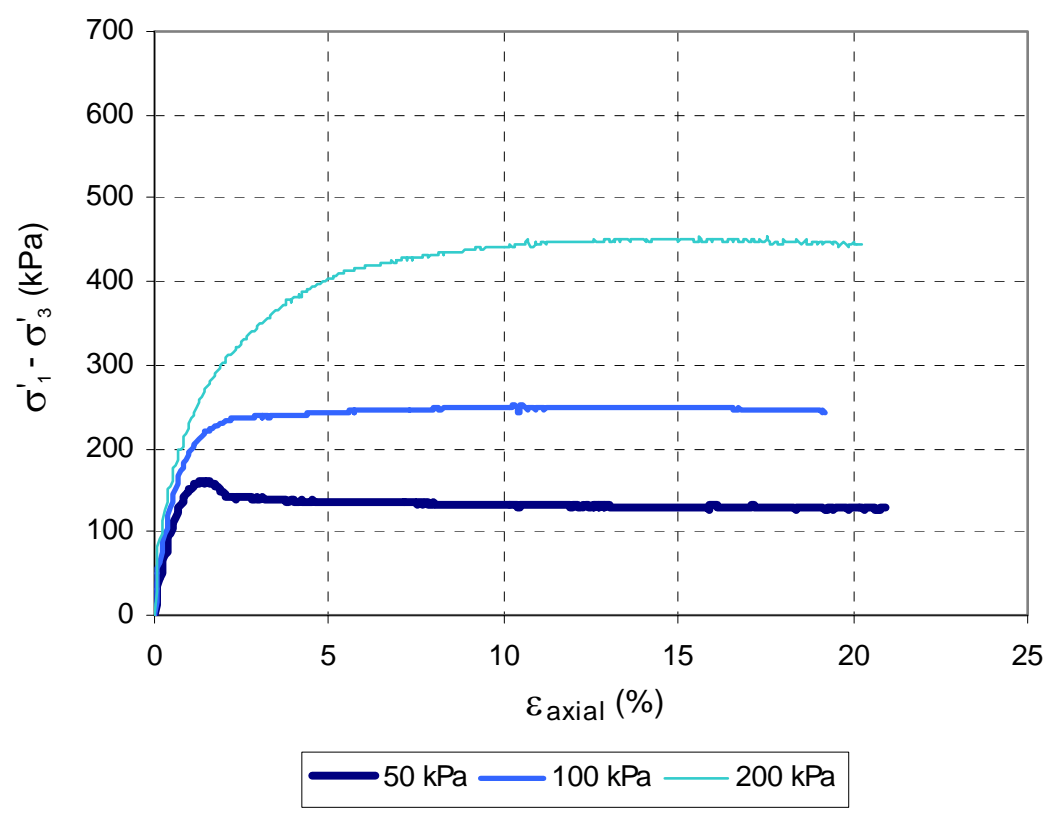

(a)

A.B. Brown Plant

CID Triaxial $(F=100 \%, R=90 \%)$

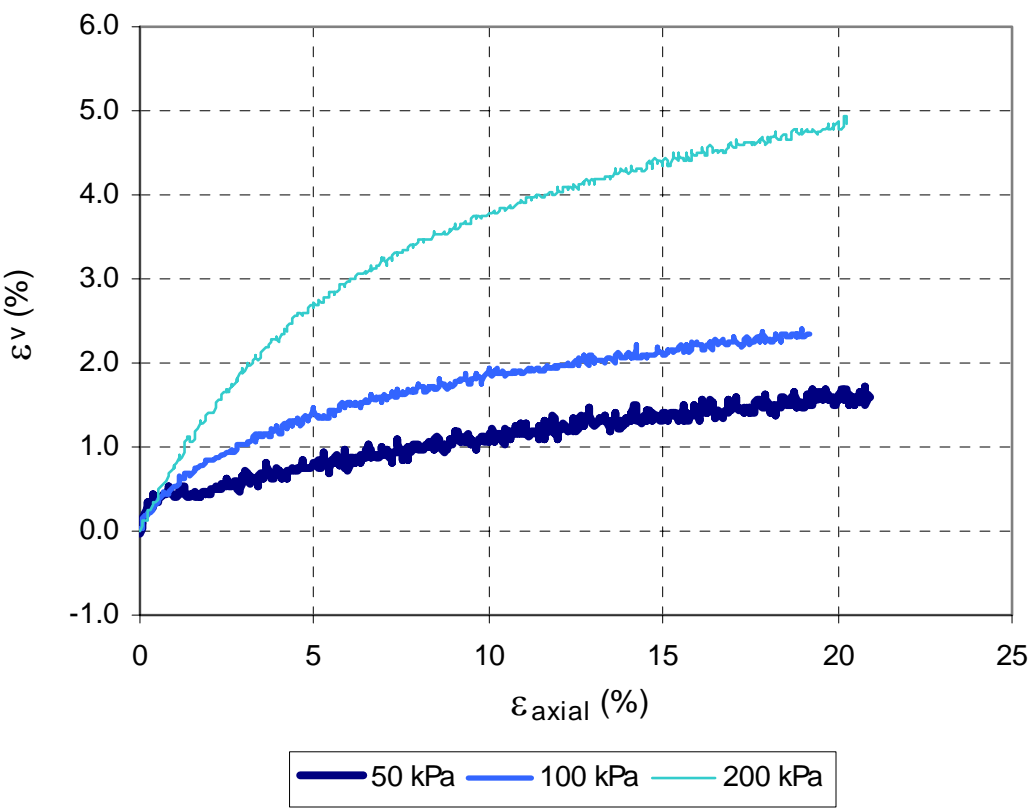

(b)

Figure 4.36 CID Triaxial Tests on $\mathrm{F}=100 \%$ from the A.B.Brown Plant $(\mathrm{R}=90 \%)$ : (a) Deviatoric Stress vs. Axial Strain (b) Volumetric Strain vs. Axial Strain. 
F.B. Culley Plant

CID Triaxial ( $\mathrm{F}=100 \%, \mathrm{R}=90 \%)$

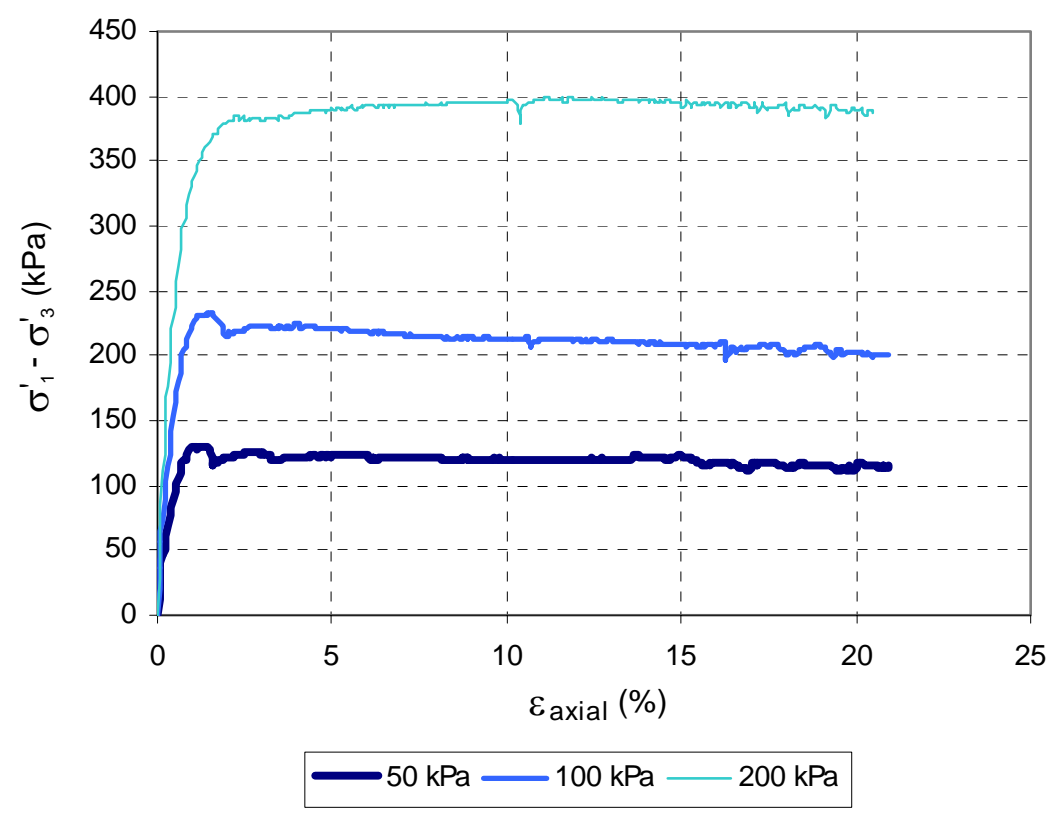

(a)

F.B. Culley Plant

CID Triaxial $(\mathrm{F}=100 \%, \mathrm{R}=90 \%)$

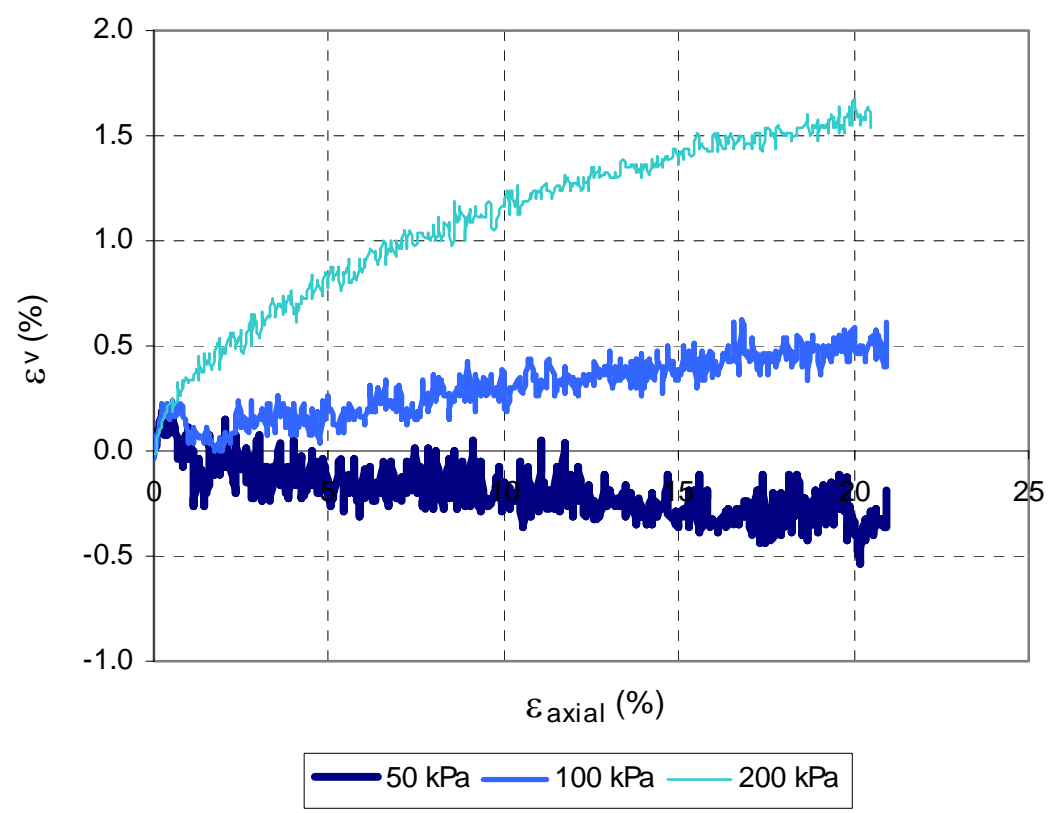

(b)

Figure 4.37 CID Triaxial Tests on $F=100 \%$ from the F.B.Culley Plant $(\mathrm{R}=90 \%)$ : (a) Deviatoric Stress vs. Axial Strain (b) Volumetric Strain vs. Axial Strain. 
Wabash River Plant

CID Triaxial ( $F=75 \%, R=90 \%)$

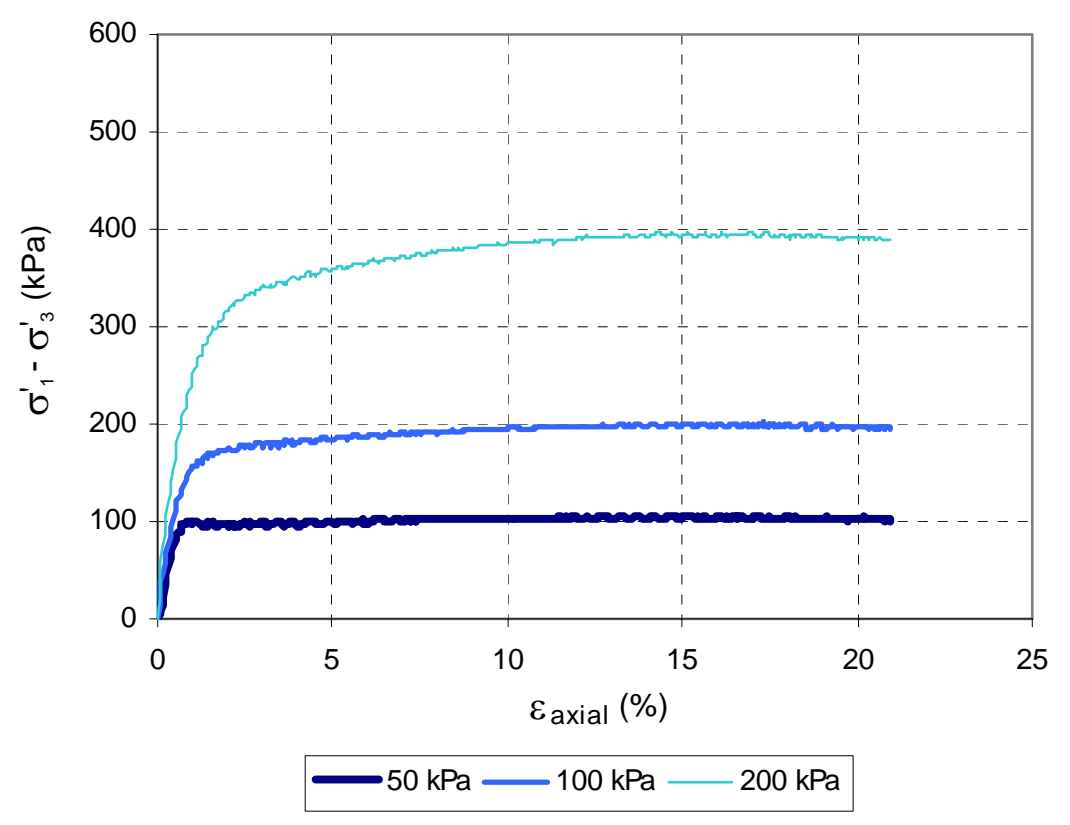

(a)

Wabash River Plant

CID Triaxial ( $F=75 \%, R=90 \%)$

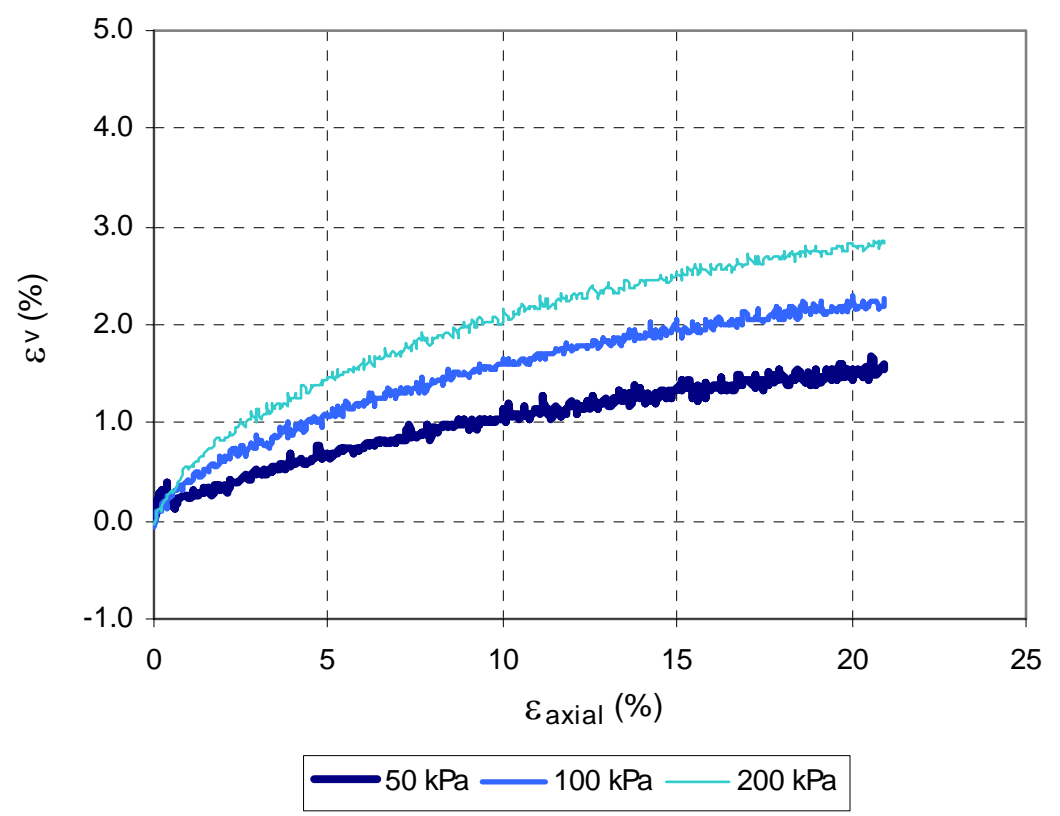

(b)

Figure 4.38 CID Triaxial Tests on $\mathrm{F}=75 \%, \mathrm{~B}=25 \%$ from the Wabash River Plant $(\mathrm{R}=$ 90\%): (a) Deviatoric Stress vs. Axial Strain (b) Volumetric Strain vs. Axial Strain. 
A.B. Brown Plant

CID Triaxial $(\mathrm{F}=75 \%, \mathrm{R}=90 \%)$

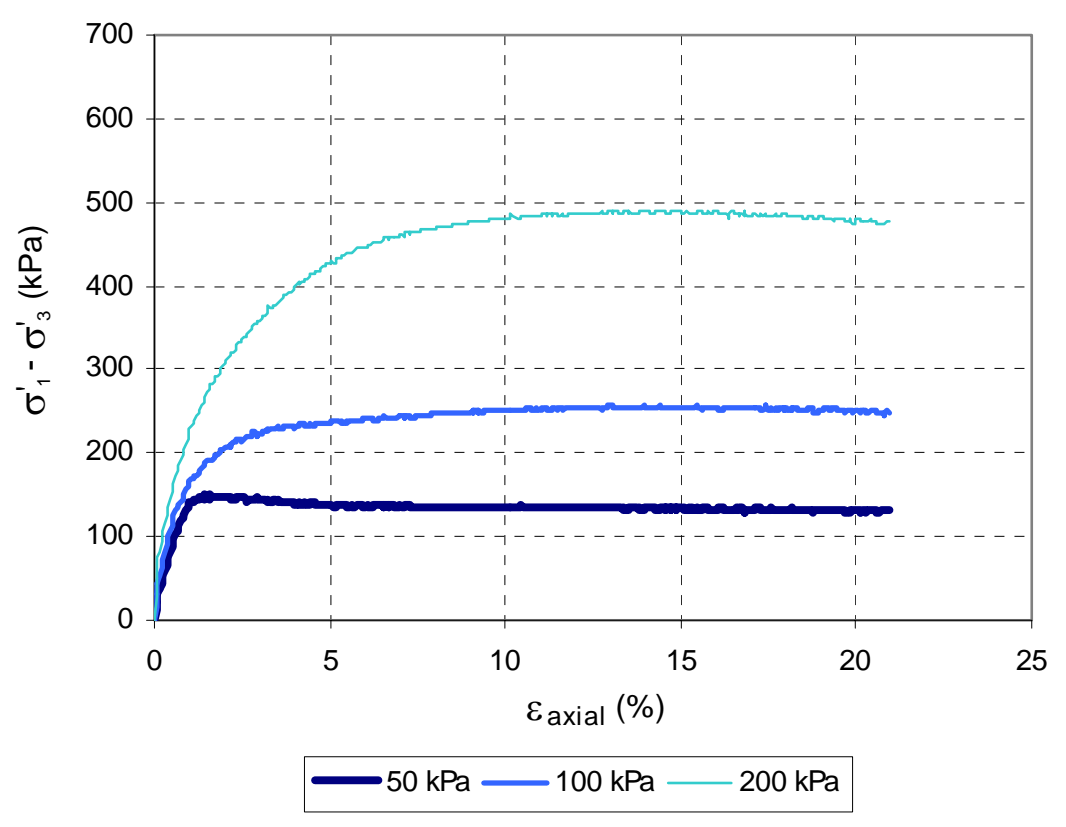

(a)

A.B. Brown Plant

CID Triaxial $(\mathrm{F}=75 \%, \mathrm{R}=90 \%)$

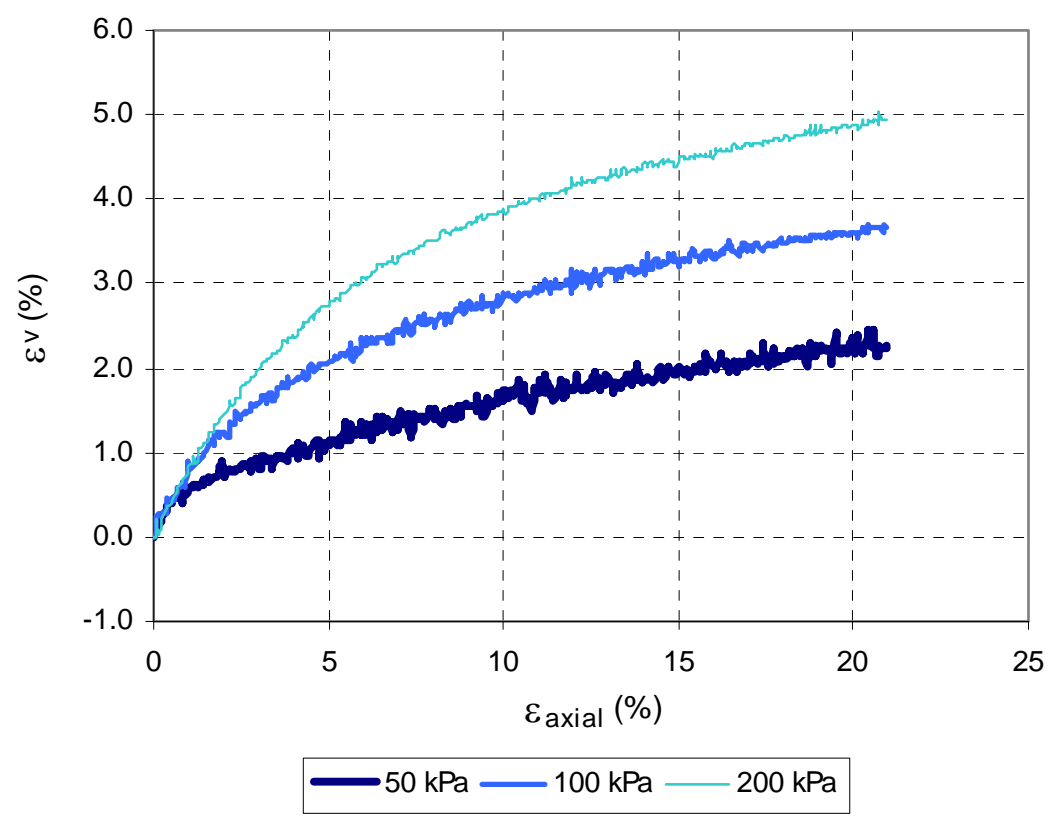

(b)

Figure 4.39 CID Triaxial Tests on $\mathrm{F}=75 \%, \mathrm{~B}=25 \%$ from the A.B.Brown Plant $(\mathrm{R}=$ 90\%): (a) Deviatoric Stress vs. Axial Strain (b) Volumetric Strain vs. Axial Strain. 
Wabash River Plant

CID Triaxial ( $F=50 \%, R=90 \%)$

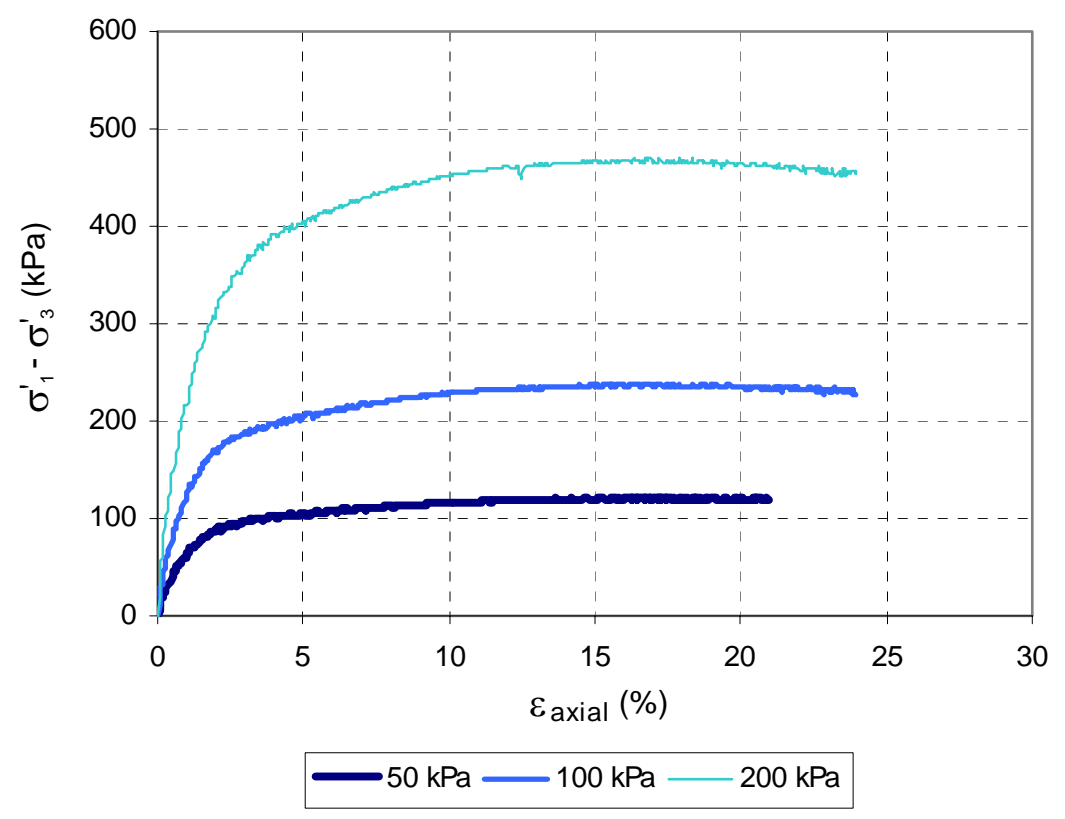

(a)

Wabash River Plant

CID Triaxial $(F=50 \%, R=90 \%)$

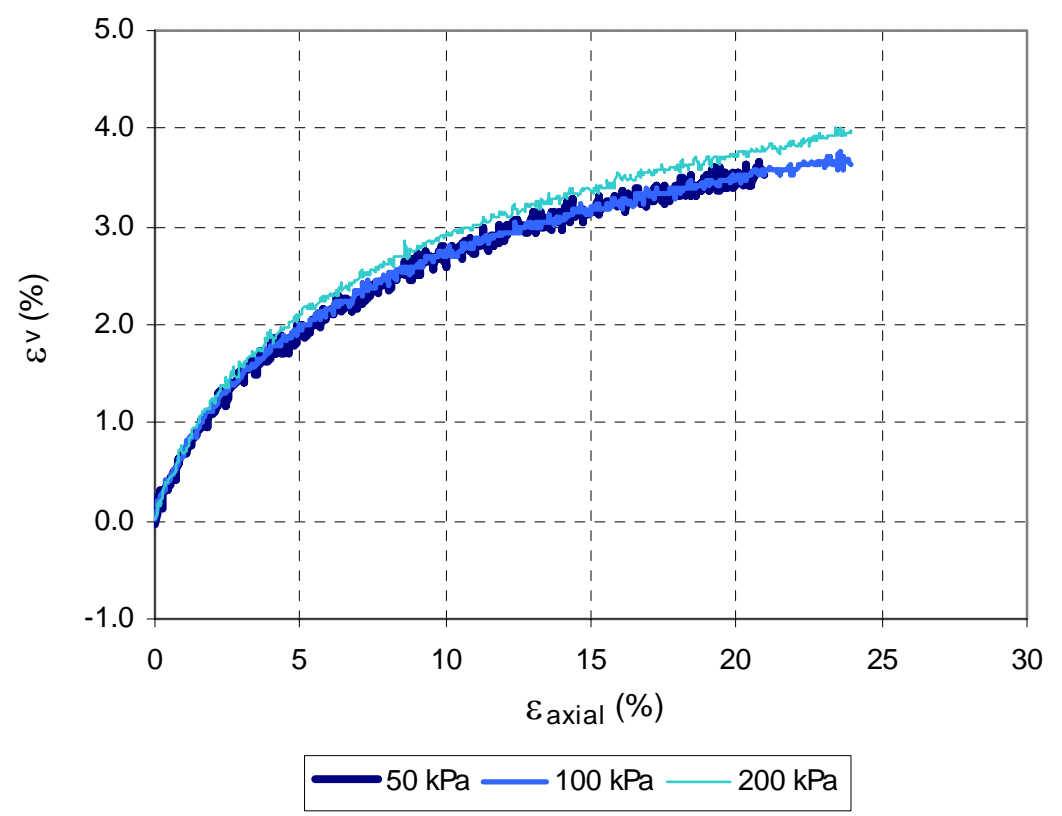

(b)

Figure 4.40 CID Triaxial Tests on $\mathrm{F}=50 \%, \mathrm{~B}=50 \%$ from the Wabash River Plant $(\mathrm{R}=$ 90\%): (a) Deviatoric Stress vs. Axial Strain (b) Volumetric Strain vs. Axial Strain. 
A.B. Brown Plant

CID Triaxial $(\mathrm{F}=50 \%, \mathrm{R}=90 \%)$

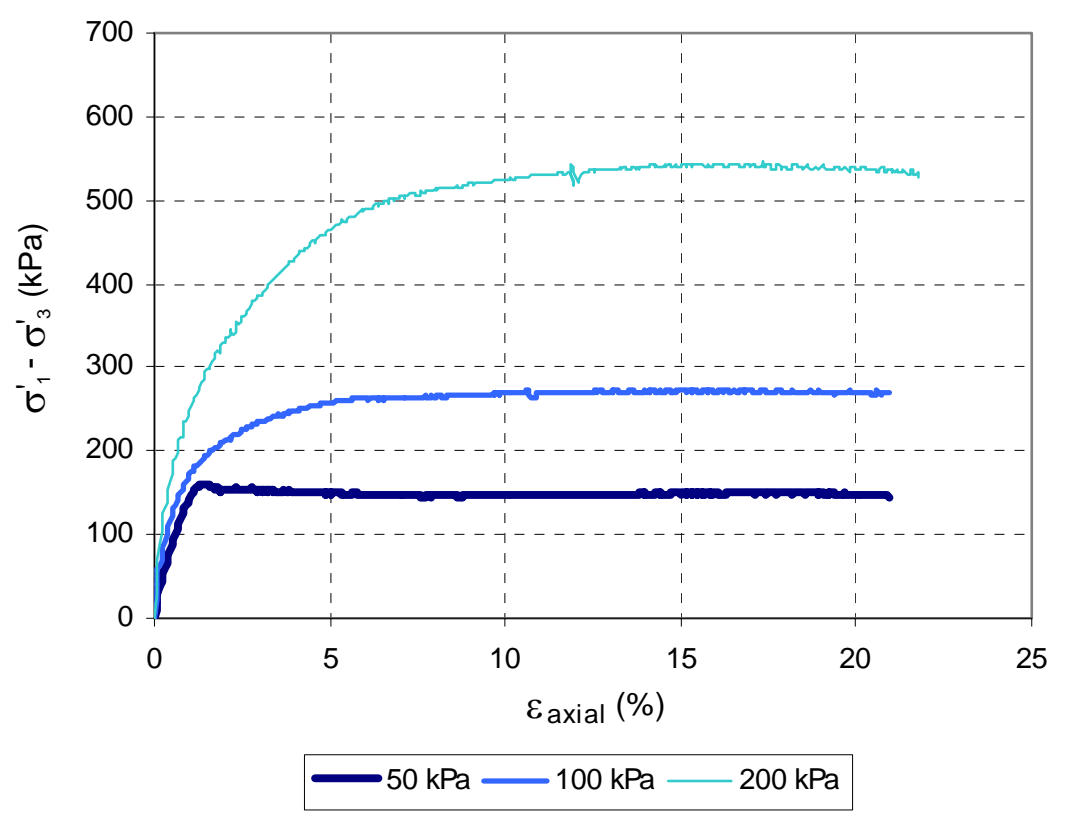

(a)

A.B. Brown Plant

CID Triaxial $(\mathrm{F}=50 \%, \mathrm{R}=90 \%)$

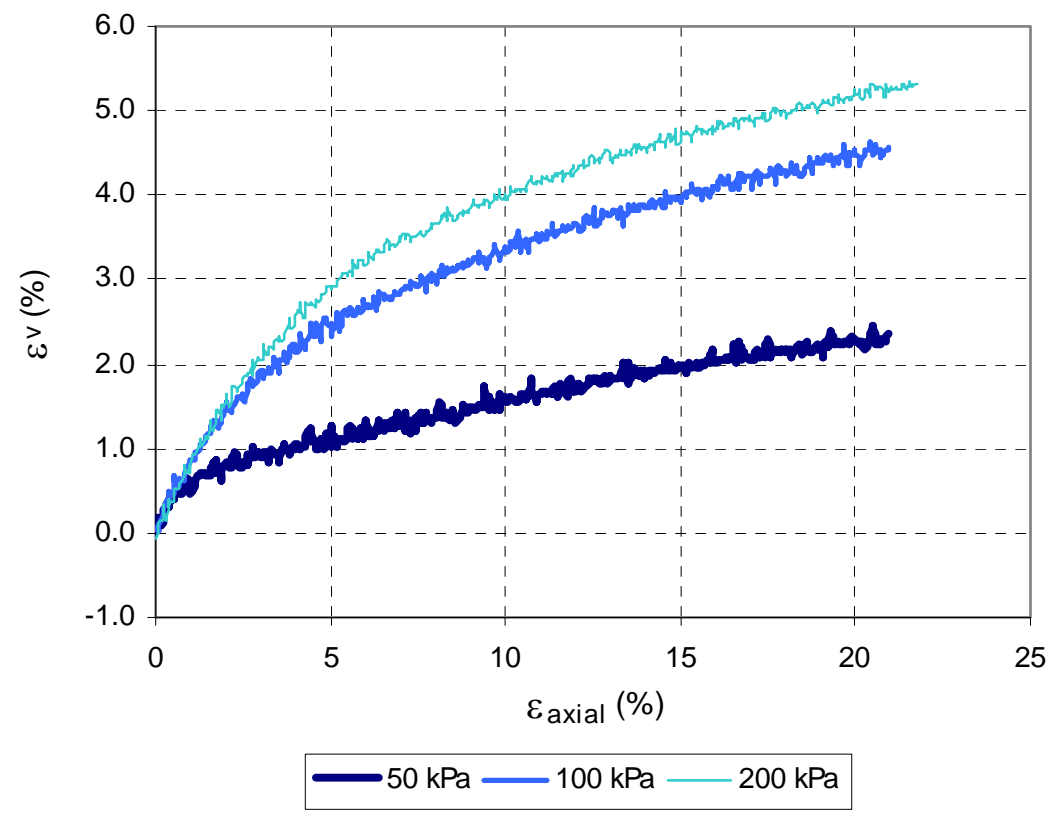

(b)

Figure 4.41 CID Triaxial Tests on $\mathrm{F}=50 \%, \mathrm{~B}=50 \%$ from the A.B.Brown Plant $(\mathrm{R}=$ 90\%): (a) Deviatoric Stress vs. Axial Strain (b) Volumetric Strain vs. Axial Strain. 
Table 4.16 Results of CID Triaxial Tests (Peak Friction Angles of Ash Mixtures Compacted at $\mathrm{R}=95 \%$ )

\begin{tabular}{|c|c|c|c|}
\hline Ash Source & $\begin{array}{c}\text { Mixture } \\
\text { Composition }\end{array}$ & $\begin{array}{c}\text { Confining Stress, } \\
\sigma^{\prime}{ }_{3}(\mathrm{kPa})\end{array}$ & $\begin{array}{c}\text { Peak Friction Angle } \\
\phi_{\text {peak }}^{\prime}(\text { degree })\end{array}$ \\
\hline \multirow{9}{*}{ Wabash River Plant } & \multirow{3}{*}{ F100 } & 50 & 35.6 \\
\hline & & 100 & 34.7 \\
\hline & & 200 & 33.5 \\
\hline & \multirow{3}{*}{ F75 B25 } & 50 & 37.2 \\
\hline & & 100 & 36.7 \\
\hline & & 200 & 33.6 \\
\hline & \multirow{3}{*}{ F50 B50 } & 50 & 39.0 \\
\hline & & 100 & 35.1 \\
\hline & & 200 & 33.5 \\
\hline \multirow{9}{*}{ A.B. Brown Plant } & \multirow{3}{*}{ F100 } & 50 & 47.1 \\
\hline & & 100 & 39.1 \\
\hline & & 200 & 35.5 \\
\hline & \multirow{3}{*}{ F75 B25 } & 50 & 46.0 \\
\hline & & 100 & 41.4 \\
\hline & & 200 & 36.6 \\
\hline & \multirow{3}{*}{ F50 B50 } & 50 & 47.5 \\
\hline & & 100 & 41.9 \\
\hline & & 200 & 37.3 \\
\hline \multirow{3}{*}{ F.B. Culley Plant } & \multirow{3}{*}{ F100 } & 50 & 45.1 \\
\hline & & 100 & 41.0 \\
\hline & & 200 & 37.4 \\
\hline
\end{tabular}


Table 4.17 Results of CID Triaxial Tests (Peak Friction Angles of Ash Mixtures Compacted at $\mathrm{R}=90 \%$ ).

\begin{tabular}{|c|c|c|c|}
\hline Ash Source & $\begin{array}{c}\text { Mixture } \\
\text { Composition }\end{array}$ & $\begin{array}{c}\text { Confining Stress, } \\
\sigma_{3}^{\prime}(\mathrm{kPa})\end{array}$ & $\begin{array}{c}\text { Peak Friction Angle, } \\
\phi_{\text {peak }}^{\prime}(\text { degree })\end{array}$ \\
\hline \multirow{9}{*}{ Wabash River Plant } & \multirow{3}{*}{ F100 } & 50 & 28.8 \\
\hline & & 100 & 28.6 \\
\hline & & 200 & 27.9 \\
\hline & \multirow{3}{*}{ F75 B25 } & 50 & 30.2 \\
\hline & & 100 & 30.0 \\
\hline & & 200 & 29.9 \\
\hline & \multirow{3}{*}{ F50 B50 } & 50 & 32.9 \\
\hline & & 100 & 32.7 \\
\hline & & 200 & 32.4 \\
\hline \multirow{9}{*}{ A.B. Brown Plant } & \multirow{3}{*}{ F100 } & 50 & 37.9 \\
\hline & & 100 & 33.6 \\
\hline & & 200 & 32.1 \\
\hline & \multirow{3}{*}{ F75 B25 } & 50 & 36.8 \\
\hline & & 100 & 33.9 \\
\hline & & 200 & 33.4 \\
\hline & \multirow{3}{*}{ F50 B50 } & 50 & 37.8 \\
\hline & & 100 & 35.3 \\
\hline & & 200 & 35.2 \\
\hline \multirow{3}{*}{ F.B. Culley Plant } & \multirow{3}{*}{ F100 } & 50 & 34.2 \\
\hline & & 100 & 32.4 \\
\hline & & 200 & 29.8 \\
\hline
\end{tabular}


increasing confining stress due to reduced dilatancy. As compared to the effects of relative compaction and confining stress, however, varying fly ash content does not appear to change $\phi_{p}^{\prime}$ significantly. As can be seen in Figure 4.42 and 4.43, the overall trend is that $\phi_{p}^{\prime}$ decreases slightly as the fly ash content increases from $50 \%$ to $75 \%$ and $100 \%$. The magnitude of the reduction in $\phi_{p}^{\prime}$, however, differs for $\mathrm{R}=95 \%$ and $90 \%$. For the contractive samples at $\mathrm{R}=90 \%, \phi_{p}^{\prime}$ decreases by about $3^{\circ}$ to $4^{\circ}$ on average for different confining stress as the fly ash content increases gradually from $50 \%$ to $100 \%$, while the decrease in $\phi_{p}^{\prime}$ for $\mathrm{R}=95 \%$ is about $1^{\circ}$ to $2^{\circ}$. The difference implies that for the dilative samples at $\mathrm{R}=95 \%$, the degree of dilatancy increased slightly with increasing fly ash content, as observed in the volumetric behavior (i.e. the degree of dilatancy decreased gradually as the fly ash content decreases).

It should be noted, however, that, for changing fly ash contents, the rate of decreasing $\phi_{p}^{\prime}$ with increasing confining stress depends on the ash source. For the Wabash river plant ash samples at $\mathrm{R}=95 \%$, the rate of decreasing $\phi_{p}^{\prime}$ with increasing confining stress decreases gradually as the fly ash content increases (i.e. as the bottom ash content decreases), which in turn implies that the decreasing rate in dilatancy with increasing confining stress increases as the bottom ash content increases from zero to 50\% (Figure 4.42(a)). The reduced dilatancy with increasing bottom ash content may be mainly due to crushing of bottom ash particles as explained previously. The degree of crushing appears to increase with increasing confining stress. For the Brown plant ash samples at $\mathrm{R}=95 \%$, however, no significant change is observed in the rate of decreasing $\phi_{p}^{\prime}$ with confining stress as the fly ash content increases (Figure 4.43(a)). But the 


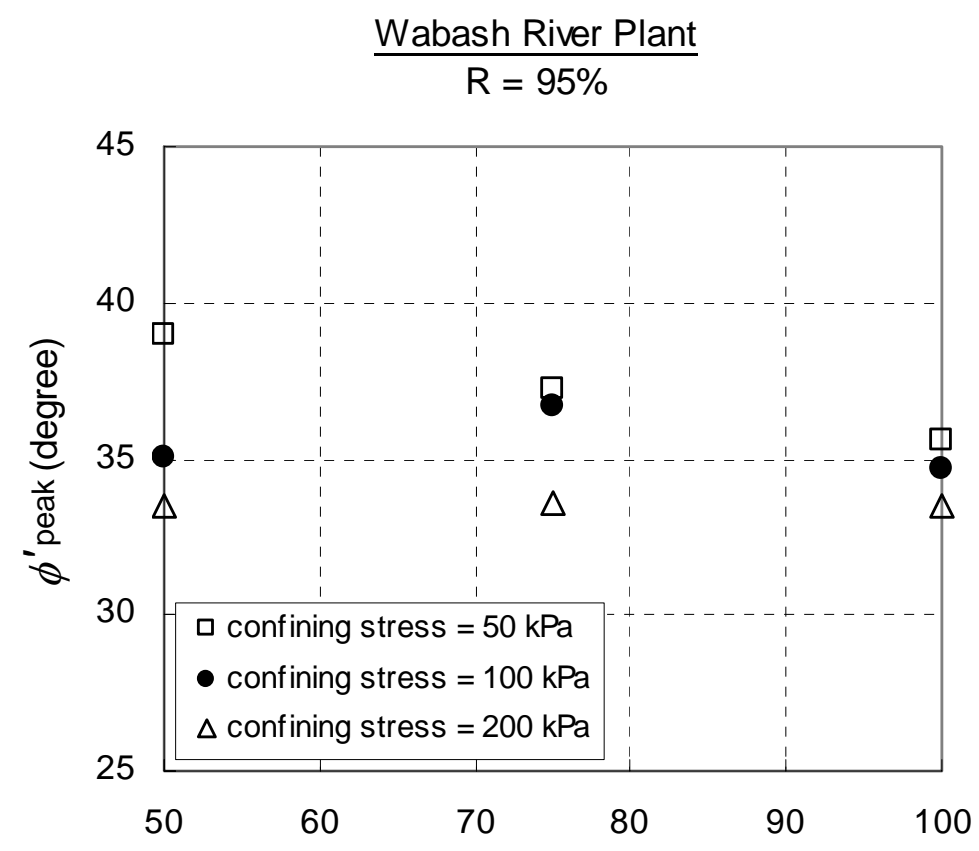

Fly ash content (\%)

(a)

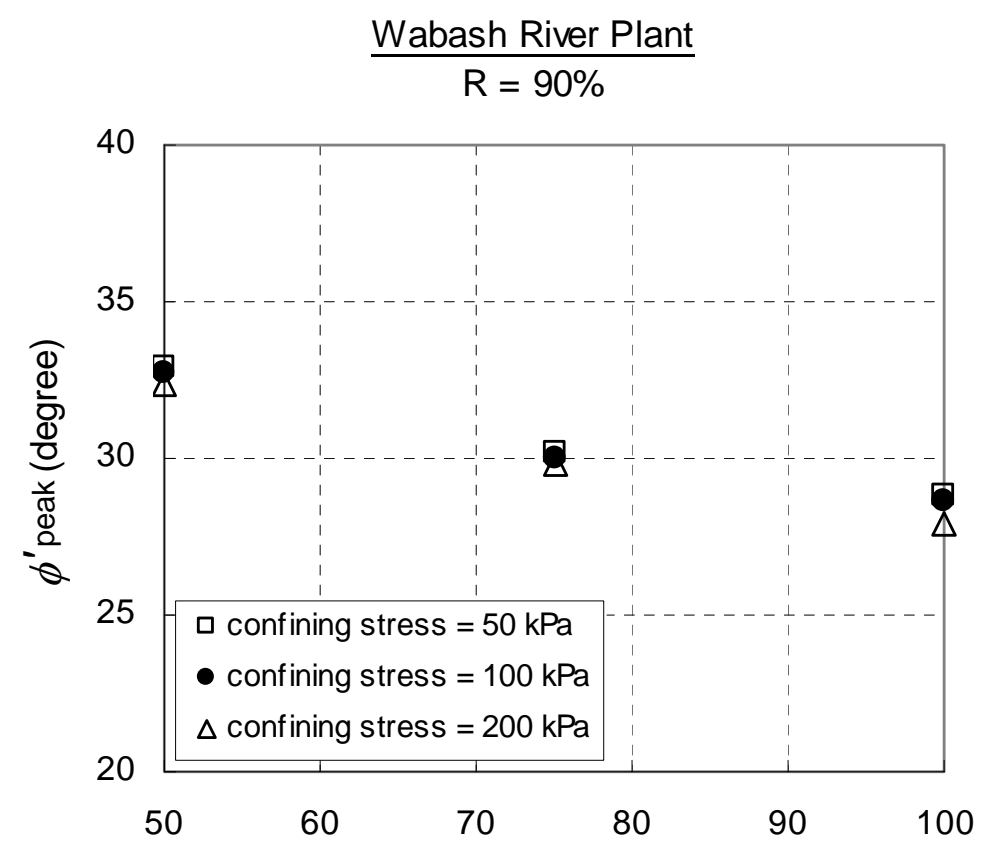

Fly ash content (\%)

(b)

Figure 4.42 Effects of Fly Ash Content and Confining Stress on Peak Friction Angle: (a) $\mathrm{R}=95 \%$ (b) $\mathrm{R}=90 \%$ (Wabash River Plant). 


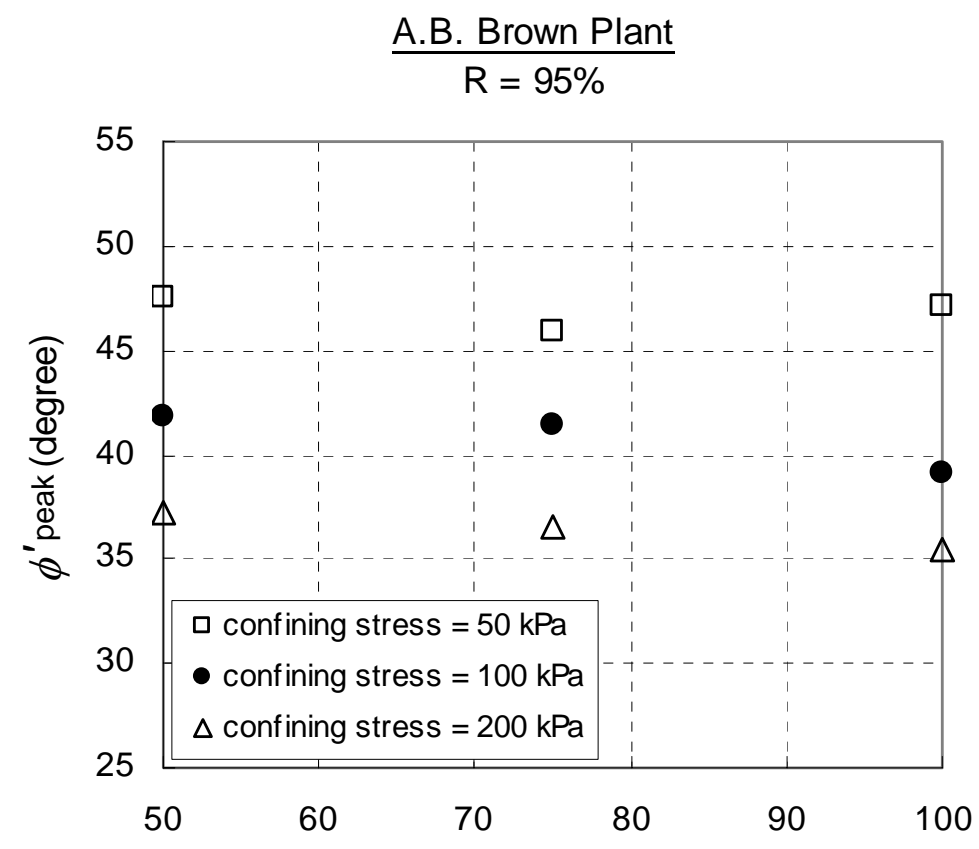

Fly ash content (\%)

(a)

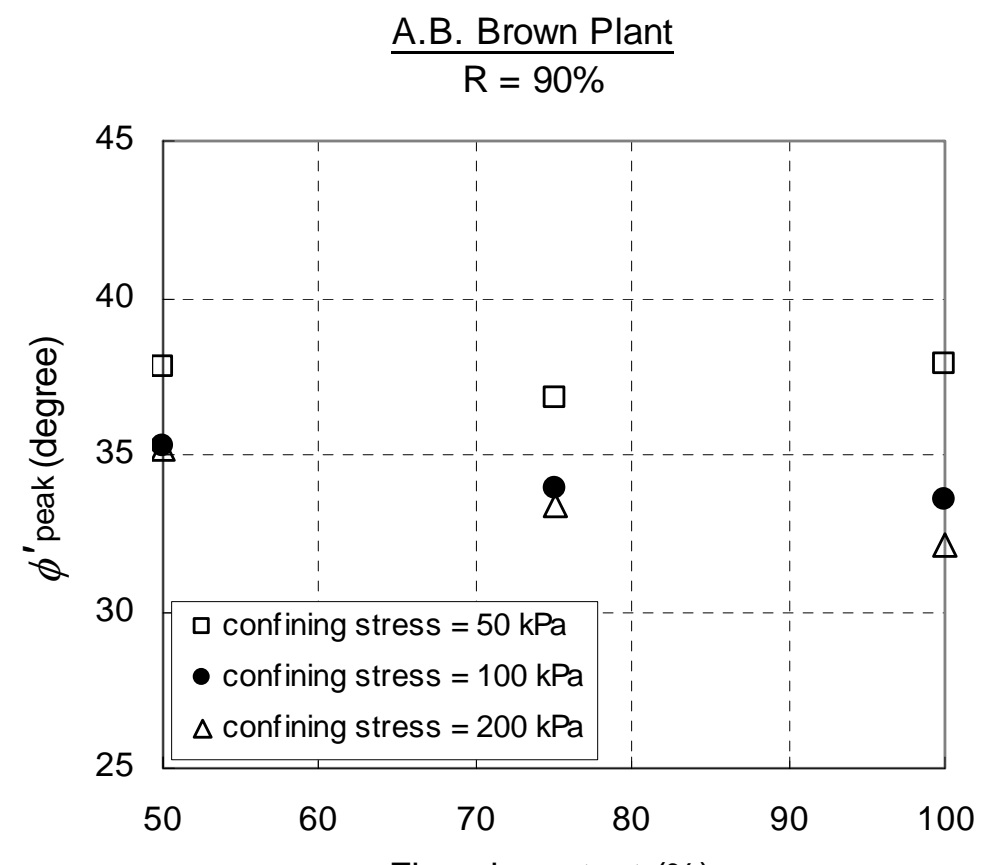

Fly ash content (\%)

(b)

Figure 4.43 Effects of Fly Ash Content and Confining Stress on Peak Friction Angle: (a) $\mathrm{R}=95 \%$ (b) $\mathrm{R}=90 \%$ (A.B.Brown Plant). 
reduction in $\phi_{p}^{\prime}$ due to increased confining stress is generally high compared with the Wabash river plant ash samples. It may suggest that more significant particle crushing occurred during shearing in the Brown plant ash samples, resulting in higher reduction in dilatancy and thus higher reduction in $\phi_{p}^{\prime}$ with increasing the confining stress. As discussed earlier, the Brown plant fly ash may contain a large portion of agglomerates of fine fly ash particles. Some of them may be weakly bound and thus broken down into finer particles under a certain pressure, while strongly bound particles may not undergo breakage even under relatively high pressures. As a result, the reason for the relatively minimal change in the rate of decreasing $\phi_{p}^{\prime}$ with increasing confining stress with respect to changing fly ash content may be because the effect of bottom ash crushing that contributes to the decrease in dilation was masked by crushing of fly ash agglomerates.

\section{Critical State Friction Angle $\phi_{c}^{\prime}$ critical}

The critical state friction angle $\phi_{c}^{\prime}$ provides a measure of the ultimate shearing strength that can be mobilized by the material. In case of ideal dilative behavior, after reaching peak strength, the strength decreases as the axial strain increases while the rate of dilation decreases. The angle $\phi_{c}^{\prime}$ is reached at large axial strains, as the material is sheared at a constant stress and a constant volume. This is particularly important for the stiff samples, which reach peak strength and then lose a significant portion of the strength at fairly small axial strains. For a granular material, the $\phi_{c}^{\prime}$ results from interparticle friction and particle rearrangement.

As can be seen in Figure $4.44, \phi^{\prime}$ decreases gradually as the fly ash content 


\section{Critical Friction Angle ( $\phi^{\prime}$ critical $)$}

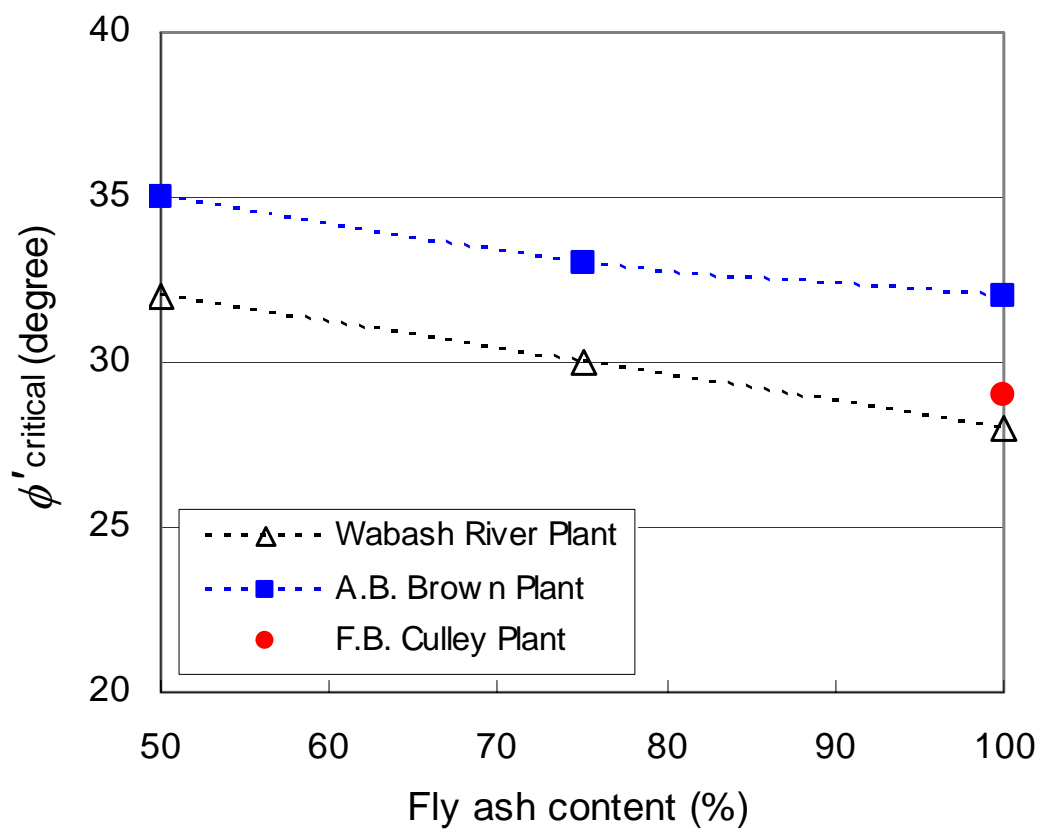

Figure 4.44 Effect of Fly Ash Content on Critical Friction Angle. 
increases from $50 \%$ to $75 \%$ and $100 \%$ (i.e. $\phi_{c}^{\prime}$ increases as the bottom ash content increases). Accordingly, it is apparent that addition of bottom ash increases $\phi_{c}^{\prime}$. This may be mainly due to angularity of bottom ash particles which provides higher resistance to the particle rearrangement for sustained shearing.

When a comparison is made between the samples from different ash sources, the Brown plant ash samples exhibit higher $\phi_{c}^{\prime}$ than the Wabash plant ash samples by as much as about $3^{\circ}$ to $4^{\circ}$. The differences appear to be primarily due to different magnitudes of $\phi_{c}^{\prime}$ between fly ashes, since the decreasing rate of $\phi_{c}^{\prime}$ with decreasing bottom ash content is very similar between two ash sources. In the Brown plant fly ash, the agglomerate of strongly bound particles, which does not undergo breakage at elevated pressures, may act as a large and angular particle with a rough surface. Therefore, the presence of the strong agglomerates may increase $\phi_{c}^{\prime}$.

Table 4.18 displays the values of $\phi_{c}^{\prime}$ for the ash mixture samples tested. For comparison, $\phi_{c}^{\prime}$ values for typical sands were also tabulated. As can be seen in Table 4.18, the range of $\phi_{c}^{\prime}$ for the ash mixtures (i.e. $28^{\circ}$ to $35^{\circ}$ ) is quite similar to that of sands (i.e. $29^{\circ}$ to $37^{\circ}$ ).

The Bolton Correlation for Friction Angle and Dilatancy

The peak shear strength may be considered as the summation of two components: the critical state shear strength and dilatancy. Following Rowe's stress-dilatancy theory (Rowe 1962; De Josselin de Jong 1976), Bolton (1986) reviewed a large number of triaxial and plane-strain test results and proposed a simple relationship between the peak 
Table 4.18 Results of CID Triaxial Tests (Critical Friction Angles).

\begin{tabular}{ccc} 
Ash Source & $\begin{array}{c}\text { Mixture } \\
\text { Composition }\end{array}$ & $\begin{array}{c}\text { Critical State Friction Angle, } \\
\phi_{\text {critical }} \text { (degree) }\end{array}$ \\
\hline \hline \multirow{2}{*}{ Wabash River Plant } & F100 & 28 \\
& F75 B25 & 30 \\
& F50 B50 & 32 \\
\hline A.B. Brown Plant & F100 & 32 \\
& F75 B25 & 33 \\
\hline F.B. Culley Plant & F50 B50 & 35 \\
\hline \hline
\end{tabular}

Ottawa sand: $29^{\circ}$ (Salgado 2000)

Berlin sand: $33^{\circ}$ (Bolton 1986)

Monterey no. 0 sand: $37^{\circ}$ (Bolton 1986)

friction angle $\phi_{p}^{\prime}$, the critical friction angle $\phi_{c}^{\prime}$, and the peak dilatancy angle $\psi$ :

$$
\phi_{p}^{\prime}=\phi_{c}^{\prime}+0.8 \psi_{p}
$$

Eq. (4.3) can be rewritten for both triaxial and plane-strain tests by using a quantity $I_{R}$, defined as the dilatancy index:

$$
\phi_{p}^{\prime}=\phi_{c}^{\prime}+5 I_{R}
$$

for plane-strain conditions, and

$$
\phi_{p}^{\prime}=\phi_{c}^{\prime}+3 I_{R}
$$

for triaxial conditions.

The dilatancy index $I_{R}$ is given, for both triaxial and plane-strain test, by 


$$
I_{R}=-\frac{10}{3}\left(\frac{d \varepsilon_{v}}{d \varepsilon_{1}}\right)_{\max }
$$

and is related to the relative density and effective confining stress level through

$$
I_{R}=I_{D}\left(Q-\ln \frac{100 p_{p}^{\prime}}{p_{A}^{\prime}}\right)-R
$$

Where $I_{D}=$ relative density expressed as a number between 0 and 1

$p_{p}^{\prime}=$ mean effective stress at peak strength

$p_{A}^{\prime}=$ reference stress $(=100 \mathrm{kPa}=0.1 \mathrm{MPa} \approx 1$ tsf $)$ in the same units as $\mathrm{p}_{\mathrm{p}}^{\prime}$.

$Q$ and $R=$ fitting parameters

Substituting (4.7) into (4.5) and rearranging, the following linear equation is obtained.

$$
\frac{\phi_{p}-\phi_{c}}{3}+I_{D} \ln \left(\frac{100 p_{p}^{\prime}}{p_{A}^{\prime}}\right)=I_{D} Q-R
$$

Referring to (4.8), dilatancy increases with increasing $Q$ and decreases with increasing $R$. Bolton (1986) reported that $Q=10$ and $R=1$ provided a good fit for several different clean silica sands. Salgado et al. (2000) found that the presence of a small amount of silt (i.e. 5 to $10 \%$ ) can increase dilatancy and peak friction angles and proposed the values of $Q=9$ to 11 and $R=0.5$.

Equation (4.8) was applied to the tested fly ashes (i.e. $\mathrm{F}=100 \%$ ) to find $Q$ and $R$. It was believed that the relative density used in the correlation equation was reliable for $\mathrm{F}$ $=100 \%$. However for $\mathrm{F}=75 \%$ and $\mathrm{F}=50 \%$, there may have been errors in determining the maximum and minimum density due to particle segregation as discussed in Section 4.6. Figure 4.45 illustrates the linear fit produced to determine the $Q$ and $R$ values based on (4.8). The obtained values of $Q$ and $R$ were 17.1 and 5.8, respectively, which are both 


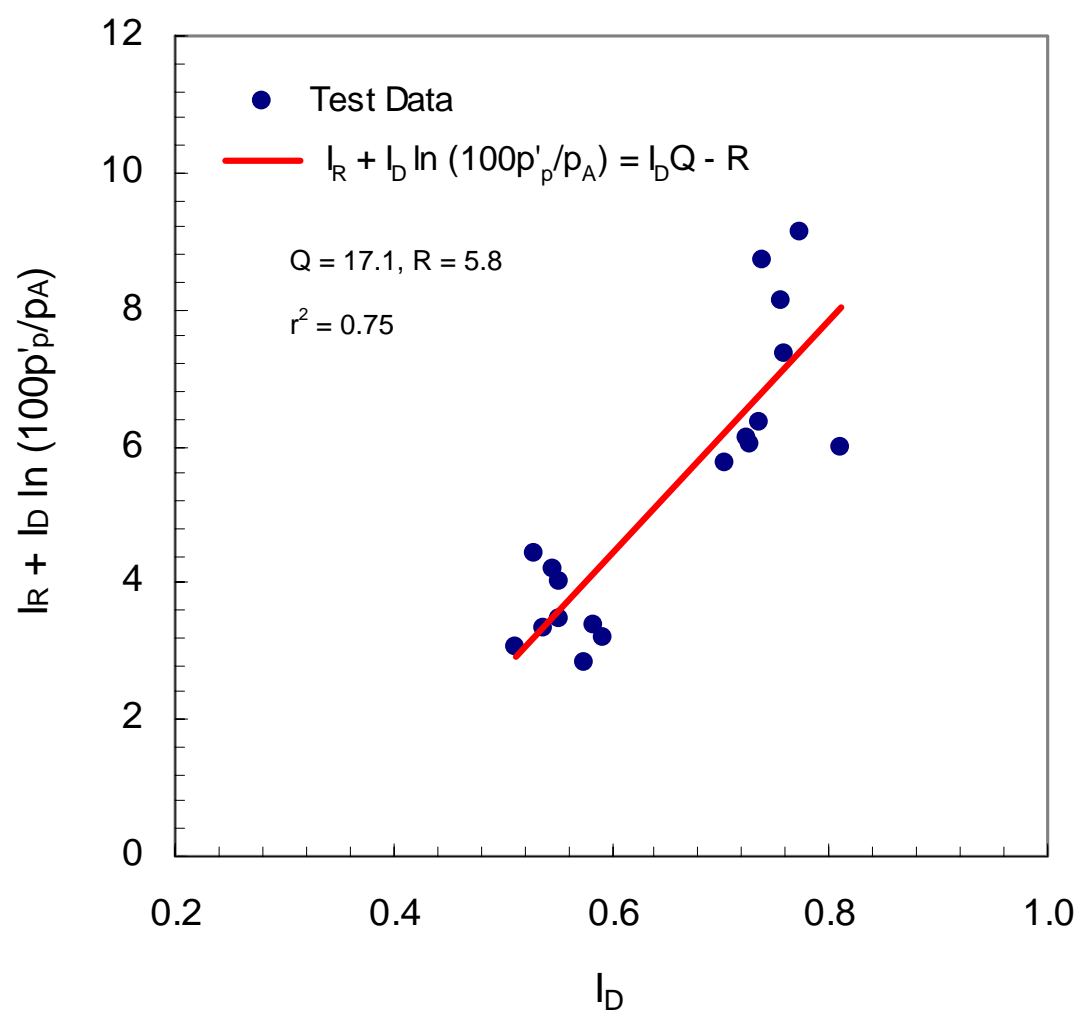

Figure 4.45 Visual Illustration of Q and R Values for Triaxial Tests on Fly Ashes. 
higher than those for sands. Comparing fly ash and sand, the high $Q$ and $R$ in fly ash may imply that, in the high relative density range (i.e. $>70 \%$ ), fly ash dilates more, while, as the relative density decreases, the degree of dilatancy becomes similar between fly ash and sand. For medium to low relative densities (i.e. $<50 \%$ ), less dilation occurs in fly ash.

\section{$\underline{4.10 \text { Corrosivity }}$}

For the investigation of corrosion potential, corrosivity tests were performed on the compacted ash mixtures, which involve the measurements of two corrosivity parameters: electrical resistivity and pH (ASTM G 57 and ASTM G 51). In a soil, in general, the corrosivity toward a buried metal object is dependent on a number of parameters, including its resistivity, water content, dissolved salts, $\mathrm{pH}$, presence of bacteria, and the amount of oxygen available at the metal surface. It is generally agreed that no one parameter can be used to accurately forecast the corrosivity of a particular soil. Nevertheless, electrical resistivity is commonly utilized as an indicator of the soil's corrosivity. Observations of soil drainage, and/or measurements of $\mathrm{pH}$, supplement resistivity measurements (Coburn 1987; Davie et al. 1996).

Table 4.19 lists the general relationship that exists between soil resistivity/pH and corrosion of ferrous metals. However, because of other factors, the relationship may not be always valid or considerable variation in the ranges tabulated can occur (Coburn 1987; Davie et al. 1996). 
Table 4.19 Soil Corrosivity Classification.

\begin{tabular}{cccccc}
\hline & \multicolumn{5}{c}{ Classification } \\
\cline { 2 - 6 } Parameter & $\begin{array}{c}\text { Little } \\
\text { Corrosive }\end{array}$ & $\begin{array}{c}\text { Mildly } \\
\text { Corrosive }\end{array}$ & $\begin{array}{c}\text { Moderately } \\
\text { Corrosive }\end{array}$ & Corrosive & $\begin{array}{c}\text { Very } \\
\text { Corrosive }\end{array}$ \\
\hline \hline Resistivity & $>10,000^{\mathrm{a}, \mathrm{b}}$ & $2,000-10,000^{\mathrm{a}}$ & $1,000-2,000^{\mathrm{a}}$ & $500-1,000^{\mathrm{a}}$ & $<500^{\mathrm{a}}$ \\
$(\mathrm{Ohm}-\mathrm{cm})$ & $5,000-10,000^{\mathrm{b}}$ & $2,000-5,000^{\mathrm{b}, \mathrm{c}}$ & $700-2,000^{\mathrm{b}, \mathrm{c}}$ & $<700^{\mathrm{b}, \mathrm{c}}$ \\
\hline $\mathrm{pH}$ & $>5.0$ and & $5.0-6.5^{\mathrm{a}}$ & $<5.0^{\mathrm{a}}$ \\
\hline
\end{tabular}

${ }^{a}$ American Petroleum Institute (1991)

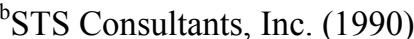

${ }^{\mathrm{c}}$ Coburn, S.K. (1987) 


\subsubsection{Electrical resistivity}

Electrical resistivities were measured for ash mixtures of fly ash contents of $50 \%$, $75 \%$, and $100 \%$. For each mixture sample, two values of the resistivity were obtained: one after compaction and the other after soaking following the first measurement. Table 4.20 shows the results of the resistivity measurements.

Table 4.20 Electrical Resistivities of Ash Mixtures.

\begin{tabular}{|c|c|c|c|}
\hline Ash Source & $\begin{array}{c}\text { Mixture } \\
\text { Composition } \\
\end{array}$ & Sample Condition & Resistivity (ohm-cm) \\
\hline \multirow{6}{*}{ Wabash River Plant } & \multirow[b]{2}{*}{ F100 } & As-compacted & 1,490 \\
\hline & & Soaked & 518 \\
\hline & \multirow{2}{*}{ F75 B25 } & As-compacted & 1,910 \\
\hline & & Soaked & 1,120 \\
\hline & \multirow{2}{*}{ F50 B50 } & As-compacted & 2,500 \\
\hline & & Soaked & 1,110 \\
\hline \multirow{6}{*}{ A.B. Brown Plant } & \multirow{2}{*}{ F100 } & As-compacted & 300 \\
\hline & & Soaked & 250 \\
\hline & \multirow[b]{2}{*}{ F75 B25 } & As-compacted & 440 \\
\hline & & Soaked & 341 \\
\hline & \multirow{2}{*}{ F50 B50 } & As-compacted & 689 \\
\hline & & Soaked & 393 \\
\hline \multirow{2}{*}{ F.B. Culley Plant } & \multirow{2}{*}{ F100 } & As-compacted & 576 \\
\hline & & Soaked & 248 \\
\hline
\end{tabular}

The results show that resistivity increases slightly with increasing bottom ash content. The Wabash river plant ash mixtures exhibit relatively high resistivities 
compared to the ash mixtures from other plants. The resistivity decreases when the ash mixture becomes soaked. When compared to the values in Table 4.19, however, the resistivities of the ash mixtures are generally low, falling within the ranges of "corrosive" to "very corrosive".

The resistivity is a function of water content and the concentration of currentcarrying soluble salts (or ions) (Palmer 1989; Edgar 1989; Davie 1996). High water contents typically produce low-resistivity since there are both larger areas of water for current to flow through and more complete hydrolysis of ions (Ke 1990). Therefore, the resistivity of a soil will have a minimum value when it is saturated. Also, the greater the soluble salts, the lower the soil resistivity. The study of soil corrosivity revealed that the most corrosive soils are those that contain large concentrations of soluble salts or free ion content in the water in the pore spaces. Also, coarse soils, i.e., most clean sands and gravels, which have good drainage and aeration, exhibit high electrical resistivity, whereas fine-grained soils, i.e., silts and clays have high water retention, poor drainage and aeration, exhibiting low resistivities. Thus, the resistivities of sands and gravels tend to decrease significantly when they contain fine grained soil particles. They can become lower in near-surface soils when pore water evaporates, leaving high concentrations of salts (Davie 1996).

The resistivities measured for the ash mixtures can be explained based on the corrosivity characteristics of soil mentioned above. For as-compacted mixture samples, the higher the fly ash contents, the higher the optimum compaction water contents and the lower the water-air permeability, resulting in lower resistivities with increasing fly ash content. The water content increased by soaking decreases the resistivity. 
Compaction water contents were similar for the ash mixtures with the same fly ash contents between different ash sources. Therefore, the relatively high resistivities in Wabash river plant ash appear to be because of fewer amounts of soluble ions in the ash compared with the ashes from other plants.

\subsection{2 pH}

$\mathrm{pH}$ was measured in each soaked ash mixture following the measurement of its resistivity. Table 4.21 displays the $\mathrm{pH}$ values of the ash mixtures.

Table $4.21 \mathrm{pH}$ Values of Ash Mixtures.

\begin{tabular}{ccc}
\hline Ash Source & $\begin{array}{c}\text { Mixture } \\
\text { Composition }\end{array}$ & $\mathrm{pH}$ \\
\hline \hline Wabash River Plant & F75 B25 & 11.9 \\
& F50 B50 & 10.9 \\
& F100 & 10.6 \\
\hline A.B. Brown Plant & F75 B25 & 10.0 \\
& F50 B50 & 9.8 \\
\hline F.B. Culley Plant & F100 & 9.3 \\
\hline
\end{tabular}

The results indicate that all the ash mixtures exhibit high alkalinity. The values decrease slightly with increasing bottom ash contents. The differences, however, are 
negligibly small. It is well known that an acid solution can cause a metal to dissolve, and the more acidic the solution, the higher the dissolution rate of the metal. Upon full hydrolysis, the acidic ions act as depolarizers, enhancing the rate of hydrogen evolution in the cathodic zone of the metal, as well as the rate of dissolution in the anodic zone of the metal (Ke 1990). Figure 4.46 shows the effect of solution $\mathrm{pH}$ upon the corrosion rate of iron (Scully 1990). The same conclusion can apply to the soil/water/air system (or ash/water/air system in this case). Attempts have been often made to relate corrosivity to the $\mathrm{pH}$ of the soil since J.W. Shipley and I.R. McHaffie (1924) first reported a relationship between soil acidity and the rate of iron corrosion. Now it is generally agreed that acid soils have higher corrosion potential. An EPA regulation states that solid waste exhibits the characteristics of corrosivity if a representative sample of the waste is aqueous and has a $\mathrm{pH}$ less than or equal to 2 or greater than or equal to 12.5 .

Based on the corrosivity criteria with respect to $\mathrm{pH}$ value, the ash mixtures would be classified as non-corrosive. As mentioned earlier, however, one single parameter may not accurately predict the corrosivity due to its complexity. Therefore, an overall evaluation of the corrosivity should be made considering more than one factor. 


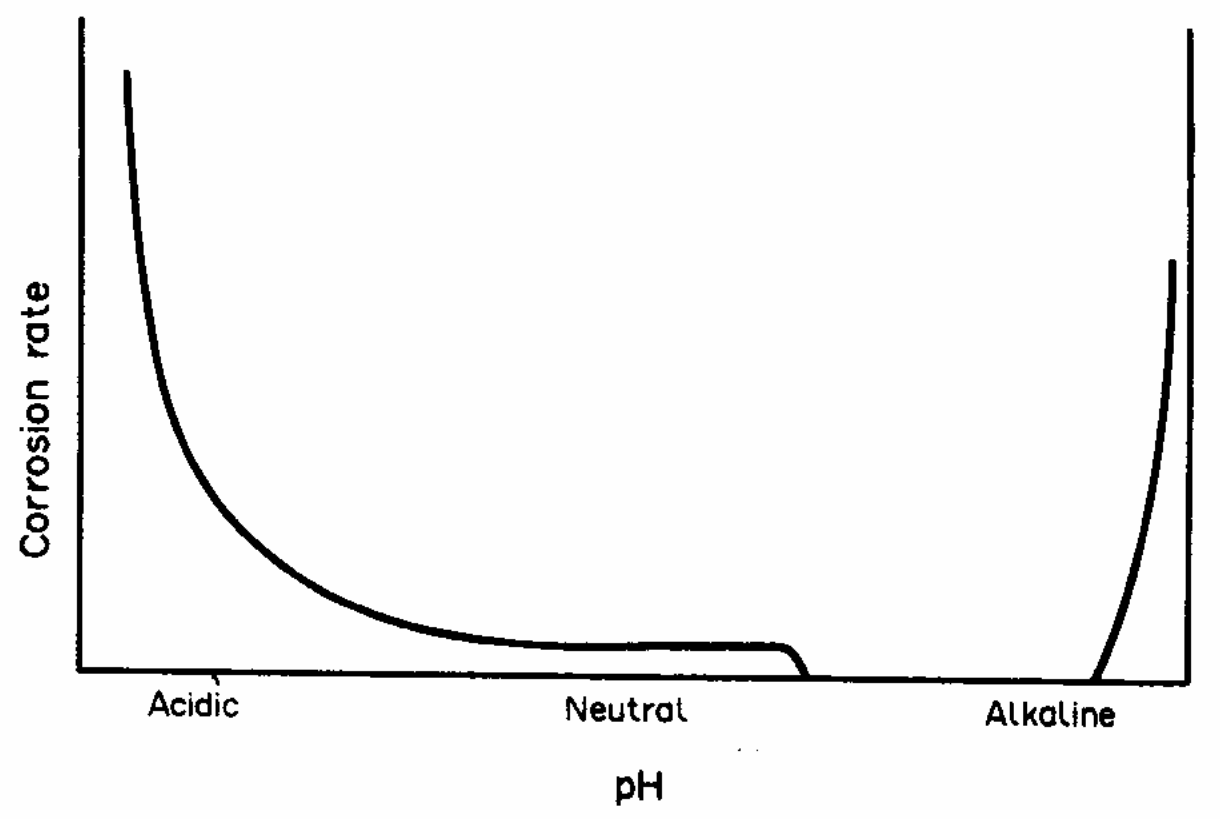

Figure 4.46 The Effect of Solution pH upon the Corrosion Rate of Iron (Scully 1990). 


\subsection{Summary}

Class F fly ash and bottom ash sampled from three Indiana power plants were extensively tested in laboratory experiments in order to evaluate the suitability of fly/bottom ash mixtures with high fly ash contents (i.e. $\mathrm{F} \geq 50 \%$ ) as a building material for highway embankments. The results obtained from the laboratory study are summarized as follows:

1) Fly ash in general has a well-graded size distribution ranging from mostly silt to fine sand sizes, while bottom ash sizes ranged from sands to small size gravels. The size distributions of fly/bottom ash mixtures became better graded as bottom ash content increased from zero to $50 \%$.

2) The tested fly ash was powder-like, with well-rounded particles with smooth surfaces. Some fly ash particles were hollow, with thin walls. A distinct morphological difference between two different ash sources (i.e. the Wabash river plant and the A.B. Brown plant) was the extent of the agglomeration of particles. The particle agglomerates appeared to be abundant in the Brown plant fly ash.

3) Bottom ash particles were angular, irregular in shape and have rough, gritty surface textures. Some large bottom ash particles were both internally and externally porous. The Brown plant bottom ash had many of the agglomerates of bottom ash particles alone or both bottom ash particles and fly ash particles, compared to the Wabash plant bottom ash. Some of these agglomerates appeared to be lightly cemented and some strongly bonded.

4) The specific gravity of fly and bottom ash varied in a wide range (i.e. 2.30 
to 2.81) between different ash sources. The variations in specific gravity are attributed to different values of iron content and amounts of hollow or porous particle contained in different ashes.

5) Compaction properties of fly/bottom ash mixtures (i.e. moisture-density relations) varied with mixture ratios. As fly ash content increased from 50\% to $100 \%$ (i.e., as bottom ash content decreased from $50 \%$ to zero), $w_{\text {opt }}$ increased, and $\gamma_{\mathrm{d}, \max }$ decreased gradually. The increase in $w_{\mathrm{opt}}$ with increasing fly ash content is needed to release the capillary tension from the greater surface area of the fly ash particles. The addition of bottom ash to fly ash (i.e., increasing bottom ash content) leads to increasingly more well-graded size distributions, which allows the fly and bottom ash particles to pack more closely, resulting in the increase in $\gamma_{\mathrm{d} \text {,max }}$. Overall the values of $\gamma_{\mathrm{d}, \max }$ of the ash mixtures ranged from about 14 to $17 \mathrm{kN} / \mathrm{m}^{3}$, which indicates that compacted ash mixtures are generally lighter than compacted soils - for which $\gamma_{\mathrm{d}, \max }$ typically ranges from 17 to $20 \mathrm{kN} / \mathrm{m}^{3}$.

6) Both $\gamma_{\mathrm{d}, \max }$ and $\gamma_{\mathrm{d}, \min }$ obtained from maximum and minimum density tests (ASTM D 4253 and 4254) decreased with increasing fly ash content. Comparisons between the $\gamma_{\mathrm{d}, \max } \mathrm{s}$ achieved by vibration and impact compaction (ASTM D 698) suggested that vibration is more effective than impact compaction in densification. The relative density of ash mixtures calculated based on the values of $\gamma_{\mathrm{d}, \max }$ and $\gamma_{\mathrm{d} \text {,min }}$ ranged from $56 \%$ to $76 \%$ (i.e., medium to dense states) for $95 \%$ relative compaction $(\mathrm{R}=95 \%)$, and from $32 \%$ to $54 \%$ (i.e. loose to medium states) for $90 \%$ relative compaction ( $\mathrm{R}=$ $90 \%)$, respectively. 
7) The hydraulic conductivity of compacted ash mixtures decreased slightly, as fly ash content increased from $50 \%$ to $100 \%$. This change is primarily due to increasing specific surfaces with increasing fines, which causes more resistance to flow of water through voids between particles. The overall range of the values was from $2 \times 10^{-}$ ${ }^{8}$ to $1 \times 10^{-7} \mathrm{~m} / \mathrm{sec}$, which corresponds to that of a fine sand $/ \mathrm{silt}$ mixture or silt.

8) In one-dimensional compression, the deformation mechanism of compacted ash mixtures (in soaked condition) was similar to that of granular soils in that the deformations occur primarily by distortion and crushing of individual particles. As fly ash content decreased from $100 \%$ to $50 \%$ (i.e., as the bottom ash content increases from zero to $50 \%$ ), ash mixtures became slightly more compressible mainly due to crushing that occurred in weak bottom ash particles. Breakage of fly ash agglomerates also greatly contributed to deformations. In general, however, at low to moderate vertical stress levels ranging from zero to $200 \mathrm{kPa}$ (stress levels expected in typical highway embankments) the compressibility of ash mixtures is comparable to that of typical compacted sands for the same compaction levels.

9) The ash mixture samples compacted dry of optimum were slightly stiffer than those compacted wet of optimum at low to moderate stress levels. However, as the stress increased further, the deformations became similar between the dry and wet sidecompacted samples. The higher compressibility in wet side samples may be associated with a lubricant effect of greater amount of water around ash particles in the wet samples. At high stress levels, however, particle crushing increasingly plays a role in sample deformations, resulting in similar deformations occurred in both dry and wet side samples. 
10) The wetting-induced collapse potentials of compacted ash mixtures ranged from $0.4 \%$ to $2.2 \%$, which corresponds to the "slightly collapsible range" in the Classification of Collapse Potential (ASTM D 5333). Infiltrated water causes the fabric of compacted ash to become unstable, resulting in deformations under a constant vertical stress (i.e., with no further stress increment). The collapse potential increased as bottom ash content increased from zero to $50 \%$. This change may be because larger relative displacements occurred between bottom ash particles or fly and bottom ash particles than between fly ash particles.

11) Direct shear tests performed on as-compacted ash mixture samples at different water contents indicated that the samples compacted dry of optimum exhibit generally higher shear strength than the samples compacted wet of optimum due to higher capillary tensions developed on dry-side samples. The differences in shear strength, however, were generally small ( $\phi_{p}$ differed by only about 1 to $2^{\circ}$ and c by $2 \mathrm{kPa}$, on average). When the samples compacted dry were soaked, small reductions in shear strength were observed due to removal of capillary forces $\left(\phi_{p}\right.$ decreased by about $2^{\circ}$ and $\mathrm{c}$ decreased by about $6 \mathrm{kPa}$, on average).

12) In order to investigate stress-strain and volumetric behavior of compacted ash mixtures under shearing and determine their shear strength, isotropically consolidated, drained (CID) triaxial compression tests were performed. The effects of mixture composition, compaction level, and confining stress were examined. The ash mixtures compacted at $\mathrm{R}=95 \%$ exhibited similar behavior to that of a granular soil in a dense state. The deviatoric stress dropped after a peak at relatively small axial strains and approached gradually a plateau as the axial strain increased further (i.e., dilative 
behavior). As fly ash content decreased (i.e., as bottom ash content increased) and confining stress increased, the degree of dilation decreased gradually. For the specimens with $\mathrm{F}=50 \%$ at low to moderate confining stress levels (i.e. $\sigma^{\prime}{ }_{3}=50$ and $100 \mathrm{kPa}$ ), a clear combined pattern of dilation and contraction (i.e. dilative initially and contractive afterward) was observed in volumetric behavior, probably due to crushing of bottom ash particles along an initial shear plane. At higher $\sigma^{\prime}{ }_{3}$, however, dilation was completely suppressed and contraction occurred throughout the shearing process. In contrast to the ash mixtures compacted at $\mathrm{R}=95 \%$, the overall behavior of ash mixtures at $\mathrm{R}=90 \%$ was similar to that of a granular soil in a loose state. The deviatoric stress increased gradually up to a peak level and then stayed practically unchanged with continuously increasing axial strain. The volumetric strains were contractive throughout shearing. The reduction in volume increased with decreasing fly ash content and increasing confining stress.

13) The peak friction angle $\phi_{p}^{\prime}$ for compacted ash mixtures was a function of the relative compaction, the confining pressure, and the mixture composition (i.e. fly/bottom ash content), in order of decreasing significance. The $\phi_{p}^{\prime}$ decreased as the relative compaction level decreased from $95 \%$ to $90 \%$, confining stress increased from 50 to $200 \mathrm{kPa}$, and fly ash content increased from $50 \%$ to $100 \%$. Particularly for the samples compacted at $\mathrm{R}=95 \%$, the reduction in $\phi_{p}^{\prime}$ with increasing fly ash content was relatively minimal. The mixture composition also affected the critical friction angle $\phi_{c}^{\prime}$ of ash mixtures. The $\phi_{c}^{\prime}$ decreased gradually with increasing fly ash content. The rate of decrease of $\phi_{c}^{\prime}$ with increasing fly ash content was higher than that of $\phi_{p}^{\prime}$ for $\mathrm{R}=95 \%$. This can be attributed to the increase in dilation with increasing fly ash content. The 
angularity of bottom ash particles leads to increases in $\phi_{c}^{\prime}$. For each $25 \%$ increment of bottom ash content, $\phi_{c}^{\prime}$ increased by about $2^{\circ}$. Values of $\phi_{c}^{\prime}$ ranged from 28 to $35^{\circ}$ for all ash mixtures tested, which is a range similar to that of sands - typically ranging from 29 to $37^{\circ}$.

14) Electrical resistivity is an important parameter used in evaluating the corrosivity of a material. High resistivity is associated with low corrosion potential. For as-compacted mixture samples, the resistivity decreased slightly with increasing fly ash content, due to decreasing water-air permeability and increasing compaction water content. Upon saturation, the resistivity dropped significantly for all ash mixtures. When compared to a soil corrosivity classification, the resistivity values of ash mixtures generally fall into the ranges of "corrosive" to "very corrosive". In contrast, however, the $\mathrm{pH}$ measurement results showed that ash mixtures exhibit high alkalinity, indicating low corrosion potential. Due to complex nature of corrosion mechanism, one single parameter may not be sufficient to evaluate corrosivity of a material. Based on the resistivity and $\mathrm{pH}$ test results, it is concluded that ash mixtures are potentially corrosive. 


\section{CHAPTER 5 USE OF COAL ASH IN HIGHWAY EMBANKMENTS}

\subsection{Overview}

This chapter discusses applications of coal fly/bottom ash mixtures as a building material for highway embankments based on the results of the experimental work included in this study. Coal is a primary energy source in the United States and coalburning for energy generation produces a huge amount of coal ash, which is mostly disposed as waste. Of the coal ash generated, class F fly ash and bottom ash are by far the most common and most underutilized. Recycling these materials through large volume applications is the most viable alternative to their disposal.

In this chapter, three aspects of interest are discussed for highway embankment applications of coal ash: potential environmental problems, design, and construction. Coal ash used in embankments must be environmentally safe. Environmental impacts of coal ash applications are discussed using case histories of ash utilization projects which have been environmentally monitored. A focus is then placed on critical discussions of the relevance of the results of the current study to design and construction aspects of coal ash embankments. Slope stability analyses were performed to examine stability of coal ash embankments with different geometries based on experimental data. The results of this analysis will also be presented in this chapter. 


\subsection{Environmental Aspects}

Application of coal ash to highway embankments requires that the material is not only mechanically sound, but also environmentally safe. Primary environmental concern regarding highway construction with coal ash is the potential for leaching of trace elements (metals) from the ash. The leaching must not adversely affect the surrounding environment, including the soil and groundwater. To minimize or prevent leaching from the ash mass, specialized designs can be applied to the embankment, including encasing the ash fill with a low permeability material and providing adequate drainage and a leachate collection system. Design for environmental protection will be discussed in detail in the next section covering design aspects of ash embankments.

Migration of metals in leachates from the ash has been evaluated in a number of field projects, including a series of high volume ash utilization demonstration projects sponsored by the Electrical Power Research Institute (EPRI) since the 1980s. Some of the earliest environmental data available concerning highway embankments using coal ash in the US were reported from the Delaware demonstration project. A highway embankment was constructed with 8,000 tons of class F fly ash, and groundwater quality was monitored (Srivastava and Collins 1989). The data indicated that there has been no evidence of detrimental effects to groundwater. Laboratory leaching tests revealed that regulated constituents in the leachates were below RCRA toxicity levels. To assess any long-term environmental impacts, the EPRI initiated investigations in 1991 on the environmental performance of coal ash at existing utilization sites, including five road construction sites in Georgia, Arkansas, Pennsylvania, Kansas, and Arizona (Rehage and 
Schrab 1995). The results of the investigations indicated that environmental impacts were generally minimal. Limited migration of trace elements into underlying soils was observed, but most traces were attenuated to background levels within the upper $3 \mathrm{ft}$ of soil beneath the ash at all sites. They also emphasized that environmental damage involving groundwater contamination due to the soluble ash constituents can be prevented with careful site planning such as geohydrological evaluation of the site before ash is placed. More recently, Alleman et al. (1996) investigated the environmental impacts of a coal ash embankment in Indianapolis, Indiana. The coal ash was encased in a system consisting of a sloping base-compacted-clay liner and a clay liner cover $(0.6 \mathrm{~m}$ thick). A sand layer of $0.3 \mathrm{~m}$ was placed above the base liner and below the ash to collect any leachate. The environmental investigation also included chemical oxygen demand (COD), metal analyses (using inductively coupled plasma, ICP), and Microtox ${ }^{\mathrm{TM}}$ bioassay tests. Based on results from the investigation, Alleman et al. (1996) concluded that use of coal ash for embankments had no significant deleterious effect on the environment.

The total trace element content for a specific ash source is dictated by the composition of the coal. Since most power plants typically have long-term coal contracts with a single mine, the overall composition of the ash, including metals, remains constant with time. In addition to the total metal content, the potential for leaching of metals would be influenced by the crystallinity of the ash, as this would indicate whether the metals are incorporated within the glasseous phase or within crystalline compounds which will hydrate. Since the degree of crystallinity is a function of boiler design and remains relatively constant for a given source, leachable materials remain relatively 
constant for a given ash source. A number of state regulatory agencies have issued source approval for specific generating facilities after the consistency of these materials had been demonstrated (Ferguson and Levorson 1999).

This research focused on the use of environmentally safe coal ash mixtures that are defined by RCRA as nonhazardous and are accepted by the Indiana Department of Environmental Management and the Indiana Department of Transportation. Specifically, these were nonhazardous mixtures of class F fly ash and bottom ash classified as Types IV and III, as defined by Indiana Administrative Code, 329 IAC 2-9-3 (Table 2.9).

\section{$\underline{5.3 \text { Design Aspects }}$}

Fly ash and bottom ash are typically collected from borrow areas in disposal sites of power plants or from storage silos (in the case of dry fly ash). A borrow area is a location in a disposal site from which the ash can be extracted. As discussed in Chapter 2, the type and quality of ash are dependent on a number of factors: coal origin, furnace type, combustion procedure, and collection technique. These parameters, which affect ash properties (i.e., chemical, physical, and engineering properties), are not typically constant from plant to plant. Moreover, due to current disposal practices, in a single borrow area in a power plant, ash mixtures may not be homogenous, having different gradations from one location to another, depending on mixture ratios. Due to the inherent variations in ashes, laboratory evaluation is essential during the design process. The selection of design parameters must be based on laboratory test results of representative ash samples.

When characterizing ash mixtures, it is proposed to use fines content (passing 
\#200 sieve) as the mixture fly ash content since it provides a more reproducible measure for the characterization of the mixture. It is noted that sample size and sampling location affect sample gradations. Surface samples are normally affected by environmental conditions (e.g. washing of fines due to rainfall and surface runoff). Small surface samples may not accurately represent the gradation in a location.

From a mechanical point of view, fill materials of highway embankments must meet two requirements: 1) sufficient strength to support safely its own weight and traffic loads applied on it, and 2) small settlement to provide a high level of serviceability during its service life. For embankment design, slope stability and settlement analyses need to be performed to determine whether these requirements will be satisfied. Laboratory tests indicated that shear strength and compression characteristics of ash mixtures (i.e. mixtures of class F fly ash and bottom ash) are very similar to those of granular materials. Hence, analyses of ash fill embankments (i.e. slope stability and settlement calculations) may be done using the same methods as used for those of typical granular soils. Slope stability of ash embankments will be examined in detail in the next section.

As mentioned in the previous section, ash embankments must be designed such that any potential for environmental problems can be minimized. The primary environmental concern is contamination of ground or surface waters in the vicinity of embankments due to leaching. Since leachate is normally produced as water infiltrates an ash embankment, this problem can be minimized by controlling the amount of water which infiltrates or runs onto the ash embankment. This can be accomplished by diverting the water around the embankment. Impermeable surfaces such as pavements on the top of the ash fill will prevent infiltration if an adequate surface water collection 
system is provided. To restrict infiltration through side slopes, the ash fill may be encased inside a liner system while a proper drainage and leachate collection system is provided. For the liner system, a low hydraulic conductivity soil (compacted clay), impermeable geosynthetics (geomembranes, e.g. Koerner 1994) or a combination of both can be used. These hydraulic barriers can be combined with filters (made of soil or geosynthetics) if needed. In addition, properly benched and graded slopes can provide lateral confinement and protection of the ash from erosion (Figure 5.1). Unprotected, compacted ash is erodible when subjected to surface runoff or high wind. Preventing intrusion of groundwater (or capillary rise) is equally important. A drainage blanket of properly sized granular materials may be placed in the bottom of ash fill to carry the water away from the embankment.

It should be noted that these environmental considerations also benefit engineering applications. Laboratory test results suggested that ash mixtures may undergo slight shear strength reduction and deformations upon wetting or saturation. Limiting water flow through ash fill enhances the mechanical properties of ash mixtures.

As indicated in the laboratory corrosion tests, ash mixtures (class F fly ash and bottom ash) are potentially corrosive. If any pipes or structural members are embedded in ash fill, it is recommended to use corrosion-resistant materials. If metallic components need to be used, they must be protected from corrosion by employing adequate protection methods such as cathodic protection or protective coatings. 


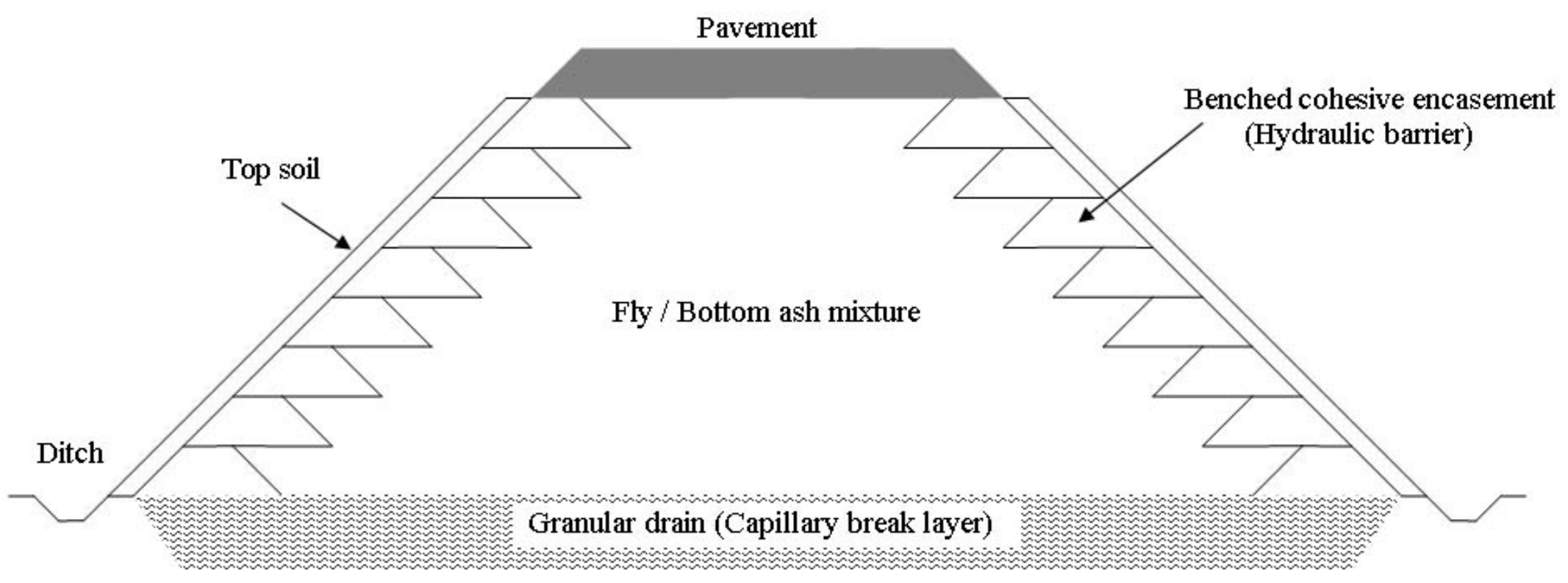

\section{NOT TO SCALE}

Figure 5.1 Proposed Ash Mixture Embankment. 


\subsection{Slope Stability Analysis of Ash Embankments}

As discussed in the previous section, embankment design normally involves slope stability analysis in order to quantify the stability of the embankment (i.e. possibility of embankment collapse). Such analysis of slopes or embankments can be achieved by using various approaches, including limit equilibrium, upper and lower bound analysis (i.e. limit analysis), finite element, and finite difference methods. Among these available methods, currently the limit equilibrium method, despite some inherent limitations, is most commonly used in slope stability analysis. The popularity of the method is mainly due to its simplicity, although it is reliable when it is applied in a correct way.

In the limit equilibrium method (of soil slope analysis), it is postulated that the slope may fail by a mass of soil sliding on a failure surface. At the moment of failure, the shear strength is fully mobilized all the way along the failure surface, and the overall slope and each part of it are in static equilibrium. For stable slopes, the shear stress mobilized under equilibrium conditions is less than the shear strength of soil, and it is conventional to introduce a factor of safety, F defined as: (Nash 1987):

$$
F=\frac{\text { Shear strength of soil }}{\text { Shear stress required for equilibrium }}
$$

Lowe (1967) and Duncan (1996) pointed out that defining the factor of safety as a factor on shear strength is logical, because shear strength is usually the quantity that involves the greatest degree of uncertainty. Indeed, the shear strength of equation (5.1) makes no distinction between peak, critical, and residual shear strength. Therefore, the 
selection of strength parameters can be crucial to analysis and must be made with care. Regarding the choice of strength parameters, Duncan (1996) reported that since limit equilibrium methods provide no information on the magnitudes of the strains within the slope, nor any indication about how they may vary along the failure surface (i.e. slip surface), unless the strengths used in the analysis can be mobilized over a wide range of strains (i.e., unless the stress-strain behavior is ductile) there is no guarantee that peak strength can be mobilized simultaneously along the full length of the failure surface. If the shearing resistance drops off after reaching the peak, progressive failure can occur, and the shearing resistance that can be mobilized at some points may be smaller than the peak strength. He concluded that the only fully reliable approach in this case is to use the residual strength rather than the peak strength in the analysis.

Many limit equilibrium methods for analyzing slope stability have been proposed (e.g., Bishop 1955; Janbu 1973; Morgenstern and Price 1965; Spencer 1967). Although different methods include different features and limitations, procedures are basically similar in concept. According to Duncan (1992), the choice of the particular method to use is not very critical, as long as the method satisfies moment and force equilibrium. The choice of the parameters involved (c, $\phi$, unit weight, and problem geometry) is more significant.

Selection of values of factor of safety normally involves consideration of the degree of uncertainty involved in evaluating the conditions and shear strengths for analysis, as well as the consequences of failure. When the uncertainty and the consequences of failure are both small, small factors of safety can be acceptable. When the uncertainties or the consequences of failure increase, larger factors of safety are 
necessary. For embankments, a value of 1.3 is typically used as a minimum acceptable factor of safety (Duncan 1996). The Indiana Department of Transportation uses 1.25 for highway embankment side slopes, 1.3 for end slopes underneath the bridge abutments and major retaining walls, and 1.5 for cut slopes in fine grained soils.

A fly and bottom ash mixture is a granular (cohesionless) material, and its properties, including shear strength and dry unit weight (at the same compaction level), vary with mixture ratios. Laboratory tests investigated the properties of ash mixtures for different mixture ratios. Based on the ash mixture properties found in the laboratory, slope stability of ash fill embankments were examined by using a limit equilibrium method. This investigation aimed to gain insight into the stability of embankments built with ash mixtures and further determine stable ash embankment geometries. Hence, analyses were made by varying embankment slope and height for a given ash mixture and examining corresponding factors of safety.

The limit equilibrium method employed in the analyses was the Bishop's simplified method of slices. Figure 5.2 describes the principles of the method. A twodimensional limit equilibrium slope analysis program, PCSTABL7, was used to model embankment geometries and properties and calculate minimum factors of safety. As the program input parameters, wet and saturated unit weights (at 95\% relative compaction) and shear strength parameters (i.e. friction angles) of ash mixtures were determined from laboratory compaction and triaxial test results. For the shear strength parameter, as Duncan (1996) pointed out, it was considered that using critical friction angle $\phi_{c}$ is more reasonable for the analyses rather than using peak friction angle $\phi_{p}$, because of possible variability of shear strength mobilized along the failure surface. The stress-strain curves 


\section{BISHOP'S SIMPLIFIED METHOD OF SLICES}

Failure is assumed to occur by rotation of a block of soil on a cylindrical slip surface centred on 0 . By examining overall moment equilibrium about $\mathrm{O}$ an expression for the factor of safety is obtained.

It is assumed that the interslice forces are horizontal.

Soil properties: $c^{\prime} \phi^{\prime} \gamma$

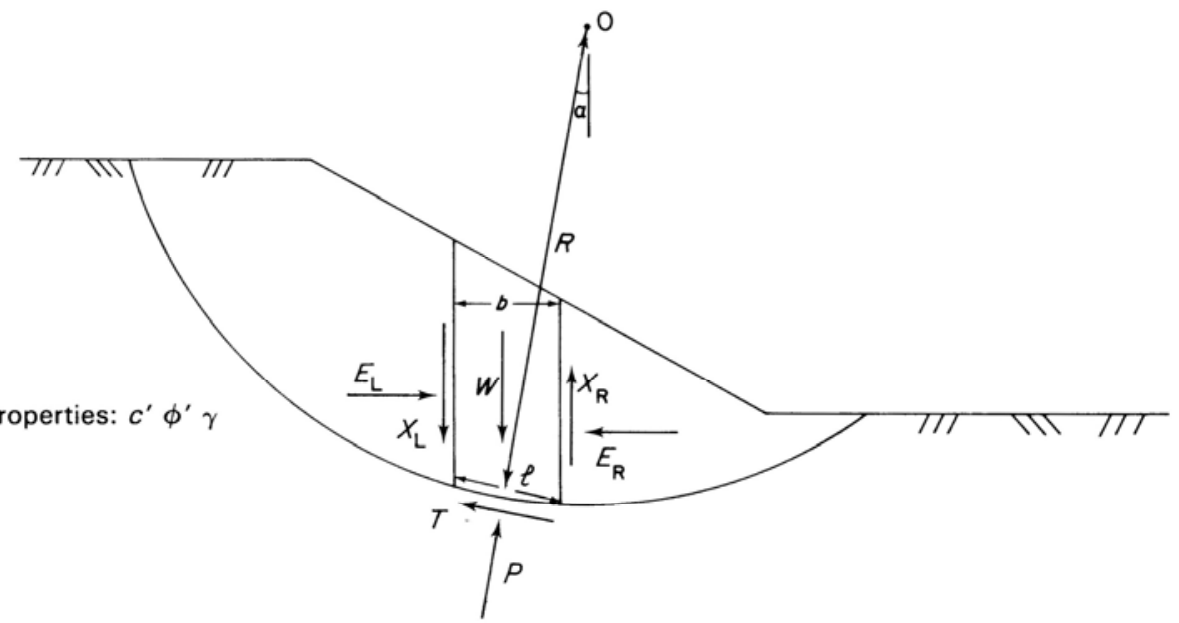

For slice shown: at base-normal stress $\sigma$, shear stress $\tau$, pore pressure $u$

Mohr-Coulomb failure criterion: $s=c^{\prime}+(\sigma-u) \tan \phi^{\prime}$

Mobilized shear strength $\tau=s / F$ where $F$ is factor of safety

Now $P=\sigma l \quad T=\pi l \quad$ so $T=\frac{I}{F}\left(c^{\prime} l+(P-u l) \tan \phi^{\prime}\right)$

Resolve vertically: $P \cos \alpha+T \sin \alpha=W-\left(X_{\mathrm{R}}-X_{\mathrm{L}}\right)$

Assuming $X_{\mathrm{R}}=X_{\mathrm{L}}=0$ (i.e. interslice forces horizontal)

$$
\begin{array}{r}
P=\left[W-\frac{1}{F}\left(c^{\prime} / \sin \alpha-u / \tan \phi^{\prime} \sin \alpha\right)\right] / m_{\alpha} \\
\text { where } m_{\alpha}=\cos \alpha\left(1+\tan \alpha \frac{\tan \phi^{\prime}}{F}\right)
\end{array}
$$

Overall MOMENT equilibrium (about 0): $\Sigma W R \sin \alpha=\Sigma T R$

Rearranging and substituting for $T$ gives

$$
F_{\mathrm{m}}=\frac{\sum\left(c^{\prime}+(P-u /) \tan \phi^{\prime}\right)}{\sum W \sin \alpha}
$$

As this equation contains $F$ on both sides it has to be solved iteratively. Convergence is usually quick and so the method is suitable for hand calculation, although it is time consuming.

Figure 5.2 Bishop Simplified Method (Bishop 1955), (Nash 1987). 
of ash mixtures compacted at $95 \%$ relative compaction suggested that compacted ash mixtures may exhibit brittle behavior when sheared (i.e. shearing resistance drops off after reaching the peak). On the other hand, however, it is important to note that this approach (i.e., setting $\phi$ to be equal to $\phi_{c}$ ) always leads to conservative results due to neglect of dilation. To consider the stability of the ash fill embankment alone, the following assumptions were made in the analyses: 1) the foundation soil is sufficiently strong to support the embankment, 2) failure does not occur through the foundation soil, and 3) the shape of the failure surface is circular. Long-term stability of the embankment (drained condition) was considered.

Figure 5.3 displays the results of slope stability analyses performed using the properties of ash mixtures from the Wabash and the Brown plants. For a given geometry of embankment, factor of safety is primarily a function of shear strength (i.e. friction angle). Since the values of $\phi_{c}$ of the Brown plant ash mixtures (i.e. 32 to $35^{\circ}$ ) were higher than those of the Wabash plant ash mixtures (i.e. 28 to $32^{\circ}$ ), generally higher factors of safety are observed in the Brown plant ash for the same geometry embankments (i.e., F is higher by about 0.1 to 0.3 in the Brown plant ash). However, the overall trend of the factor of safety with embankment geometry is very similar between the two ash sources.

As can be seen in Figure 5.3, the minimum factor of safety F increases slightly with decreasing fly ash content from $100 \%$ to $50 \%$ for a given embankment geometry (height and slope), and decreases slightly with increasing embankment height from $5 \mathrm{~m}$ to $20 \mathrm{~m}$ for a given fly ash content and slope. The effect of slope change on the factor of safety is comparatively significant. As slope increases from $3 \mathrm{H}: 1 \mathrm{~V}\left(18.4^{\circ}\right)$ to $1 \mathrm{H}: 1 \mathrm{~V}$ $\left(45^{\circ}\right), \mathrm{F}$ decreases by as much as about 1.3 , on average, for a given mixture ratio and 

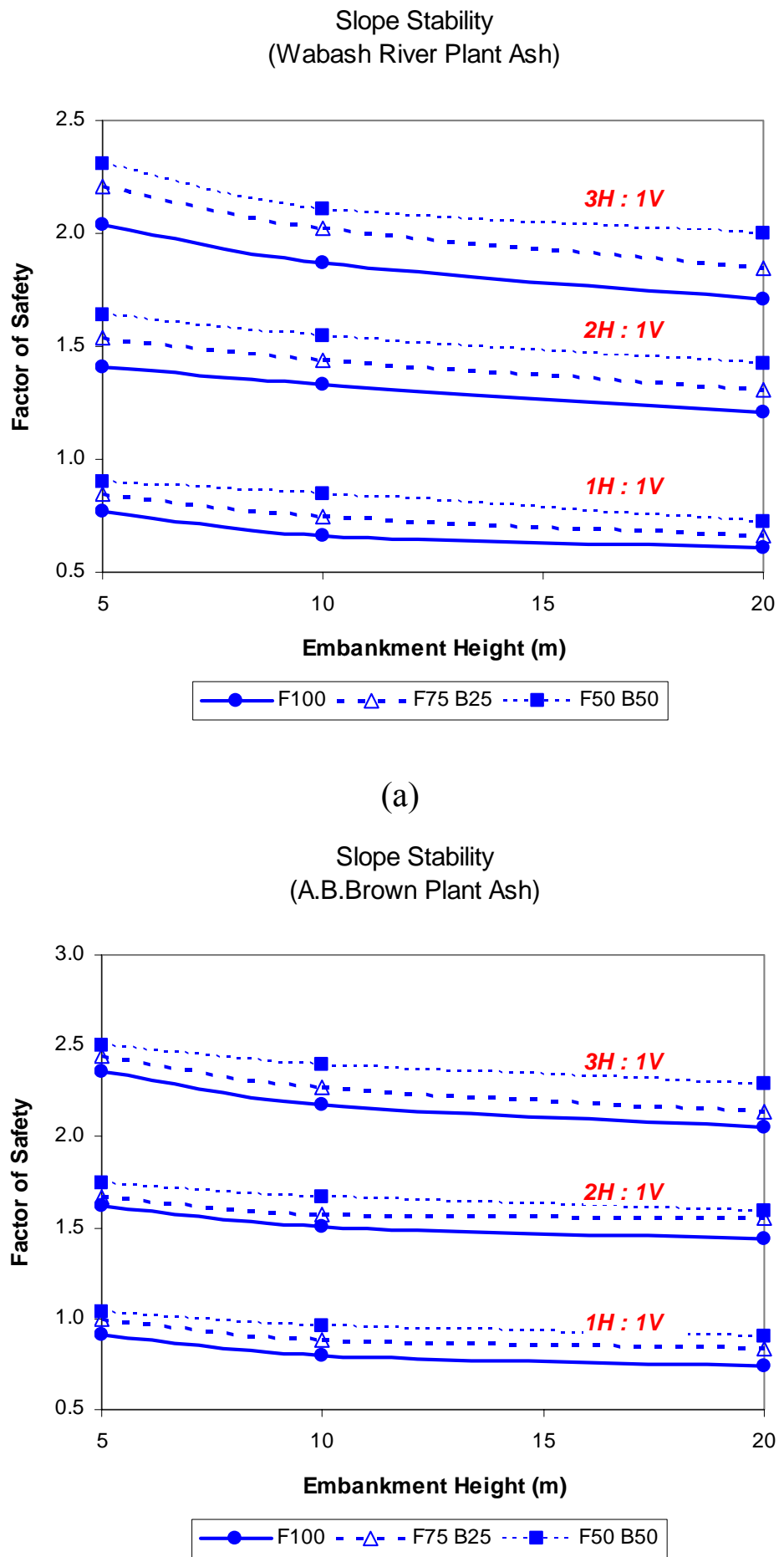

(b)

Figure 5.3 Slope Stability of Ash Embankments with Different Geometries: (a) Wabash River Plant (b) A.B.Brown Plant. 
embankment height.

As mentioned earlier, a typical minimum acceptable factor of safety is 1.3 for embankments. The results show that for the embankments with $2 \mathrm{H}$ and $3 \mathrm{H}: 1 \mathrm{~V}$ slope, the calculated minimum factors of safety were higher than 1.3 for all examined mixture ratios and embankment heights, except for one case, the 20m high embankment using Wabash plant pure fly ash (i.e. $\mathrm{F}=100 \%$ ). In practice, it is not common for highway embankments to be constructed with a maximum height exceeding $20 \mathrm{~m}$ (66ft). As a result, it is concluded that for embankments built with ash mixtures of high fly ash content (i.e. F > $50 \%)$ and typical heights $(\mathrm{H}<20 \mathrm{~m}), 2 \mathrm{H}: 1 \mathrm{~V}$ or flatter side slopes are likely to be suitable slope geometries from the point of view of stability.

\section{$\underline{5.5 \text { Construction Aspects }}$}

According to DiGioia and Brendel (1992), construction using coal ash in place of conventional materials follows the same generally accepted construction practices as conventional construction. The coal ash embankments may be built using normal techniques for building soil embankments, plus techniques used in landfill construction. The landfill construction procedures are typically required because of environmental concerns. The construction aspects relating to the environmental concerns were discussed in the Section 5.3.

From the standpoint of the embankment engineering, compaction control is a primary concern. As discussed previously, stable slopes and acceptable settlements are basic requirements of highway embankments. As is the case with conventional soil 
embankments, the coal ash embankments will be designed such that the requirements are satisfied based on strength and deformation properties of the ash, typically determined in the laboratory. Achieving the desired degree of compaction is crucial so that the ash will possess the properties used in the design.

As discussed earlier, the strength and stiffness of ash mixtures were greatly affected by the degree of compaction. For a given mixture ratio, the peak friction angles between $90 \%$ and $95 \%$ relative compaction differed by about $6^{\circ}$ to $9^{\circ}$, depending on the mixture ratio. The volumetric behavior of ash mixtures changed from dilative to contractive behavior with a decrease in relative compaction from $95 \%$ to $90 \%$. The contractive behavior implies that short-term positive pore pressures may be produced by shearing, which can be a problem, particularly for dynamic loadings such as earthquake or heavy trucks. Therefore, it is advisable to use the higher degree of compaction.

In controlling the compaction of ash mixtures, difficulties may arise when the ash mixture for a fill material lacks uniformity. This case may arise when ashes are borrowed from co-disposal areas of fly and bottom ash or when borrowed from multiple ash sources and placed for compaction in the field (i.e. a project site) without control of mixture uniformity. As indicated in the laboratory compaction tests, ash mixtures with different mixture ratios exhibit different moisture-density relationships (i.e. as fly ash content increases, the optimum moisture content increases and the maximum dry unit weight decreases). If a fill is composed of several, highly varied mixtures and compacted at the same compactive effort and moisture range, some materials may be highly undercompacted. Also, the materials can be either too dry or too wet for compaction. Excessively dry compaction can create a dusting problem, whereas excessively wet 
compaction can cause the materials to liquefy. Increasing compaction effort may increase dry density, but there may be economic limitations to increasing the compaction effort, as well as a potential for overcompaction. For ash mixtures with a high volume of bottom ash with weak, porous particles, overcompaction may break the porous fragments, leading to significantly greater maximum dry density than found in laboratory tests. In this case, the advantage of having a lightweight fill may be lost.

When significant variability exists in a fill material, one approach for proper compaction control may be to use a "family" of compaction curves. For a disposal site (i.e. a borrow area) where fly and bottom ash co-exist, the family of compaction curves can be developed by examining mixture compositions and performing a series of laboratory compaction tests on samples collected from different areas of the disposal site (i.e. disposal pond or landfill). The family of compaction curves can then be used to determine degree of compaction and allowable moisture range for field ash mixtures. In this case, monitoring to identify the mixture ratios of the ash mixtures being placed in the field is necessary.

Alternatively, compaction control of ash mixtures, as a granular material, may be performed using the relative density approach. This approach may only be used with mixtures of relatively low fine contents (i.e. low fly ash contents). According to Townsend (1973), a value of $12 \%$ fines is a general bound placed by the U.S. Bureau of Reclamation (USBR) and ASTM. The relative density approach is particularly useful because correlation can be made between the relative density and measured properties of ash mixtures.

As mentioned in chapter 2, dusting control is also an important concern in the 
construction of ash embankment. Dry ash can be easily blown around. Adequate measures should be taken during construction to control dust. During drying conditions, such as drying weather, high winds, or delay in construction, the ash needs to be kept continuously moist to prevent the release of dust. Spraying with water, lime water, bituminous sprays, or other sealing sprays may be helpful for providing dusting controls.

\subsection{Projections for Marketing Potential}

The information will be available after completion of the test embankment monitoring.

\subsection{Planning for Large-scale Application}

Construction of a demonstration embankment is planned. The fill material will consist of approximately $80 \%$ fly ash and $20 \%$ bottom ash. It will be fully instrumented so that its performance in the longer term can be evaluated. Monitoring wells will be installed to determine the impact of fly ash on the groundwater quality. More details on this project will be provided in the near future. 


\section{CHAPTER 6 CONCLUSIONS AND RECOMMENDATIONS}

\section{$\underline{6.1 \text { Conclusions }}$}

This study aimed to evaluate the suitability of coal fly/bottom ash mixtures with high fly ash content as substitutes for conventional fill materials in highway embankments. An extensive literature review has been presented on the current state of knowledge of fly and bottom ash properties, their production, disposal, and utilization. Representative, large samples of class F fly ash and bottom ash, collected from three utility power plants in Indiana, were extensively studied in the laboratory for the mechanical evaluation of fly/bottom ash mixtures. Slope stability analyses were performed to investigate stability of ash embankments and determine stable embankment geometries by using the properties of ash mixtures found in the laboratory. Although focus was placed on the geotechnical evaluation of the materials for highway embankments, environmental aspects of their utilization were also reviewed and documented. The following conclusions are drawn from our study:

1) Fly ash is composed of fine, nearly spherical particles with sizes ranging from mostly silt to fine sand, whereas bottom ash is made of coarse, angular particles with sizes ranging from sand to small gravel 
sizes. Fly and bottom ash exhibit some special morphological characteristics that are distinctly different from typical soils. Some fly ash particles are hollow spheres with thin walls. Some bottom ash particles have complex pore structures. Also, some of the fly ash or bottom ash particles are agglomerations of finer particles. The morphological characteristics of fly and bottom ash affect their specific gravity, particle strength, and consequently other mechanical properties to varying degrees. The impact of these morphological characteristics on mechanical properties tends to be constant for a given ash source, but vary between different ash sources.

2) Fly/bottom ash mixtures (with mixture ratios ranging from $50 \%$ to $100 \%$ fly ash content) exhibit relatively well-defined moisture-density relationships, and the relationships vary with mixture ratios. As the fly ash content increases from $50 \%$ to $100 \%$ (i.e., as bottom ash content decreases from $50 \%$ to zero), $w_{\mathrm{opt}}$ increases, and $\gamma_{\mathrm{d} \text {,max }}$ decreases gradually. The values of $\gamma_{\mathrm{d}, \max }$ for compacted ash mixtures tend to vary greatly from plant to plant, due to a relatively wide range of specific gravity values from plant to plant. However, overall, the values of $\gamma_{\mathrm{d}, \max }$ of ash are lower than those of typical compacted soils.

3) In general, compacted ash mixtures are slightly more compressible than typical compacted sands at the same compaction levels, mainly due to the higher crushability of fly and bottom ash. The source of crushing in fly ash is due to agglomerations of finer fly ash particles rather than 
individual fly ash particles, while for bottom ash the cause is agglomerations plus individual bottom ash particles. Hence, with more significant quantities of agglomerations in fly or bottom ash, larger deformations occur with increased loading. Moreover, for a given ash source, mixtures rich in bottom ash tend to have more deformation than those with less bottom ash, due to the additional effect of crushing occurring in relatively weak bottom ash particles. The significance of agglomerations in fly or bottom ash and weak bottom ash particles varies typically from ash source to source, which results in a variation in the compressibility of ash mixtures between different ash sources. For a given source, however, the increase in compressibility of ash mixtures with increasing bottom ash is small. And, at the low to moderate stress levels expected in typical highway embankments, the compressibility of compacted ash mixtures is comparable to that of typical compacted sands.

4) Ash mixtures exhibit both relatively high peak and critical state shear strength (i.e. $\phi_{p}^{\prime}$ and $\phi_{c}^{\prime}$ ). Compacted ash mixtures at moderately high compaction levels (e.g., 95\% relative compaction) exhibit comparable or even higher peak shear strength than that of compacted sands of similar compaction levels. The critical state shear strength of ash mixtures is in a very similar range to that of typical sands. The addition of bottom ash to fly ash increases critical state friction angles gradually (i.e., about $2^{\circ}$ for every $25 \%$ increase of bottom ash content in a 
mixture), while peak friction angles do not change significantly with increasing bottom ash content.

5) The degree of relative compaction, confining stress, and mixture ratio affect significantly the stress-strain and volumetric behavior of an ash mixture under shearing, and therefore its peak shear strength. Ash mixtures at $95 \%$ relative compaction typically exhibit a similar behavior to granular soils in dense states (i.e. dilatant behavior), whereas those at $90 \%$ relative compaction resemble sand in loose states (i.e. contractive behavior). Increasing confining stress decreases dilation or a tendency for dilation, and thus decreases peak friction angles. Increasing bottom ash content also tends to decrease dilation (or a tendency for dilation), primarily due to crushing bottom ash particles in a shear plane during shearing.

6) The effects of compaction water content and inundation (saturation) on the shear strength and compressibility of compacted ash mixtures do not appear to be significant. In general, ash mixtures compacted dry of optimum exhibit slightly higher shear strength and lower compressibility. Inundation leads to a slight decrease in the shear strength and increase in the deformation of ash mixtures.

7) Slope stability of an embankment is primarily a function of the shear strength of the embankment material. Limit equilibrium slope stability analyses of embankments with different geometries using large displacement strengths (i.e. critical state shear strength) of all ash 
mixtures with mixture ratios ranging from $50 \%$ to $100 \%$ fly ash content were performed. Due to relatively high shear strength, analysis confirmed that for embankments with heights less than $20 \mathrm{~m}$, a $2 \mathrm{H}: 1 \mathrm{~V}$ or flatter slope satisfies stability requirements (i.e., factor of safety higher than 1.3).

8) Appropriate compaction control is important for ash mixtures to possess certain desirable properties, such as a minimum acceptable shear strength and compressibility. The degree of compaction (i.e. relative compaction) can be used effectively to control the compaction of ash mixtures. Difficulties may arise when compacting ash mixtures in a wide range of mixture ratios resulting from current disposal practices. For proper compaction control, a family of compaction curves can be constructed for the range of existing mixtures in a power plant. The relative compaction can then be checked against a compaction curve for a material with grain-size distribution similar to the field-compacted fill. The compaction moisture range and the compaction effort must be adjusted so that the minimum value expected for the relative compaction reaches the target value (e.g., at least 95\%).

9) The environmental impact of construction utilizing coal fly/bottom ash mixtures may be a concern to potential users of these materials. Previous laboratory and field experiences confirmed that most coal (fly or bottom) ash used in the constructions did not have detrimental 
effects on their surrounding environments, such as groundwater contamination due to leaching. To minimize any potential for environmental problems, landfill construction techniques need to be incorporated in building embankments utilizing ash mixtures. Environmental considerations (i.e., limiting water flow through ash fill) also provide beneficial effects to embankment performance by enhancing the mechanical properties of ash mixtures.

10) Compacted ash mixtures are potentially corrosive. If any pipes or structural members are embedded in ash fill, it is recommended to use corrosion-resistant materials. If metallic components need to be used, they must be protected from corrosion by employing adequate protection methods, such as cathodic protection or protective coating.

Based on the results of this study, it appears that class $\mathrm{F}$ fly/bottom ash mixtures with high fly ash content are suitable for use in highway embankments, if proper design and construction procedures are followed. Prior to use, the materials must pass the appropriate environmental requirements typically required from state regulatory agencies. As the environmental requirements are satisfied, the fly/bottom ash mixtures can provide fill materials of comparable strength and compressibility to most granular soils while having the advantage of lesser dry unit weights. 


\subsection{Recommendations for Future Research}

1) Laboratory investigations in this study have shown that fly/bottom ash mixtures with high fly ash content appear to be suitable for use in highway embankments. The ultimate indicator of a material's quality is its ability to perform under actual service conditions. It is suggested that further research needs to focus on correlating the laboratory test results to the field performance of ash mixtures. An instrumented prototype test section should serve this purpose.

2) For an embankment susceptible to large dynamic loadings, such as those caused by earthquakes, the dynamic response of the material is an important parameter that must be evaluated. For analysis of the dynamic response of ash mixtures, the dynamic behavior of compacted ash mixtures needs to be studied by performing dynamic tests such as cyclic triaxial tests.

3) Based on the results of laboratory tests and field performance data, a numerical model (i.e., constitutive model) for ash mixtures can be developed, and used in design to predict the actual behavior of the materials more precisely, rather than using typical models for soils.

4) New procedures need to be developed for more reliable relative density determination for the ash mixtures with high fly ash content. Current procedures are difficult to follow and achieve reliable results for these specific materials. Easily and reproducibly determined relatively densities can be used to control compaction appropriately, as an alternative to relative compaction. Correlations can then be developed between relative density and mechanical properties of ash mixtures. 
5) The problem that complicates large volume ash utilizations may be the lack of uniformity of the mixtures at disposal sites. New methods need to be developed for controlling and engineering the disposal process of coal ash in the power plants. The discharging and deposition process can be designed with the goal of generating more homogeneous mixtures of the materials at the disposal sites. 


\section{LIST OF REFERENCES}

Abernethy, R. F., Peterson, M. J., and Gibson, F. H. (1969), "Major Ash Constituents in U.S. Coals," Report of Investigation 7240, Bureau of Mines.

Alleman, E. J., Fox, P. J., and De Battista, D. (1996), "Performance Evaluation of Highway Embankment Constructed Using Coal Ash," Report No. FHWA/IN/JHRP-96/5, School of Civil Engineering, Purdue University, West Lafayette, Indiana.

American Coal Ash Association, ACAA, (1996), "Coal Combustion Product (CCP) Production \& Use: 1966-1994: Report for Coal Burning Electric Utilities in the United States, May, $68 \mathrm{pp}$.

American Coal Ash Association, ACAA, (2001), CCP Survey, Retrieved from http://www.acaa-usa.org/PDF/ACAA2001CCPSurvey.pdf.

American Petroleum Institute (1991), "Cathodic Protection of Aboveground Petroleum Storage Tanks, API Recommended Practice 651, Washington, D. C.

American Society for Testing and Materials, ASTM, "Standard Classification of Coals by Rank," Designation D 388-99, Philadelphia, PA.

American Society for Testing and Materials, ASTM, "Standard Test Method for Field Measurement of Soil Resistivity Using the Wenner Four-Electrode Method," Designation G 57-95a, Philadelphia, PA.

American Society for Testing and Materials, ASTM, "Standard Test Method for Measuring $\mathrm{pH}$ of Soil for Use in Corrosion Testing," Designation G 51-95, Philadelphia, PA.

American Society for Testing and Materials, ASTM, "Standard Test Methods for Specific Gravity of Soil Solids by Water Pycnometer," Designation D 854-00, Philadelphia, PA.

American Society for Testing and Materials, ASTM, "Standard Test Methods for Maximum Index Density and Unit Weight of Soils Using a Vibratory Table," Designation D 4253-00, Philadelphia, PA. 
American Society for Testing and Materials, ASTM, "Standard Test Methods for Minimum Index Density and Unit Weight of Soils and Calculation of Relative Density," Designation D 4254-00, Philadelphia, PA.

American Society for Testing and Materials, ASTM, "Standard Test Method for Direct Shear Test of Soils under Consolidated Drained Conditions," Designation D 3080-98, Philadelphia, PA.

American Society for Testing and Materials, ASTM, "Standard Test Method for ParticleSize Analysis of Soils,” Designation D 422-63, Philadelphia, PA.

American Society for Testing and Materials, ASTM, "Standard Test Methods for Laboratory Compaction Characteristics of Soil Using Standard Effort $\left(12,400 \mathrm{ft}-\mathrm{lbf} / \mathrm{ft}^{3}\right.$ $\left.\left(600 \mathrm{kN}-\mathrm{m} / \mathrm{m}^{3}\right)\right)$," Designation D 698-00a, Philadelphia, PA.

American Society for Testing and Materials, ASTM, "Standard Test Method for Measurement of Hydraulic Conductivity of Porous Material Using a Rigid-Wall, Compaction-Mold Permeameter," Designation D 5856-95, Philadelphia, PA.

American Society for Testing and Materials, ASTM, "Standard Test Method for OneDimensional Consolidation Properties of Soils," Designation D 2435-96, Philadelphia, PA.

American Society for Testing and Materials, ASTM, "Standard Test Method for Measurement of Collapse Potential of Soils," Designation D 5333-92, Philadelphia, PA.

Anderson, D. A. (1978), "Utilization of Bottom Ash in Highway Construction," Proceedings, International Conference on the Use of By-Products and Waste in Civil Engineering, Vol. 2, Paris, France, November 28-30, pp. 327-332.

Anderson, D. A., Usmen, M., and Moulton, L. K. (1976), "Use of Power Plant Aggregate in Bituminous Construction," Transportation Research Record 595, pp. 18-24.

Barber, E. G. (1970), “The Utilization of Pulverized-Fuel Ash,” Journal of the Institute of Fuel, Vol. 43, No. 348, January, pp. 4-9.

Barden, L., McGown, A., and Collins, K. (1973), “The Collapse Mechanism in Partly Saturated Soil,” Engrg. Geol., Vol. 7, No. 1, pp. 49-60.

Been, K., Jefferies, M. G., and Hachey, J. (1991), "The Critical State of Sands," Geotechnique, London, Vol. 41, No.3, pp. 365-381. 
Bishop, A.W. (1955), "The Use of the Slip Circle in the Stability Analysis of Slopes," Geotechnique, Vol. 5, No. 1, pp. 7-17.

Bolton, M. D. (1986), "The Strength and Dilatancy of Sands," Geotechnique, London, Vol. 36, No.1, pp. 65-78.

Brendel, G. F. and Glogowski, P. E. (1989), “Ash Utilization in Highways: Pennsylvania Demonstration Project,” Interim Report, EPRI, GS-6431, Research Project 2422-19.

Brendel, G. F., Glogowwski, P. E., Kelly J. M., and Curry, A. M. (1988), "Fly Ash Construction Manual for Road and Site Applications, Volume 1: Specification Guidelines," Final Report, EPRI, CS-5981, Vol. 1, Research Project 2422-2, October.

Carrier III, W. D. (2000), "Compressibility of A Compacted Sand," Journal of Geotechical and Geoenvironmental Engineering, Vol. 126, No. 3, March, pp. 273-275.

Chaker, V. (1996), "Measuring Soil Resistivity," ASTM Standardization News, April, pp. 30-33.

Coburn, S. K. (1987), "Soil Corrosion," Selection of Materials for Service Environments, ASTM International Metals Park, Ohio, pp. 303-309.

CT\&E Environmental Services Inc. (2001), Chemical Analysis Laboratory Data, Submitted to Cinergy Corp. IN.

Davie, J. R., Young, L. W. Jr., and Stashik, G. A. (1996), "Soil Electrical Resistivity: An Essential Parameter for Power Plant Design," Proceedings of the American Power Conference, Vol. 2, Illinois Inst. of Technology, Chicago, IL, pp. 746-751.

De Josselin de Jong, G. (1976), "Rowe's Stress-Dilatancy Relation Based on Friction," Geotechnique, London, Vol. 26, No. 3. pp. 527-534.

Diamond, S. (1985), "Selection and Use of Fly Ash for Highway Concrete," Report No. FHWA/IN/JHRP-85/8, Final Report, Purdue University, W. Lafayette, Indiana.

DiGioia and Brendel (1992), "Fly Ash Design Manual For Road and Site Application, Vol. 1: Dry or Conditioned Placement," Vol. 1, Manual Prepared for EPRI, TR-100472, Final Report.

DiGioia, A. M. (1994), "Ash Utilization in Embankment Construction," in Use of Coal Combustion By-Products in Highway Construction Workshop, Coordinated by: University of Southern Indiana Forum for Coal Ash Utilization (USIFCAU) in Cooperation with Indiana Department of Transportation (INDOT), Indianapolis, IN. 
DiGioia, A. M., McLaren, R. J., Burns, D. L., and Miller, D. E. (1986), "Fly Ash Design Manual for Road and Site Application, Vol. 1: Dry or Conditioned Placement," Manual Prepared for EPRI, CS-4419, Research Project 2422-2, Interim Report, February.

Dry, C. M. (1995), "The Potential Use of Waste (Ash) Materials for EIFS Insulation and Related Components," Development, Use, and Performance of Exterior Insulation and Finish Systems (EIFS), ASTM STP 1187, Mark F. Williams and Richard G. Lampo, Eds., ASTM, Philadelphia.

Duncan, J. M. (1992), "State of the Art: Static Stability and Deformation Analysis," ASCE conference, Stability and Performance of Slopes and Embankments-II, edited by R.B. Seed and R.W. Boulanger, Geotechnical Special Publication No. 31.

Duncan, J. M. (1996), "State of the Art: Limit Equilibrium and Finite Element Analysis of Slopes," Journal of Geotechnical Engineering, Vol. 122, No. 7, pp. 577-596.

Edgar, T. V. (1989), "In-Service Corrosion of Galvanized Culvert Pipe," Effects of Soil Characteristics on Corrosion, V. Chaker and J. D. Palmer, Eds., American Society for Testing and Materials, Philadelphia, PA., pp. 133-143.

Energy Information Administration, EIA, (1995), “Coal data: A Reference,” DOE/EIA0064 (93), U.S. Department of Energy, Washington D. C.

Energy Information Administration, EIA, (2000), "Coal Industry Annual 2000," DOE/EIA-0584 (2000), U.S. Department of Energy, Washington D. C.

Energy Information Administration, EIA, (2002), “Annual Energy Review 2000,” U.S. Department of Energy, Washington D. C.

Engineering News Record, ENR, (1980), "Billions at Stake in Coal Waste Fight," Vol. 204, No. 2, January 10.

Federal Highway Administration, FHWA, (2002), "User Guidelines for Waste and Byproduct Materials in Pavement Construction," Turner-Fairbank Highway Research Center, U. S. Department of Transportation.

Federal Register (2002), Title 40, Code of Federal Regulations, Protection of Environment, Dec.

Ferguson, G. (1989), "Use of Coal Ash in Highway Construction: Kansas Demonstration Project," GS-6460, Research Project 2422-15, Electric Power Research Institute, Palo Alto, CA. 
Ferguson, G. and Levorson, S. M. (1999), "Soil and Pavement Base Stabilization with Self-Cementing Coal Fly Ash," American Coal Ash Association, Alexandria, VA.

Fitzgerald III, J. H. (1993), "Evaluating Soil Corrosivity-Then and Now," Material Performance, Vol. 32, No. 10, October, pp. 17-19.

Foster, C. R. (1962), "Field Problems: Compaction," in Foundation Engineering, Edited by Leonards, G. A. McGraw Hill Book Co., Inc., New York.

GAI Consultants, Inc. and USIFCAU (1993), "Use of Coal Combustion By-Products in Highway Construction," Prepared for the General Assembly of Indiana and the Indiana Department of Transportation in response to House Enrolled Act 1056 and Senate Bill 209.

Glogowski, P. E. (1989), “Ash Utilization in Highways: Pennsylvania Demonstration Project,” GS-6431, Interim Report, Electric Power Research Institute, Palo Alto, CA.

Guo, R. Q., Rohatgi, P. K., and Nath, D. (1996), "Compacting Characteristics of Aluminium-Fly Ash Power Mixtures,” Journal of Materials Science, Vol. 31, pp. 55135519.

Head, K. H. (1980), "Manual of Soil Laboratory Testing, Volume 1: Soil Classification and Compaction Tests," Engineering Laboratory Equipment Limited.

Head, K. H. (1982), "Manual of Soil Laboratory Testing, Volume 2: Permeability, Shear Strength and Compressibility Tests," Engineering Laboratory Equipment Limited.

Hendron, A. J. Jr. (1963), “The Behavior of Sand in One-Dimensional Compression,” Ph. D. Dissertation, University of Illinois, Urbana.

Highway Research Board (1952), "Compaction of Embankments, Subgrades, and Bases," HRB Bulletin 58.

Hilf, J. W. (1991), “Compacted Fill," in Foundation Engineering Handbook, Edited by Fang, H. S., Van Nostrand Reinhold, New York.

Holtz, R. D. and Kovacs, W. D. (1981), “An Introduction to Geotechnical Engineering," Prentice-Hall, Inc., Englewood Cilffs, New Jersey.

Hough, B. K. (1969), "Basic Soils Engineering," $2^{\text {nd }}$ Ed., The Ronald Press Co., New York. 
Huang, H. W. (1990), "The Use of Bottom Ash in Highway Embankments, Subgrade, and Subbases," Joint Highway Research Project, Final Report, FHWA/IN/JHRP-90/4, Purdue University, W. Lafayette, Indiana.

Huang, H. W. and Lovell, C. W. (1993), "Use of Bottom Ash and Slags in Highway Construction," Fourth International Symposium on the Reclamation, Treatment, and Utilization of Coal Mining Wastes, Karakow, Poland, Sep., pp. 358-368.

Indiana Administrative Code (1996 edition), Vol. 7/14, Conway Green Pub. Co., Cleveland, OH, 1996.

Janbu, N. (1973), "Slope Stability Computations," in Hirschfield and Poulos, eds., Embankment Dam Engineering, Casagrande Memorial Volume, John Wiley \& Sons, New York, pp. 47-86.

Kalyoncu, R. S. (1999), "Coal Combustion Products," in Metals and Minerals: U.S. Geological Survey Minerals Yearbook 1997, Vol. I, pp. 19.1-19.13.

Kalyoncu, R. S. (2002), "Coal Combustion Products," in Metals and Minerals: U.S. Geological Survey Minerals Yearbook 2000, Vol. I, pp. 20.1-20.12.

Karim, Ahmed M. K. (1997), "Building Highway Embankments of Fly/Bottom Ash Mixtures," Joint Highway Research Project, Final Report, FHWA/IN/JTRP-97/1, Purdue University, W. Lafayette, Indiana.

Ke, T.-C. and Lovell, C. W. (1992), "Corrosivity of Indiana Bottom Ash,” Transportation Research Record No. 1345, pp. 113-117.

Ke, Te-Chih (1990), "The Physical Durability and Electrical Resistivity of Indiana Bottom Ash," Joint Highway Research Project, Final Report, FHWA/IN/JHRP-90/6, Purdue University, W. Lafayette, Indiana.

Koerner, R. M. (1994), “Designing with Geosynthetics,” $3^{\text {nd }}$ Edition, Prentice Hall.

Kuerbis, R., Negussey, D., and Vaid, Y. P. (1988), "Effect of Gradation and Fines Content on the Undrained Response of Sand," Hydraulic Fill Structures, Geotechnical Special Publication, No. 21, ASCE, New York, pp. 330-345.

Lade, P. and Yamamuro, J. (1997), "Effects of Non-Plastic Fines on Static Liquefaction of Sands," Canadian Geotechnical Journal, Ottawa, Vol. 34, No.6, pp. 918-928.

Lambe, T. W. and Whitman, R. V. (1979), "Soil Mechanics, SI Version,” Wiley Eastern Limited, New Delhi, 553 pp. 
Larrimore, C. L. and Pike, C. W. (1987), "Use of Coal Ash in Highway Construction: Georgia Demonstration Project," CS-5225, Research Project 2422-4, Electric Power Research Institute, Palo Alto, CA.

Lawton, E. C. (1986), "Wetting-Induced Collapse in Compacted Soil," Ph.D. Thesis, Washington State University, Pullman, Washington.

Lawton, E. C., Fragaszy, R. J., and Hetherington, M. D. (1992), "Review of Wetting Induced Collapse in Compacted Soil," J. Geotech. Engrg, Vol. 118, No. 9, September, pp. 1376-1394.

Lee, K. L. and Farhoomand, I. (1967), "Compressibility and Crushing of Granular Soil in Anisotropic Triaxial Compression," Canadian Geotechnical Journal, Vol. IV, No. 1, pp. 68-99

Leonards, G. A. (1962), "Engineering Properties of Soil," in Foundation Engineering, G. A. Leonards, ed., McGraw-Hill Book Co., New York.

Leonards, G. A. and Bailey, B. (1982), "Use of Pulverized Coal Ash as Structural Fill," Journal of the Geotechnical Engineering Division, ASCE, Vol. 108, No. GT4, pp. 517531.

Likos, W. J. and Lu, N. (2002), "Hysteresis of Capillary Cohesion in Unsaturated Soils," $15^{\text {th }}$ ASCE Engineering Mechanics Conference, June 2-5, Columbia University, New York, NY.

Lovell, J. and Diamond, S. (1986), "A Simple Technique for Fly Ash Specimen Preparation for Scanning Electron Microscopy," Material Research Society Symposium Proceedings, Vol. 65, Material Research Society, pp. 131-136.

Lowe, J. (1967), "Stability Analysis of Embankments," Journal of Soil Mechanics and Foundation Division, ASCE, Vol. 93, No.SM4, pp. 1-33.

Majidzadeh, K., El-Mitiny, R. N., and Bokowski, G. (1977), "Power Plant Bottom Ash in Black Base and Bituminous Surfacing," Vol. 2, User's Manual, Federal Highway Administration, Report No. FHWA-RD-78-148, Washington, D. C., June.

Mason, B. J. and Carlile, D. W. (1986), "Round-Robin Evaluation of Regulatory Extraction Methods for Soild Wastes," EA-4740, Interim Report, Electric Power Research Institute, Palo Alto, CA. 
McLaren, R. J. and DiGioia, A. M. (1987), "The Typical Engineering Properties of Fly Ash," Geotechnical Practice for Waste Disposal '87, Proc. of a Specialty Conf. ASCE, University of Michigan, Ann Arbor, Michigan, June 15-17, Geotechnical Special Publication No. 13, edited by Edward Wood, ASCE, New York, pp. 683-697.

Mitchell, J. K. (1976), "Fabric, Structure, and Property Relationships," Fundamentals of Soil Behavior, John Wiley \& Sons, New York, N.Y., pp. 222-252.

Morgenstern, N.R. and Price, V.E. (1965), "The Analysis of the Stability of General Slip Surfaces," Geotechnique, Vol. 15, No. 1, pp. 79-93.

Moulton, L. K. (1973), "Bottom Ash and Boiler Slag," Proceedings of Third International Ash Utilization Symposium, Pittsburgh, PA, March, Bureau of Mines, Information Circular 8640, pp. 148-169.

Nash, D. (1987), "A Comparative Review of Limit Equilibrium Methods of Stability Analysis," in M.G. Anderson and K.S. Richards, eds., Slope Stability, John Wiley \& Sons, New York, pp. 11-75.

NAVFAC DM-7 (1971), Naval Facilities Engineering Command, Design Manual: Soil Mechanics, Foundations and Earth Structures, Washington, D.C., March.

Palmer, J. D. (1989), "Environmental Characteristics Controlling the Soil Corrosion of Ferrous Piping," Effects of Soil Characteristics on Corrosion, ASTM STP 1013, V. Chaker and J. D. Palmer, Eds., American Society for Testing and Materials, Philadelphia, PA., pp. 5-17.

Radian Corporation (1985), "Characterization of Utility Low Volume Wastes," EPRI CS3737, Electric Power Research Institute, Palo Alto, CA.

Rehage, J. A. and Schrab, G. E. (1995), "Environmental Performance Assessment of Coal Combustion Byproduct Use Sites: Road Construction Applications," TR-105127, Research Project 2796-01, Final Report, Electric Power Research Institute, Palo Alto, CA.

Roberts, J. E. and DeSouza, J. M. (1958), “The Compressibility of Sands,” Proceedings of the American Society for Testing and Materials, Vol. 58, pp. 1269-1277.

Rodriguez, A. K., del Castillo, H., and Sowers, G. F. (1988), "Soil Mechanics in Highway Engineering," Trans. Tech. Publications, Clausthal-Zellerfeld, Germany.

Rowe, P. W. (1962), "The Stress-Dilatancy Relation for Static Equilibrium of an Assembly of Particles in Contact," Proc., Royal Soc., London, A269, pp. 500-527. 
Sahu, B. K. and Piyo, P. M. (2000), "Improvement in Strength Characteristics of White Kalahari Sands by Fly Ash," $2^{\text {nd }}$ International Conference on Construction in Developing Countries: Challenges facing the construction industry in developing countries, November 15-17, Gabarone, Botswana.

Salgado, R., Bandini, P., and Karim., A. (2000), "Shear Strength and Stiffness of Silty Sand," Journal of Geotechnical and Geoenvironmental Engineering, ASCE, Vol. 126, No. 5, pp. 451-462.

Salgado, R., Boulanger, R. W., and Mitchell, J. K. (1997a), "Lateral Stress Effects on CPT Liquefaction Resistance Correlations," Journal of Geotechnical and Geoenvironmental Engineering, ASCE, Vol. 123, No. 8, pp. 726-735.

Salgado, R., Mitchell, J. K., and Jamiolkowski, M. (1997b), "Cavity Expansion and Penetration Resistance in Sand," Journal of Geotechnical and Geoenvironmental Engineering, ASCE, Vol. 123, No. 4, pp. 344-354.

Schultze, E. and Moussa, A. (1961), "Factors Affecting the Compressibility of Sand," Proceedings of the Fifth International Conference on Soil Mechanics and Foundation Engineering, Vol. 1, pp. 335-340.

Scully, J. C. (1990), “The Fundamentals of Corrosion,” Pergamon Press.

Seals, R. K., Moulton, L. K., and Kinder, D. L. (1977), “In Situ Testing of a Compacted Fly Ash Fill," Presented at the ASCE Specialty Conference on Geotechnical Practice for Disposal of Solid Waste Materials, Ann Arbor, Michigan, pp. 493-516.

Seals, R. K., Moulton, L. K., and Ruth, B. E. (1972), "Bottom Ash: An Engineering Material," Journal of the Soil Mechanics and Foundations Division, ASCE, Vol. 98, No. SM4, April, pp. 311-325.

Selig, E. T. and Ladd, R. S. (1973), "Evaluation of Relative Density Measurement and Applications," Evaluation of Relative Density and Its Role in Geotechnical Projects Involving Cohesionless Soils, ASTM STP 523, ASTM, West Conshohocken, Pa., pp. 487-504.

Selvig, W. A. and Gibson, F. H. (1956), "Analysis of Ash from United States Coals," Bulletin 567, Bureau of Mines.

Sheu, T. C., Quo, L. W., and Kou, S. T. (1990), “Class F Fly Ash,” Material Research Society Symposium Proceedings, Vol. 178, Material Research Society, pp. 159-166.

Shipley, J. W. and McHaffie, I. R. (1924), “Chemistry and Metallurgy,” 8, 121. 
Smith, P. H. (1962), "Field Trials on Fly Ash," Contract Journal, London, England, September.

Sowers, G. F. (1979), "Introductory Soil Mechanics and Foundations: Geotechnical Engineering, $4^{\text {th }}$ edition, Macmillan Co., New York.

Spencer, E. (1967), "A Method of Analysis of the Stability of Embankments Assuming Parallel Inter-Slice Forces," Geotechnique, Vol. 17, No. 1, pp. 11-26.

Srivastava, L. and Collins, R. J. (1989), "Ash Utilization in Highways: Delaware Demonstration Project," GS-6481, Research Project 2422-3, Interim Report, Electric Power Research Institute, Palo Alto, CA.

STS Consultants, Inc. (1990), "Reinforced Soil Structures," Vol. 1, Design and Construction Guidelines, FHWA Report No. FHWA-RD-89-043, McLean, VA.

Terzaghi, K., Peck, R. B., and Mesri, G. (1996), "Soil Mechanics in Engineering Practice," 3rd ed., John Wiley \& Sons, New York.

Townsend, F. C. (1973), "Comparison of Vibrated Density and Standard Compaction Tests on Sands with Varying Amounts of Fines," Evaluation of Relative Density and its Role in Geotechnical Projects Involving Cohesionless Soils, ASTM STP 523, ASTM, West Conshohocken, Pa., pp. 348-363.

Tyson, S. and Kalyoncu, R. (2000), "Electric Power Utility’s Material Flow in the United States," The Use and Disposal of Coal Combustion By-Products at Coal Mines: A Technical Interactive Forum Held at The National Energy Technology Laboratory, April 10-13, Morgantown, West Virginia.

Usmen, M. A. (1977), “A Critical Review of the Applicability of Conventional Test Methods and Materials Specifications to the Use of Coal-Associated Wastes in Pavement Construction,” Ph. D. Dissertation, West Virginia University, Morgantown, WV.

Valley Forge Laboratories (1984), Technical Background Document in Support of Development of Federal Procurement Guidelines for Use of Power Plant Ash in Transportation Construction Products, Report submitted to the U. S. Environmental Protection Agency, May.

Watt, J. D. and Thorne, D. J. (1965), "Composition and Pozzolanic Properties of Pulverized Fuel Ashes. I. Composition of Fly Ashes from Some British Power Stations and Properties of their Component Particles," Journal of the Applied Chemistry, Vol. 15, December, pp. 585-594. 
Wayne, M. H., Susavidge M. A., Hullings, D. E., Martin, J. P. and Cheng, S. C. (1991), "An Assessment of the Geotechnical Strength Characteristics of Fly Ash," Proc. of Ninth International Ash Utilization Symp., American Coal Assoc., Pub. by EPRI, Vol. 3.

Wood, D. M. (1990), "Soil Behavior and Critical State Soil Mechanics," Cambridge University Press, New York. 